\title{
ITINERARIUM BURDIGALENSE UEL HIEROSOLYMITANUM (ITINERÁRIO DE BORDEAUX OU DE JERUSALÉM): TEXTO LATINO, MAPAS E TRADUÇÃO COMENTADA
}

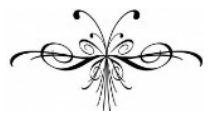 \\ GUSTAVO H. S. S. SARTIN ${ }^{1}$ (EDIÇÃO E TRADUÇ̃̃o) \\ GustaVo AlthofF² (REVISÃo)
}

\begin{abstract}
Resumo: O Itinerarium Burdigalense (Itinerário de Bordeaux) - também conhecido como Itinerarium Hierosolymitanum (Itinerário de Jerusalém) - é o mais antigo relato cristão de uma peregrinação a Terra Santa. Ele relata uma viagem de Bordeaux a Jerusalém realizada durante os anos 333 e 334 . O texto chegou a nossos dias em quatro manuscritos, copiados entre os séculos VIII e X. O que se segue é nossa edição do texto latino, acompanhada de sua tradução comentada para o Português do Brasil e por mapas.
\end{abstract}

Palavras-chave: Antiguidade Tardia. Peregrinação cristã. Terra Santa. Estradas romanas. Itinerarium Burdigalense.

\begin{abstract}
The Itinerarium Burdigalense (Bordeaux Itinerary) - also known as Itinerarium Hierosolymitanum (Jerusalem Itinerary) - is the oldest record of a Christian pilgrimage to the Holy Land. It recounts a journey from Bordeaux to Jerusalem that took place during the years 333 and 334. The text survives in four manuscripts, copied between the $8^{\text {th }}$ and $10^{\text {th }}$ centuries. The following is our edition of the Latin text, accompanied by its translation into Brazilian Portuguese, with commentaries and maps.
\end{abstract}

Keywords: Late Antiquity. Christian pilgrimage. Holy Land. Roman roads. Itinerarium Burdigalense.

\footnotetext{
${ }^{1}$ Mestre em História (área de concentração: História e Espaços) pela Universidade Federal do Rio Grande do Norte (UFRN), além de Bacharel e Licenciado em História pela Universidade Federal de Santa Catarina. Currículo Lattes: <http://lattes.cnpq.br/2409252978610663>.

2 Doutor em Estudos da Tradução pela Universidade Federal de Santa Catarina (UFSC) e Bacharel em Ciências Sociais pela mesma instituição. Atualmente é co-editor-chefe de Scientia Traductionis.
} 


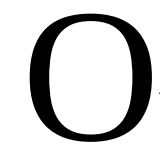
Itinerarium Burdigalense (às vezes chamado "Itinerarium Hierosolymitanum") relata uma viagem de Burdigala/Bordegala (Bordeaux) a Hierusalem (Jerusalém), com retorno até Mediolanum (Milão), que ocupou parte dos anos de 333 e $334 .^{3}$ Trata-se do mais antigo relato de uma peregrinação cristã à Terra Sancta. O nome do peregrino, infelizmente, se perdeu.

É preciso ter em mente que os viajantes romanos não dispunham de mapas como os nossos, valendo-se em vez disso de itineraria (itinerários), listas com locais de parada ao longo das vias e as distâncias entre eles. A julgar pelo único exemplar de um mapa romano que chegou aos nossos dias, a Tabula Peutingeriana, ${ }^{4}$ que mede 0,34 por 6,75 metros, os mapas romanos eram grandes e desajeitados demais para serem usados durante as viagens. Eles, além disso, não reproduziam a geografia da região retratada com a fidelidade a que estamos acostumados, servindo sobretudo para dar indicações acerca dos trajetos. Na Tabula Peutingeriana, por exemplo, as cidades de Aulona (atual Vlorë, $40^{\circ} 27.9^{\prime} \mathrm{N}$ $19^{\circ} 29.1^{\prime} \mathrm{E}$ ) e Ydrunte/Odrontum (atual Otranto, $40^{\circ} 09^{\prime} \mathrm{N} 18^{\circ} 29^{\prime} \mathrm{E}$ ) são retratadas um tanto afastadas uma da outra, apesar de estarem praticamente na mesma latitude e separadas somente por uma faixa de mar de cerca de noventa e cinco quilômetros (figura 1). Isso revela a importância dos itineraria, que serviam inclusive de base para a feitura dos mapas.

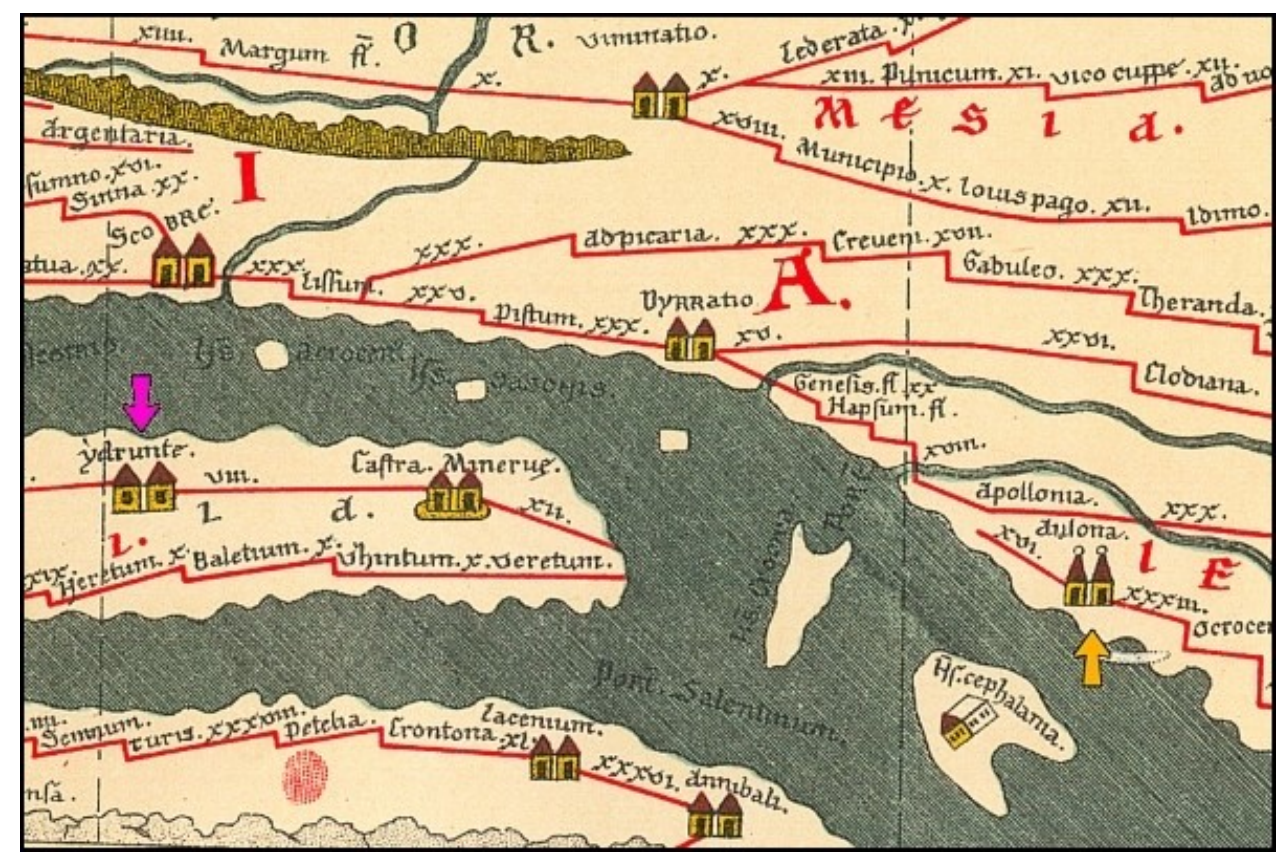

\footnotetext{
${ }^{3}$ A datação é segura, pois o viajante menciona os dois cônsules em exercício durante o primeiro ano da viagem: Flávio Dalmácio e Domítio Zenófilo (na passagem 571:6-8). O mandato de cônsul era anual e, por conta disso, a menção aos dois cônsules em exercício era a forma usual pela qual os romanos se referiam a um determinado ano. Para uma lista de cônsules romanos, vide: $<$ http://en.wikipedia.org/wiki/List_of_Roman_consuls>.

${ }^{4}$ Os manuscritos do Codex Vindobonensis 324, conhecido vulgarmente como "Tabula Peutingeriana”, podem ser vistos em: <http://www.euratlas.net/cartogra/peutinger/index.html>.
} 
Figura 1 (página anterior): detalhe do fac-simile da Tabula Peutingeriana publicado por Konrad Miller em 1887; ${ }^{5}$ em destaque, Aulona (Vlorë, 40²7.9' $\mathrm{N} 19^{\circ} 29.1^{\prime} \mathrm{E}$ ), seta amarela;

Ydrunte/Odrontum (Otranto, $40^{\circ} 09^{\prime} \mathrm{N} 18^{\circ} 29^{\prime} \mathrm{E}$ ), seta lilás - locais também destacados no mapa 12.

Quase na mesma latitude, as duas cidades ficam praticamente defronte uma a outra, ainda que separadas por uma faixa de mar de cerca de 95 quilômetros, no sul do Adriático.

Ainda que os romanos tenham produzido itinerários maiores e mais complexos, como o Antonini Itinerarium (Itinerário do [imperador] Antonino [Pio]), do início do século III, e que os cristãos antigos tenham nos legado outros relatos de peregrinação aos locais sagrados para a sua religião, como a Peregrinatio Aetheriae ad Loca Sancta, escrita entre 381 e 384, nenhum outro documento combina os dois gêneros textuais como o Itinerarium Burdigalense, porquanto esse não consiste simplesmente em uma lista com locais e distâncias, mas contém também uma descrição de locais da Palestina - o autor do itinerário, ademais, alude a passagens bíblicas quando trata da região.

O Itinerarium Burdigalense foi escrito no que se convencionou denominar "Latim Tardio", língua viva que progressivamente incorporava mesmo em sua versão escrita cada vez mais elementos do chamado "Latim Vulgar" (termo que a um só tempo se refere à linguagem coloquial e à fala das camadas populares). Deve-se notar, outrossim, que o registro linguístico do trecho relativo a Hierusalem e arredores - o único onde haveria a possibilidade de arroubos retóricos - é baixo mesmo para os padrões do Latim Tardio. Além de indicar um autor pouco letrado, tal fato talvez possa ser interpretado como marca de oralidade. Seria concebível, nesse caso, que o viajante houvesse ditado o texto a um acompanhante.

\section{Tradição manuscrita}

O Itinerarium Burdigalense chegou até nossos dias através de quatro manuscritos: os códices Parisinus 4808, Veronensis 52, Sangallensis 732 e Matritensis (Arch. Hist. Nat. 1279). Dentre eles, a versão mais antiga e completa é a do Codex Parisinus 4808, que data provavelmente do século VIII e perfaz um total de vinte e quatro páginas. A versão do Veronensis 52, provavelmente do século X, por sua vez, consiste em um texto um pouco menos completo, com uma grande lacuna no trecho de retorno a Mediolanum (Milão), e perfaz um total de treze páginas. A versão presente no Sangallensis 732 (figura 2), provavelmente produzida no início do século IX, traz somente a parte relativa a Hierusalem (Jerusalém) e arredores - perfazendo um total de dez páginas. A versão presente no Matritensis, que provavelmente data do século $\mathrm{X}$, é similar em conteúdo à do Sangallensis 732, mas tem apenas cinco páginas de extensão.

Dos quatro manuscritos, o Codex Sangallensis 732 é, pelo que nos consta, o único disponível online: <http://www.e-codices.unifr.ch/en/list/one/csg/0732>.

\footnotetext{
${ }^{5}$ MILLER, Konrad (ed). Castori Romanorum cosmographi tabula quae dicitur Peutingeriana. Revensburg: Meyer, 1887. O mapa completo da edição de Konrad Miller pode ser visto em: <http://commons.wikimedia.org/wiki/File:Tabula_Peutingeriana-nc.tif>.
} 


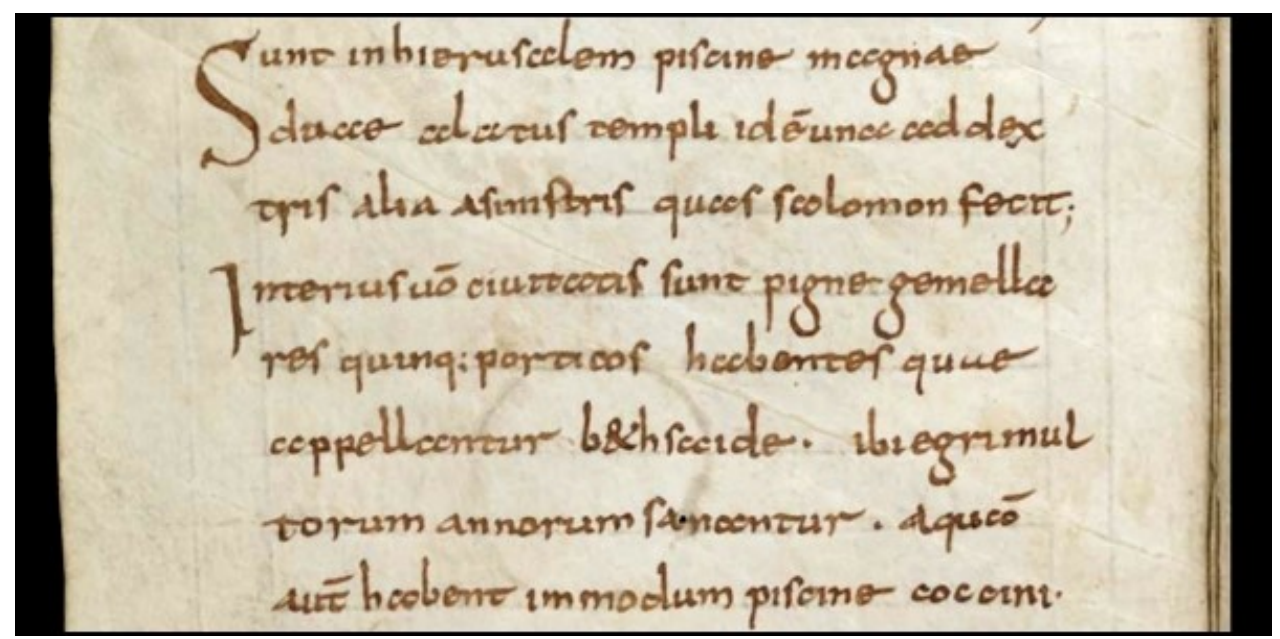

Figura 2: detalhe da página 104 do Codex Sangallensis 732. O trecho reproduzido corresponde ao trecho 589:9-14. Nele, uma vez devidamente interpretadas as abreviaturas, pode-se ler: "Sunt in Hierusalem piscine magnae duae ad latus templi, id est una ad dextris, alia ad sinistris, quas Salomon fecit, interius uero ciuitati sunt piscine gemellares, quinque porticos habentes, quae appellantur Betsaida. Ibi egri multorum annorum sanabantur. Aqua autem habent immodum piscinae coccini [turbatam]".

\section{Edições Impressas}

O Itinerarium Burdigalense teve como editio princeps - primeira edição impressa - um obscuro volume publicado pelo francês Petrus Pithoeus em 1589. Pouco depois, em 1600, Andreas Schottus publicou outra edição, em Colônia, ${ }^{6}$ baseando-se no texto do Codex Parisinus 4808, descoberto por Pithoeus. ${ }^{7}$ Mais famosa do que essas, porém, foi a edição de Petrus Wesselingius, que veio a lume em Amsterdã no ano de $1735 .^{8}$ Importante, também, foi a edição de G. Parthey e M. Pinder, publicada em Berlim em 1848. ${ }^{9}$ Em 1864, Anatole de Barthélemy publicou uma edição baseada exclusivamente no Codex Veronensis $52 .{ }^{10} \mathrm{Em} \mathrm{1879, \text {em }}$ Genebra, Titus Tobler e Augustus Molinier publicaram sua versão do Itineriarum Burdigalense, baseada nos códices Parisinus 4808 e Veronensis $52 .{ }^{11}$ Em 1898, nas cidades de Praga, Viena e Leipzig, foi a vez de Paulus Geyer publicar sua edição,

\footnotetext{
${ }^{6}$ SCHOTTUS, Andreas (ed.). Itinerarium Antonini Augusti, et Burdigalense. Quorum hoc nunc primum est editum, illud ad diversos manusc. codices et impressos comparatum, emendatum et Hieronymi Suritae Casesaraugustani, doctissimo comentario explicatum. Colonia Agrippina: In officina Birckmannica suptibus Arnold Mylij, 1600.

${ }^{7}$ SCHOTTUS (1600, Praefatio): "Itinerarium item Bordegala Hierosolymam usque; a P. Pithoeo viro doctissimo in membranis repertum”.

${ }^{8}$ WESSELINGIUS, Petrus (ed.). Vetera Romanorum Itineraria, sive Antonini Augusti Itinerarium, cum integris Jos. Simleri, Hieron. Suritae, et and. Schotti Notis. Itinerarium Hierosolytanum, et Hieroclis Grammatici Synecdemus. Amstelaedami: Aput J. Wetstenium \& G. Smith, 1735.

${ }^{9}$ PARTHEY, G., PINDER, M. (eds.). Itinerarium Antonini Augusti et Hierosolymitanum: ex libris manu scriptis ediderunt. Berolini: Impensis Friderici Nicolai, 1848.

${ }^{10}$ BARTHÉLEMY, Anatole de. Itinéraire de Bordeaux a Jérusalem d'après un manuscript de la Bibliothèque du Chapitre de Vérone Suivi d'une description des lieux saints tirée d'un manuscrit de la Bibliothèque impériale. Revue Archéologique, Nouvelle Série. v. 10, Juillet à Décembre 1864, pp. 98-112.

11 TOBLER, Titus, MOLINIER, Augustus (eds.). Itinera Hierosolyma et Descriptiones Terrae Sanctae bellis sacris anteriora \& Latina lingua exarata sumptibus Societatis illustrandis Orientis Latini monumentis. Genevae: J.-G. Fick, 1879.
} 
baseada nos códices Parisinus 4808, Veronensis 52, Sangallensis $732 .{ }^{12}$ Geyer manteve como divisão do texto a numeração das páginas da edição de Wesselingius (de 549 a 617), prática que também adotamos.

\section{Nossa edição}

Nossa edição do Itinerarium Burdigalense foi elaborada a partir da comparação dos textos contidos nos códices Sangallensis 732, Veronensis 52 e Parisinus 4808. Desses, o Sangallensis 732, por estar disponível online, foi consultado em primeira mão. O Veronensis 52 e o Parisinus 4808 só puderam ser consultados indiretamente. A fim de ter acesso ao texto do Veronensis 52, valemonos da edição do Itinerarium Burdigalense produzida por Anatole de Barthélemy (1864). Nessa edição, o texto é apresentado sem reparos na parte principal da página e corrigido nas notas de rodapé. De modo similar, a fim de acessar o texto do Parisinus 4808, valemo-nos da edição de Parthey e Pinder (1848). Nela, o texto é apresentado com “correções” na parte principal da página, enquanto os “erros” do manuscrito são indicados nos rodapés. O leitor encontrará nas notas de rodapé de nossa edição o registro das variantes textuais que identificamos existir, indicadas pelas letras “S” (Sangallensis 732), "V” (Veronensis 52) e "P” (Parisinus 4808).

Talvez o leitor esteja se perguntando a esta altura como escolhemos entre tais variantes textuais quando da edição do texto latino que serviria de base para nossa tradução. Nosso processo de edição foi orientado por dois princípios normalmente empregados na crítica textual dos manuscritos bíblicos: (1) lectio difficilior praeferenda (o texto mais difícil deve ser preferido); e (2) lectio brevior potior (o texto mais curto é o mais provável). O primeiro princípio pressupõe que um copista, quando alterava um determinado texto, fazia-o sobretudo com o objetivo de torná-lo mais claro; de modo que variantes de mais difícil interpretação tendem a ser as mais antigas. O segundo princípio relaciona-se com o primeiro e pressupõe que as tentativas, por parte dos copistas, de tornar mais claros os sentidos dos textos se davam mais através de acréscimos do que de supressões.

No caso do Itinerarium Burdigalense há uma considerável diferença entre os três códices no que diz respeito tanto à ortografia como à estrutura gramatical das frases. O Parisinus 4808 apresenta o Latim "mais correto" entre eles (ou seja, mais próximo das normas clássicas), enquanto o Veronensis 52 é o que traz o texto "menos correto". Curiosamente, a despeito do princípio lectio difficilior praeferenda ser conhecido desde o segundo quartel do século XVIII, os editores anteriores do Itinerarium Burdigalense tenderam a valorizar mais as variantes textuais contidas no Parisinus 4808.

De todo modo, independentemente de quais princípios de edição adotar, o editor de um texto contido em um códice medieval deve, ao se deparar com o que parece ser um "erro", questionar-se acerca de sua natureza. Em outras palavras, ele deve tentar descobrir se tal "erro" foi produzido pelo autor do texto ou por algum dos copistas responsáveis por sua transmissão. Para tanto, cumpre comparar os manuscritos e analisar as variantes textuais. Vejamos, a título de exemplo, algumas variantes textuais da passagem 589. Nela, o autor do Itinerarium Burdigalense faz referência a uma anedota bíblica na qual há o encontro entre um profeta velho e um

${ }^{12}$ GEYER, Paulus (ed.). Itinera Hierosolymitana: saeculi IIII - VIII. Pragae, Vindobonae et Lipsiae:

F. Tempsky et G. Freytag, 1898. 
mais jovem (1 Reis 13). Embora Deus houvesse ordenado ao mais jovem que não se alimentasse durante uma viagem, o velho o engana e os dois acabam por compartilhar uma refeição. Em seguida, como punição por sua desobediência, um leão tira a vida do mais jovem.

\begin{abstract}
S: "et iussum fuerat prophetae ne cum seodoprophetam quos rex secum habebat manducaret; rediens ocurrit propheta leo in uia occidit eum"

V: "et iussum fuerat prophetae, ne cum seodoprophetam, quem secum habebat rex manducaret, et quia secutus est ad seodopropheta et cum eo manducauit rediens ocurrit prophetae leo in uia et occidit eum".

P: "et iussum fuerat prophetae, ne cum pseudoprophetam, quem secum rex habebat, manducaret, et quia seductus est a pseudopropheta et cum eo manducauit, rediens ocurrit prophetae leo in uia et occidit eum"
\end{abstract}

Como se vê, sublinhamos uma passagem que $\mathrm{V}$ e $\mathrm{P}$ trazem, mas que inexiste em S. Tanto em V quanto em $\mathrm{P}$, seu sentido é algo como "mas então foi enganado pelo pseudoprofeta e com ele alimentou-se". A partir de nossos dois princípios de edição, lectio difficilior praeferenda (o texto mais difícil deve ser preferido) e lectio brevior potior (o texto mais curto é o mais provável), concluímos que o trecho sublinhado, ainda que conste em um número maior de manuscritos, é provavelmente uma interpolação. Desse modo, não consta, pois, de nossa versão, que busca aproximar-se ao máximo do que cremos ser o texto original.

Cabe tratarmos, agora, da palavra "seodoprophetam" - que em um Latim “correto" estaria grafada "pseudoprophetam”, como em P. A questão nesse caso é se o erro de ortografia foi produzido pelo autor do Itinerarium Burdigalense ou por um copista. Ainda que não fosse raro que um copista distraído omitisse uma letra (ou uma palavra, uma linha ou até mesmo duas páginas inteiras), não é incomum encontrarmos, em textos compostos durante a Antiguidade Tardia, erros de ortografia resultantes não do trabalho de copistas distraídos, mas da evolução fonética da língua. A falta do "p" em "seodoprophetam" parece ser um desses casos.

Ainda que o autor do itinerário estivesse provavelmente a esforçar-se por escrever em um "bom Latim" - do contrário ele talvez houvesse escrito "seodoprofetam" (ou até mesmo "seodoprofeta", sem o "m” final) -, ele parece ter omitido o "p" inicial por conta desse provavelmente não ser pronunciado em seu dialeto. Além disso, o registro linguístico do texto sugere um autor pouco letrado,

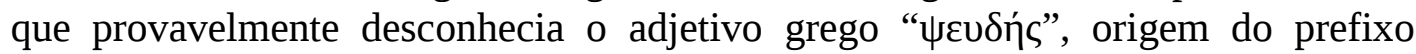
latino "pseudo-".

O encontro entre [p] e [s], de todo modo, devia ser pronunciado com alguma dificuldade por muitos dos falantes do Latim. Devia ocorrer muitas vezes um processo de assimilação regressiva, através do qual [ps] passava a ser pronunciado [ss] - sendo que, por vezes, a transformação continuava com a degeminação do [ss], que então transformava-se em um [s] (como o pronunciado em Português mesmo quando grafamos a letra "s" duas vezes). No caso do prefixo "pseudo-”, o registro formal e escrito da nossa língua não preservou essas transformações fonéticas. Em Castelhano, porém, "seudo-” é ainda sua forma predominante.

Mesmo a presença da letra "o" em lugar da "u” na forma "seodo-" tem uma explicação fonética. A articulação prévia do [e], uma vogal anterior semifechada não arredondada, devia produzir uma "abertura” na pronúncia do [u] que deveria ser uma vogal posterior fechada arredondada. Isso significa que, nessa 
posição, as letras "o" e "u” deviam soar muito parecidas. Uma situação semelhante pode ser observada, por exemplo, na palavra latina "ego". Após a síncope do [g], que resultou na pronúncia [eo], os falantes de diferentes regiões deram destinos diferentes à vogal final, de modo que hoje dizemos [eu], enquanto os espanhóis dizem [jo] e os italianos [i'o].

Diante de tudo isso, na passagem em questão, consideramos que o texto apresentado por $\mathrm{S}$ deve ser o preferido, por possivelmente aproximar-se mais do que escrevera originalmente o autor.

Resta-nos, ainda, a questão das positurae, ou sinais de pontuação. O leitor deve ser informado, nesse caso, que é absolutamente improvável que os códices de fins do primeiro milênio, como os que trazem o Itinerarium Burdigalense, reproduzam fielmente a pontuação de manuscritos produzidos antes do século VI por conta das mudanças nas convenções de escrita. O texto original do Itinerarium Burdigalense, composto a partir de 334, deve ter sido escrito em estilo chamado "scriptura continua", sem espaçamento entre as palavras e com uma pontuação muito exígua para padrões posteriores.

Um exemplo de scriptura continua pode ser visto no chamado Codex Fuldensis, um manuscrito do século VI que traz uma versão latina da Bíblia. Nele, um ponto centralizado faz as vezes tanto de vírgula (ou quiçá ponto-e-vírgula) como de ponto final - sendo omitido, porém, no fim dos parágrafos. Dois pontos dispostos horizontalmente no fim de uma citação tinham a função das nossas aspas. Escrito provavelmente no início do século IX, o Codex Sangallensis 732, em comparação, traz não apenas as palavras separadas, como dois outros sinais de pontuação: o ponto e o ponto-e-vírgula. Como no uso moderno, o ponto indica não somente uma pausa longa no discurso, mas também uma abreviatura (embora nem todas as abreviaturas sejam indicadas dessa forma). O ponto-e-vírgula, por seu turno, indica uma pausa mais curta, normalmente encontrada entre duas orações coordenadas. As vírgulas, com as quais muitas vezes indicamos a presença de orações subordinadas, inexistem. As aspas inexistem.

Não causa surpresa, assim, que a imensa maioria dos editores anteriores de textos antigos tenham se sentido à vontade para revisar as pontuações presentes nos manuscritos medievais. Essas, afinal, não remetem a um texto original, mas são simplesmente convenções da época em que o manuscrito em questão foi copiado. Adotamos esse mesmo procedimento. Portanto, para além do ponto e do ponto-evírgula, que se tem no Codex Sangallensis 732, nosso texto latino contém também vírgulas e dois pontos.

\section{Traduções}

Não deve nos causar surpresa o fato de os itinerários romanos, apesar de terem recebido um significativo número de edições impressas, terem sido praticamente negligenciados no que diz respeito à produção de edições nas línguas modernas. Esses itinerários eram, afinal, pouco mais do que listas com locais e distâncias, de modo que o projeto de traduzi-los talvez pouco se justificasse. O Itinerarium Burdigalense, contudo, difere dos itinerários romanos típicos por conta da natureza descritiva do trecho relativo a Hierusalem e arredores. Ainda assim, encontramos um número exíguo de traduções: uma para o Inglês, publicada por 
Aubrey Stewart em Londres no ano de $1887^{13}$; e outra para o Francês, disponível no site "L'Arbre Celtique"14, aparentemente fruto de Julien Quiret, colaborador do site.

\section{Nossa tradução}

Cremos que bem traduzir um texto é, entre outras coisas, torná-lo compreensível para quem o lerá na língua alvo. Essa foi a perspectiva que animou, durante todo o tempo, nossa empreitada tradutória. Um itinerário é um texto que leva o leitor a percorrer - ao menos mentalmente - os trajetos nele indicados. Todavia, como tornar as localidades do itinerário apreensíveis a um leitor nãoespecialista do século XXI, considerando que em boa parte do tempo tal itinerário refere-se a locais mudaram que mudaram de nome e cujos status são outros? Nossa solução para tal questão foi indicar os locais atuais que correspondem aos mencionados no texto latino. Isso foi uma tarefa mais difícil do que talvez pareça à primeira vista! Claro que, por exemplo, a antiga Mediolanum corresponde à moderna Milão (557:10), Bordegala a Bordeaux (549:7-9), mas e quanto a Maximianopolis (603:2)? Ou Tardequeia (580:5)?

Dentro dessa mesma lógica, a de tornar o texto compreensível ao leitor não-especialista, elaboramos os mapas que o acompanham. Eles foram criados a partir do site "Digital Atlas of the Roman Empire" (doravante, DARE) ${ }^{15}$ Consultamos, também, o site “Omnes Viae: Roman routplanner" (doravante, OmnesViae), que traz uma sobreposição da Tabula Peutingeriana a um mapa digital moderno. ${ }^{16}$ Nem sempre, porém, havia concordância entre os locais mencionados no Itinerarium Burdigalense e os expostos nos dois sites. Tal dificuldade pode ser explicada, em parte, por uma questão cronológica. O DARE foi pensado sobretudo como um recurso que dá conta da época clássica, do apogeu do Império Romano, enquanto o Itinerarium Burdigalense foi escrito durante a Antiguidade Tardia, quando muitos dos topônimos já haviam mudado. A Tabula Peutingeriana, por seu turno, foi escrita ainda mais tarde, cerca de um século depois do Itinerarium Burdigalense. Recorremos, pois, em caso de conflito, a outras fontes. Mesmo sites como o "Google Maps"17 e o "Yahoo! Maps"18 foram de grande valia, visto que muitas vezes permitiam identificar algum obscuro lugarejo moderno situado entre duas cidades romanas conhecidas. Em tempo: as notas apresentam as informações dos sites DARE e OmnesViae mesmo quando não concordamos com a identificação por eles apresentada. O leitor pode, desse modo, fazer seus próprios juízos acerca do que é cada local.

Apresentamos o texto do Itinerarium Burdigalense em quatro colunas. A primeira e a segunda indicam, respectivamente, o número da página e da linha do trecho em questão na edição de Petrus Wesselingius, conforme fez Paulus Geyer. $\mathrm{Na}$ terceira coluna apresentamos o texto latino do Itinerarium Burdigalense. A

\footnotetext{
13 STEWART, Aubrey, WILSON, C. W. (eds.). Itinerary from Bordeaux to Jerusalém. 'The Bordeaux Pilgrim' (333 A. D.). Translated by Aubrey Stewart and annotated by Colonel Sir C. W. Wilson. London: I, Adam Street, Adelphi, 1887.

${ }^{14}$ Site "L'Arbre Celtique", endereço do Itinerarium Burdigalense:

$<$ http://www.arbre-celtique.com/encyclopedie/itineraire-de-bordeaux-a-jerusalem-6866.htm>.

15 "Digital Atlas of the Roman Empire” (doravante, "DARE”): < http://imperium.ahlfeldt.se/>.

16 “Omnes Viae: Roman routplanner” (doravante, “OmnesViae”): <http://omnesviae.org/>.

${ }^{17}$ Google Maps: <https://maps.google.com/>.

${ }^{18}$ Yahoo! Maps: <https://maps.yahoo.com/>.
} 
quarta coluna, por fim, traz nossa versão do itinerário em Português do Brasil. Alí o leitor encontrará em itálico os nomes latinos dos locais mencionados pelo viajante, seguidos do nome atual desses locais, entre parênteses. Os colchetes indicam sempre adições. As chaves indicam passagens claramente erradas, mas que decidimos, ainda assim, registrar.

Dividimos o texto em seções, para que o leitor possa melhor acompanhar nos mapas o deslocamento do viajante. Cada seção se inicia com o último local da seção anterior. 


\section{Seção 1: de Bordegala (Bordeaux) a Arelate (Arles)}

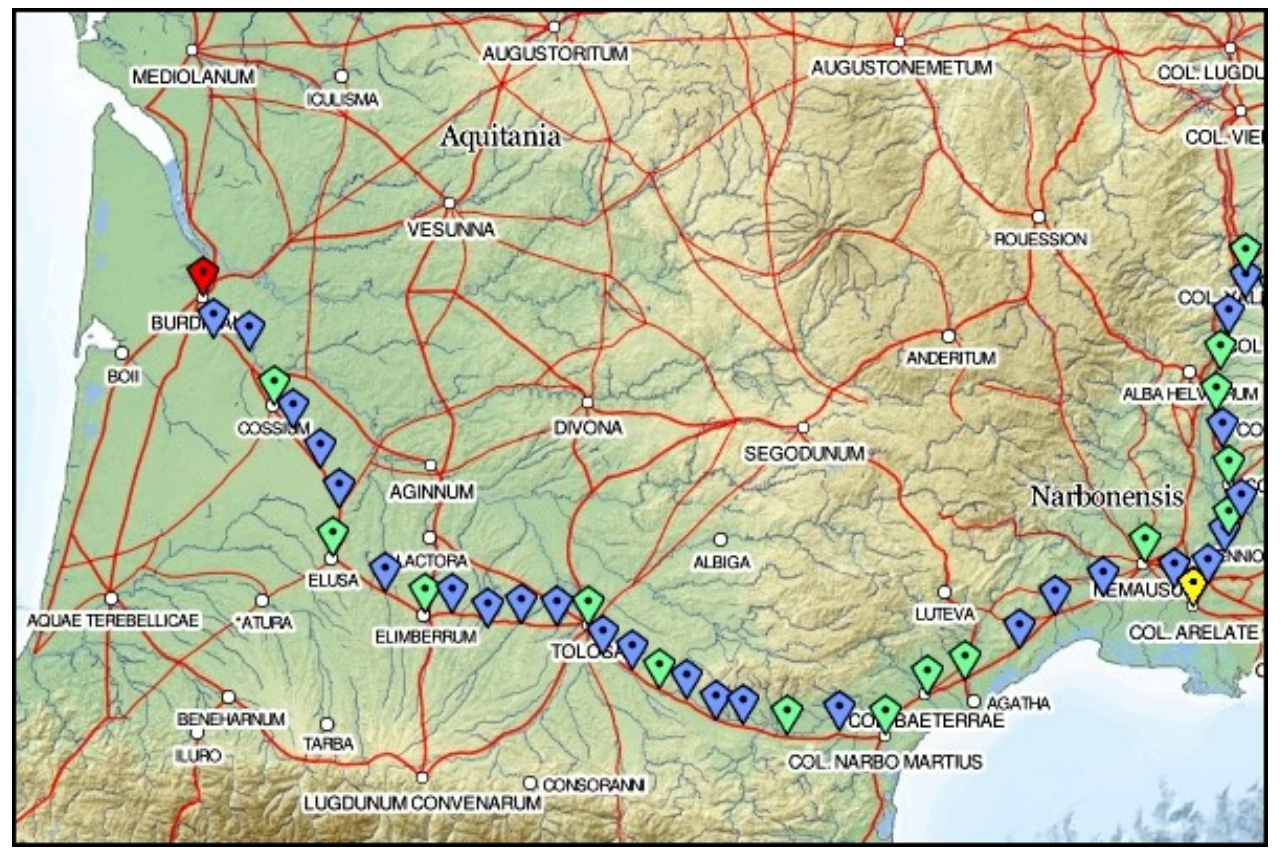

Mapa 1: trecho entre Bordegala (Bordeaux), em vermelho, e Arelate (Arles), em amarelo; em azul estão registradas as mutationes (postos de muda) e em verde as mansiones (pousos).

\begin{tabular}{|c|c|c|c|}
\hline 549 & $\begin{array}{l}1- \\
6\end{array}$ & $\begin{array}{l}\text { Itinerarium a Bordegala } \\
\text { Hierusalem usque et ab } \\
\text { Heraclea per Aulonam et } \\
\text { per urbem Romam } \\
\text { Mediolanum usque sic: }\end{array}$ & $\begin{array}{l}\text { Itinerário de Bordegala (Bordeaux) até } \\
\text { Hierusalem (Jerusalém) e de Heraclea } \\
\text { (Marmara Ereğlisi), passando por Aulona } \\
\text { (Vlorë) e pela cidade de Roma (idem), até } \\
\text { Mediolanum (Milão), como se segue: }\end{array}$ \\
\hline 549 & $\begin{array}{l}7- \\
9\end{array}$ & $\begin{array}{l}\text { Ciuitas Bordegala, ubi est } \\
\text { fluuius Garonna, per quem } \\
\text { facit mare oceanum accessa } \\
\text { et recessa per leugas plus } \\
\text { minus centum. }{ }^{19}\end{array}$ & 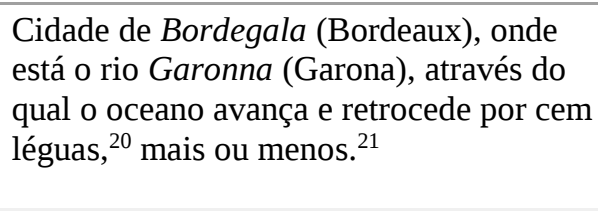 \\
\hline 550 & 1 & Mutatio Stomatas leug VII & $\begin{array}{l}\text { Posto de muda }{ }^{22} \text { em Stomatae (Castres- } \\
\text { Gironde), } 7 \text { léguas; }{ }^{23}\end{array}$ \\
\hline & 2 & $\begin{array}{l}\text { mutatio Serione leug } \\
\text { VIIII }^{24}\end{array}$ & $\begin{array}{l}\text { posto de muda em Serio (Ceróns), } 9 \\
\text { léguas; }{ }^{25}\end{array}$ \\
\hline
\end{tabular}

\footnotetext{
${ }^{19} \mathrm{~V}$ : "Bordegala” - P: "Burdigala”.

${ }^{20}$ A milia (milha) romana corresponde a cerca de 1.480 metros; enquanto a leuga (légua) - unidade gaulesa talvez anterior aos romanos - equivale a uma vez e meia esse valor, ou a aproximadamente 2.220 metros. Discutimos em maior detalhe o modo como os romanos registravam as distâncias viárias no comentário de tradução número IV.

${ }^{21}$ OmnesViae: Bordegalo=Bordeaux, Bordegala. DARE: <http://imperium.ahlfeldt.se/places/147>.

${ }^{22}$ Discutimos a tradução de "mutatio" como "posto de muda” no comentário de tradução número II.

${ }^{23}$ Escolhemos, no texto em Português, o ponto-e-vírgula para separar uns dos outros os locais visitados pelo viajante, sendo que o fim de cada uma das listagens de lugares visitados é indicado por um ponto final. Quanto ao local em questão, DARE: <http://imperium.ahlfeldt.se/places/17473>. ${ }^{24} \mathrm{~V}$ : "Senone" - P: "Sirione".

${ }^{25}$ OmnesViae: Serione. DARE: <http://imperium.ahlfeldt.se/places/8009>.
} 


\begin{tabular}{|c|c|c|c|}
\hline & 3 & Ciuitas Uasatas leug VIIII & $\begin{array}{l}\text { [pouso na] cidade de Uasates (Bazas), } 9 \\
\text { léguas; }{ }^{26}\end{array}$ \\
\hline & 4 & $\begin{array}{l}\text { mutatio Tres Arbores leug } \\
\text { V }\end{array}$ & $\begin{array}{l}\text { posto de muda em Tres Arbores (Maillas), } \\
5 \text { léguas; }{ }^{27}\end{array}$ \\
\hline & 5 & $\begin{array}{l}\text { mutatio Oscineium leug } \\
\text { VIII }^{28}\end{array}$ & $\begin{array}{l}\text { posto de muda em Oscineium (Houeillès), } \\
8 \text { léguas; }{ }^{29}\end{array}$ \\
\hline & 6 & mutatio Scittio leug VIII ${ }^{30}$ & $\begin{array}{l}\text { posto de muda em Scittium (Sos), } 8 \\
\text { léguas; }{ }^{31}\end{array}$ \\
\hline & 7 & Ciuitas Elusa leug VIII & $\begin{array}{l}\text { [pouso na] }{ }^{32} \text { cidade de Elusa (Eauze), } 8 \\
\text { léguas; }{ }^{.33}\end{array}$ \\
\hline & 8 & mutatio Vanesia leug XII & $\begin{array}{l}\text { posto de muda em Vanesia (Saint-Jean- } \\
\text { Poutge, departamento de Gers), } 12 \\
\text { léguas; }{ }^{34}\end{array}$ \\
\hline & 9 & Ciuitas Auscius leug VIII & $\begin{array}{l}\text { [pouso na] cidade de Auscius (Auch), } 8 \\
\text { léguas; }{ }^{: 5}\end{array}$ \\
\hline & 10 & mutatio ad sextum leug VI & $\begin{array}{l}\text { posto de muda no sexto [marco] (Marsan), } \\
6 \text { léguas; }{ }^{36}\end{array}$ \\
\hline & 11 & $\begin{array}{l}\text { mutatio Hungunerro leug } \\
\text { VII }^{37}\end{array}$ & $\begin{array}{l}\text { posto de muda em Hungunerrum } \\
\text { (Maurens, departamento de Gers), } 6 \\
\text { léguas; }^{.8}\end{array}$ \\
\hline & 12 & mutatio Bucconis leug VII & $\begin{array}{l}\text { posto de muda em Buccones (Foret de } \\
\text { Bouconne), } 7 \text { léguas; } 39\end{array}$ \\
\hline 551 & 1 & mutatio ad Iouem leug VII & $\begin{array}{l}\text { posto de muda no [templo de] Ioue } \\
\text { (Jupiter) (Pibrac), } 7 \text { léguas; }{ }^{40}\end{array}$ \\
\hline & 2 & Ciuitas Tolosa leug VII ${ }^{41}$ & $\begin{array}{l}\text { [pouso na] cidade de Tolosa (Toulouse), } 7 \\
\text { léguas; } 42\end{array}$ \\
\hline
\end{tabular}

\footnotetext{
${ }^{26}$ Antigamente também chamada "Cossium”. <http://fr.wikipedia.org/wiki/Bazas>: "Le nom de Bazas vient de civitas basatica, "cité des Vasates ». Son nom antique était Cossium, une latinisation de l'aquitanique *koiz, gascon Coç 'tertre'”. DARE: <http://imperium.ahlfeldt.se/places/148>.

${ }^{27}$ DARE: <http://imperium.ahlfeldt.se/places/17477>.

${ }^{28}$ V: “Oscyneio" - P: “Oscineio".

${ }^{29}$ Oscincium = Houeillès, conforme o DARE: <http://imperium.ahlfeldt.se/index.php?id=17478>.

${ }^{30}$ V: "Scotio" - P: "Scittio".

${ }^{31}$ Sotium/Scittio = Sos, conforme o DARE: <http://imperium.ahlfeldt.se/index.php?id=11133>.

32 Discutimos, na nota de tradução número III, a questão das mansiones (pousos).

${ }^{33}$ OmnesViae: Elusa (Eause). Elusio = Eause, conforme:

<http://www.perseus.tufts.edu/hopper/text?doc=Perseus:text:1999.04.0006:id=elusa-1>. O mesmo conforme o DARE: <http://imperium.ahlfeldt.se/index.php?id=401>

${ }^{34}$ DARE, Vanesia = Saint-Jean-Poutge: $<$ http://imperium.ahlfeldt.se/index.php?id=11142>.

35 "Elimberrum" é o nome mais antigo do local. O DARE identifica Elimberrum com Auch: $<$ http://imperium.ahlfeldt.se/index.php?id=154>. OmnesViae: Eliberre (Auch).

36 O DARE identifica essa posto de muda com L'Augergé, na comuna de Marsan (Gers): $<$ http://imperium.ahlfeldt.se/index.php?id=154>.

${ }^{37} \mathrm{~V}$ : "Hungunerro" - P: "Hungunuerro".

${ }^{38}$ La Tonguère, em Maurens (Gers), conforme o DARE:

$<$ http://imperium.ahlfeldt.se/index.php?id=154>.

${ }^{39}$ DARE: <http://imperium.ahlfeldt.se/index.php?id=17483>.

${ }^{40}$ DARE: <http://imperium.ahlfeldt.se/index.php?id=17485>.

${ }^{41}$ V: “Tolosa” - P: “Tholosa”.

42 OmnesViae: Tolosa (Toulouse). DARE: <http://imperium.ahlfeldt.se/places/153>.
} 


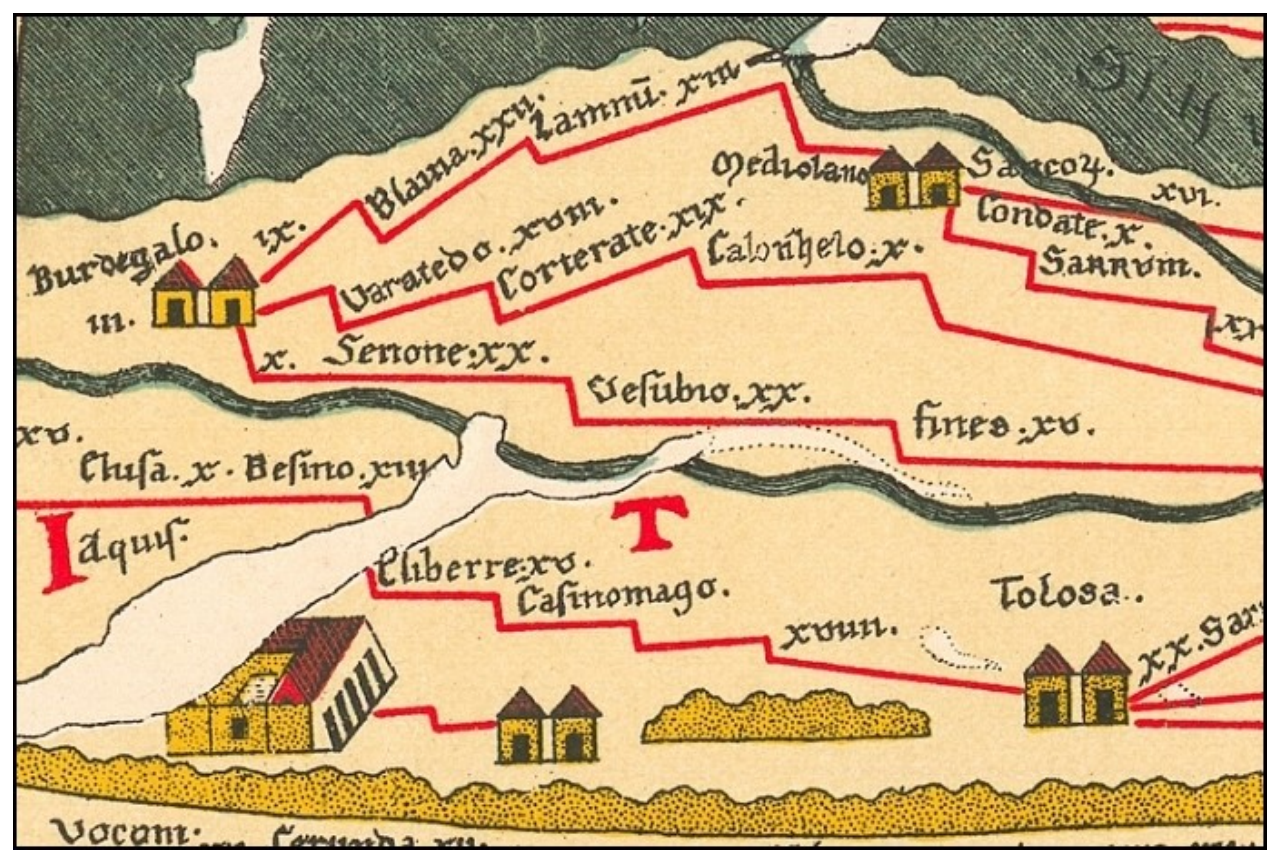

Figura 3: detalhe do fac-simile da Tabula Peutingeriana, com destaque para Burdegalo/Bordegala (Bordeaux) e Tolosa/Tholosa (Toulouse); note-se que não há indicação de ligação direta entre os dois locais.

\begin{tabular}{|c|c|c|c|}
\hline 551 & 3 & mutatio ad nonum mil VIIII & $\begin{array}{l}\text { posto de muda no nono [miliário] } \\
\text { (Pompertuzat), } 9 \text { milhas; }{ }^{43}\end{array}$ \\
\hline & 4 & $\begin{array}{l}\text { mutatio ad uicesimum mil } \\
\text { XI }\end{array}$ & $\begin{array}{l}\text { posto de muda no vigésimo [miliário] } \\
\text { (Villenouvelle, departamento de Haute- } \\
\text { Garonne), } 11 \text { milhas; }{ }^{44}\end{array}$ \\
\hline & 5 & mansio Elusione mil VIIII & $\begin{array}{l}\text { pouso em Elusio (Montferrand, } \\
\text { departamento de Aude), } 9 \text { milhas; }{ }^{45}\end{array}$ \\
\hline & 6 & $\begin{array}{l}\text { mutatio Sustomago mil } \\
\text { VIIII }^{46}\end{array}$ & $\begin{array}{l}\text { posto de muda em Sustomagus } \\
\text { (Castelnaudary), } 9 \text { milhas; }{ }^{47}\end{array}$ \\
\hline & 7 & uicus Ebromago mil $\mathrm{X}^{48}$ & $\begin{array}{l}\text { povoado de Ebromagus (Bram), } 10 \\
\text { milhas; }{ }^{49}\end{array}$ \\
\hline & 8 & mutatio Cedros mil VI ${ }^{50}$ & $\begin{array}{l}\text { posto de muda em Cedri (Caux-et- } \\
\text { Sauzens), } 6 \text { milhas; }{ }^{51}\end{array}$ \\
\hline & 9 & $\begin{array}{l}\text { castellum Carcassone mil } \\
\text { VIIII }\end{array}$ & $\begin{array}{l}\text { [pouso no] forte em Carcasso } \\
\text { (Carcassone), } 9 \text { milhas; }{ }^{52}\end{array}$ \\
\hline
\end{tabular}

${ }^{43}$ A nota de tradução IV trata especificamente de como os marcos viários romanos por vezes serviam para denominar as estações de apoio ao viajante. DARE:

$<$ http://imperium.ahlfeldt.se/index.php?id=11147>

${ }^{44}$ DARE: <http://imperium.ahlfeldt.se/index.php?id=11149>.

${ }^{45}$ DARE: <http://imperium.ahlfeldt.se/index.php?id=11106>.

${ }^{46} \mathrm{~V}$ : - "Sustomago" - P: "Sostomago".

47 DARE: <http://imperium.ahlfeldt.se/index.php?id=11152>. Sostomagus = Castelnaudary, conforme:

http://www.perseus.tufts.edu/hopper/text?doc=Perseus:text:1999.04.0006:entry=sostomagus

${ }^{48}$ V: "Ebromago" - P: "Hebromago".

${ }^{49}$ OmnesViae: Eburomagi (Bram). DARE: <http://imperium.ahlfeldt.se/index.php?id=8013>.

${ }^{50}$ V: "Cedros" - P: "Coedros".

${ }^{51}$ DARE: <http://imperium.ahlfeldt.se/index.php?id=14083>.

52 OmnesViae: Carcassione (Casrcassione, sic). DARE:

$<$ http://imperium.ahlfeldt.se/index.php?id=155>. 


\begin{tabular}{|c|c|c|c|}
\hline & 10 & $\begin{array}{l}\text { mutatio Trecesimum mil } \\
\mathrm{XV}^{53}\end{array}$ & $\begin{array}{l}\text { posto de muda no trigésimo [miliário] } \\
\text { (Floure, departamento de Aude), } 15 \\
\text { milhas; }^{54}\end{array}$ \\
\hline \multirow[t]{10}{*}{552} & 1 & mutatio Hosuerbas mil XV & $\begin{array}{l}\text { posto de muda em Hosuerbas (Lézignan- } \\
\text { Corbières), } 15 \text { milhas; }{ }^{55}\end{array}$ \\
\hline & 2 & Ciuitas Narbone mil $\mathrm{XV}^{56}$ & $\begin{array}{l}\text { [pouso na] Cidade de Narbo (Narbonna), } \\
15 \text { milhas; } 5\end{array}$ \\
\hline & 3 & Ciuitas Beterris mil XVI ${ }^{58}$ & $\begin{array}{l}\text { [pouso na] cidade de Beterrae (Béziers), } \\
16 \text { milhas; } 59\end{array}$ \\
\hline & 4 & mansio Cessarone mil XII & $\begin{array}{l}\text { pouso em Cessaro (St. Thibéry), } 12 \\
\text { milhas; } 60\end{array}$ \\
\hline & 5 & $\begin{array}{l}\text { mutatio Foro Domiti mil } \\
\text { XVIII }\end{array}$ & $\begin{array}{l}\text { posto de muda no Forum Domitii } \\
\text { (Montbazin), } 18 \text { milhas; }{ }^{11}\end{array}$ \\
\hline & 6 & $\begin{array}{l}\text { mutatio Sustancione mil } \\
\mathrm{XV}^{62}\end{array}$ & $\begin{array}{l}\text { posto de muda em Sustancio (Castelnau- } \\
\text { le-Lez), } 15 \text { milhas; }{ }^{3}\end{array}$ \\
\hline & 7 & mutatio Ambrosi mil XV $\mathrm{XV}^{64}$ & $\begin{array}{l}\text { posto de muda em Ambrosius (Pont- } \\
\text { Ambroix), } 15 \text { milhas; }{ }^{65}\end{array}$ \\
\hline & 8 & mutatio Nemauso mil XV & $\begin{array}{l}\text { [pouso na] cidade de Nemausus (Nimes), } \\
15 \text { milhas; } 66\end{array}$ \\
\hline & 9 & $\begin{array}{l}\text { mutatio Ponte Aerarium mil } \\
\text { XII }^{67}\end{array}$ & $\begin{array}{l}\text { posto de muda na ponte Aerarius } \\
\text { (Bellegarde), } 12 \text { milhas; } 68\end{array}$ \\
\hline & 10 & Ciuitas Arelate mil VIII. ${ }^{69}$ & $\begin{array}{l}\text { [pouso na] cidade de Arelate (Arles), } 8 \\
\text { milhas. }^{70}\end{array}$ \\
\hline 553 & $\begin{array}{l}1, \\
2\end{array}$ & $\begin{array}{l}\text { Fit a Bordegala Arelate } \\
\text { usque mil CCCLXXII, } \\
\text { mutationes XXX, } \\
\text { mansiones XI. }\end{array}$ & $\begin{array}{l}\text { Percorridas de Bordegala (Bordeaux) até } \\
\text { Arelate (Arles) } 372 \text { milhas, [passando por] } \\
30 \text { postos de muda e } 11 \text { pousos. }\end{array}$ \\
\hline
\end{tabular}

53 V: “Trecesimum” - P: “Trincensimum”.

${ }^{54}$ DARE: <http://imperium.ahlfeldt.se/index.php?id=11170>.

${ }^{55}$ DARE: <http://imperium.ahlfeldt.se/index.php?id=8015>.

${ }^{56} \mathrm{~V}$ : "Narbonae" - P: "Narbone".

${ }^{57}$ OmnesViae: Narbone (Narbonne). DARE: < http://imperium.ahlfeldt.se/index.php?id=156>.

${ }^{58} \mathrm{~V}$ : "Beterris" - P: "Biterris".

${ }^{59}$ OmnesViae: Beteris (Béziers). DARE: <http://imperium.ahlfeldt.se/index.php?id=159>.

${ }^{60}$ OmnesViae: Cesse Rone (St. Thibéry). Cessero/Aurara = Saint-Thibery, conforme DARE:

$<$ http://imperium.ahlfeldt.se/index.php?id=8020>.

${ }^{61}$ OmnesViae: Foro Domiti (Montbazin). DARE: <http://imperium.ahlfeldt.se/index.php?id=8026>.

${ }^{62} \mathrm{~V}$ : "Sustancione" - P: "Sostantione".

63 OmnesViae: Sextatione (Castelnau-le-Lez). Sextantio = "Soustantion, near Montpellier”, segundo D'ANVILLE. Compendium of Ancient Geography (1810, p. 394). Sextatione/Substantion = Substantion, em Castelnau-le-Lez (Héraut), conforme: DARE:

$<$ http://imperium.ahlfeldt.se/index.php?id=8027>.

${ }^{64} \mathrm{~V}$ : “Ambrosi” - P: “Ambrosio".

65 OmnesViae: Ambrusiu ( Lunel). Ambrosium = Pont-Ambroix, em Villetelle (Hérault). DARE: $<$ http://imperium.ahlfeldt.se/index.php?id=11102>.

${ }^{66}$ OmnesViae: Nemuso (Nîmes). DARE: <http://imperium.ahlfeldt.se/index.php?id=171>.

67 V: "Herarum" - P: "Aerarum".

${ }^{68}$ DARE: <http://imperium.ahlfeldt.se/index.php?id=11171>.

${ }^{69} \mathrm{~V}$ : “Arelate” - P: “Arillate”.

${ }^{70}$ OmnesViae: Arelato (Arles). DARE: < http://imperium.ahlfeldt.se/index.php?id=173>. 


\section{Seção 2: de Arelate (Arles) a Mediolanum (Milão)}

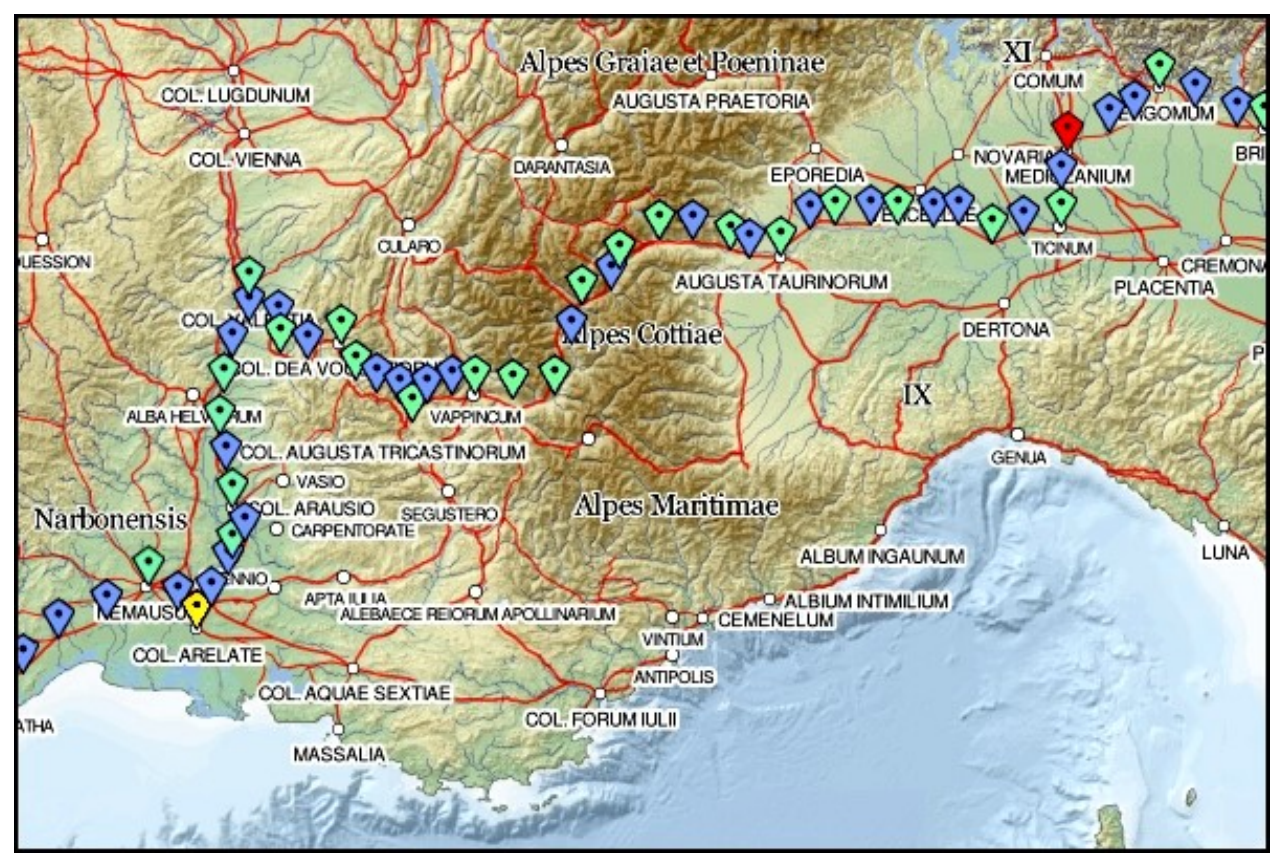

Mapa 2: trecho entre Arelate (Arles), em amarelo, e Mediolanum (Milão), em vermelho; em azul estão registradas as mutationes (postos de muda) e em verde as mansiones (pousos).

\begin{tabular}{|c|c|c|c|}
\hline 552 & 10 & Ciuitas Arelate mil VIII. & $\begin{array}{l}\text { [pouso na] cidade de Arelate (Arles), } 8 \\
\text { milhas. }\end{array}$ \\
\hline \multirow[t]{6}{*}{553} & $\begin{array}{l}1 \\
2\end{array}$ & $\begin{array}{l}\text { Fit a Bordegala Arelate } \\
\text { usque mil CCCLXXII, } \\
\text { mutationes XXX, } \\
\text { mansiones XI. }\end{array}$ & $\begin{array}{l}\text { Percorridas de Bordegala (Bordeaux) até } \\
\text { Arelate (Arles) } 372 \text { milhas, [passando por] } \\
30 \text { postos de muda e } 11 \text { pousos. }\end{array}$ \\
\hline & 3 & $\begin{array}{l}\text { Mutatio Arnagene mil } \\
\text { VIII }^{71}\end{array}$ & $\begin{array}{l}\text { posto de muda em Arnagene (Tarascon- } \\
\text { sur-Rhône), } 8 \text { milhas; }{ }^{72}\end{array}$ \\
\hline & 4 & mutatio Bellinto mil X & $\begin{array}{l}\text { posto de muda em Bellintum (Graveson), } \\
10 \text { milhas; }{ }^{73}\end{array}$ \\
\hline & 5 & Ciuitas Auenione mil VI ${ }^{74}$ & $\begin{array}{l}\text { [pouso na] cidade de Avinio (Avignon), } 5 \\
\text { milhas; } 75\end{array}$ \\
\hline & 6 & mutatio Cypresseta mil VI ${ }^{76}$ & $\begin{array}{l}\text { posto de muda em Cepressata (Sorgues, } \\
\text { no departamento de Vaucluse), } 5 \text { milhas; }{ }^{77}\end{array}$ \\
\hline & 7 & ciuitas Arausione mil XV & $\begin{array}{l}\text { [pouso na] cidade de Arausio (Orange), } 15 \\
{\text { milhas; }{ }^{78}}\end{array}$ \\
\hline
\end{tabular}

${ }^{71} \mathrm{~V}$ : “Arnagene” - P: “Arnagine”.

72 OmnesViae: Ernagina (Tarascon). Ermaginum = St. Étienne-du-Grès, segundo: $<$ http://fr.wikipedia.org/wiki/Ernaginum>. Segundo o DARE, Ermaginum corresponde à localidade de Saint-Gabriel, pertencente à comuna de Tarascon (Bouches-du-Rhône):

$<$ http://imperium.ahlfeldt.se/index.php?id=7792>.

${ }^{73}$ DARE: <http://imperium.ahlfeldt.se/index.php?id=19150>.

${ }^{74} \mathrm{~V}$ : “Auinione" - P: “Auenione”.

${ }^{75}$ OmnesViae: Avennione (Avignon). DARE: <http://imperium.ahlfeldt.se/index.php?id=172>.

${ }^{76}$ V: “Cepressata” - P: "Cypressata”.

${ }^{77}$ DARE: <http://imperium.ahlfeldt.se/index.php?id=11172>.

${ }^{78}$ OmnesViae: Arusione (Orange). DARE: < http://imperium.ahlfeldt.se/index.php?id=166>. 


\begin{tabular}{|c|c|c|c|}
\hline & 8 & $\begin{array}{l}\text { mutatio ad Letoce mil } \\
\text { XIII }^{79}\end{array}$ & $\begin{array}{l}\text { posto de muda em Letoce (Bollène), } 13 \\
\text { milhas; }{ }^{80}\end{array}$ \\
\hline & 9 & $\begin{array}{l}\text { mutatio Nouem Craris mil } \\
\mathrm{X}\end{array}$ & $\begin{array}{l}\text { pouso em Novem Craris (Les Granges- } \\
\text { Gontardes), } 10 \text { milhas; } 81\end{array}$ \\
\hline & 10 & mansio Acuno mil X & pouso em Acunum (Ancône), 10 milhas; ${ }^{82}$ \\
\hline \multirow[t]{9}{*}{554} & 1 & mutatio Uacianis mil XII ${ }^{83}$ & $\begin{array}{l}\text { posto de muda em Uaciana (Saulce-sur- } \\
\text { Rhône), } 12 \text { milhas; } 84\end{array}$ \\
\hline & 2 & mutatio Umbenno mil XII & $\begin{array}{l}\text { posto de muda em Umbennum (Étoile-sur- } \\
\text { Rhône), } 12 \text { milhas; } 85\end{array}$ \\
\hline & 3 & Ciuitas Ualentia mil VIIII & $\begin{array}{l}\text { [pouso na] cidade de Ualentia (Valence, } \\
\text { no departamento de Drôme), } 9 \text { milhas; }{ }^{86}\end{array}$ \\
\hline & 4 & $\begin{array}{l}\text { mutatio Cerebelliaca mil } \\
\text { XII }\end{array}$ & $\begin{array}{l}\text { posto de muda em Cerebeliaca (Ourches), } \\
7 \text { milhas; }{ }^{87}\end{array}$ \\
\hline & 5 & mansio Agusta mil $\mathrm{X}^{88}$ & $\begin{array}{l}\text { pouso em Agusta (Aouste-sur-Sye), } 10 \\
\text { milhas; } 89\end{array}$ \\
\hline & 6 & mutatio Darentiaca mil XII & $\begin{array}{l}\text { posto de muda em Darentiaca (Saillans, } \\
\text { no departamento de Drôme), } 12 \text { milhas; }{ }^{90}\end{array}$ \\
\hline & 7 & $\begin{array}{l}\text { ciuitas Dea Uocontiorum } \\
\text { mil XVI }\end{array}$ & $\begin{array}{l}\text { [pouso na] cidade de Dea Uocontiorum } \\
\text { (Die), } 16 \text { milhas; }{ }^{92}\end{array}$ \\
\hline & 8 & mansio Luco mil XII & $\begin{array}{l}\text { pouso em Lucus (Luc-en-Diois), } 12 \\
\text { milhas; } 93\end{array}$ \\
\hline & 9 & $\begin{array}{l}\text { mutatio Vologates mil } \\
\text { VIIII. }^{94}\end{array}$ & $\begin{array}{l}\text { posto de muda em Vologatae (Beaurières), } \\
9 \text { milhas; }{ }^{95}\end{array}$ \\
\hline \multirow[t]{2}{*}{555} & 1 & $\begin{array}{l}\text { Inde ascenditur Gaura } \\
\text { mons. }\end{array}$ & $\begin{array}{l}\text { A partir daqui sobe-se o monte Gaura } \\
\text { (Col de Cabre); }\end{array}$ \\
\hline & 2 & Mutatio Cambono mil VIII & $\begin{array}{l}\text { posto de muda em Cambonum (Saint- } \\
\text { Pierre-d'Argençon), } 8 \text { milhas; } 97\end{array}$ \\
\hline
\end{tabular}

\footnotetext{
${ }^{79}$ A passagem “mutatio ad Letoce mil XIII” não consta de V:.

${ }^{80}$ DARE: <http://imperium.ahlfeldt.se/index.php?id=17000>.

${ }^{81}$ DARE: <http://imperium.ahlfeldt.se/index.php?id=17340>.

${ }^{82}$ OmnesViae: Acunum (Montélimar). Montélimar é cidade vizinha a Ancône. DARE:

$<$ http://imperium.ahlfeldt.se/index.php?id=7790>. DARE:

$<$ http://imperium.ahlfeldt.se/index.php?id=7790>.

${ }^{83}$ V: "Bancianis" - P: "Vancianis".

${ }^{84}$ OmnesViae: Batiana (Saulce-sur-Rhone). O DARE identifica Batiana com a moderna Bance, localidade pertencente à comuna de Saulce-sur-Rhone:

$<$ http://imperium.ahlfeldt.se/index.php?id=17338>.

${ }^{85}$ DARE: <http://imperium.ahlfeldt.se/index.php?id=23136>.

${ }^{86}$ OmnesViae: Valentia (Valence). DARE: <http://imperium.ahlfeldt.se/index.php?id=191>.

${ }^{87}$ DARE: <http://imperium.ahlfeldt.se/index.php?id=17337>.

${ }^{88} \mathrm{~V}$ : “Agusta” - P: “Augusta”.

${ }^{89}$ OmnesViae: Augustum (Aouste-sur-Sye). DARE:

$<$ http://imperium.ahlfeldt.se/index.php?id=8046>.

${ }^{90}$ DARE: <http://imperium.ahlfeldt.se/index.php?id=11176>.

${ }^{91} \mathrm{~V}$ : "Deanocontinorum" - P: "Dea Uocontiorum".

92 OmnesViae: Bocontiorvm Addeam (Dio). DARE:

$<$ http://imperium.ahlfeldt.se/index.php?id=190>.

${ }^{93}$ OmnesViae: Luco (Luc-en-Diois). DARE: <http://imperium.ahlfeldt.se/index.php?id=8047>.

${ }^{94}$ V: "Vologates" - P: "Vologatis".

${ }^{95}$ DARE: <http://imperium.ahlfeldt.se/index.php?id=11174>.

${ }^{96}$ Gaura mons = Col de Cabre, segundo:

http://www.perseus.tufts.edu/hopper/text?doc=Perseus:text:1999.04.0064:entry=gaura-mons-geo

${ }^{97}$ DARE: <http://imperium.ahlfeldt.se/index.php?id=17336>.
} 


\begin{tabular}{|c|c|c|c|}
\hline & 3 & $\begin{array}{l}\text { mansio monte Seleuci mil } \\
\text { VIII }\end{array}$ & $\begin{array}{l}\text { pouso no monte Seleucus (La Bâtie- } \\
\text { Montsaléon), } 8 \text { milhas; } 98\end{array}$ \\
\hline & 4 & mutatio Dauiano mil VIII & $\begin{array}{l}\text { posto de muda em Davianum (Veynes), } 8 \\
\text { milhas; } 99\end{array}$ \\
\hline & 5 & mutatio ad Fine mil VIII ${ }^{100}$ & $\begin{array}{l}\text { posto de muda na fronteira (La Roche-des- } \\
\text { Arnauds), } 8 \text { milhas; }{ }^{101}\end{array}$ \\
\hline & 6 & mansio Uapinco mil XI ${ }^{102}$ & pouso em Uapincum (Gap), 11 milhas; ${ }^{103}$ \\
\hline & 7 & mansio Catorigas mil XII ${ }^{104}$ & $\begin{array}{l}\text { pouso em Catorigae (Chorges), } 12 \\
\text { milhas; } 105\end{array}$ \\
\hline & 8 & $\begin{array}{l}\text { mansio Ebreduno mil } \\
\text { XVI. }{ }^{106}\end{array}$ & $\begin{array}{l}\text { pouso em Ebreduno (Embrun), } 16 \\
\text { milhas. }{ }^{107}\end{array}$ \\
\hline & 9 & $\begin{array}{l}\text { Inde incipiunt Alpes } \\
\text { Cottiae. }{ }^{108}\end{array}$ & $\begin{array}{l}\text { A partir daqui começam os Alpes Cottiae } \\
\text { (Alpes Cótios). }\end{array}$ \\
\hline & 10 & Mutatio Rame mil XVII ${ }^{109}$ & $\begin{array}{l}\text { posto de muda em Rama (La Roche-de- } \\
\text { Rame), } 17 \text { milhas; }{ }^{110}\end{array}$ \\
\hline & 11 & $\begin{array}{l}\text { mansio Byrigane mil } \\
\text { XVII. }{ }^{111}\end{array}$ & $\begin{array}{l}\text { pouso em Byrigante (Briançon), } 17 \\
\text { milhas. } 112\end{array}$ \\
\hline \multirow[t]{6}{*}{556} & 1 & Inde ascendis Matronam. & $\begin{array}{l}\text { A partir daqui sobes o [monte] Matrona } \\
\text { (Mont Genêvre). }{ }^{113}\end{array}$ \\
\hline & 2 & Mutatio Gesdaone mil X & $\begin{array}{l}\text { posto de muda em Gesdaona (Cesana } \\
\text { Torinese), } 10 \text { milhas; }{ }^{114}\end{array}$ \\
\hline & 3 & mansio ad Marte mil VIIII & $\begin{array}{l}\text { pouso no [templo] de Marte (Oulx), } 9 \\
\text { milhas; }{ }^{115}\end{array}$ \\
\hline & 4 & ciuitas Segucio mil XVI. ${ }^{116}$ & $\begin{array}{l}\text { [pouso na] cidade de Segucio (Susa), } 16 \\
\text { milhas. }\end{array}$ \\
\hline & 5 & Inde incipit Italia. & A partir daqui começa a Italia. \\
\hline & 6 & $\begin{array}{l}\text { Mutatio ad Duodecimum } \\
\text { mil XII }\end{array}$ & $\begin{array}{l}\text { posto de muda no décimo segundo } \\
\text { [miliário] (San Didero), } 12 \text { milhas; }{ }^{118}\end{array}$ \\
\hline
\end{tabular}

${ }^{98}$ DARE: <http://imperium.ahlfeldt.se/index.php?id=8048>.

${ }^{99}$ DARE: < http://imperium.ahlfeldt.se/index.php?id=11175>.

${ }^{100}$ V: “Ad Finem" - P: “Ad Fine”.

${ }^{101}$ DARE: <http://imperium.ahlfeldt.se/index.php?id=17335>.

${ }^{102} \mathrm{~V}$ : "Vappiuco" - "P: Vapinco".

${ }^{103}$ OmnesViae: Vapincum (Gap). DARE: <http://imperium.ahlfeldt.se/index.php?id=189>.

${ }^{104}$ V: “Catoricas” - P: “Catorigas”.

105 OmnesViae: Catorigomago (Chorges). DARE: <http://imperium.ahlfeldt.se/index.php?id=8044>.

${ }^{106}$ V: "Ebreduno" - P: "Hebriduno".

${ }^{107}$ OmnesViae: Eburuno (Embrun). DARE: < http://imperium.ahlfeldt.se/index.php?id=188>.

${ }^{108} \mathrm{~V}$ : Inde incipiunt Alpes Penninae - P: Inde incipiunt Alpes Cottiae.

${ }^{109}$ V: "Rame" - P: "Ramae".

110 OmnesViae: Rama (Rame). DARE: <http://imperium.ahlfeldt.se/index.php?id=8045>.

${ }^{111} \mathrm{~V}$ : "Byrigane" - P: "Byrigantum”.

112 OmnesViae: Brigantione (Briançon). DARE: <http://imperium.ahlfeldt.se/index.php?id=1853>.

113 OmnesViae: In Alpe Cottia ( Montgenèvre). Matrona Mons = Montgenèvre, segundo: $<$ http://www.perseus.tufts.edu/hopper/text?doc=Perseus\%3Atext\%3A1999.04.0064\%3Aentry\%3D matrona-geo $>$.

${ }^{114}$ DARE: <http://imperium.ahlfeldt.se/index.php?id=11066>.

115 OmnesViae: Martis. DARE: <http://imperium.ahlfeldt.se/index.php?id=11065>.

${ }^{116}$ V: "Segucio" - P: "Secussione".

${ }^{117}$ OmnesViae: Segusione (Susa). DARE: < http://imperium.ahlfeldt.se/index.php?id=1868>.

118 DARE: <http://imperium.ahlfeldt.se/index.php?id=17125>. 


\begin{tabular}{|c|c|c|c|}
\hline & 7 & mansio ad Fines mil XII & $\begin{array}{l}\text { pouso na fronteira (Avigliana), } 12 \\
\text { milhas; }{ }^{119}\end{array}$ \\
\hline & 8 & $\begin{array}{l}\text { mutatio ad Octauu mil } \\
\text { VIII }^{120}\end{array}$ & $\begin{array}{l}\text { posto de muda no oitavo [miliário] } \\
\text { (Rivoli), } 8 \text { milhas; }{ }^{121}\end{array}$ \\
\hline & 9 & Ciuitas Taurinis mil VIII & [pouso na] cidade de Taurini (Turim); ${ }^{122}$ \\
\hline & 10 & mutatio ad Decimum mil X & $\begin{array}{l}\text { posto de muda no décimo [miliário] } \\
\text { (Brandizzo), } 10 \text { milhas; }{ }^{123}\end{array}$ \\
\hline \multirow[t]{11}{*}{557} & 1 & mansio Quadratis mil XII & $\begin{array}{l}\text { pouso em Quadrate (Verolengo), } 7 \\
\text { milhas; }{ }^{124}\end{array}$ \\
\hline & 2 & mutatio Ceste mil XI & $\begin{array}{l}\text { posto de muda em Ceste (Crescentino), } 11 \\
\text { milhas; }{ }^{125}\end{array}$ \\
\hline & 3 & $\begin{array}{l}\text { mansio Regomago mil } \\
\text { VIII }^{126}\end{array}$ & pouso em Regomagus (Trino), 8 milhas; ${ }^{127}$ \\
\hline & 4 & mutatio ad Medias mil VIII & $\begin{array}{l}\text { posto de muda em Mediae (Villanova } \\
\text { Monferrato), } 8 \text { milhas; }{ }^{128}\end{array}$ \\
\hline & 5 & mutatio ad Cottias mil XIII & $\begin{array}{l}\text { posto de muda em Cottiae (Cozzo), } 8 \\
\text { milhas; }{ }^{129}\end{array}$ \\
\hline & 6 & mansio Laumello mil XII & $\begin{array}{l}\text { pouso em Laumellum (Lomello), } 12 \\
\text { milhas; } 130\end{array}$ \\
\hline & 7 & mutatio Duriis mil VIII ${ }^{131}$ & $\begin{array}{l}\text { posto de muda em Durie (Dorno), } 8 \\
\text { milhas; }{ }^{132}\end{array}$ \\
\hline & 8 & Ciuitas Ticeno mil XII ${ }^{133}$ & $\begin{array}{l}\text { [pouso na] cidade de Ticenum (Pavia), } 12 \\
\text { milhas; }^{134}\end{array}$ \\
\hline & 9 & mutatio ad decimum mil X & $\begin{array}{l}\text { posto de muda no décimo [miliário] } \\
\text { (Lacchiarella), } 10 \text { milhas; }{ }^{135}\end{array}$ \\
\hline & 10 & Ciuitas Mediolano mil $\mathrm{X}^{136}$ & $\begin{array}{l}\text { [pouso na] cidade de Mediolanum (Milão), } \\
10 \text { milhas; }{ }^{137}\end{array}$ \\
\hline & 11 & $\begin{array}{l}\text { \{mansio fluuio frigido mil } \\
\text { XII. }\}^{138}\end{array}$ & \{pouso no rio gelado, 12 milhas. ${ }^{139}$ \\
\hline
\end{tabular}

119 DARE: <http://imperium.ahlfeldt.se/index.php?id=17191>.

${ }^{120}$ V: “ad Octauu” - P: “ad Octauum”.

${ }^{121}$ DARE: <http://imperium.ahlfeldt.se/index.php?id=17127>.

122 OmnesViae: Augusta Taurinorum (Torino). DARE:

$<$ http://imperium.ahlfeldt.se/index.php?id=1467>.

123 DARE: <http://imperium.ahlfeldt.se/index.php?id=17128>.

124 DARE: <http://imperium.ahlfeldt.se/index.php?id=17129>.

125 DARE: <http://imperium.ahlfeldt.se/index.php?id=17130>.

${ }^{126}$ V: "Regomago" - P: "Rigomago".

127 DARE: <http://imperium.ahlfeldt.se/index.php?id=11062>.

${ }^{128}$ DARE: <http://imperium.ahlfeldt.se/index.php?id=17131>.

129 OmnesViae: Cutiae (Cozzo Candia Lomellina). DARE:

$<$ http://imperium.ahlfeldt.se/index.php?id=11115>.

${ }^{130}$ OmnesViae: Laumellum (Lomello). DARE: <http://imperium.ahlfeldt.se/index.php?id=5442> .

131 V: "Duris" - P: "Duniis".

132 DARE: <http://imperium.ahlfeldt.se/index.php?id=11146>.

${ }^{133}$ V: “Ticino" - P: “Ticeno".

134 OmnesViae: Ticenum (Pavia). DARE: <http://imperium.ahlfeldt.se/index.php?id=1437>.

135 DARE: <http://imperium.ahlfeldt.se/index.php?id=17141>.

136 V: "Mediolano" - P: "Mediolanum".

137 OmnesViae: Mediolanum (Milano). DARE: <http://imperium.ahlfeldt.se/index.php?id=1445>.

${ }^{138}$ A passagem "mansio fluuio frigido mil XII" consta tanto de V quanto de P.

139 No Itinerarium Antonini, do século anterior, “Fluuius Frigidus” identificava uma estação entre Aquileia (idem) e Logaticum (Logatec). Existiriam, então, dois “fluuii frigidi”? Não há consenso em 


\begin{tabular}{|l|l|l|l|}
\hline 558 & 1, & $\begin{array}{l}\text { Fit ab Arillato Mediolano } \\
\text { usque mil CCCLXXV, } \\
\text { mutationes LXIII, } \\
\text { mansiones XXII. }\end{array}$ & $\begin{array}{l}\text { Percorridas de Arelate (Arles) até } \\
\text { Mediolanum (Milão) 475 milhas, } \\
\text { [passando por] 63 postos de muda e } 22 \\
\text { pousos. }\end{array}$ \\
\hline
\end{tabular}

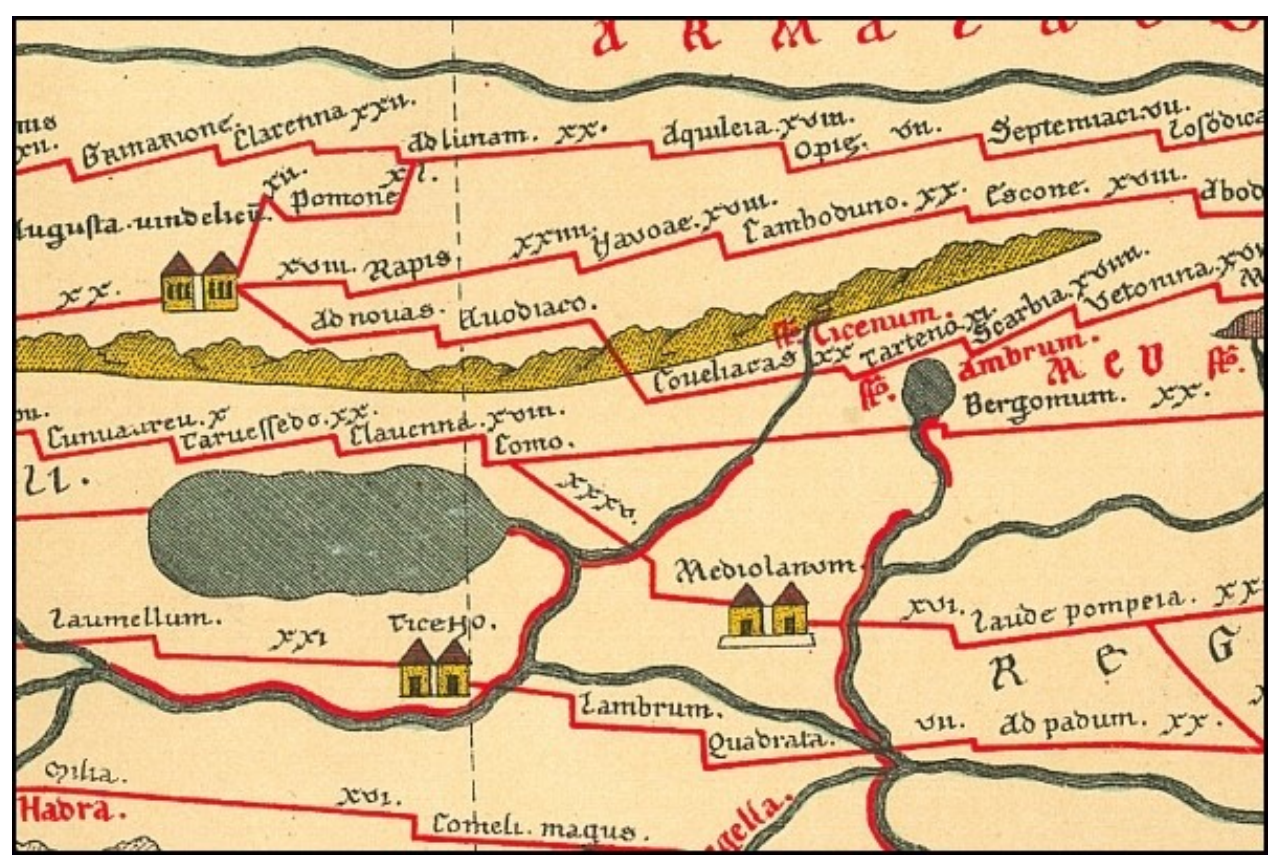

Figura 4: detalhe do fac-simile da Tabula Peutingeriana, com destaque para Mediolanum (Milão); indicado ao leste da cidade está o rio Ambrum (Lambro) e não o Frigidus.

relação a isso entre os editores do Itinerarium Burdigalense. Para Parthey e Pinder (1848), haveria apenas um rio, mas um copista teria cometido um erro e transcrito aí uma entrada da página seguinte do manuscrito à sua disposição: "haec mansio, post finitum Mediolanense iter superflua, in codice huc transposita est ex pagina sequente, ubi desideratur” (p. 264). Paul Geyer (1898), segue-os: "cum haec mansio post finem itineris Mediolanensis hic superflua si, Parthey huc ex pagina sequente uersum translatum esse statuit” (p. 6); assim como Stewart (1887): “This station is superfluous in its present position, and has apparently been transfered by its proper place before the Julian Alps” (p. 4). Petrus Wesselingius (1735), porém, defendeu a existência de dois “fluuii frigidi”, identificando o rio próximo a Mediolanum (Milão) com o Lamber (Lambro). Para tanto, recorreu à autoridade do geógrafo Philippus Cluverius (1580 - 1622), autor de Italia Antiqua (1624), publicado postumamente: "FLVVIO FRIGIDO.] Est hoc cognomine fluvius in A. Itin. p. 128. inter Aquileiam \& Longaticum mansionem, sed ab hoc divertissiums. Hunc nullum alium esse posse, quam qui alio nomine celebratur Lamber, hoc nominis hodieque custodiens, Ph. Cluverius L. I. Ital. Ant. C. 24 decernit; id si verum fuerit, oportet in numeris fit peccatum, proprius enim Mediolano abest” (p. 557). O principal problema da teoria de Wesselingius, parece-nos, é o fato do Lambro passar a apenas cerca de três quilômetros do centro de Milão. Não faria sentido a existência de duas mansiones tão próximas uma da outra, uma em Mediolanum e outra no rio. 


\section{Seção 3: de Mediolanum (Milão) a Aquileia}

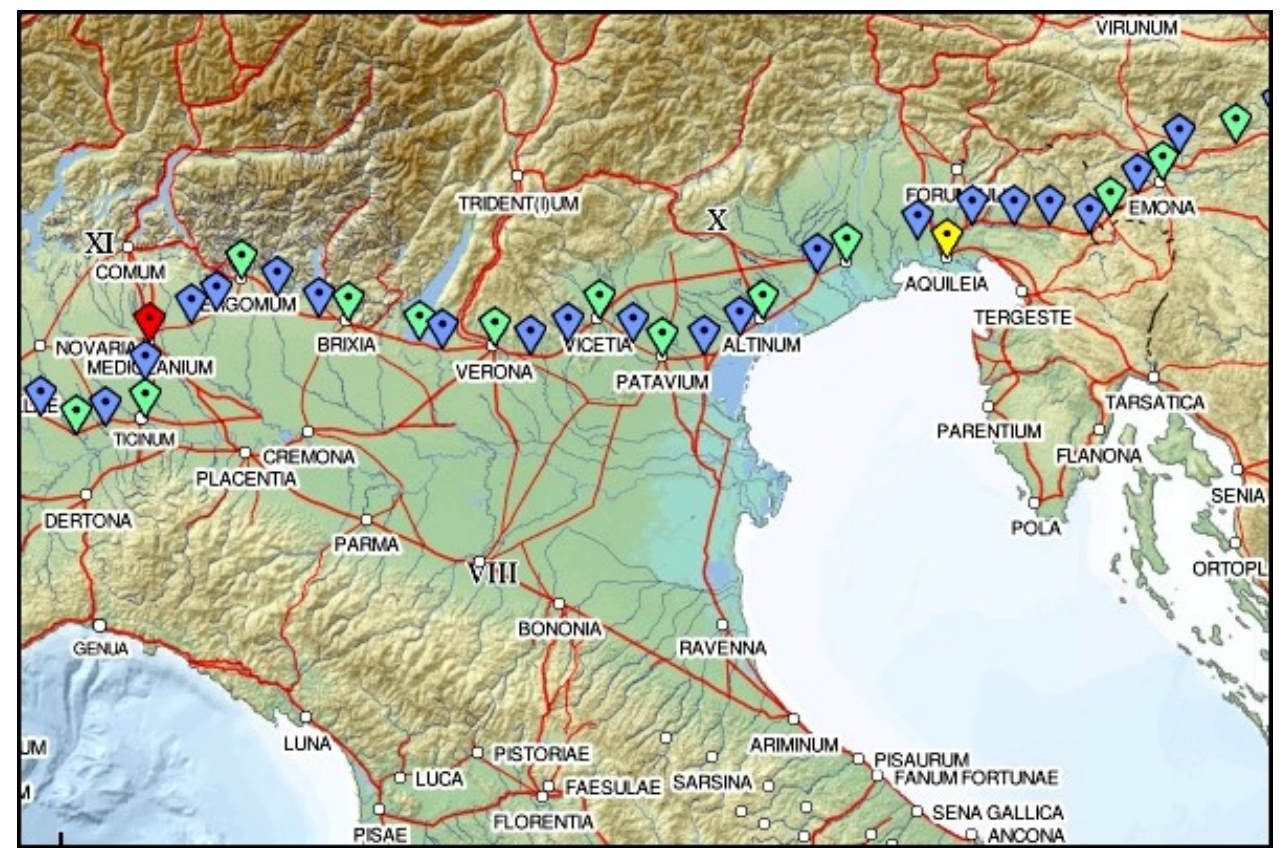

Mapa 3: trecho entre Mediolanum (Milão), em vermelho, e Aquileia (idem), em amarelo; em azul estão registradas as mutationes (postos de muda) e em verde as mansiones (pousos).

\begin{tabular}{|c|c|c|c|}
\hline & 10 & Ciuitas Mediolano mil X & $\begin{array}{l}\text { [pouso na] cidade de Mediolanum (Milão), } \\
10 \text { milhas; }\end{array}$ \\
\hline & 11 & $\begin{array}{l}\text { \{mansio fluuio frigido mil } \\
\text { XII. }\end{array}$ & \{pouso no rio gelado, 12 milhas.\} \\
\hline \multirow[t]{5}{*}{558} & $\begin{array}{l}1 \\
2\end{array}$ & $\begin{array}{l}\text { Fit ab Arillato Mediolano } \\
\text { usque mil CCCLXXV, } \\
\text { mutationes LXIII, } \\
\text { mansiones XXII. }\end{array}$ & $\begin{array}{l}\text { Percorridas de Arelate (Arles) até } \\
\text { Mediolanum (Milão) } 475 \text { milhas, } \\
\text { [passando por] } 63 \text { postos de muda e } 22 \\
\text { pousos. }\end{array}$ \\
\hline & 3 & Mutatio Argentea mil $\mathrm{X}^{140}$ & $\begin{array}{l}\text { posto de muda em Argentea (Gorgonzola), } \\
10 \text { milhas; }{ }^{141}\end{array}$ \\
\hline & 4 & $\begin{array}{l}\text { mutatio Ponte Aurioli mil } \\
\mathrm{X}^{142}\end{array}$ & $\begin{array}{l}\text { posto de muda na ponte de Aureolus } \\
\text { (Canonica d'Adda), } 10 \text { milhas; }{ }^{143}\end{array}$ \\
\hline & 5 & $\begin{array}{l}\text { Ciuitas Vergamo mil } \\
\text { XIII }^{144}\end{array}$ & $\begin{array}{l}\text { [pouso na] cidade de Vergamum } \\
\text { (Bergamo), } 13 \text { milhas; }{ }^{145}\end{array}$ \\
\hline & 6 & mutatio Tellegate mil XII & $\begin{array}{l}\text { posto de muda em Tellegate (Telgate), } 12 \\
\text { milhas; }{ }^{146}\end{array}$ \\
\hline
\end{tabular}

\footnotetext{
${ }^{140}$ V: “Argentea” - P: “Argentia”.

${ }^{141}$ DARE: <http://imperium.ahlfeldt.se/index.php?id=17142>.

142 V: "Ponte Aureoli" - P: "Ponte Aurioli".

143 Pons Aureolus = Pontirolo Vecchio, uma região da comuna de Canonica d'Adda, segundo: $<$ http://it.wikipedia.org/wiki/Canonica_d'Adda\#Storia>. DARE:

$<$ http://imperium.ahlfeldt.se/index.php?id=17143>.

${ }^{144}$ V: "Bergamo" - P: "Bergamo".

145 OmnesViae: Bergomum (Bergamo). DARE: <http://imperium.ahlfeldt.se/index.php?id=1465>.

146 DARE: <http://imperium.ahlfeldt.se/index.php?id=17144>.
} 


\begin{tabular}{|c|c|c|c|}
\hline & 7 & mutatio Tetellus mil X & $\begin{array}{l}\text { posto de muda em Tetellus (Ospitaletto), } \\
10 \text { milhas; }{ }^{147}\end{array}$ \\
\hline & 8 & Ciuitas Brixa mil $\mathrm{X}$ & $\begin{array}{l}\text { [pouso na] cidade de Brixa (Brescia), } 10 \\
\text { milhas; }{ }^{148}\end{array}$ \\
\hline & 9 & mansio ad flexum mil XI & pouso no desvio (Sirmione), 11 milhas; ${ }^{149}$ \\
\hline & 10 & mutatio Beneuentum mil X & $\begin{array}{l}\text { posto de muda em Beneuentum } \\
\text { (Castelnuovo del Garda), } 10 \text { milhas; }{ }^{150}\end{array}$ \\
\hline & 11 & Ciuitas Verona mil X & $\begin{array}{l}\text { [pouso na] cidade de Verona (Verona), } 10 \\
\text { milhas; }{ }^{: 51}\end{array}$ \\
\hline & 12 & mutatio Cadiano mil $\mathrm{X}^{152}$ & $\begin{array}{l}\text { posto de muda em Cadianum (Caldiero), } \\
10 \text { milhas; }{ }^{153}\end{array}$ \\
\hline & 13 & mutatio Aureos mil X ${ }^{154}$ & $\begin{array}{l}\text { posto de muda em Aurei (Montebello } \\
\text { Vicentino), } 10 \text { milhas; } 155\end{array}$ \\
\hline 559 & 1 & Ciuitas Uicentia mil $\mathrm{X}^{156}$ & $\begin{array}{l}\text { [pouso na] cidade de Uicentia (Vicenza), } \\
10 \text { milhas; }{ }^{157}\end{array}$ \\
\hline & 2 & mutatio ad finem mil XI & $\begin{array}{l}\text { posto de muda na fronteira (Mestrino), } 11 \\
\text { milhas; }{ }^{\text {: }} \text { (18 }\end{array}$ \\
\hline & 3 & Ciuitas Pataui mil X & $\begin{array}{l}\text { [pouso na] cidade de Patavium (Pádua), } \\
10 \text { milhas; } 159\end{array}$ \\
\hline & 4 & $\begin{array}{l}\text { mutatio ad duodecimum } \\
\text { mil XII }\end{array}$ & $\begin{array}{l}\text { posto de muda no décimo segundo } \\
\text { [miliário] (Dolo), } 12 \text { milhas; }{ }^{161}\end{array}$ \\
\hline & 5 & mutatio ad nonum XI & $\begin{array}{l}\text { posto de muda no nono [miliário] } \\
\text { (Veneza), } 11 \text { milhas; }{ }^{162}\end{array}$ \\
\hline & 6 & Ciuitas Altino mil VIIII & $\begin{array}{l}\text { [pouso na] cidade de Altinum (Altino), } 9 \\
\text { milhas; } 163\end{array}$ \\
\hline & 7 & mutatio Sanos mil X & $\begin{array}{l}\text { posto de muda em Sanos (Santo Stino di } \\
\text { Livenza), } 10 \text { milhas; }{ }^{164}\end{array}$ \\
\hline & 8 & Ciuitas Concordia mil VIIII & $\begin{array}{l}\text { [pouso na] cidade de Concordia } \\
\text { (Concordia Sagittaria), } 9 \text { milhas; }{ }^{165}\end{array}$ \\
\hline & 9 & mutatio Apicilia mil VIIII & $\begin{array}{l}\text { posto de muda em Apicilia (Latisana), } 9 \\
\text { milhas; } 166\end{array}$ \\
\hline
\end{tabular}

${ }^{147}$ DARE: <http://imperium.ahlfeldt.se/index.php?id=17145>.

148 OmnesViae: Brixia (Brescia). DARE: <http://imperium.ahlfeldt.se/index.php?id=1463>.

149 DARE: <http://imperium.ahlfeldt.se/index.php?id=22353>.

${ }^{150}$ DARE: <http://imperium.ahlfeldt.se/index.php?id=17147>.

${ }^{151}$ OmnesViae: Verona (Verona). DARE: <http://imperium.ahlfeldt.se/index.php?id=1439>.

152 V: "Cadianno" ou "Caclianno" - P: "Cadiano".

153 DARE: <http://imperium.ahlfeldt.se/index.php?id=17842>.

154 V: "Aureus" - P: “Auraeus".

155 DARE: <http://imperium.ahlfeldt.se/index.php?id=17841>.

156 V: "Uicentia” - P: “Uincentia”.

${ }^{157}$ OmnesViae: Vicetia. DARE: <http://imperium.ahlfeldt.se/index.php?id=1461>.

158 DARE: <http://imperium.ahlfeldt.se/index.php?id=17840>.

159 OmnesViae: Patavis (Podova, sic). DARE: <http://imperium.ahlfeldt.se/index.php?id=10647>.

${ }^{160}$ Há uma lacuna no nome do local em $\mathrm{V}$.

${ }^{161}$ DARE: <http://imperium.ahlfeldt.se/index.php?id=17836>.

162 Ponte di Pietra, na comuna de Veneza, segundo o DARE:

$<$ http://imperium.ahlfeldt.se/index.php?id=17838>.

163 OmnesViae: Altinum (Altino). DARE: <http://imperium.ahlfeldt.se/index.php?id=17839>.

164 DARE: <http://imperium.ahlfeldt.se/index.php?id=16617>.

165 OmnesViae: Concordia (Concordia Sagittaria). DARE:

$<$ http://imperium.ahlfeldt.se/index.php?id=10645>.

166 DARE: <http://imperium.ahlfeldt.se/index.php?id=17983>. 


\begin{tabular}{|c|c|c|}
\hline 10 & mutatio ad undecimum $\mathrm{X}$ & $\begin{array}{l}\text { posto de muda no décimo primeiro } \\
\text { [miliário] (San Giorgio di Nogaro), } 10 \\
\text { milhas; }^{167}\end{array}$ \\
\hline 11 & Ciuitas Aquileia mil XI. & $\begin{array}{l}\text { [pouso na] cidade de Aquileia (Idem), } 11 \\
\text { milhas. }{ }^{168}\end{array}$ \\
\hline $\begin{array}{l}12 \\
13\end{array}$ & $\begin{array}{l}\text { Fit a Mediolanum Aquileia } \\
\text { usque milia CCLI, } \\
\text { mutationes XXIIII, } \\
\text { mansiones VIIII. }\end{array}$ & $\begin{array}{l}\text { Percorridas de Mediolanum (Milão) a } \\
\text { Aquileia (idem) } 251 \text { milhas, [passando } \\
\text { por] } 24 \text { postos de muda e } 9 \text { pousos. }\end{array}$ \\
\hline
\end{tabular}

${ }^{167}$ DARE: <http://imperium.ahlfeldt.se/index.php?id=17984>.

168 OmnesViae: Aquileia (Aquileia). DARE: <http://imperium.ahlfeldt.se/index.php?id=1468>. 


\section{Seção 4: de Aquileia (idem) a Sirmium (Sremska Mitrovica)}

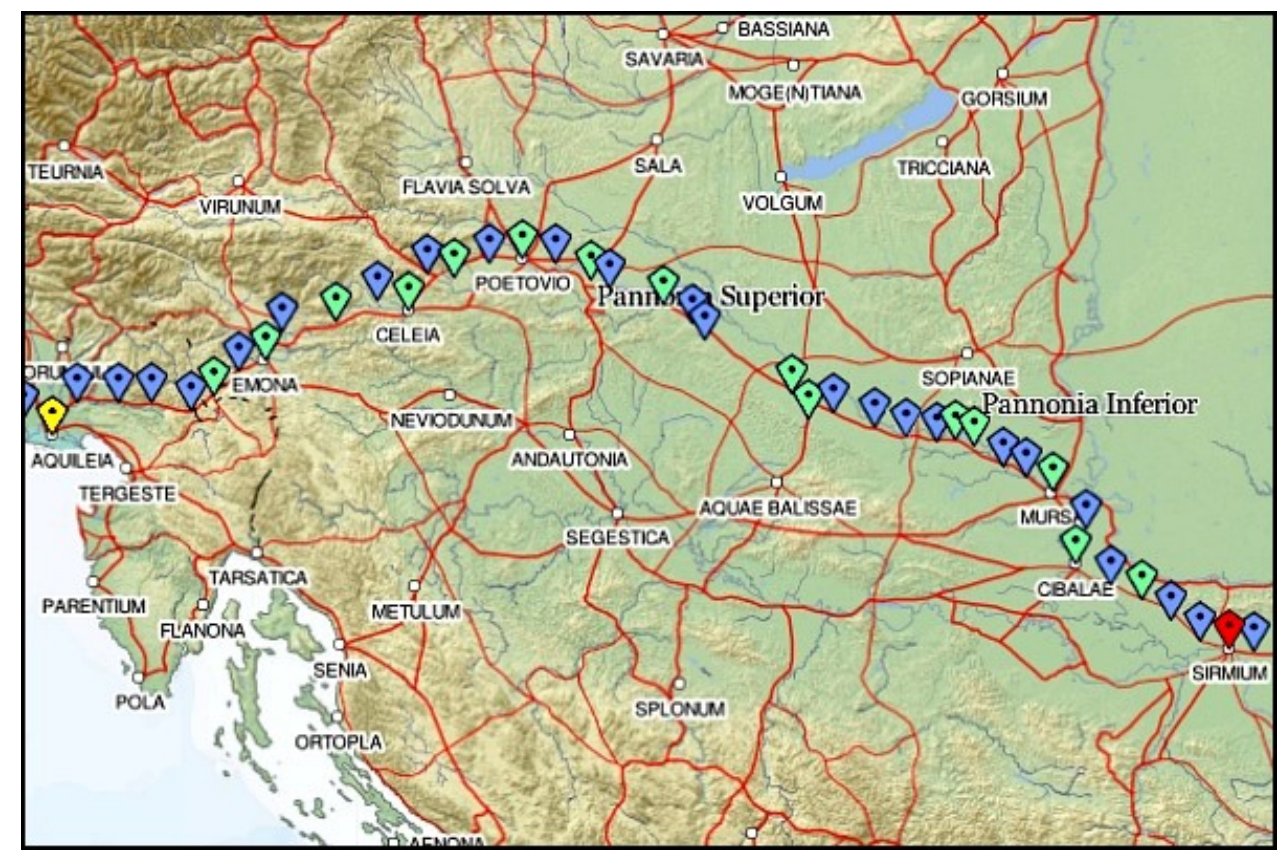

Mapa 4: trecho entre Aquileia (idem), em amarelo, e Sirmium (Sremska Mitrovica), em vermelho; em azul estão registradas as mutationes (postos de muda) e em verde as mansiones (pousos).

\begin{tabular}{|c|c|c|c|}
\hline & 11 & Ciuitas Aquileia mil XI. & $\begin{array}{l}\text { [pouso na] cidade de Aquileia (Idem), } 11 \\
\text { milhas. }\end{array}$ \\
\hline & $\begin{array}{l}12 \\
13\end{array}$ & $\begin{array}{l}\text { Fit a Mediolanum Aquileia } \\
\text { usque milia CCLI, } \\
\text { mutationes XXIIII, } \\
\text { mansiones VIIII. }\end{array}$ & $\begin{array}{l}\text { Percorridas de Mediolanum (Milão) a } \\
\text { Aquileia (idem) } 251 \text { milhas, [passando } \\
\text { por] } 24 \text { postos de muda e } 9 \text { pousos. }\end{array}$ \\
\hline & 14 & $\begin{array}{l}\text { Mutatio ad undecimum mil } \\
\text { XI }\end{array}$ & $\begin{array}{l}\text { posto de muda no décimo primeiro } \\
\text { [miliário] (Gradisca d'Isonzo), } 11 \\
\text { milhas; }{ }^{169}\end{array}$ \\
\hline 560 & 1 & $\begin{array}{l}\text { mutatio ad Fornolus mil } \\
\text { XII }\end{array}$ & $\begin{array}{l}\text { posto de muda em Fornolus (Prvačina), } 12 \\
\text { milhas; } ; 170\end{array}$ \\
\hline & 2 & $\begin{array}{l}\text { \{mutatio Castra mil XII }\}^{171} \\
\text { [mansio fluuio frigido mil } \\
\text { XII.] }\end{array}$ & $\begin{array}{l}\text { \{posto de muda [na] fortaleza } \\
\text { (Ajdovscina), } 12 \text { milhas; } \\
\text { [pouso no rio gelado (atual Vipava), } 12 \\
\text { milhas.] }{ }^{172}\end{array}$ \\
\hline
\end{tabular}

${ }^{169}$ Mutatio ad undecimum = Gradisca d'Insonzo, segundo Magnani, Banchig e Ventura (2005, p. 86). MAGNANI, Stefano, BANCHIG, Pierluigi, VENTURA, Paola. Il ponte romano alla Mainizza e la via Aquileia-Enona. Estrato da Aquileia Nostra, anno LXXVI, 2005. DARE: $<$ http://imperium.ahlfeldt.se/index.php?id=17985>.

${ }^{170}$ DARE: <http://imperium.ahlfeldt.se/index.php?id=17987>.

${ }^{171}$ A passagem “mutatio Castra mil XII" consta tanto de V: quanto de P:.

172 Segundo Magnani, Banchig e Ventura (2005, p. 86), "mutatio Castra mil XII” do Itinerarium Burdigalense provavelmente coincide com "Fl[uuio] Frigido" da Tabula Peutingeriana e corresponde à atual Ajdovscina. DARE: <http://imperium.ahlfeldt.se/index.php?id=10732>. A polêmica quanto à identificação de tal "Fluuis Frigidus" não é nova. Sobre isso, vide a nota para a entrada 557:11, acima. Para Parthey e Pinder (1848), “mutatio Castra mil XII” é um acréscimo de um copista que percebeu que havia aí uma lacuna deixada por outro. Estaria faltando, aí, "mansio Fluvio Frigido mil XII”, colocada após 557:10. O Itinerarium Antonini daria suporte a tal teoria, porquanto ne- 


\begin{tabular}{|c|||l|l|}
\hline \multicolumn{1}{|c|}{3} & Inde sunt Alpes Iuliae. ${ }^{173}$ & $\begin{array}{l}\text { A partir daqui estão os Alpes Iuliae (Alpes } \\
\text { Júlios). }\end{array}$ \\
\hline 4 & $\begin{array}{l}\text { Ad Pirum summas Alpes } \\
\text { mil VIIII; }\end{array}$ & $\begin{array}{l}\text { Para o Pirum (platô Hrušica/selva di Piro) } \\
\text { por sobre os Alpes, 9 milhas; }{ }^{174}\end{array}$ \\
\hline 5 & mansio Longatico mil X & $\begin{array}{l}\text { pouso em Longaticum (Logatec), } 10 \\
\text { milhas; }{ }^{175}\end{array}$ \\
\hline
\end{tabular}

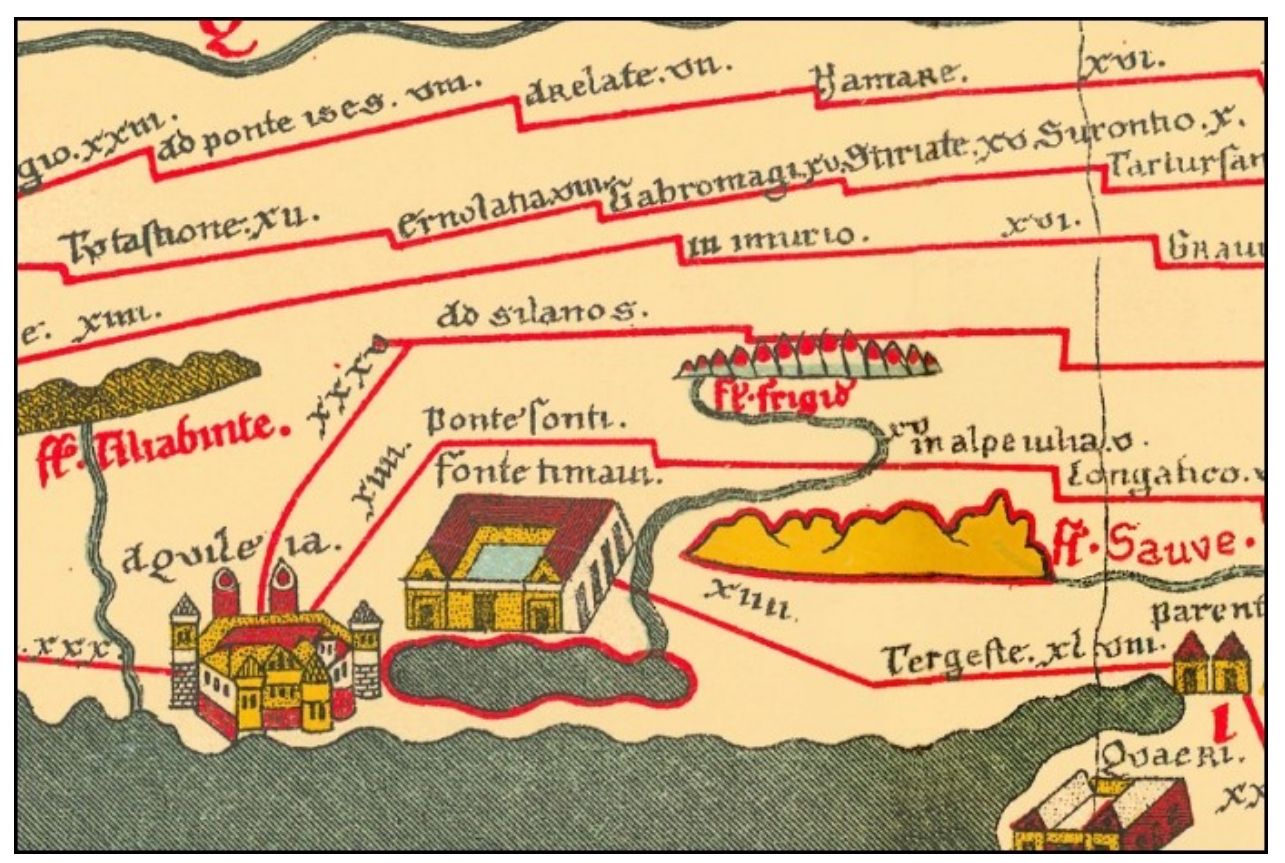

Figura 5: detalhe do fac-simile da Tabula Peutingeriana, com destaque para Aquileia (idem); indicado ao leste da cidade está o rio Frigio/Frigidus (atual Vipava).

\begin{tabular}{|c|c|c|c|}
\hline 560 & 6 & mutatio ad nonum mil VIIII & $\begin{array}{l}\text { posto de muda no nono [miliário] (Log pri } \\
\text { Brezovici), } 8 \text { milhas; }{ }^{176}\end{array}$ \\
\hline & 7 & Ciuitas Semona mil XIIII ${ }^{177}$ & $\begin{array}{l}\text { [pouso na] cidade de Semona (Liubliana), } \\
14 \text { milhas; }{ }^{178}\end{array}$ \\
\hline & 8 & $\begin{array}{l}\text { mutatio ad quartodecimo } \\
\text { mil X }\end{array}$ & $\begin{array}{l}\text { posto de muda no décimo quarto [miliário] } \\
\text { (Groblje pri Mengšu), } 10 \text { milhas; }{ }^{179}\end{array}$ \\
\hline & 9 & $\begin{array}{l}\text { mansio Hadrante mil } \\
\text { XIII }^{180}\end{array}$ & $\begin{array}{l}\text { pouso em Hadrante (Trojane), } 13 \\
\text { milhas; }{ }^{: 81}\end{array}$ \\
\hline & 10 & Fines Italiae et Norci. ${ }^{182}$ & Fronteira entre Italia (Itália) e Norcum \\
\hline
\end{tabular}

le se encontraria, para esse mesmo local, uma mansio: "versum omisit librarius. quod nunc legitur mut castra milia XII, ab alia manu postea adscriptum est. sed excidit potius hic, quod supra abundat, mansio Fluvio Frigido mil XII. eam enim mansionem hoc loco, id est XXXVI mil ultra Aquileiam, collocat Itinerarium Antonini p. 128” (p. 265).

${ }^{173} \mathrm{~V}$ : Inde surgunt Alpes Iuliae - P: Inde sunt Alpes Iuliae.

174 DARE: <http://imperium.ahlfeldt.se/index.php?id=10733>.

175 DARE: <http://imperium.ahlfeldt.se/index.php?id=10731>.

176 DARE: <http://imperium.ahlfeldt.se/index.php?id=13847>.

177 V: "Semona" - P: "Emona".

${ }^{178}$ OmnesViae: Emona (Liubliana). DARE: < http://imperium.ahlfeldt.se/index.php?id=10717>.

179 DARE: <http://imperium.ahlfeldt.se/index.php?id=10717>.

${ }^{180}$ A passagem "mansio Hadrante mil XIII" consta apenas de P:.

181 OmnesViae: Adrante (Trojane). DARE: <http://imperium.ahlfeldt.se/index.php?id=10765>.

182 V: "Fines Italiae" - P: "Fines Italiae et Norci". 


\begin{tabular}{|c|c|c|c|}
\hline & & & (Nórico). \\
\hline & 11 & Mutatio ad Medias mil XIII & $\begin{array}{l}\text { Posto de muda em Mediae (Ločica ob } \\
\text { Savinji), } 13 \text { milhas; }{ }^{183}\end{array}$ \\
\hline & 12 & Ciuitas Celeia mil XIII ${ }^{184}$ & $\begin{array}{l}\text { [pouso na] cidade de Celeia (Celje), } 13 \\
\text { milhas; }{ }^{185}\end{array}$ \\
\hline \multirow[t]{10}{*}{561} & 1 & mutatio Lotodos mil XII & $\begin{array}{l}\text { posto de muda em Lotodos (Stranice), } 12 \\
\text { milhas; }{ }^{186}\end{array}$ \\
\hline & 2 & $\begin{array}{l}\text { mansio Ragindone mil } \\
\text { XII }^{187}\end{array}$ & $\begin{array}{l}\text { Pouso em Ragindone (Spodnje Grušovje), } \\
12 \text { milhas; }{ }^{188}\end{array}$ \\
\hline & 3 & mutatio Pultovia mil XII ${ }^{189}$ & $\begin{array}{l}\text { posto de muda em Pultovia (Stražgonjca), } \\
12 \text { milhas; }{ }^{190}\end{array}$ \\
\hline & 4 & $\begin{array}{l}\text { Ciuitas Petouione mil } \\
\text { XII }^{191}\end{array}$ & $\begin{array}{l}\text { [pouso na] cidade de Potouio (Ptuj), } 12 \\
\text { milhas. }{ }^{192}\end{array}$ \\
\hline & 5,6 & $\begin{array}{l}\text { Transis pontem, intras } \\
\text { Pannoniam inferiorem. }\end{array}$ & $\begin{array}{l}\text { Atravessas a ponte e entras na Pannonia } \\
\text { Inferior (Panônia Inferior). }\end{array}$ \\
\hline & 7 & $\begin{array}{l}\text { Mutatio Ramista mil } \\
\text { VIIII }^{193}\end{array}$ & $\begin{array}{l}\text { Posto de muda em Ramesta (Formin, na } \\
\text { municipalidade de Gorišnica), } 9 \text { milhas; }{ }^{194}\end{array}$ \\
\hline & 8 & $\begin{array}{l}\text { mansio Aqua Uiua mil } \\
\text { VIIII }\end{array}$ & $\begin{array}{l}\text { pouso em Aqua Uiua (Petrijanec), } 9 \\
\text { milhas; } 195\end{array}$ \\
\hline & 9 & mutatio Popolis mil X ${ }^{196}$ & $\begin{array}{l}\text { posto de muda em Popili (Varaždin), } 10 \\
\text { milhas; }{ }^{197}\end{array}$ \\
\hline & 10 & Ciuitas Iouia mil VIIII & $\begin{array}{l}\text { [pouso na] cidade de Iouia (Ludbreg), } 9 \\
\text { milhas; }{ }^{198}\end{array}$ \\
\hline & 11 & mutatio Sunista mil VIIII & $\begin{array}{l}\text { posto de muda em Sunista (Kunovec } \\
\text { Breg), } 9 \text { milhas; }{ }^{199}\end{array}$ \\
\hline 562 & 1 & mutatio Peritur mil XII & $\begin{array}{l}\text { posto de muda em Peritur (Draganovec), } \\
12 \text { milhas; } ; 00\end{array}$ \\
\hline
\end{tabular}

183 DARE: <http://imperium.ahlfeldt.se/index.php?id=13843>.

184 V: “Caeia” - P: “Celeia”.

185 OmnesViae: Celeia (Celje). DARE: < http://imperium.ahlfeldt.se/index.php?id=10718>.

186 DARE: <http://imperium.ahlfeldt.se/index.php?id=13118>.

${ }^{187}$ V: "Ragendone" - P: "Ragindone".

188 OmnesViae: Ragandone (Spodnje Gruskovje). DARE:

$<$ http://imperium.ahlfeldt.se/index.php?id=13839>.

189 V: "Pultovia" - P: "Pultonia”.

190 DARE: <http://imperium.ahlfeldt.se/index.php?id=13838>.

${ }^{191}$ V: Potouione - P: Petouione.

192 OmnesViae: Petatione (Ptuj). Poetovio (atual Ptuj) era local de uma fortaleza romana, conforme mapa em CAMPBELL (2006, p. 10). DARE: <http://imperium.ahlfeldt.se/index.php?id=10719>.

193 V: "Ramesta" - P: "Ramista".

194 DARE: <http://imperium.ahlfeldt.se/index.php?id=13834>.

195 Aqua Viva = Petrijanec conforme: PESKAN, Ivana, PASCUTTINI, Vesna. Transformation of the Roman Aglomerations in the Northwestern Croatia. Economia e Territorio nell'Adriatico Centrale tra tarda Antichità e alto Medioevol (IV-VIII secolo). Ravena: 28 Febbraio - 1 marzo 2014. DARE: $<$ http://imperium.ahlfeldt.se/index.php?id=13832>.

196 V: "Popolis" - P: "Populis".

197 OmnesViae: Populos (Populi). DARE: <http://imperium.ahlfeldt.se/index.php?id=13831>.

198 Iovia = Ludbreg conforme: PESKAN, PASCUTTINI (2014). DARE:

$<$ http://imperium.ahlfeldt.se/index.php?id=10859>.

199 DARE: <http://imperium.ahlfeldt.se/index.php?id=13830>.

200 Omnes Viae: Piretis (Draganovec). DARE: < http://imperium.ahlfeldt.se/index.php?id=13829>. 


\begin{tabular}{|c|c|c|}
\hline 2 & mansio Lentolis mil XII & $\begin{array}{l}\text { pouso em Lentolae (Stari Gradac), } 12 \\
\text { milhas; }{ }^{201}\end{array}$ \\
\hline 3 & mutatio Cardono mil X & $\begin{array}{l}\text { posto de muda em Cardonum (talvez } \\
\text { Virovitica), } 10 \text { milhas; }{ }^{202}\end{array}$ \\
\hline 4 & $\begin{array}{l}\text { mutatio Coccones mil } \\
\text { XII }^{203}\end{array}$ & $\begin{array}{l}\text { posto de muda em Cocconi (talvez Sopje), } \\
12 \text { milhas; }{ }^{204}\end{array}$ \\
\hline 5 & mansio Serota mil X & $\begin{array}{l}\text { pouso em Serota (talvez próximo a } \\
\text { Podravska Moslavina), } 10 \text { milhas; }{ }^{205}\end{array}$ \\
\hline 6 & mutatio Bolenta mil X ${ }^{206}$ & $\begin{array}{l}\text { posto de muda em Bolenta (talvez } \\
\text { próxima a Viljevo), } 10 \text { milhas; }\end{array}$ \\
\hline 7 & mansio Maurianis mil VIIII & $\begin{array}{l}\text { pouso em Mauriana (talvez Donji } \\
\text { Miholjac), } 9 \text { milhas. }{ }^{207}\end{array}$ \\
\hline 8 & $\begin{array}{l}\text { Intras Pannoniam } \\
\text { superiorem. }\end{array}$ & $\begin{array}{l}\text { Entras na Pannonia Superior (Panônia } \\
\text { Superior). }\end{array}$ \\
\hline 9 & Mutatio Serena mil VIII & $\begin{array}{l}\text { Posto de muda em Serena (talvez } \\
\text { Podravski Podgajci), } 8 \text { milhas; }{ }^{208}\end{array}$ \\
\hline
\end{tabular}

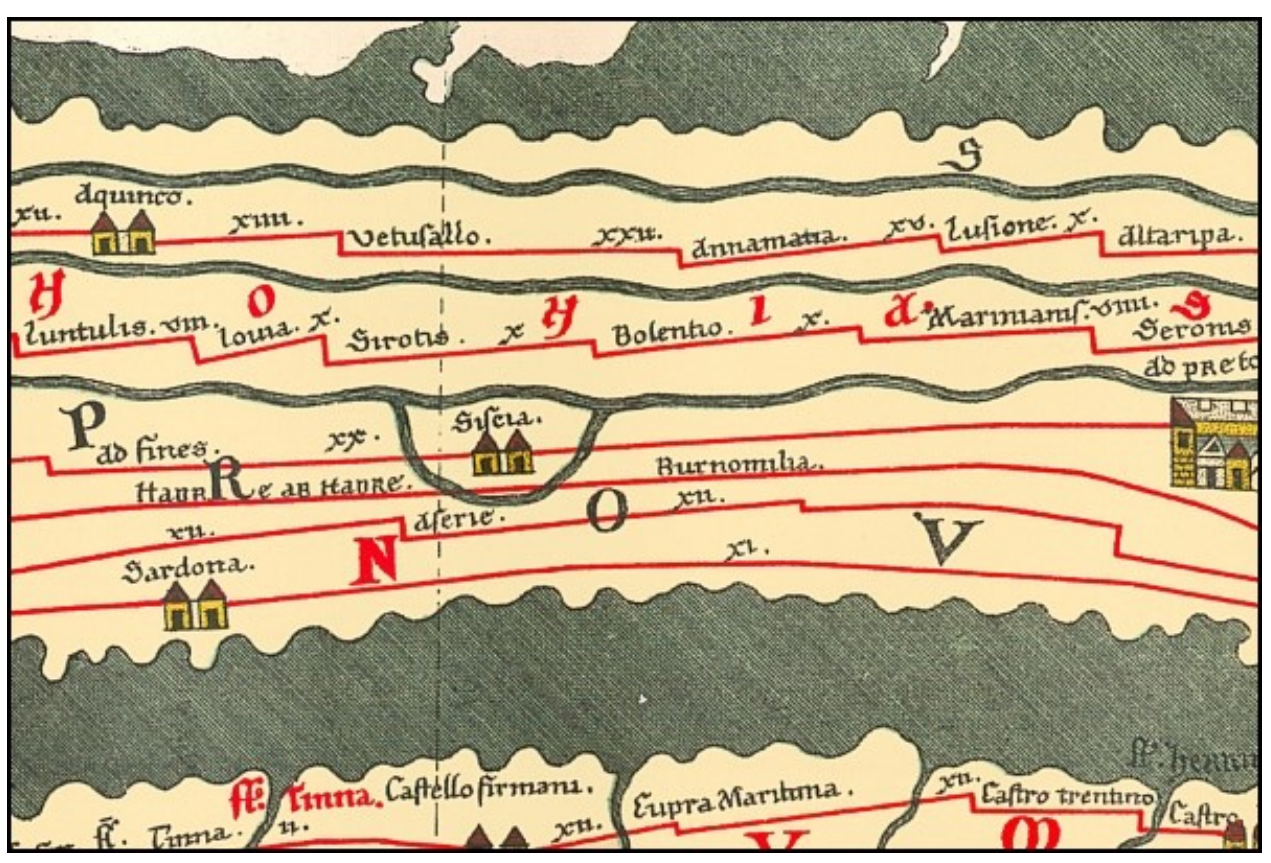

Figura 6: detalhe do fac-simile da Tabula Peutingeriana, com destaque para o trecho entre Luntulis/Lentolis e Seronis/Serena; note-se que nem todos os locais mencionados no Itinerarium Burdigalense aí aparecem: Luntulis/Lentolis (562:2) > Iouia/Cardono (562:3) > $(562: 4)>$ Sirotus/Serota (562:5) > Bolentio/Bolenta (562:6) > Marinianis/Mauriana (562:7) > Seronis/Serena (562:8) - a lacuna representa Cocconi (562:4).

${ }^{201}$ OmnesViae: Luntulis (Stari Gradac). DARE: <http://imperium.ahlfeldt.se/index.php?id=13828>.

202 OmnesViae: Iovia=Cardono. DARE: <http://imperium.ahlfeldt.se/places/10933> .

${ }^{203}$ V: "Coccones" - P: "Cocconis".

${ }^{204}$ DARE: <http://imperium.ahlfeldt.se/places/13785>.

${ }^{205}$ OmnesViae: Sirotis=Vitrovica. DARE: <http://imperium.ahlfeldt.se/places/13826>.

${ }^{206}$ V: "Bolentia" - P: "Bolenta".

207 OmnesViae: Marinianis=Magniana. DARE: <http://imperium.ahlfeldt.se/places/13825>.

${ }^{208}$ DARE: <http://imperium.ahlfeldt.se/places/13824>. 


\begin{tabular}{|c|c|c|c|}
\hline \multirow[t]{4}{*}{562} & 10 & mansio Vereis mil $\mathrm{X}$ & $\begin{array}{l}\text { pouso em Verei (talvez nos arredores de } \\
\text { Veliškovci), } 10 \text { milhas; } 209\end{array}$ \\
\hline & 11 & $\begin{array}{l}\text { mutatio Iouenalia mil } \\
\text { VIII }^{210}\end{array}$ & $\begin{array}{l}\text { posto de muda em Iouenalia (Valpovo), } 8 \\
\text { milhas; }\end{array}$ \\
\hline & 12 & mutatio Mersella mil VIII & $\begin{array}{l}\text { posto de muda em Mersella (Petrievce), } 8 \\
\text { milhas; }{ }^{212}\end{array}$ \\
\hline & 13 & Ciuitas Mursa mil X & $\begin{array}{l}\text { [pouso na] cidade de Mursa (Osijek), } 10 \\
\text { milhas; }{ }^{213}\end{array}$ \\
\hline \multirow[t]{8}{*}{563} & 1 & mutatio Leutuano mil XII & $\begin{array}{l}\text { posto de muda em Leutuanum (Bobota), } \\
12 \text { milhas; }{ }^{214}\end{array}$ \\
\hline & 2 & Ciuitas Cibalis mil XII ${ }^{215}$ & $\begin{array}{l}\text { [pouso na] cidade de Cibalae (Vincovci), } \\
12 \text { milhas; }\end{array}$ \\
\hline & 3 & mutatio Celena mil XI & $\begin{array}{l}\text { posto de muda em Celena (Orolik), } 11 \\
\text { milhas; } 217\end{array}$ \\
\hline & 4 & mansio Ulmo mil XI & pouso em Ulmus (Tovarnik), 11 milhas; ${ }^{218}$ \\
\hline & 5 & mutatio Spaneta mil X & $\begin{array}{l}\text { posto de muda em Spaneta (Bačinci), } 10 \\
\text { milhas; }{ }^{219}\end{array}$ \\
\hline & 6 & mutatio Uedulia mil VIII & $\begin{array}{l}\text { posto de muda em Uedulia (Martinci), } 8 \\
\text { milhas; }{ }^{220}\end{array}$ \\
\hline & 7 & Ciuitas Sirmium mil VIII. & $\begin{array}{l}\text { [pouso na] cidade de Sirmium (Sremska } \\
\text { Mitrovica), } 8 \text { milhas. }{ }^{221}\end{array}$ \\
\hline & $\begin{array}{l}8- \\
9\end{array}$ & $\begin{array}{l}\text { Fit ab Aquileia Sirmium } \\
\text { usque milia CCCCXII, } \\
\text { mansiones XIIII, } \\
\text { mutationes XXXVIIII. }\end{array}$ & $\begin{array}{l}\text { Percorridas de Aquileia (idem) a Sirmium } \\
\text { (Sremska Mitrovica), } 412 \text { milhas, } \\
\text { [passando por] } 14 \text { pousos e } 39 \text { postos de } \\
\text { muda. }\end{array}$ \\
\hline
\end{tabular}

${ }^{209}$ DARE: <http://imperium.ahlfeldt.se/index.php?id=13823>.

${ }^{210}$ V: "Iouenalia" - P: "Ioualia”.

${ }^{211}$ DARE: <http://imperium.ahlfeldt.se/index.php?id=10860>.

212 DARE: <http://imperium.ahlfeldt.se/index.php?id=10858>.

213 OmnesViae: Mursa Maior (Osijek). DARE: <http://imperium.ahlfeldt.se/index.php?id=10770>.

${ }^{214}$ DARE: <http://imperium.ahlfeldt.se/index.php?id=13809>.

215 V: “Cilicialis" - P: "Cibalis".

216 OmnesViae: Cibalae (Vincovci). DARE: < http://imperium.ahlfeldt.se/index.php?id=10862>.

${ }^{217}$ DARE: <http://imperium.ahlfeldt.se/index.php?id=13810>.

${ }^{218}$ DARE: <http://imperium.ahlfeldt.se/index.php?id=11091>.

${ }^{219}$ DARE: <http://imperium.ahlfeldt.se/places/11093>.

${ }^{220}$ DARE: <http://imperium.ahlfeldt.se/index.php?id=10863>.

${ }^{221}$ OmnesViae: Sirmium (Sremska Mitrovica). DARE:

$<$ http://imperium.ahlfeldt.se/index.php?id=10865>. 


\section{Seção 5: de Sirmium (Sremska Mitrovica) a Serdica (Sófia)}

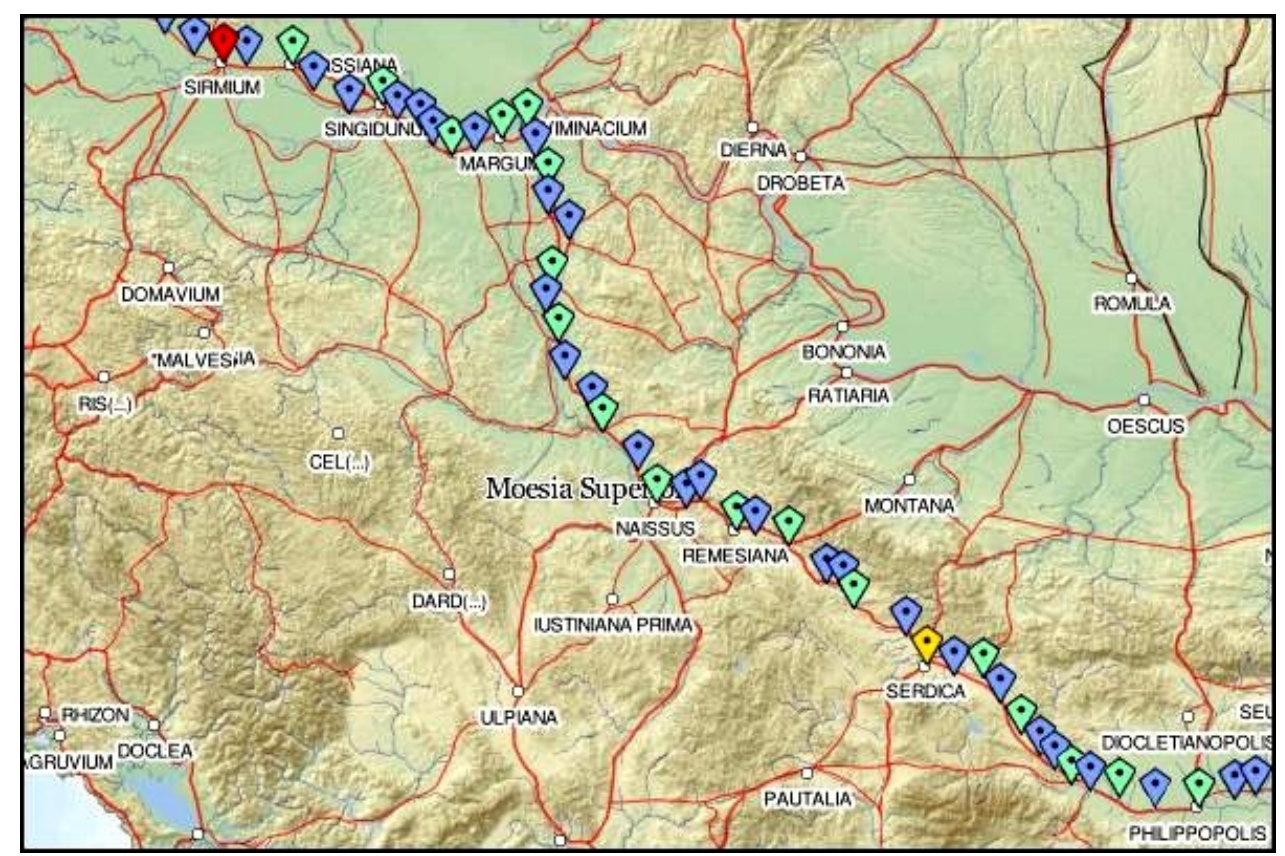

Mapa 5: trecho entre Sirmium (Sremska Mitrovica), em vermelho, e Serdica (Sófia), em amarelo; em azul estão registradas as mutationes (postos de muda) e em verde as mansiones (pousos).

\begin{tabular}{|c|c|c|c|}
\hline 563 & 7 & Ciuitas Sirmium mil VIII. & $\begin{array}{l}\text { [pouso na] cidade de Sirmium (Sremska } \\
\text { Mitrovica), } 8 \text { milhas. }\end{array}$ \\
\hline & $\begin{array}{l}8- \\
9\end{array}$ & $\begin{array}{l}\text { Fit ab Aquileia Sirmium } \\
\text { usque milia CCCCXII, } \\
\text { mansiones XIIII, } \\
\text { mutationes XXXVIIII. }\end{array}$ & $\begin{array}{l}\text { Percorridas de Aquileia (idem) a Sirmium } \\
\text { (Sremska Mitrovica), } 412 \text { milhas, } \\
\text { [passando por] } 14 \text { pousos e } 39 \text { postos de } \\
\text { muda. }\end{array}$ \\
\hline & 10 & Mutatio Fossis mil VIIII & $\begin{array}{l}\text { Posto de muda em Fossi (Sasinci), } 9 \\
\text { milhas; } 222\end{array}$ \\
\hline & 11 & Ciuitas Bassianis mil X & $\begin{array}{l}\text { [pouso na] cidade de Bassiani (Donji } \\
\text { Petrovci), } 10 \text { milhas; }{ }^{223}\end{array}$ \\
\hline & 12 & mutatio Nouiciani mil XII & $\begin{array}{l}\text { posto de muda em Nouiciani (Šimanovci), } \\
12 \text { milhas; } 224\end{array}$ \\
\hline & 13 & mutatio Altina mil XI & $\begin{array}{l}\text { posto de muda em Altina (Surčin), } 12 \\
\text { milhas; }{ }^{225}\end{array}$ \\
\hline & 14 & Ciuitas Singiduno mil VIII. & $\begin{array}{l}\text { [pouso na] cidade de Singidunum } \\
\text { (Belgrado), } 8 \text { milhas. }{ }^{226}\end{array}$ \\
\hline 564 & 1 & Finis Pannoniae et Misiae. & $\begin{array}{l}\text { Fronteira entre Pannonia (Panônia) e } \\
\text { Misia (Mésia). }\end{array}$ \\
\hline
\end{tabular}

222 DARE: $<$ http://imperium.ahlfeldt.se/index.php?id=13850>.

${ }^{223}$ DARE: <http://imperium.ahlfeldt.se/index.php?id=13848>.

224 Trata-se, provavelmente, do que o DARE identifica com o nome antigo de Scordisci: $<$ http://imperium.ahlfeldt.se/index.php?id=36507 $>$. Deve corresponder a esse local a moderna Šimanovci.

${ }^{225}$ DARE: <http://imperium.ahlfeldt.se/index.php?id=13849>.

${ }^{226}$ OmnesViae: Singiduno (Beograd). DARE: <http://imperium.ahlfeldt.se/index.php?id=10878>. 


\begin{tabular}{|c|c|c|c|}
\hline & 2 & mutatio ad sextum mil VI & $\begin{array}{l}\text { posto de muda no sexto [miliário] (Mali } \\
\text { Mokri Lug), } 6 \text { milhas; } 227\end{array}$ \\
\hline & 3 & $\begin{array}{l}\text { mutatio Tricornia Castra } \\
\text { mil VI }\end{array}$ & $\begin{array}{l}\text { posto de muda em Tricornia Castra } \\
\text { (Ritopek), } 6 \text { milhas; }{ }^{228}\end{array}$ \\
\hline & 4 & $\begin{array}{l}\text { mutatio ad sextum miliare } \\
\text { mil VII }\end{array}$ & $\begin{array}{l}\text { posto de muda no sexto milhar (Grocka), } \\
\text { sete milhas; } 229\end{array}$ \\
\hline & 5 & $\begin{array}{l}\text { Ciuitas Aureo Monte mil } \\
\text { VI }\end{array}$ & $\begin{array}{l}\text { [pouso na] cidade de Aureus Mons } \\
\text { (Seone), } 6 \text { milhas; } 230\end{array}$ \\
\hline & 6 & mutatio Uingeio mil VI ${ }^{231}$ & $\begin{array}{l}\text { posto de muda em Uingeium (Smederevo), } \\
6 \text { milhas; }{ }^{232}\end{array}$ \\
\hline & 7 & Ciuitas Margo mil VIIII & $\begin{array}{l}\text { [pouso na] cidade de Margum (Orašje), } 9 \\
\text { milhas; }{ }^{233}\end{array}$ \\
\hline & 8 & Ciuitas Uimitacio mil $\mathrm{X}^{234}$ & $\begin{array}{l}\text { [pouso na] cidade de Uiminacium (na } \\
\text { "velha” Kostolac ou Stari Kostolac), } 10 \\
\text { milhas. }\end{array}$ \\
\hline & 9 & $\begin{array}{l}\text { Ubi Diocletianus occidit } \\
\text { Carinum. }\end{array}$ & $\begin{array}{l}\text { Onde [o imperador] Diocletianus } \\
\text { (Diocleciano) matou Carinus (Carino). }\end{array}$ \\
\hline & 10 & $\begin{array}{l}\text { Mutatio ad nonum mil } \\
\text { VIIII }\end{array}$ & $\begin{array}{l}\text { Posto de muda no nono [miliário] } \\
\text { (Nabrđe, Požarevac), } 9 \text { milhas; }\end{array}$ \\
\hline 565 & 1 & $\begin{array}{l}\text { mansio Munecipio mil } \\
\text { VIIIII }^{237}\end{array}$ & $\begin{array}{l}\text { pouso em Munecipium (Kalište,na } \\
\text { municipalidade de Malo Crniće), } 9 \\
\text { milhas; }{ }^{238}\end{array}$ \\
\hline & 2 & mutatio Iouespago mil $\mathrm{X}^{239}$ & $\begin{array}{l}\text { posto de muda em Iouespagus (Veliki } \\
\text { Popovac), } 10 \text { milhas; }{ }^{240}\end{array}$ \\
\hline & 3 & mutatio Bao mil VII & $\begin{array}{l}\text { posto de muda em Bao (Veliko Laole), } 7 \\
\text { milhas; }{ }^{241}\end{array}$ \\
\hline & 4 & mansio Idomo mil VIIII & pouso em Idomum (Medveđa), 9 milhas; ${ }^{242}$ \\
\hline & 5 & $\begin{array}{l}\text { mutatio ad octauum mil } \\
\text { VIIII }\end{array}$ & $\begin{array}{l}\text { posto de muda no oitavo [miliário] } \\
\text { (Glogovac), } 8 \text { milhas; }{ }^{243}\end{array}$ \\
\hline & 6 & mansio Oromago mil VIII & $\begin{array}{l}\text { pouso em Oromagus (Ćuprija), } 8 \\
\text { milhas. }{ }^{244}\end{array}$ \\
\hline
\end{tabular}

${ }^{227}$ DARE: <http://imperium.ahlfeldt.se/index.php?id=26419>.

${ }^{228}$ OmnesViae: Tricornio (Grocka?). DARE: <http://imperium.ahlfeldt.se/index.php?id=17947>.

${ }^{229}$ DARE: <http://imperium.ahlfeldt.se/index.php?id=17948>.

230 OmnesViae: Monte |Aureo (Smederevo?). DARE:

$<$ http://imperium.ahlfeldt.se/index.php?id=23229>.

${ }^{231}$ V: "Mingeio" - P: "Vingeio".

${ }^{232}$ DARE: <http://imperium.ahlfeldt.se/index.php?id=17949>.

${ }^{233}$ DARE: <http://imperium.ahlfeldt.se/index.php?id=21368>.

${ }^{234}$ V: “Uiminacium” - P: “Uiminatium”.

235 OmnesViae: Viminatio (Drmno Kostolac). DARE:

$<$ http://imperium.ahlfeldt.se/index.php?id=10877>. Vide, também:

$<$ http://en.wikipedia.org/wiki/Kostolac $>$.

${ }^{236}$ DARE: <http://imperium.ahlfeldt.se/index.php?id=43381>.

${ }^{237}$ V: "Munecipium" - P: "Muncipium”.

238 OmnesViae: Municipio. DARE: <http://imperium.ahlfeldt.se/index.php?id=23263>.

${ }^{239}$ V: “Iouespago" - P: "Iouis Pago".

${ }^{240}$ OmnesViae: Iovis Pago. DARE: <http://imperium.ahlfeldt.se/index.php?id=23262>.

${ }^{241}$ DARE: <http://imperium.ahlfeldt.se/index.php?id=36464>.

242 OmnesViae: Idimo. DARE: <http://imperium.ahlfeldt.se/index.php?id=23261>.

${ }^{243}$ DARE: <http://imperium.ahlfeldt.se/index.php?id=36463>.

${ }^{244}$ OmnesViae: Horrea Margi (Cuprija). DARE: <http://imperium.ahlfeldt.se/index.php?id=10883>. 


\begin{tabular}{|c|c|c|c|}
\hline & 7 & Finis Myssiae et Daciae. ${ }^{245}$ & $\begin{array}{l}\text { Fronteira entre Myssia (Mésia) e Dacia } \\
\text { (Dácia). }\end{array}$ \\
\hline & 8 & $\begin{array}{l}\text { Mutatio Sarmatorum mil } \\
\text { XII }\end{array}$ & $\begin{array}{l}\text { Posto de muda em Sarmatae (Gornje } \\
\text { Vidovo), } 12 \text { milhas; }{ }^{246}\end{array}$ \\
\hline & 9 & $\begin{array}{l}\text { mutatio Caminetas mil } \\
\mathrm{XI}^{247}\end{array}$ & $\begin{array}{l}\text { posto de muda em Caminetae (Ražanj), } 11 \\
\text { milhas; }{ }^{248}\end{array}$ \\
\hline \multirow[t]{12}{*}{566} & 1 & mansio Ipompeis mil VIIII & pouso em Ipompei (Rutevac), 9 milhas; ${ }^{249}$ \\
\hline & 2 & $\begin{array}{l}\text { mutatio Rampiana mil } \\
\text { XII }^{250}\end{array}$ & $\begin{array}{l}\text { posto de muda em Rampiana (Draževac, } \\
\text { no município de Aleksinac), } 12 \text { milhas; }{ }^{251}\end{array}$ \\
\hline & 3 & Ciuitas Naisso mil XII & $\begin{array}{l}\text { [pouso na] cidade de Naissum (Niš), } 12 \\
\text { milhas; } 252\end{array}$ \\
\hline & 4 & $\begin{array}{l}\text { mutatio Redicibus mil } \\
\text { XII }^{253}\end{array}$ & $\begin{array}{l}\text { posto de muda em Redices (Jelašnica), } 12 \\
\text { milhas; }{ }^{254}\end{array}$ \\
\hline & 5 & mutatio Ulmo mil VII & $\begin{array}{l}\text { posto de muda em Ulmum (Ostrovica, no } \\
\text { município de Niška Banja), } 7 \text { milhas; }{ }^{255}\end{array}$ \\
\hline & 6 & $\begin{array}{l}\text { mansio Romansiana mil } \\
\text { VIIII }\end{array}$ & $\begin{array}{l}\text { [pouso na] cidade de Romansiana (Bela } \\
\text { Palanka), } 9 \text { milhas; }{ }^{256}\end{array}$ \\
\hline & 7 & mutatio Latina mil VIIII & $\begin{array}{l}\text { posto de muda em Latina (Telovac, na } \\
\text { municipalidade de Pirto), } 9 \text { milhas; }{ }^{257}\end{array}$ \\
\hline & 8 & mansio Turribus mil VIIII & $\begin{array}{l}\text { [pouso na] cidade de Turros (Pirot), } 9 \\
\text { milhas; }\end{array}$ \\
\hline & 9 & $\begin{array}{l}\text { mutatio Translitis mil } \\
\text { XII }^{259}\end{array}$ & $\begin{array}{l}\text { posto de muda em Translites } \\
\text { (Dimitrovgrad), } 12 \text { milhas; }{ }^{260}\end{array}$ \\
\hline & 10 & mutatio Ballanstra mil X & $\begin{array}{l}\text { posto de muda em Ballanstra (Kalotina), } \\
10 \text { milhas; }{ }^{261}\end{array}$ \\
\hline & 11 & mansio Meldia mil VIIII & $\begin{array}{l}\text { [pouso na] cidade de Meldia (Dragoman), } \\
9 \text { milhas; }{ }^{262}\end{array}$ \\
\hline & 12 & mutatio Scretisca mil XII ${ }^{263}$ & $\begin{array}{l}\text { posto de muda em Scretisca (Kostinbrod), } \\
12 \text { milhas; }{ }^{264}\end{array}$ \\
\hline
\end{tabular}

\footnotetext{
${ }^{245}$ V: “Daciae” - P: “Asiae”.

246 DARE: <http://imperium.ahlfeldt.se/index.php?id=36506>.

${ }^{247}$ V: "Caminitas" - P: "Cametas".

${ }^{248}$ DARE: <http://imperium.ahlfeldt.se/index.php?id=36465>.

249 OmnesViae: Presidio Pompei. DARE: < http://imperium.ahlfeldt.se/index.php?id=10882>.

${ }^{250}$ V: “Rampiana” - P: “Rappiana”.

${ }^{251}$ OmnesViae: Gramrianis. DARE: <http://imperium.ahlfeldt.se/index.php?id=23259>.

252 OmnesViae: Naisso (Nis). DARE: < http://imperium.ahlfeldt.se/index.php?id=10879>.

253 A passagem "mutatio Redicibus mil XII" consta apenas de P.

${ }^{254}$ DARE: <http://imperium.ahlfeldt.se/index.php?id=36504>.

${ }^{255}$ DARE: <http://imperium.ahlfeldt.se/index.php?id=36509>.

${ }^{256}$ OmnesViae: Romesiana (Bela Palanka). DARE:

$<$ http://imperium.ahlfeldt.se/index.php?id=10347>.

${ }^{257}$ DARE: <http://imperium.ahlfeldt.se/index.php?id=36503>.

${ }^{258}$ OmnesViae: Turribus (Pirot). DARE: <http://imperium.ahlfeldt.se/index.php?id=10312>.

${ }^{259}$ V: "Translites" - P: "Translitis".

${ }^{260}$ DARE: <http://imperium.ahlfeldt.se/index.php?id=10290>.

261 DARE: <http://imperium.ahlfeldt.se/index.php?id=10881>.

262 OmnesViae: Meldiis. DARE: <http://imperium.ahlfeldt.se/index.php?id=10876>.

${ }^{263}$ V: "Scretesca" - P: "Scretisca".

264 DARE: <http://imperium.ahlfeldt.se/index.php?id=36508>.
} 


\begin{tabular}{|l|l|l|l|}
\hline 567 & 1 & Ciuitas Serdica mil XI & $\begin{array}{l}\text { [pouso na] cidade de Serdica (Sófia), 11 } \\
\text { milhas; }{ }^{265}\end{array}$ \\
\hline \multirow{2nn}{*}{2,3} & $\begin{array}{l}\text { Fit a Syrmium Serdica } \\
\text { usque milia CCCXIIII, } \\
\text { mutationes XXIIII, } \\
\text { mansiones XIII. }\end{array}$ & $\begin{array}{l}\text { Percorridas de Sirmium (Sremska } \\
\text { Mitrovica) a Serdica (Sófia), 314 milhas, } \\
\text { [passando por] 24 postos de muda e 13 } \\
\text { pousos. }\end{array}$ \\
\hline
\end{tabular}

${ }^{265}$ OmnesViae: Sertica (Sophia). DARE: < http://imperium.ahlfeldt.se/index.php?id=10880> 


\section{Seção 6: de Serdica (Sófia) a Constantinopolis (Istambul)}

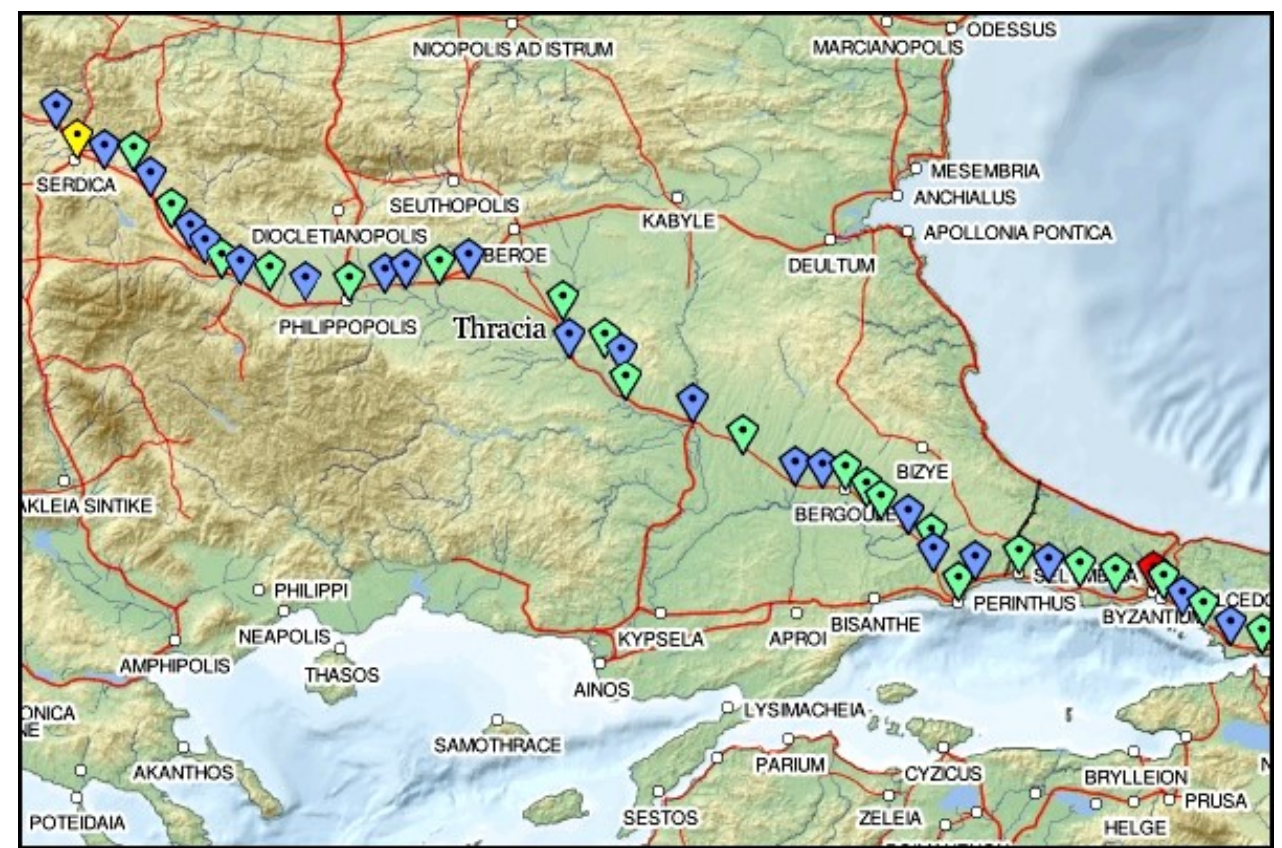

Mapa 6: trecho entre Serdica (Sófia), em amarelo, e Constantinopolis (Istambul), em vermelho; em azul estão registradas as mutationes (postos de muda) e em verde as mansiones (pousos).

\begin{tabular}{|c|c|c|c|}
\hline \multirow[t]{2}{*}{567} & 1 & Ciuitas Serdica mil XI & $\begin{array}{l}\text { [pouso na] cidade de Serdica (Sófia), } 11 \\
\text { milhas; }\end{array}$ \\
\hline & 2,3 & $\begin{array}{l}\text { Fit a Syrmium Serdica usque } \\
\text { milia CCCXIIII, mutationes } \\
\text { XXIIII, mansiones XIII. }\end{array}$ & $\begin{array}{l}\text { Percorridas de Sirmium (Sremska } \\
\text { Mitrovica) a Serdica (Sófia), } 314 \text { milhas, } \\
\text { [passando por] } 24 \text { postos de muda e } 13 \\
\text { pousos. }\end{array}$ \\
\hline \multirow[t]{5}{*}{567} & 4 & Mutatio Extuomne mil VIII ${ }^{266}$ & $\begin{array}{l}\text { Posto de muda em Extuomnes } \\
\text { (Kazichene), } 8 \text { milhas; }{ }^{267}\end{array}$ \\
\hline & 5 & mansio Buragara mil VIIII'268 & $\begin{array}{l}\text { pouso em Buragara (Lesnovo), } 9 \\
\text { milhas; } 269\end{array}$ \\
\hline & 6 & mutatio Sparata mil VIII & $\begin{array}{l}\text { posto de muda em Sparata (Vakarel), } 8 \\
\text { milhas; }{ }^{270}\end{array}$ \\
\hline & 7 & mansio Iliga mil $\mathrm{X}^{271}$ & pouso em Iliga (Ihtiman), 10 milhas; ${ }^{272}$ \\
\hline & 8 & mutatio Soneio mil VIIII ${ }^{273}$ & $\begin{array}{l}\text { posto de muda em Soneium (Trayanovi } \\
\text { vrata, próxima a Mirovo), } 9 \text { milhas; }{ }^{274}\end{array}$ \\
\hline
\end{tabular}

${ }^{266}$ V: "Extuome" - P: "Extuomne”.

${ }^{267}$ DARE: <http://imperium.ahlfeldt.se/index.php?id=36440>.

${ }^{268}$ V: "Buracara” - P: "Buragara”.

${ }^{269}$ DARE: <http://imperium.ahlfeldt.se/index.php?id=36439>.

${ }^{270}$ OmnesViae: Sarto (Sparata). Sparata = Vakarel, segundo:

$<$ http://pleiades.stoa.org/places/481998>. DARE:

$<$ http://imperium.ahlfeldt.se/index.php?id=23308>.

${ }^{271}$ V: “Hilica” - P: “Iliga”. 272 DARE: <http://imperium.ahlfeldt.se/places/36442>.

272 DARE: <http://imperium.ahlfeldt.se/places/36442>.

${ }^{273}$ V: "mutatio So..." - P: "mutation Soneio mil VIIII".

${ }^{274}$ DARE: <http://imperium.ahlfeldt.se/index.php?id=36444>. 


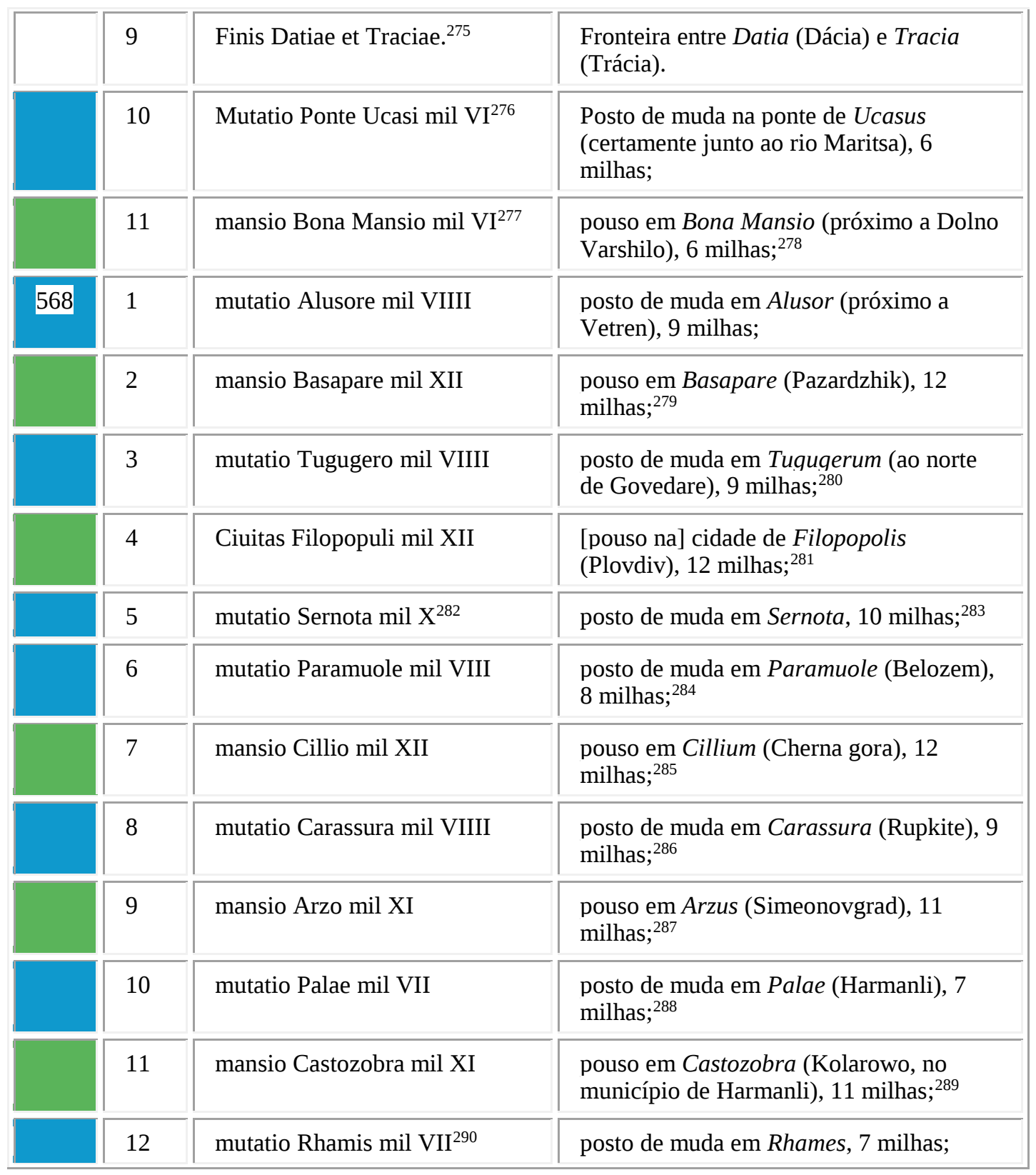

275 V: "Datiae” - P: "Dacie”.

${ }^{276}$ V: "Ponteugas" - P: "Ponte Ucasi”.

277 V: "Bona Mansio" - P: "Bonamans".

${ }^{278}$ Identificamos, ainda que hesitantemente, Bona Mansio com a antiga Pistiros: DARE:

$<$ http://imperium.ahlfeldt.se/index.php?id=41877>. Vide, também:

$<$ http://en.wikipedia.org/wiki/Pistiros>.

${ }^{279}$ DARE: <http://imperium.ahlfeldt.se/index.php?id=27848>.

${ }^{280}$ Ao norte de DARE: <http://imperium.ahlfeldt.se/places/37245>.

281 Omnes Viae: Phinipopolis (Plovdiv). DARE: < http://imperium.ahlfeldt.se/index.php?id=21408>.

${ }^{282} \mathrm{~V}$ : "Sernota" - P: "Syrnota".

${ }^{283}$ DARE: <http://imperium.ahlfeldt.se/index.php?id=36177>.

${ }^{284}$ DARE: <http://imperium.ahlfeldt.se/index.php?id=36175>.

${ }^{285}$ DARE: <http://imperium.ahlfeldt.se/index.php?id=36171>.

${ }^{286}$ DARE: <http://imperium.ahlfeldt.se/index.php?id=23333>.

${ }^{287}$ OmnesViae: Arzum (Kalugerovo). DARE: <http://imperium.ahlfeldt.se/index.php?id=23335>.

288 Talvez a moderna Harmanli. DARE: <http://imperium.ahlfeldt.se/index.php?id=32330>.

${ }^{289}$ OmnesViae: Castris Rubris. DARE: <http://imperium.ahlfeldt.se/index.php?id=22959>.

290 V: "Rammes"- P: "Rhamis". 


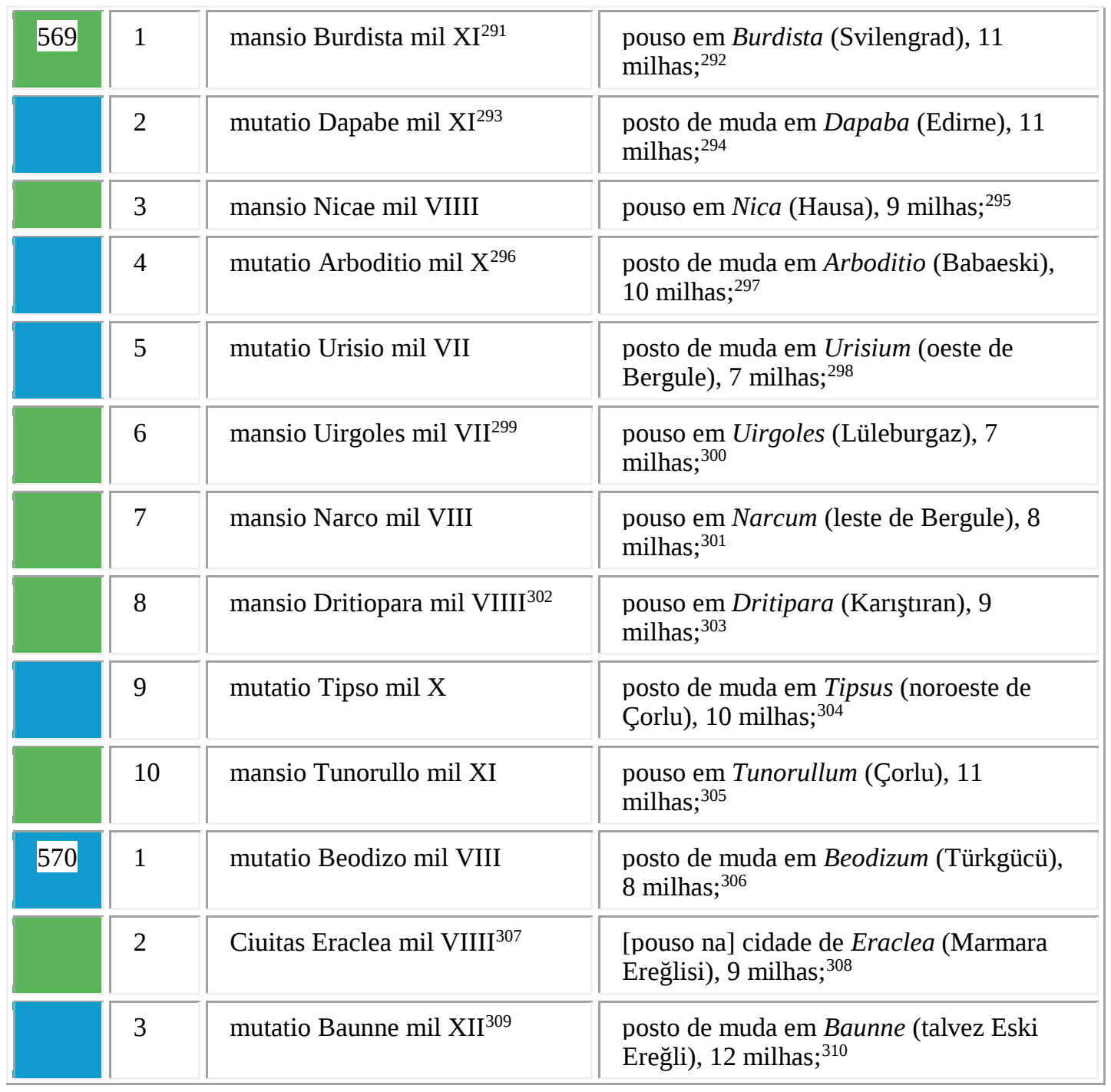

291 V: "Burdicta” - P: "Burdista”.

${ }^{292}$ OmnesViae: Burdenis (Svilengrad). DARE: <http://imperium.ahlfeldt.se/index.php?id=23336>.

${ }^{293}$ V: "Dapabe" - P: "Daphabae".

294 A julgar pelas distâncias envolvidas, Daphaba a Hadrianopolis (atual Edirne). OmnesViae: Hadrianopoli (Edirne). DARE: <http://imperium.ahlfeldt.se/index.php?id=23005>.

295 DARE: <http://imperium.ahlfeldt.se/index.php?id=21902>.

296 V: “Arboditio" - P: “Tarpodizo”.

${ }^{297}$ DARE: <http://imperium.ahlfeldt.se/index.php?id=23356>.

298 DARE: <http://imperium.ahlfeldt.se/index.php?id=36437>.

${ }^{299}$ V: "Uirgoles" - P: “Uirgolis”.

${ }^{300}$ OmnesViae: Bergule (Lüleburgaz). DARE: <http://imperium.ahlfeldt.se/index.php?id=17026>.

${ }^{301}$ DARE: <http://imperium.ahlfeldt.se/index.php?id=36431>.

${ }^{302}$ V: "Dritiopara" - P: "Druzipara”.

303 OmnesViae: Drysiporo ( Karıştıran). DARE:

$<$ http://imperium.ahlfeldt.se/index.php?id=23354>.

${ }^{304}$ DARE: <http://imperium.ahlfeldt.se/index.php?id=36436>.

${ }^{305}$ DARE: <http://imperium.ahlfeldt.se/index.php?id=31448>.

${ }^{306}$ DARE: <http://imperium.ahlfeldt.se/index.php?id=36421>.

${ }^{307}$ V: "Eraclea" - P: "Heraclea”.

${ }^{308}$ Também chamada antigamente de “Perinthus". DARE:

$<$ http://imperium.ahlfeldt.se/index.php?id=21399>.

${ }^{309}$ V: "Baunnae" - P: "Baunne".

310 Talvez o mesmo que a antiga Daunion Teichos, identificada com a moderna Eski Ereğli. DARE:

$<$ http://imperium.ahlfeldt.se/index.php?id=31378>. 


\begin{tabular}{|c|c|c|}
\hline 4 & mansio Salamembria mil $X^{311}$ & $\begin{array}{l}\text { pouso em Salamembria (Silivri), } 10 \\
\text { milhas; }{ }^{312}\end{array}$ \\
\hline 5 & mutatio Callum mil X $\mathrm{X}^{313}$ & $\begin{array}{l}\text { posto de muda em Callum (leste de } \\
\text { Silivri), } 10 \text { milhas; }{ }^{314}\end{array}$ \\
\hline 6 & mansio Atyra mil X ${ }^{315}$ & $\begin{array}{l}\text { pouso em Atyra (Büyükçekmece), } 10 \\
\text { milhas; }\end{array}$ \\
\hline 7 & mansio Regio mil XII & $\begin{array}{l}\text { pouso em Regium (Küçükçekmece), } 12 \\
\text { milhas; }{ }^{317}\end{array}$ \\
\hline 8 & $\begin{array}{l}\text { Ciuitas Constantinopoli mil } \\
\text { XII }\end{array}$ & $\begin{array}{l}\text { [pouso na] cidade de Constantinopolis } \\
\text { (Istambul), } 12 \text { milhas. }{ }^{318}\end{array}$ \\
\hline
\end{tabular}

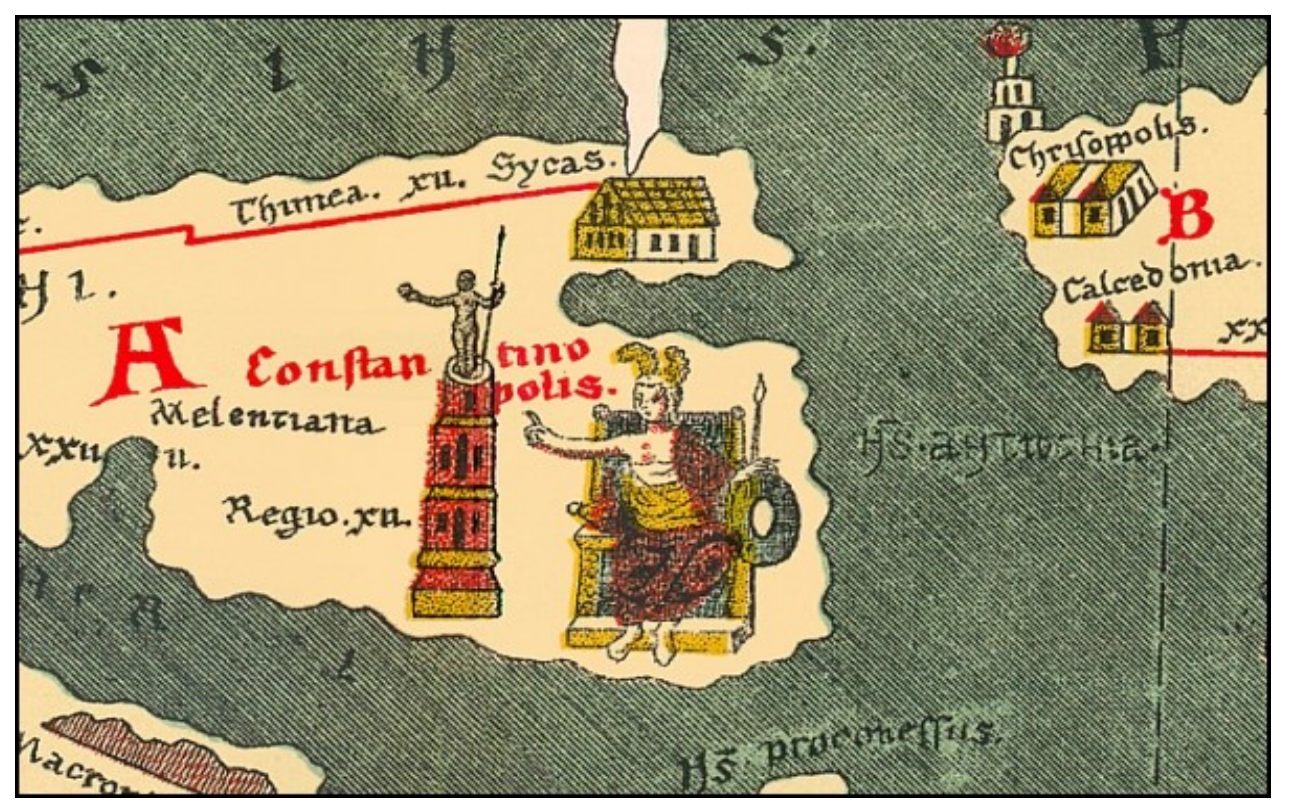

Figura 7: detalhe do fac-simile da Tabula Peutingeriana, com destaque para Constantinopolis (Istambul); é notável a presença de um farol próximo à Chrisoppolis.

\begin{tabular}{|c|c|c|c|}
\hline 571 & 1,2 & $\begin{array}{l}\text { Fit a Serdica } \\
\text { Constantinopolim milia } \\
\text { CCCCXIII, mutationes XII, } \\
\text { mansiones XX. }\end{array}$ & $\begin{array}{l}\text { Percorridas de Serdica (Sófia) a } \\
\text { Constantinopolis (Istambul), } 413 \text { milhas, } \\
\text { [passando por] } 12 \text { postos de muda e } 20 \\
\text { pousos. }\end{array}$ \\
\hline & $3-5$ & $\begin{array}{l}\text { Fit omnis summa a } \\
\text { Bordegala Constantinopolim } \\
\text { uicies bis centena uiginti } \\
\text { unum milia, mutationes } \\
\text { CCXXX, mansiones CXII. }\end{array}$ & $\begin{array}{l}\text { Percorridas na soma total de Bordegala } \\
\text { (Bordeaux) a Constantinopolis (Istambul) } \\
2.221 \text { milhas, [passando por] } 230 \text { postos de } \\
\text { muda e } 112 \text { pousos. }\end{array}$ \\
\hline
\end{tabular}

311 V: "Salambria” - P: "Salamembria”.

312 DARE: <http://imperium.ahlfeldt.se/index.php?id=21400>.

313 V: "Eallum" - P: "Callum".

${ }^{314}$ DARE: <http://imperium.ahlfeldt.se/index.php?id=36423>.

315 V: “Alesra” - P: “Atyra”.

316 DARE: <http://imperium.ahlfeldt.se/index.php?id=31364>.

${ }^{317}$ DARE: <http://imperium.ahlfeldt.se/index.php?id=22281>.

318 OmnesViae: Constantinopolis (Istambul). DARE:

$<$ http://imperium.ahlfeldt.se/index.php?id=5472>. 


\section{Seção 7: de Constantinopolis (Istambul) a Anchira Galaciae (Ancara)}

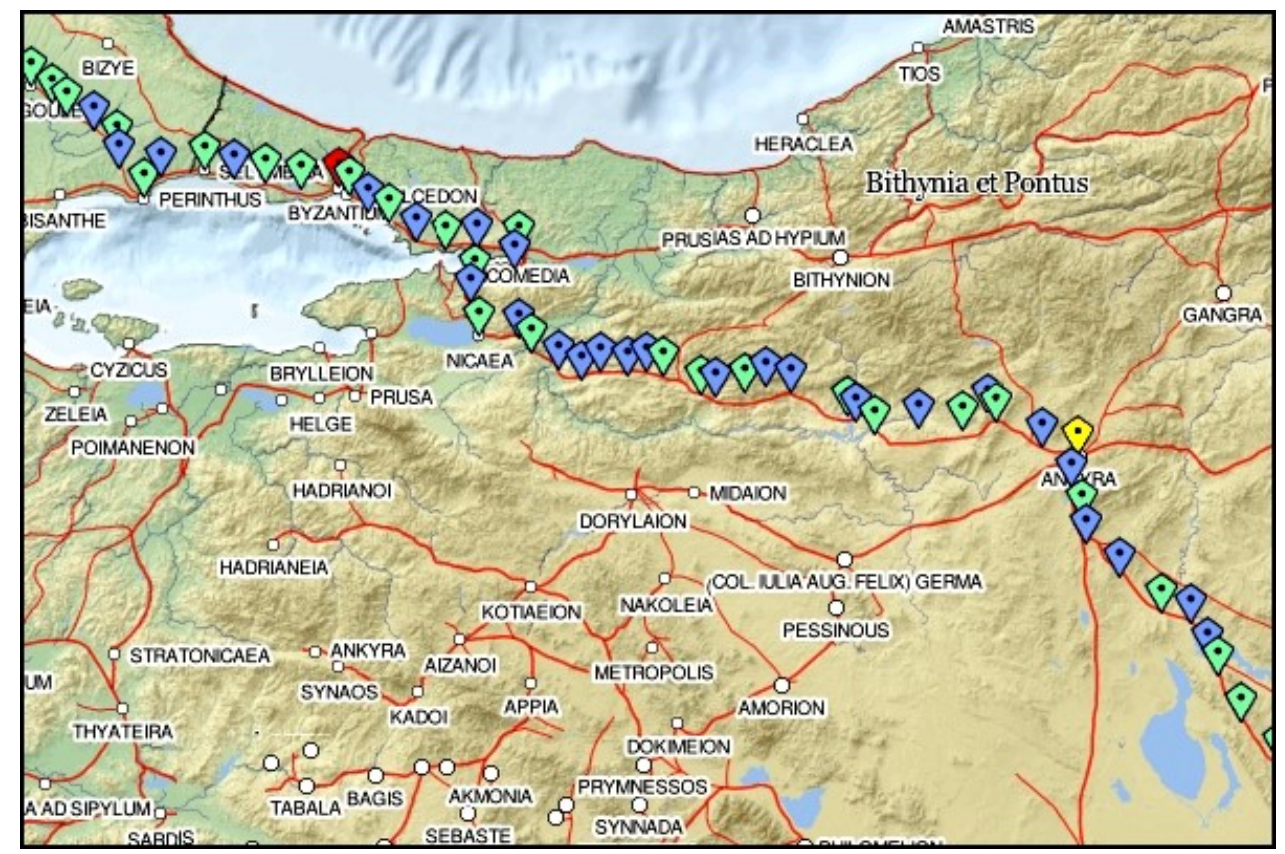

Mapa 7: trecho entre Constantinopolis (Istambul), em vermelho, e Anchira Galaciae (Ancara), em amarelo; em azul estão registradas as mutationes (postos de muda) e em verde as mansiones (pousos).

\begin{tabular}{|c|c|c|c|}
\hline 570 & 8 & $\begin{array}{l}\text { Ciuitas Constantinopoli mil } \\
\text { XII }\end{array}$ & $\begin{array}{l}\text { [pouso na] cidade de Constantinopolis } \\
\text { (Istambul), } 12 \text { milhas. }\end{array}$ \\
\hline \multirow[t]{2}{*}{571} & 1,2 & $\begin{array}{l}\text { Fit a Serdica } \\
\text { Constantinopolim milia } \\
\text { CCCCXIII, mutationes XII, } \\
\text { mansiones XX. }\end{array}$ & $\begin{array}{l}\text { Percorridas de Serdica (Sófia) a } \\
\text { Constantinopolis (Istambul), } 413 \text { milhas, } \\
\text { [passando por] } 12 \text { postos de muda e } 20 \\
\text { pousos. }\end{array}$ \\
\hline & $3-5$ & $\begin{array}{l}\text { Fit omnis summa a } \\
\text { Bordegala Constantinopolim } \\
\text { uicies bis centena uiginti } \\
\text { unum milia, mutationes } \\
\text { CCXXX, mansiones CXII. }\end{array}$ & $\begin{array}{l}\text { Percorridas na soma total de Bordegala } \\
\text { (Bordeaux) a Constantinopolis (Istambul) } \\
2.221 \text { milhas, [passando por] } 230 \text { postos de } \\
\text { muda e } 112 \text { pousos. }\end{array}$ \\
\hline 571 & $6-8$ & $\begin{array}{l}\text { Item ambulauimus } \\
\text { Dalmatico et Zenofilo cons. } \\
\text { III. kal. Iun. a Calcidonia et } \\
\text { reuersi sumus } \\
\text { Constantinopolim VII. kal. } \\
\text { Ian. consule suprascripto. }{ }^{19}\end{array}$ & $\begin{array}{l}\text { Também caminhamos durante o consulado } \\
\text { de Dalmaticus (Dalmácio) e Zenofilus } \\
\text { (Zenófilo) }^{320} \text {, deixando a Calcidonia } \\
\text { (Kadıköy) em } 30 \text { de maio, e retornamos a } \\
\text { Constantinopolis (Istambul) em } 25 \text { de } \\
\text { dezembro do mesmo consulado. }\end{array}$ \\
\hline \multirow[t]{2}{*}{570} & 8 & $\begin{array}{l}\text { Ciuitas Constantinopoli mil } \\
\text { XII }\end{array}$ & $\begin{array}{l}\text { [pouso na] cidade de Constantinopolis } \\
\text { (Istambul), } 12 \text { milhas. }\end{array}$ \\
\hline & 9,1 & A Constantinopoli transis & De Constantinopolis (Istambul) cruzas o \\
\hline
\end{tabular}

${ }^{319}$ V: “uenis Calcedonia, ambulas prouinciam Bitinam” - P: “uenis Calcedoniam, ambulas prouinciam Bithiniam”.

V: "Dalmatico et Zenophilo" - P: "Dalmatio et Zenofilo".

${ }^{320}$ O viajante se refere a Flauius Dalmatius e Domitius Zenophilus, cônsules no ano de 333. 


\begin{tabular}{|c|c|c|c|}
\hline & & $\begin{array}{l}\text { Pontum, uenis Calcedoniam, } \\
\text { ambulas prouinciam } \\
\text { Bitiniam. }\end{array}$ & $\begin{array}{l}\text { Pontus, vens a Calcedonia (Kadıköy) e } \\
\text { caminhas até a província da Bitinia } \\
\text { (Bitínia). }{ }^{322}\end{array}$ \\
\hline & 11 & Mutatio Nassete mil VII S 323 & $\begin{array}{l}\text { Posto de muda em Nasses (próxima a } \\
\text { Maltepe), } 7 \text { semi-milhas; }{ }^{.24}\end{array}$ \\
\hline \multirow[t]{7}{*}{572} & 1 & mansio Pandicia mil VII S & $\begin{array}{l}\text { pouso em Pandicia (Pendik), } 7 \text { semi- } \\
\text { milhas; }{ }^{.325}\end{array}$ \\
\hline & 2 & mutatio Pontamus mil XIII & $\begin{array}{l}\text { posto de muda em Pontamus (arredores de } \\
\text { Şekerpınar), } 13 \text { milhas; }\end{array}$ \\
\hline & 3 & mansio Libissa mil VIIII ${ }^{326}$ & Pouso em Libissa (Gebze), 9 milhas. ${ }^{327}$ \\
\hline & $4-5$ & $\begin{array}{l}\text { Ibi positus est rex } \\
\text { Annibalianus, qui fuit } \\
\text { Afrorum. }\end{array}$ & $\begin{array}{l}\text { Aí jaz Annibalianus (Aníbal), que foi rei } \\
\text { dos africanos. }\end{array}$ \\
\hline & 6 & Mutatio Brunga mil XII & $\begin{array}{l}\text { Posto de muda em Brunga (Hereke), } 12 \\
\text { milhas; } 328\end{array}$ \\
\hline & 7 & Ciuitas Nicomedia mil XIII & $\begin{array}{l}\text { [pouso na] cidade de Nicomedia (İzmit), } 13 \\
\text { milhas; } 329\end{array}$ \\
\hline & $8-9$ & $\begin{array}{l}\text { Fit a Constantinopoli } \\
\text { Nicomedia usque milia VIII, } \\
\text { mutationes VII, mansiones. }\end{array}$ & $\begin{array}{l}\text { Percorridas de Constantinopolis (Istambul) } \\
\text { a Nicomedia (İzmit) } 50 \text { milhas, [passando } \\
\text { por] } 7 \text { postos de muda e } 3 \text { pousos. }\end{array}$ \\
\hline \multirow[t]{5}{*}{573} & 1 & Mutatio Heribolum mil X 330 & $\begin{array}{l}\text { posto de muda em Heribolum (Gölcük, } \\
\text { Kocaeli), } 10 \text { milhas; } 331\end{array}$ \\
\hline & 2 & mansio Libum mil XI & $\begin{array}{l}\text { pouso em Libum (próximo a Senaiye), } 11 \\
\text { milhas; }{ }^{.32}\end{array}$ \\
\hline & 3 & mutatio Liada mil XII & $\begin{array}{l}\text { posto de muda em Liada (Sarıăıll), } 12 \\
\text { milhas; }\end{array}$ \\
\hline & 4 & Ciuitas Nicia mil VIII & $\begin{array}{l}\text { [pouso na] cidade de Nicia (İznik), } 9 \\
\text { milhas; }\end{array}$ \\
\hline & 5 & mutatio Schenae mil VIII ${ }^{335}$ & $\begin{array}{l}\text { posto de muda em Schene (arredores de } \\
\text { Gaziler, a sudoeste do lago Çerkeşli Göleti), } \\
8 \text { milhas; }\end{array}$ \\
\hline
\end{tabular}

\footnotetext{
${ }^{321}$ VP: “Calcedonia”.

322 OmnesViae: Calcedonia (Kadıköy). DARE: <http://imperium.ahlfeldt.se/places/16677>.

${ }^{323}$ V: "Narsitae" - P: "Nasses".

${ }^{324}$ DARE: <http://imperium.ahlfeldt.se/index.php?id=36438>.

${ }^{325}$ DARE: < http://imperium.ahlfeldt.se/places/31486.html>.

${ }^{326}$ V: "Libosa"- P: "Libissa”.

${ }^{327}$ OmnesViae: Livissa (Gebze). DARE: <http://imperium.ahlfeldt.se/index.php?id=36426>.

${ }^{328}$ DARE: <http://imperium.ahlfeldt.se/index.php?id=36422>.

${ }^{329}$ OmnesViae: Nicomedia (İzmit). DARE: < http://imperium.ahlfeldt.se/index.php?id=21204>.

${ }^{330}$ V: "Heribolum" - P: "Hyribolum".

${ }^{331}$ DARE: <http://imperium.ahlfeldt.se/index.php?id=23432>.

${ }^{332}$ DARE: <http://imperium.ahlfeldt.se/index.php?id=36429>.

333 DARE: <http://imperium.ahlfeldt.se/index.php?id=36428>.

334 OmnesViae: Nicea (İznik). DARE: <http://imperium.ahlfeldt.se/index.php?id=21212>.

335 V: "Schenae" - P: "Schinae".
} 


\begin{tabular}{|c|c|c|c|}
\hline & 6 & mansio Mido mil VII ${ }^{336}$ & $\begin{array}{l}\text { pouso em Midum (arredores de Osmaneli), } \\
7 \text { milhas; }{ }^{337}\end{array}$ \\
\hline & 7 & mutatio Chogeae mil VI ${ }^{338}$ & $\begin{array}{l}\text { posto de muda em Chogea (Metedli), } 6 \\
\text { milhas; } 339\end{array}$ \\
\hline & 8 & mutatio Thateso mil X & $\begin{array}{l}\text { posto de muda em Thatesus (próximo a } \\
\text { Kurşunlu, Çankiri), } 10 \text { milhas; }{ }^{340}\end{array}$ \\
\hline & 9 & mutatio Tutado mil VIIII ${ }^{341}$ & $\begin{array}{l}\text { posto de muda em Tutadus (Aricaklar), } 9 \\
\text { milhas; }{ }^{342}\end{array}$ \\
\hline & 10 & mutatio Protoniaca mil XI ${ }^{343}$ & $\begin{array}{l}\text { posto de muda em Protoniaca (talvez nos } \\
\text { arredores de Karaahmetler, no distrito de } \\
\text { Gölpazarı), } 11 \text { milhas; }\end{array}$ \\
\hline & 11 & mutatio Artemis mil XII & $\begin{array}{l}\text { posto de muda em Artemis (Kilciler, no } \\
\text { distrito de Göynük), } 12 \text { milhas; } 344\end{array}$ \\
\hline 574 & 1 & mansio Doblae mil VI ${ }^{345}$ & $\begin{array}{l}\text { pouso em Dobla (Çayköy, no distrito } \\
\text { Göynük), } 6 \text { milhas; }{ }^{: 46}\end{array}$ \\
\hline & 2 & mansio Ceratae mil VI ${ }^{347}$ & $\begin{array}{l}\text { pouso em Cerate (Beydili, no distrito de } \\
\text { Nallıhan), } 6 \text { milhas; }{ }^{348}\end{array}$ \\
\hline & 3 & Finis Bitiniae et Galaciae. ${ }^{349}$ & $\begin{array}{l}\text { Fronteira entre Bitinia (Bitínia) e Galacia } \\
\text { (Galácia). }\end{array}$ \\
\hline & 4 & Mutatio Fines mil $X^{350}$ & $\begin{array}{l}\text { posto de muda na fronteira (leste de Beydili } \\
\text { Köyü, no distrito de Nallıhan), } 10 \text { milhas; }{ }^{351}\end{array}$ \\
\hline & 5 & mansio Dadastau mil VI ${ }^{352}$ & $\begin{array}{l}\text { pouso em Dadastau (talvez Karahisar } \\
\text { Köyü), } 6 \text { milhas; } 353\end{array}$ \\
\hline & 6 & mutatio trans monte mil VI & $\begin{array}{l}\text { posto de muda na passagem do monte } \\
\text { (provavelmente Aşağıbağlıca), } 6 \text { milhas; }{ }^{354}\end{array}$ \\
\hline & 7 & mutatio Melia mil XI ${ }^{355}$ & $\begin{array}{l}\text { posto de muda em Melia (provavelmente } \\
\text { Nallihan), } 11 \text { milhas; }\end{array}$ \\
\hline
\end{tabular}

336 V: “Mancio Mido" - P: "Mansio Mido”.

${ }^{337}$ DARE: <http://imperium.ahlfeldt.se/places/36430.html>.

${ }^{338}$ V: "Chogia" - P: "Chogeae".

339 DARE: <http://imperium.ahlfeldt.se/index.php?id=36425>.

340 DARE: <http://imperium.ahlfeldt.se/places/36435>.

341 V: "Tutado"- P: “Tutaio".

342 DARE: <http://imperium.ahlfeldt.se/index.php?id=31439>.

${ }^{343}$ V: "Protoniaca" - P: "Protunica".

${ }^{344}$ DARE: <http://imperium.ahlfeldt.se/index.php?id=36420>.

${ }^{345}$ V: "Doblae" - P: "Dablae".

346 OmnesViae: Dablis (Dableis). DARE: <http://imperium.ahlfeldt.se/places/23507>.

347 V: “Caeratae" - P: "Ceratae".

348 DARE: <http://imperium.ahlfeldt.se/index.php?id=36131>.

${ }^{349} \mathrm{~V}$ : "Bitiniae et Galaciae" - P: "Bythiniae et Galatiae CCCXX".

${ }^{350}$ V: "Fines" - P: "Finis".

${ }^{351}$ DARE: <http://imperium.ahlfeldt.se/places/36132>.

${ }^{352}$ V: "Dadartano" - P: "Dadastau".

353 OmnesViae: Dadastana. DARE: <http://imperium.ahlfeldt.se/places/23508>.

354 DARE: <http://imperium.ahlfeldt.se/places/36140>.

355 V: "Melia” - P: “Milia”. 


\begin{tabular}{|c|c|c|c|}
\hline & 8 & Ciuitas Iuliopolis mil VIII & $\begin{array}{l}\text { [pouso na] cidade de Iuliopolis } \\
\text { (Davutoğlan, no distrito de Nallıhan), } 8 \\
\text { milhas; }{ }^{356}\end{array}$ \\
\hline & 9 & $\begin{array}{l}\text { mutatio Hieronpotamum mil } \\
\text { XIII }^{357}\end{array}$ & $\begin{array}{l}\text { posto de muda no rio Hieron } \\
\text { (provavelmente ao sul de Çayırhan, junto ao } \\
\text { rio Sakarya), } 13 \text { milhas; }\end{array}$ \\
\hline & 10 & mansio Agannia mil XI & $\begin{array}{l}\text { pouso em Agannia (Kırbaşı, no distrito de } \\
\text { Beypazarı), } 11 \text { milhas; }{ }^{358}\end{array}$ \\
\hline & 11 & mutatio Petobrogen mil VI & $\begin{array}{l}\text { posto de muda em Ipetobrogen (talvez } \\
\text { Acisu), } 6 \text { milhas; }{ }^{359}\end{array}$ \\
\hline 575 & 1 & mansio Mnizos mil $X^{360}$ & $\begin{array}{l}\text { pouso em Mnizos (talvez Akkaya), } 10 \\
\text { milhas; } ; 61\end{array}$ \\
\hline & 2 & mutatio Trasmon mil XII ${ }^{362}$ & $\begin{array}{l}\text { posto de muda em Trasmon (talvez } \\
\text { arredores de Gökçebağ, no distrito de } \\
\text { Ayaş), } 12 \text { milhas; }{ }^{363}\end{array}$ \\
\hline & 3 & $\begin{array}{l}\text { mansio Malagordis mil } \\
\text { VIIIII }^{364}\end{array}$ & $\begin{array}{l}\text { Pouso em Malagoridis (talvez ao sul de } \\
\text { Başbereket, no distrito de Ayaş), } 9 \text { milhas; }\end{array}$ \\
\hline & 4 & $\begin{array}{l}\text { mutatio Cenaxem palidem } \\
\text { mil XIII }^{365}\end{array}$ & $\begin{array}{l}\text { posto de muda no pântano Cenaxis } \\
\text { (Etimesgut), } 13 \text { milhas; }{ }^{366}\end{array}$ \\
\hline & 5 & $\begin{array}{l}\text { Ciuitas Anchira Galaciae mil } \\
\text { XIII }^{367}\end{array}$ & $\begin{array}{l}\text { [pouso na] cidade de Anchira Galaciae } \\
\text { (Ancara), } 13 \text { milhas. }{ }^{368}\end{array}$ \\
\hline & $6-8$ & $\begin{array}{l}\text { Fit a Nicomedia Anchira } \\
\text { Galaciae usque milia } \\
\text { CCLVIII, mutationes XXVI, } \\
\text { mansiones XII. }\end{array}$ & $\begin{array}{l}\text { Percorridas de Nicomedia (İzmit) a Anchira } \\
\text { Galaciae (Ancara) } 258 \text { milhas, [passando } \\
\text { por] } 26 \text { postos de muda e } 12 \text { pousos. }\end{array}$ \\
\hline
\end{tabular}

${ }^{356}$ OmnesViae: Iuliopoli (Emremsultan). DARE: <http://imperium.ahlfeldt.se/places/23509>.

${ }^{357}$ V: "Hieronpotamum" - P: "Hypocrontamum".

${ }^{358}$ OmnesViae: Lagania (Beypazarl). DARE: <http://imperium.ahlfeldt.se/places/27460>.

${ }^{359}$ DARE: < http://imperium.ahlfeldt.se/places/36137>.

${ }^{360}$ V: "Sinonizous" - P: "Mnizos".

${ }^{361}$ OmnesViae: Mizago (Minizos). DARE: <http://imperium.ahlfeldt.se/places/23511>.

${ }^{362} \mathrm{~V}$ : “Trasmon" - P: “Crasmon”.

${ }^{363}$ DARE: <http://imperium.ahlfeldt.se/places/36138> .

${ }^{364} \mathrm{~V}$ : "Malogordis" - P: "Malagordis".

365 V: "Cenaxempalide" - P: "Cenaxem palidem".

${ }^{366}$ DARE: <http://imperium.ahlfeldt.se/index.php?id=36148>.

${ }^{367}$ V: “Anchira Galaciae” - P: "Anchira Galatia”.

${ }^{368}$ OmnesViae: Ancyra (Ankara). DARE: <http://imperium.ahlfeldt.se/index.php?id=21220>. 


\section{Seção 8: de Anchira Galaciae (Ancara) a Tarsus (Tarso)}

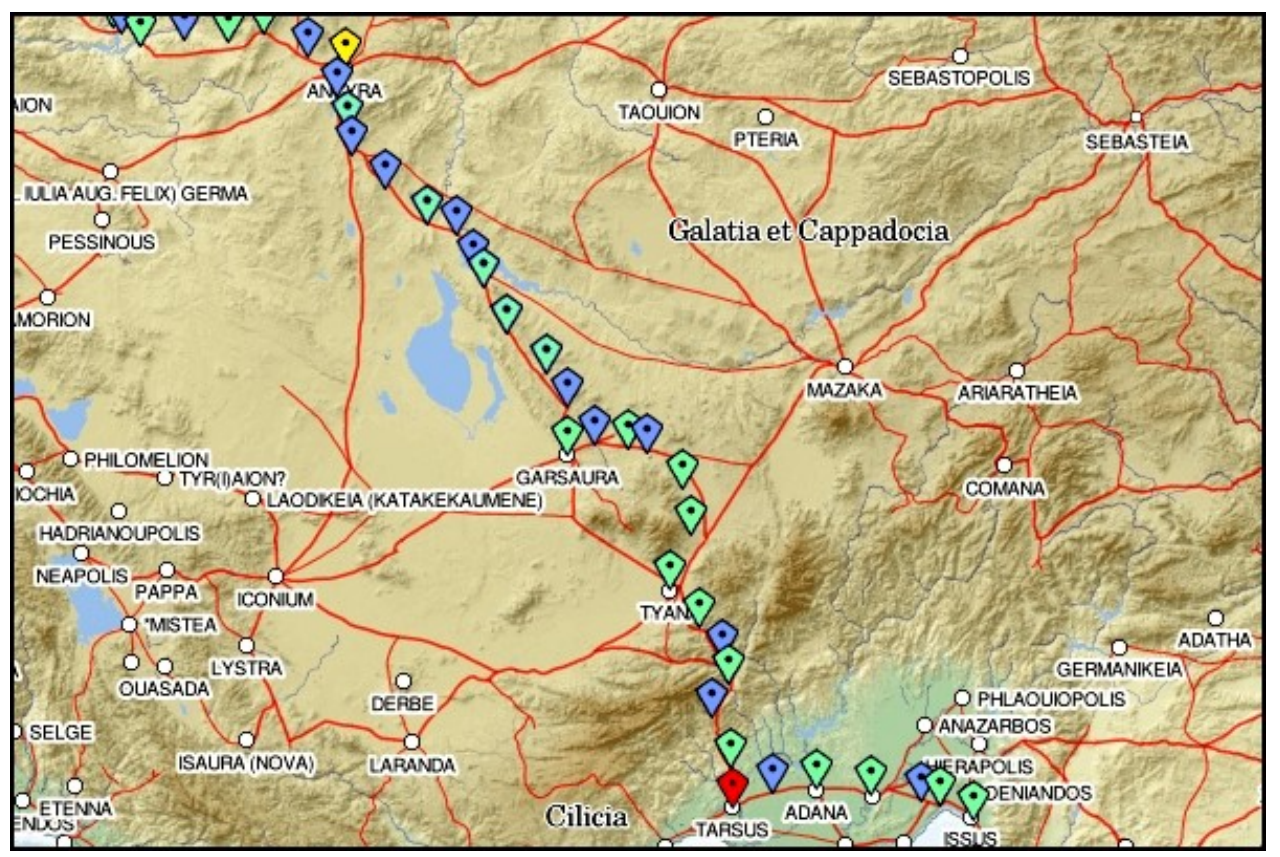

Mapa 8: trecho entre Anchira Galaciae (Ancara), em amarelo, e Tarsus (Tarso), em vermelho; em azul estão registradas as mutationes (postos de muda) e em verde as mansiones (pousos).

\begin{tabular}{|c|c|c|c|}
\hline 575 & 5 & $\begin{array}{l}\text { Ciuitas Anchira Galaciae mil } \\
\text { XIII }\end{array}$ & $\begin{array}{l}\text { [Pouso na] cidade de Anchira Galaciae } \\
\text { (Ancara), } 13 \text { milhas; }\end{array}$ \\
\hline & $6-8$ & $\begin{array}{l}\text { Fit a Nicomedia Anchira } \\
\text { Galaciae usque milia } \\
\text { CCLVIII, mutationes XXVI, } \\
\text { mansiones XII. }\end{array}$ & $\begin{array}{l}\text { Percorridas de Nicomedia (İzmit) a } \\
\text { Anchira Galaciae (Ancara) } 258 \text { milhas, } \\
\text { [passando por] } 26 \text { postos de muda e } 12 \\
\text { pousos. }\end{array}$ \\
\hline & 9 & Mutatio Delemna mil X & $\begin{array}{l}\text { posto de muda em Delemna (norte de } \\
\text { Gölbaşı, na província de Ancara), } 10 \\
\text { milhas; }{ }^{369}\end{array}$ \\
\hline & 10 & mansio Curueonta mil XI ${ }^{370}$ & $\begin{array}{l}\text { pouso em Curueonta (Gölbaşı, na } \\
\text { província de Ancara), } 11 \text { milhas; }{ }^{371}\end{array}$ \\
\hline & 11 & $\begin{array}{l}\text { mutatio Rosolodiaco mil } \\
\text { XII }^{372}\end{array}$ & $\begin{array}{l}\text { posto de muda em Rosolodiacum } \\
\text { (Oğulbey, no distrito de Gölbaşı), } 12 \\
\text { milhas; }\end{array}$ \\
\hline & 12 & mutatio Aliassum mil XIII ${ }^{374}$ & posto de muda em Aliasus, 13 milhas; ${ }^{375}$ \\
\hline & 13 & Ciuitas Aspona mil XVIII & $\begin{array}{l}\text { [pouso na] cidade de Aspona } \\
\text { (provavelmente nos arredores de } \\
\text { Sarıüüyük, Bala), } 18 \text { milhas; }\end{array}$ \\
\hline
\end{tabular}

369 DARE: <http://imperium.ahlfeldt.se/places/36150>.

${ }^{370}$ V: “Curueonta” - P: “Curueunta”.

${ }^{371}$ DARE: <http://imperium.ahlfeldt.se/places/23563>.

372 V: "Rosolodiacho" - P: "Rosolodiaco".

${ }^{373}$ DARE: <http://imperium.ahlfeldt.se/places/36154>.

${ }^{374}$ V: “Aliasum” - P: “Aliassum”.

375 DARE: <http://imperium.ahlfeldt.se/places/36141>. 


\begin{tabular}{|c|c|c|c|}
\hline \multirow[t]{2}{*}{576} & 1 & mutatio Galea mil XIII & $\begin{array}{l}\text { posto de muda em Galea (provavelmente } \\
\text { nos arredores de Büyükbıylk, no distrito de } \\
\text { Bala), } 13 \text { milhas; }{ }^{376}\end{array}$ \\
\hline & 2 & mutatio Andrapa mil VIIII & $\begin{array}{l}\text { posto de muda em Andrapa (talvez Kaçarli, } \\
\text { no distrito de Şereflikoçhisar), } 9 \text { milhas;; }\end{array}$ \\
\hline & 3 & $\begin{array}{l}\text { Finis Galatiae et } \\
\text { Cappadociae. }\end{array}$ & $\begin{array}{l}\text { Fronteira entre Galatia (Galácia) e } \\
\text { Cappadocia (Capadócia). }\end{array}$ \\
\hline & 4 & Mansio Parnasso mil XIII & $\begin{array}{l}\text { Pouso em Parnassus (Değirmenyolu, no } \\
\text { distrito de Şereflikoçhisar). } 13 \text { milhas; }{ }^{379}\end{array}$ \\
\hline & 5 & mansio Iogola mil XVI 380 & $\begin{array}{l}\text { pouso em Iogola (talvez Üzengilik, no } \\
\text { distrito de Şereflikoçhisar), } 16 \text { milhas;;81 }\end{array}$ \\
\hline & 6 & mansio Nitalis mil XVIII & $\begin{array}{l}\text { pouso em Nitalis (talvez próximo a } \\
\text { Kirimini, no distrito de Aksaray), } 18 \\
\text { milhas; }{ }^{382}\end{array}$ \\
\hline & 7 & mutatio Argustana mil XIII & $\begin{array}{l}\text { posto de muda em Argustana (talvez } \\
\text { próxima a Altinkaya, no distrito de } \\
\text { Aksaray), } 8 \text { milhas; } 383\end{array}$ \\
\hline & 8 & Ciuitas Colonia mil XVI & $\begin{array}{l}\text { [pouso na] cidade de Colonia (Aksaray), } \\
16 \text { milhas; } ; 84\end{array}$ \\
\hline \multirow[t]{5}{*}{577} & 1 & $\begin{array}{l}\text { mutatio Mumoassum mil } \\
\text { XII }^{385}\end{array}$ & $\begin{array}{l}\text { posto de muda em Mumoassum (Gökçe, no } \\
\text { distrito de Aksaray), } 12 \text { milhas; } 386\end{array}$ \\
\hline & 2 & $\begin{array}{l}\text { mansio Anachiango mil } \\
\mathrm{XII}^{387}\end{array}$ & $\begin{array}{l}\text { pouso em Anachiango (talvez Gosterli, na } \\
\text { província de Niğde), } 12 \text { milhas; }{ }^{388}\end{array}$ \\
\hline & 3 & mutatio Chusa mil XII & $\begin{array}{l}\text { posto de muda em Chusa (talvez Kiledere, } \\
\text { na província de Niğde), } 12 \text { milhas; }{ }^{389}\end{array}$ \\
\hline & 4 & mansio Sasema mil XII ${ }^{390}$ & $\begin{array}{l}\text { pouso em Sasema (Hasaköy, na província } \\
\text { de Niğde), } 12 \text { milhas; }{ }^{391}\end{array}$ \\
\hline & 5 & mansio Andauilis mil XVI 392 & $\begin{array}{l}\text { pouso em Andauilis (próximo a Güllüce, na } \\
\text { província de Niğde), } 16 \text { milhas; }\end{array}$ \\
\hline
\end{tabular}

${ }^{376}$ DARE: <http://imperium.ahlfeldt.se/places/36151>.

377 DARE: <http://imperium.ahlfeldt.se/places/36142>.

${ }^{378}$ V: "Fines Galaciae et Cappadociae" - P: "Finis Gallatiae et Cappadociae".

${ }^{379}$ DARE: <http://imperium.ahlfeldt.se/places/23564>.

${ }^{380}$ V: "Iogula" - P: "Iogola".

${ }^{381}$ DARE: <http://imperium.ahlfeldt.se/places/36155>.

382 DARE: <http://imperium.ahlfeldt.se/places/23560>.

${ }^{383}$ DARE: < http://imperium.ahlfeldt.se/places/36143>.

${ }^{384}$ DARE: <http://imperium.ahlfeldt.se/places/21244>. Vide, também:

$<$ http://en.wikipedia.org/wiki/Aksaray\#History>.

385 V: "Mummoassum" - P: "Momoassom".

${ }^{386}$ DARE: <http://imperium.ahlfeldt.se/places/36152>.

${ }^{387}$ V: "Anachiango" - P: "Anathiango".

${ }^{388}$ DARE: < http://imperium.ahlfeldt.se/places/27620>.

${ }^{389}$ DARE: <http://imperium.ahlfeldt.se/places/36149>.

390 V: "Sasema" - P: "Sasima".

${ }^{391}$ DARE: <http://imperium.ahlfeldt.se/places/27630>.

392 V: "Andauiles" - P: “Andauilis".

393 DARE: <http://imperium.ahlfeldt.se/index.php?id=27620>. 


\begin{tabular}{|c|c|c|c|}
\hline & 6 & $\begin{array}{l}\text { Ibi est uilla Pammati, unde } \\
\text { ueniunt equi curoles. }{ }^{394}\end{array}$ & $\begin{array}{l}\text { Aí fica a fazenda de Pammatus (Pammato), } \\
\text { de onde vêm os cavalos de procissão. }\end{array}$ \\
\hline & 7 & Ciuitas Tiana mil XVI ${ }^{396}$ & $\begin{array}{l}\text { [Pouso na] cidade de Tiana (Kemerhisar), } \\
18 \text { milhas; }{ }^{397}\end{array}$ \\
\hline \multirow[t]{5}{*}{578} & 1 & Inde fuit Appollonius magus. & $\begin{array}{l}\text { De onde veio o mago Appollonius } \\
\text { (Apolônio). }\end{array}$ \\
\hline & 2 & Ciuitas Faustinopoli mil XII & $\begin{array}{l}\text { [Pouso na] cidade de Faustinopolis } \\
\text { (Başmakçı, na província de Niğde), } 12 \\
\text { milhas; }^{398}\end{array}$ \\
\hline & 3 & mutatio Caena mil XIII 399 & $\begin{array}{l}\text { posto de muda em Caena (próxima a } \\
\text { Çiftehan, na província de Niğde), } 13 \\
\text { milhas; }{ }^{400}\end{array}$ \\
\hline & 4 & mansio Opodanda mil XII ${ }^{401}$ & $\begin{array}{l}\text { pouso em Opodandum (Pozanti, no distrito } \\
\text { de Adana), } 12 \text { milhas; } 402\end{array}$ \\
\hline & 5 & mutatio Pilas mil XIIII & $\begin{array}{l}\text { posto de muda em Pylae (Gülek, no distrito } \\
\text { de Adana), } 14 \text { milhas; } 403\end{array}$ \\
\hline \multirow[t]{5}{*}{579} & 1 & Finis Cappadocia et Ciliciae. & $\begin{array}{l}\text { Fronteira entre Cappadocia (Capadócia) e } \\
\text { Cilicia (Cilícia). }\end{array}$ \\
\hline & 2 & Mansio Mansucrinae mil XII & $\begin{array}{l}\text { Pouso em Mansucrina (próximo a Çiftlik, } \\
\text { no distrito de Tarso), } 12 \text { milhas; }{ }^{404}\end{array}$ \\
\hline & 3 & Ciuitas Tarso mil XII ${ }^{405}$ & $\begin{array}{l}\text { [pouso na] cidade de Tarsus (Tarso), } 12 \\
\text { milhas. }{ }^{406}\end{array}$ \\
\hline & 4 & Inde fuit apostolus Paulus. & De onde veio o apóstolo Paulus (Paulo). \\
\hline & 5 & $\begin{array}{l}\text { Fit ab Anchira Galaciae } \\
\text { Tarso usque milia } \\
\text { CCCXLIII, }{ }^{407}\end{array}$ & $\begin{array}{l}\text { Percorridas de Anchira Galaciae (Ancara) } \\
\text { a Tarsus (Tarso) } 343 \text { milhas, }\end{array}$ \\
\hline 580 & 1 & $\begin{array}{l}\text { mutationes XXV, mansiones } \\
\text { XVIII. }\end{array}$ & $\begin{array}{l}\text { [passando por] } 25 \text { postos de muda e } 18 \\
\text { pousos. }\end{array}$ \\
\hline
\end{tabular}

${ }^{394}$ V: Ibi est uilla pammati unde uenit equi curoles - P: Ibi est uilla Pampati unde uenit equi curules. 395 “Equi curules" eram cavalos utilizados em desfiles e jogos, conforme: BOJESEN, E. F. A Handbook of Roman Antiquities. London: Francis and John Rivington, 1848. pp. 38-39.

${ }^{396}$ V: “Thyana” - P: "Thiana”.

397 OmnesViae: Tyana (Kemerhisar Niğde); DARE: <http://imperium.ahlfeldt.se/places/21243>.

${ }^{398}$ DARE: <http://imperium.ahlfeldt.se/places/21581>.

399 V: “Cona” - P: “Caena”.

${ }^{400}$ DARE: <http://imperium.ahlfeldt.se/places/36282>.

401 V: “Opodando" - P: “Opodanda”.

402 DARE: <http://imperium.ahlfeldt.se/places/23569>.

${ }^{403}$ Cilician Gates $=$ Cilician Pylae $=$ Gülek Boğazı, conforme:

$<$ http://referenceworks.brillonline.com/entries/brill-s-new-pauly/cilician-gates-ciliciae-pylae-

e613690>. DARE: <http://imperium.ahlfeldt.se/places/38529>.

${ }^{404}$ Antiga Nampsucrone, conforme:

$<$ http://referenceworks.brillonline.com/search?s.q=mansucrina\&s.f.s2_parent=s.f.book.brill-s-newpauly\&search-go=Search>. DARE: <http://imperium.ahlfeldt.se/places/36284>.

405 V: "Tarso Ciliciae" - P: "Tharso".

${ }^{406}$ OmnesViae: Tarso cilicie (Tarsus). DARE: <http://imperium.ahlfeldt.se/places/21245>.

407 V: “Anchira Galaciae Tarso”- P: “Anchira Galatia Tharso”. 


\section{Seção 9: de Tarsus (Tarso) a Tirus (Ṣūr)}

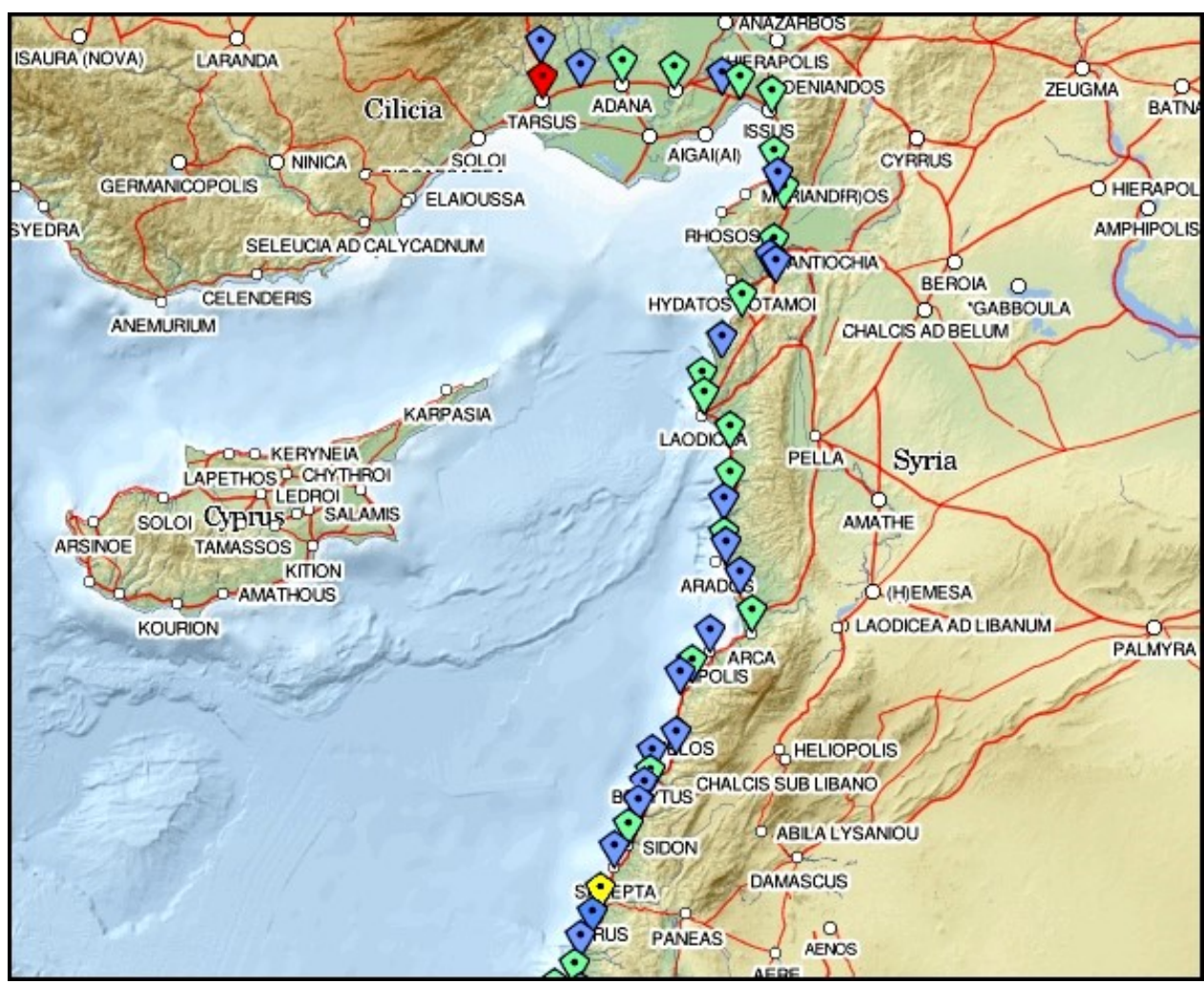

Mapa 9: trecho entre Tarsus (Tarso), em vermelho, e Tirus (Șūr), em amarelo; em azul estão registradas as mutationes (postos de muda) e em verde as mansiones (pousos).

\begin{tabular}{|c|c|c|c|}
\hline 579 & 3 & Ciuitas Tarso mil XII & $\begin{array}{l}\text { [Pouso na] cidade de Tarsus (Tarso), } 12 \\
\text { milhas. }\end{array}$ \\
\hline & 4 & Inde fuit apostolus Paulus. & De onde veio o apóstolo Paulus (Paulo). \\
\hline & 5 & $\begin{array}{l}\text { Fit ab Anchira Galaciae } \\
\text { Tarso usque milia } \\
\text { CCCXLIII, }\end{array}$ & $\begin{array}{l}\text { Percorridas de Anchira Galaciae (Ancara) a } \\
\text { Tarsus (Tarso) } 343 \text { milhas, }\end{array}$ \\
\hline 580 & 1 & $\begin{array}{l}\text { mutationes XXV, mansiones } \\
\text { XVIII. }\end{array}$ & $\begin{array}{l}\text { [passando por] } 25 \text { postos de muda e } 18 \\
\text { pousos. }\end{array}$ \\
\hline & 2 & Mutatio Pargas mil XIII ${ }^{408}$ & $\begin{array}{l}\text { posto de muda em Pargas (ao leste de } \\
\text { Yenice, no distrito de Tarsus), } 13 \text { milhas; } 409\end{array}$ \\
\hline & 3 & Ciuitas Gadana mil XIIII ${ }^{410}$ & $\begin{array}{l}\text { [pouso na] cidade de Gadana (Adana), } 14 \\
\text { milhas; }\end{array}$ \\
\hline & 4 & Ciuitas Mansista mil XVIII & $\begin{array}{l}\text { [pouso na] cidade de Mansista (leste de } \\
\text { Suluca, no distrito de Adana), } 18 \text { milhas; }{ }^{412}\end{array}$ \\
\hline
\end{tabular}

408 V: "Pargas" - P: "Pargais".

409 DARE: <http://imperium.ahlfeldt.se/places/36286>.

${ }^{410}$ V: "Gadana" - P: "Abdana”.

${ }^{411}$ DARE: <http://imperium.ahlfeldt.se/places/21246>.

412 OmnesViae: Mompsistea (Yakapınar). DARE: <http://imperium.ahlfeldt.se/places/21247>. 


\begin{tabular}{|c|c|c|c|}
\hline & 5 & mutatio Tardequeia mil XV & $\begin{array}{l}\text { posto de muda em Tardequeia } \\
\text { (possivelmente Kurtkulağı, no distrito de } \\
\text { Adama), } 15 \text { milhas; }{ }^{413}\end{array}$ \\
\hline & 6 & mansio Catauolo mil XVI & $\begin{array}{l}\text { pouso em Catauolo (possivelmente } \\
\text { Karatepe, na província de Osmaniye), } 16 \\
\text { milhas; } 414\end{array}$ \\
\hline & 7 & mansio Baiae mil XVII & $\begin{array}{l}\text { pouso em Baiae (ao norte de Dörtyol), } 17 \\
\text { milhas; } 415\end{array}$ \\
\hline & 8 & $\begin{array}{l}\text { mansio Alexandria Scabiosa } \\
\text { mil XVI }\end{array}$ & $\begin{array}{l}\text { [pouso na] cidade de Alexandria Scabiosa } \\
\text { (İskenderun), } 16 \text { milhas; }{ }^{416}\end{array}$ \\
\hline \multirow[t]{6}{*}{581} & 1 & mutatio Pictanus mil VIIII ${ }^{417}$ & $\begin{array}{l}\text { posto de muda em Pictanus (Belen, na } \\
\text { província de Hatay), } 9 \text { milhas; } 418\end{array}$ \\
\hline & 2 & Fines Ciliciae et Syria. ${ }^{419}$ & $\begin{array}{l}\text { Fronteira entre Cilicia (Cilícia) e Syria } \\
\text { (Síria). }\end{array}$ \\
\hline & 3 & Mansio Pangrios mil VIII & Pouso em Pangrios (Bagras), 8 milhas; ${ }^{420}$ \\
\hline & 4 & $\begin{array}{l}\text { Ciuitas Anchiochia mil } \\
\mathrm{XVI}^{421}\end{array}$ & $\begin{array}{l}\text { [pouso na] cidade de Anchiochia (Antakya), } \\
16 \text { milhas; }{ }^{422}\end{array}$ \\
\hline & 5,6 & $\begin{array}{l}\text { Fit a Tarso Ciliciae } \\
\text { Anchiotiam milia CXLI, } \\
\text { mutationes X, mansiones } \\
\text { VII. }{ }^{423}\end{array}$ & $\begin{array}{l}\text { Percorridas de Tarsus (Tarso), na Cilicia } \\
\text { (Cilícia) a Anchiotia (Antakya), } 141 \text { milhas, } \\
\text { [passando por] } 10 \text { postos de muda e } 7 \\
\text { pousos. }\end{array}$ \\
\hline & 7 & Ad palatium Dafne mil V & $\begin{array}{l}\text { Até o palácio em Dafne (Harbiye, no } \\
\text { distrito de Hatay), } 5 \text { milhas; } 424\end{array}$ \\
\hline \multirow[t]{3}{*}{582} & 1 & mutatio Stadata mil XI ${ }^{425}$ & $\begin{array}{l}\text { posto de muda em Stadata (talvez ao sul de } \\
\text { Şenköy, Hatay), } 11 \text { milhas; } 426\end{array}$ \\
\hline & 2 & mansio Platanus mil VIII ${ }^{427}$ & $\begin{array}{l}\text { pouso em Platanus (talvez Yayladağı, } \\
\text { Hatay), } 8 \text { milhas; }{ }^{428}\end{array}$ \\
\hline & 3 & mutatio Bachaias mil VIII & posto de muda em Bacchaiae, 8 milhas; 429 \\
\hline
\end{tabular}

413 DARE: <http://imperium.ahlfeldt.se/places/36263>

${ }^{414}$ OmnesViae: Catabolo. DARE: <http://imperium.ahlfeldt.se/places/23586>.

415 DARE: <http://imperium.ahlfeldt.se/places/23587>.

416 OmnesViae: Alexandria catisson (İskenderun). DARE:

$<$ http://imperium.ahlfeldt.se/places/21820>.

${ }^{417}$ V: "Platanus" - P: "Pictanus".

${ }^{418}$ DARE: <http://imperium.ahlfeldt.se/places/23407>. Vide, também:

$<$ http://en.wikipedia.org/wiki/Belen_Pass>.

${ }^{419}$ VP: "Fines Ciliciae et Syriae".

${ }^{420}$ DARE: <http://imperium.ahlfeldt.se/places/23408>.

${ }^{421}$ V: "Anchiotia" - P: "Anthiochia".

422 DARE: <http://imperium.ahlfeldt.se/places/21094>.

${ }^{423}$ V: "Tarso Ciliciae Anchiotia” - P: "Tharso Cilicia Anthiochia”.

${ }^{424}$ DARE: <http://imperium.ahlfeldt.se/places/21504>.

${ }^{425}$ V: "Stadata" - P: "Hysdata".

${ }^{426}$ Ao sul da antiga Charandama, DARE: <http://imperium.ahlfeldt.se/places/30355>.

427 VP: "Platanus".

428 Talvez DARE: <http://imperium.ahlfeldt.se/places/37402>.

429 Talvez próxima de Poseidon: DARE: < http://imperium.ahlfeldt.se/places/33218> 


\begin{tabular}{|c|c|c|c|}
\hline & 4 & Ciuitas Catelas mil XVI ${ }^{430}$ & [pouso na] cidade de Catelae, 16 milhas; ${ }^{431}$ \\
\hline & 5 & Ciuitas Ladica mil XVI ${ }^{432}$ & $\begin{array}{l}\text { [pouso na] cidade de Ladica (Al } \\
\text { Lathqiyah), } 16 \text { milhas; } 433\end{array}$ \\
\hline & 6 & Ciuitas Gauala mil XIIII & $\begin{array}{l}\text { [pouso na] cidade de Gauala (Jablah), } 14 \\
\text { milhas; }{ }^{434}\end{array}$ \\
\hline & 7 & Ciuitas Balaneas mil XIII & $\begin{array}{l}\text { [pouso na] cidade de Balaneae (Baniyas), } \\
13 \text { milhas; } 435\end{array}$ \\
\hline & 8 & $\begin{array}{l}\text { Fines Syriae Coelis et } \\
\text { Foenicis. }{ }^{436}\end{array}$ & $\begin{array}{l}\text { Fronteira entre Syria Coele (Síria Coele) e } \\
\text { Foenice (Fenícia). }\end{array}$ \\
\hline & 9 & Mutatio Maraccas mil X & $\begin{array}{l}\text { posto de muda em Maraccae (ao norte de } \\
\text { Tartus), } 10 \text { milhas; }{ }^{437}\end{array}$ \\
\hline & 10 & mansio Antaradus mil XVI & $\begin{array}{l}\text { pouso em Antaradus (ao leste de Tartus), } 16 \\
\text { milhas, }{ }^{438}\end{array}$ \\
\hline & 11 & $\begin{array}{l}\text { est ciuitas in mare a ripa mil } \\
\text { II. }\end{array}$ & uma cidade a duas milhas do litoral. \\
\hline & 12 & mutatio Spiclin mil XII & $\begin{array}{l}\text { posto de muda em Spiclin (ao sul de } \\
\text { Tartus), } 12 \text { milhas; } 439\end{array}$ \\
\hline 583 & 1 & mutatio Baselisco mil XII ${ }^{440}$ & $\begin{array}{l}\text { posto de muda em Baseliscum (próxima a } \\
\text { Al-Hamidiyah), } 12 \text { milhas; }{ }^{441}\end{array}$ \\
\hline & 2 & mansio Arcas mil VIII & pouso em Arcae (Arqa, Akkar), 8 milhas; 442 \\
\hline & 3 & mutatio Bruttus mil IIII ${ }^{443}$ & $\begin{array}{l}\text { posto de muda em Bruttus (próxima a El- } \\
\text { Abda, Tripoli), } 4 \text { milhas; }{ }^{444}\end{array}$ \\
\hline & 4 & Ciuitas Trepoli mil XII ${ }^{445}$ & $\begin{array}{l}\text { [pouso na] cidade de Trepoli (Trípoli), } 12 \\
\text { milhas; }{ }^{446}\end{array}$ \\
\hline & 5 & mutatio Treclis mil XII ${ }^{447}$ & $\begin{array}{l}\text { posto de muda em Treclis (El Heri), } 12 \\
\text { milhas; } 448\end{array}$ \\
\hline
\end{tabular}

${ }^{430}$ V: “Catelas” - P: “Cattelas”.

${ }^{431}$ Possivelmente a nordeste de Leukos Linen, DARE: < http://imperium.ahlfeldt.se/places/33209>.

432 V: "Lasdeca" - P: "Ladica".

${ }^{433}$ OmnesViae: Laudiciae (Al Lathqiyah). DARE: <http://imperium.ahlfeldt.se/places/21505>.

${ }^{434}$ OmnesViae: Gabala (Jablah). DARE: <http://imperium.ahlfeldt.se/places/21506>.

435 DARE: <http://imperium.ahlfeldt.se/places/21721>.

${ }^{436}$ V: "Fines Syriae Coelis et Fohine" - P: "Finis Syriae Coelis et Foenices".

${ }^{437}$ DARE: <http://imperium.ahlfeldt.se/places/36486>.

438 OmnesViae: Andarado. DARE: <http://imperium.ahlfeldt.se/places/21722>.

439 Talvez ao sul da antiga Marathos, DARE: <http://imperium.ahlfeldt.se/places/21750>.

440 V: "Baselisco" - P: "Basiliscum”.

${ }^{441}$ Provavelmente próxima a Symira, DARE: <http://imperium.ahlfeldt.se/places/33235>.

442 DARE: <http://imperium.ahlfeldt.se/places/21569>. Antiga sede episcopal, destruída, conforme: $<$ http://en.wikipedia.org/wiki/Arcae>.

${ }^{443}$ V: "Bruttus" - P: "Bruttius".

${ }^{444}$ DARE: <http://imperium.ahlfeldt.se/places/36484>.

${ }^{445}$ V: "Trepoli” - P: “Tripoli”.

446 OmnesViae: Tripoli/Tarābulus. DARE: <http://imperium.ahlfeldt.se/places/21567>.

447 V: “Trecles” - P: “Tridis”.

448 DARE: <http://imperium.ahlfeldt.se/places/33241>. 


\begin{tabular}{|c|c|c|c|}
\hline & 6 & $\begin{array}{l}\text { mutatio Brattosalia mil } \\
\text { XII }^{449}\end{array}$ & $\begin{array}{l}\text { posto de muda na outra Brattosalia } \\
\text { (Batroun), } 12 \text { milhas; } 450\end{array}$ \\
\hline & 7 & mutatio Alcouile mil XII ${ }^{451}$ & $\begin{array}{l}\text { posto de muda em Alcouilis (próxima a } \\
\text { Jounieh), } 12 \text { milhas; } 452\end{array}$ \\
\hline & 8 & Ciuitas Birito mil XII ${ }^{453}$ & $\begin{array}{l}\text { [pouso na] cidade de Biritus (Beirute), } 12 \\
\text { milhas; }{ }^{454}\end{array}$ \\
\hline & 9 & mutatio Eldua mil XII ${ }^{455}$ & $\begin{array}{l}\text { posto de muda em Eldua (oeste da cidade } \\
\text { de Baabda), } 12 \text { milhas; }{ }^{456}\end{array}$ \\
\hline & 10 & mutatio Parpirion mil VIII ${ }^{457}$ & $\begin{array}{l}\text { posto de muda em Parpirion (sudoeste da } \\
\text { cidade de Baabda), } 8 \text { milhas; }{ }^{458}\end{array}$ \\
\hline & 11 & Ciuitas Sidona & $\begin{array}{l}\text { [pouso na] cidade de Sidona (Șaydā), } 8 \\
\text { milhas; }{ }^{459}\end{array}$ \\
\hline & $11 b$ & Inde Sarepta mil VIIII. ${ }^{460}$ & $\begin{array}{l}\text { A partir daí até Sarepta (Sarafand), } 9 \\
\text { milhas. } 461\end{array}$ \\
\hline & 12 & $\begin{array}{l}\text { Ibi Helias ad uiduam } \\
\text { ascendit et petiit sibi cybum. }\end{array}$ & $\begin{array}{l}\text { Aí Helias (Elias) levantou-se diante da } \\
\text { viúva e lhe pediu alimento. }\end{array}$ \\
\hline & 13 & Mutatio ad nonum mil IIII & $\begin{array}{l}\text { posto de muda no nono [miliário] (Aadlon), } \\
4 \text { milhas; }{ }^{462}\end{array}$ \\
\hline 584 & 1 & Ciuitas Tiro mil XII & $\begin{array}{l}\text { [pouso na] cidade de Tirus (Șūr), } 12 \\
\text { milhas; }{ }^{463}\end{array}$ \\
\hline & 2,3 & $\begin{array}{l}\text { Fit ab Anciocia Tiro usque } \\
\text { milia CLXXIIII, mutationes } \\
\text { XX, mansiones XI. }\end{array}$ & $\begin{array}{l}\text { Percorridas de Anciocia (Antakya) a Tirus } \\
\text { (Șūr) } 174 \text { milhas, [passando por] } 20 \text { postos } \\
\text { de muda e } 11 \text { pousos. }\end{array}$ \\
\hline
\end{tabular}

${ }^{449}$ V: "Brattosalia” - P: "Bruttus alia".

${ }^{450}$ OmnesViae: Botrus (Batroun). DARE: <http://imperium.ahlfeldt.se/places/21518>.

${ }^{451}$ V: “Alcouile” - P: “Alcobile”.

452 DARE: <http://imperium.ahlfeldt.se/places/23405>.

${ }^{453}$ V: "Bireto" - P: “Birito".

${ }^{454}$ OmnesViae: Berizto (Beirut). DARE: <http://imperium.ahlfeldt.se/places/21115>.

${ }^{455}$ V: "Eldua" - P: "Heldua".

456 DARE: <http://imperium.ahlfeldt.se/places/36495>.

${ }^{457}$ V: "Parpinon" - P: "Parphirion”.

458 DARE: <http://imperium.ahlfeldt.se/places/28258>.

459 OmnesViae: Sidone (Saida). DARE: < http://imperium.ahlfeldt.se/places/21115>.

${ }^{460}$ A passagem "Inde Sarepta mil VIIII" consta apenas de V.

${ }^{461}$ DARE: <http://imperium.ahlfeldt.se/places/21572>. Vide, também:

$<$ http://en.wikipedia.org/wiki/Sarepta $>$.

462 Ao norte da ponte sobre o rio Leontes (atual Litani). DARE:

$<$ http://imperium.ahlfeldt.se/places/38381>.

463 OmnesViae: Tyro (Sour). DARE: <http://imperium.ahlfeldt.se/places/21116>. 


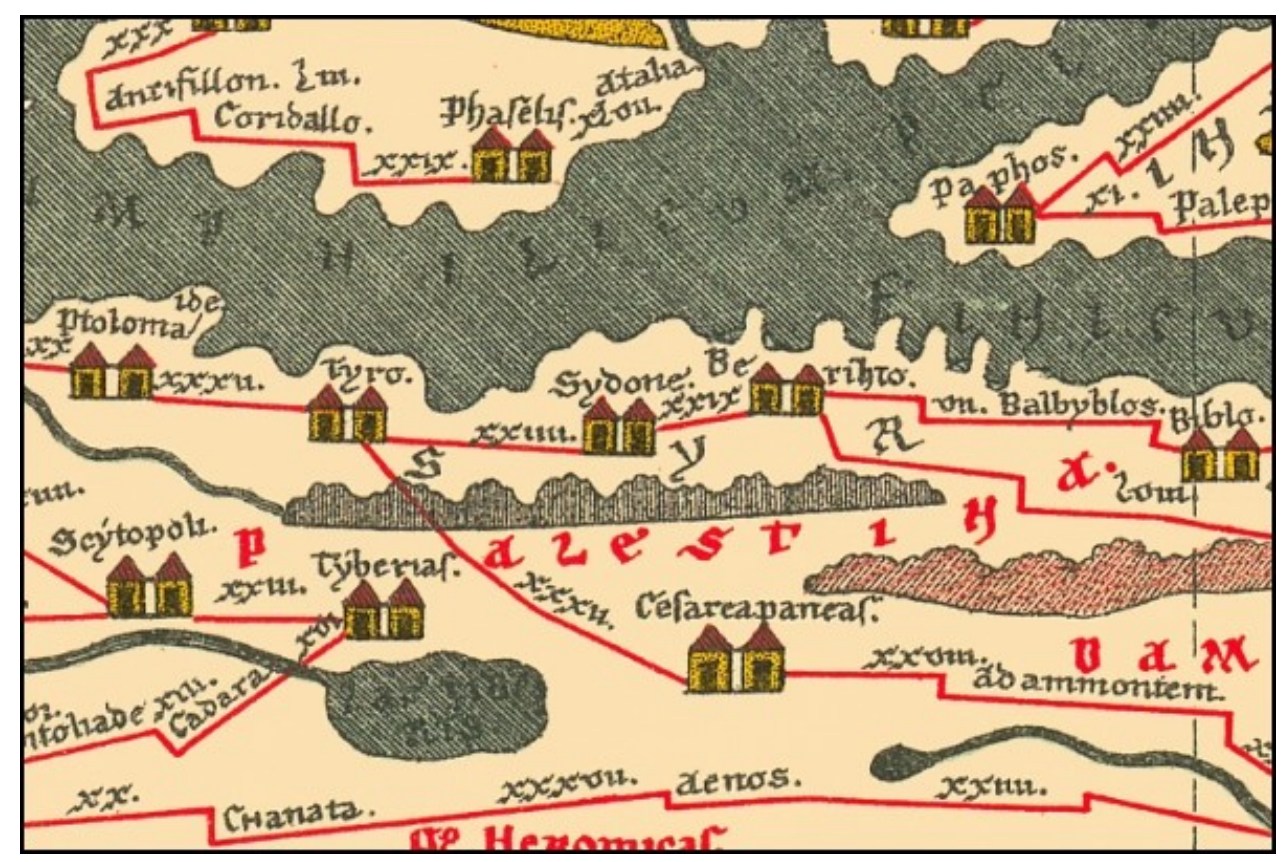

Figura 8: detalhe do fac-simile da Tabula Peutingeriana, com destaque para Tyro/Tirus; note-se que na parte superior aparece, surpreendentemente, um trecho da Asia Minor (na atual Turquia). 


\section{Seção 10: de Tirus (Șūr) a Hierusalem (Jerusalém) e depois Cesarea (Kesariya)}

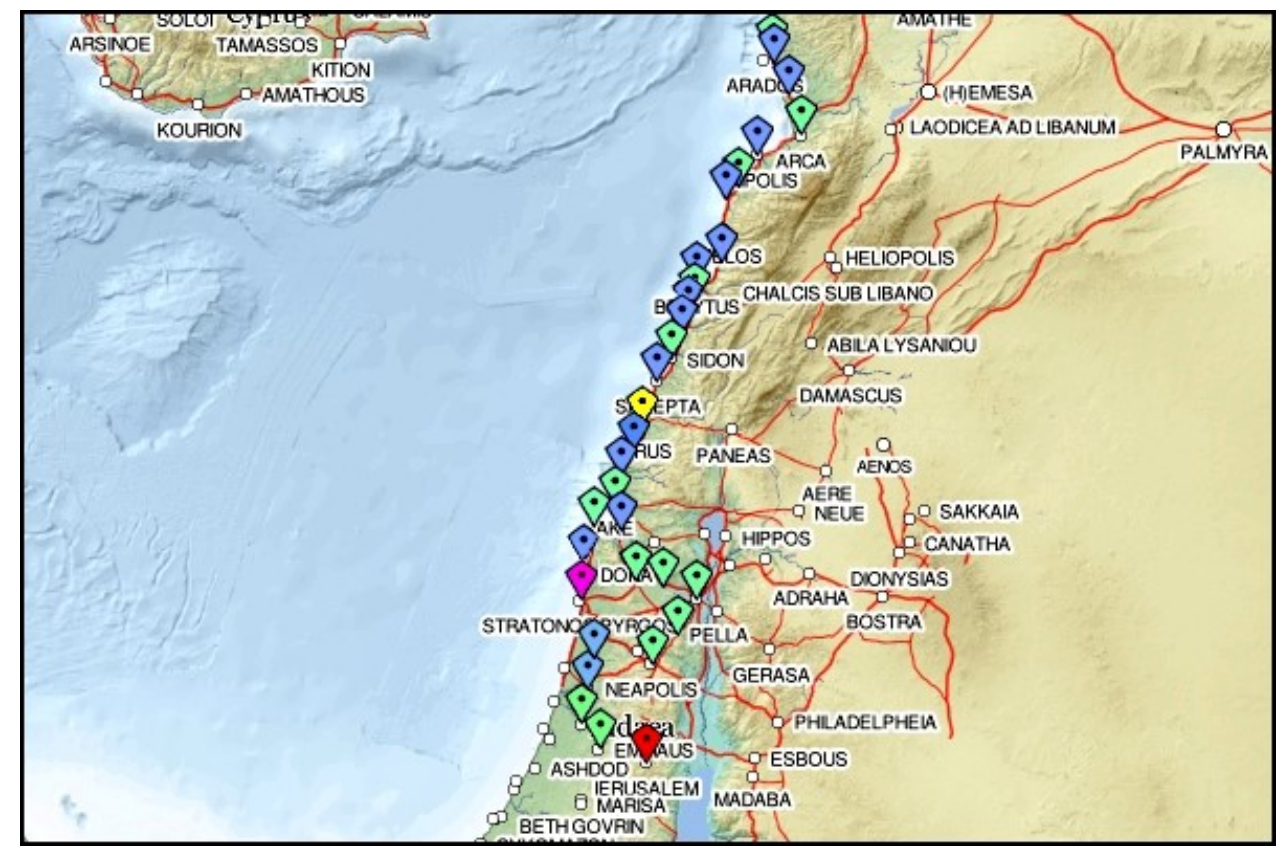

Mapa 10: trecho entre Tirus (Șūr), em amarelo, e Hierusalem (Jerusalém), em vermelho; Caesarea Palestina (Kesariya), em lilás, é tanto parte do percurso de ida até Hierusalem quanto de retorno à Europa; em azul estão registradas as mutationes (postos de muda) e em verde as mansiones (pousos).

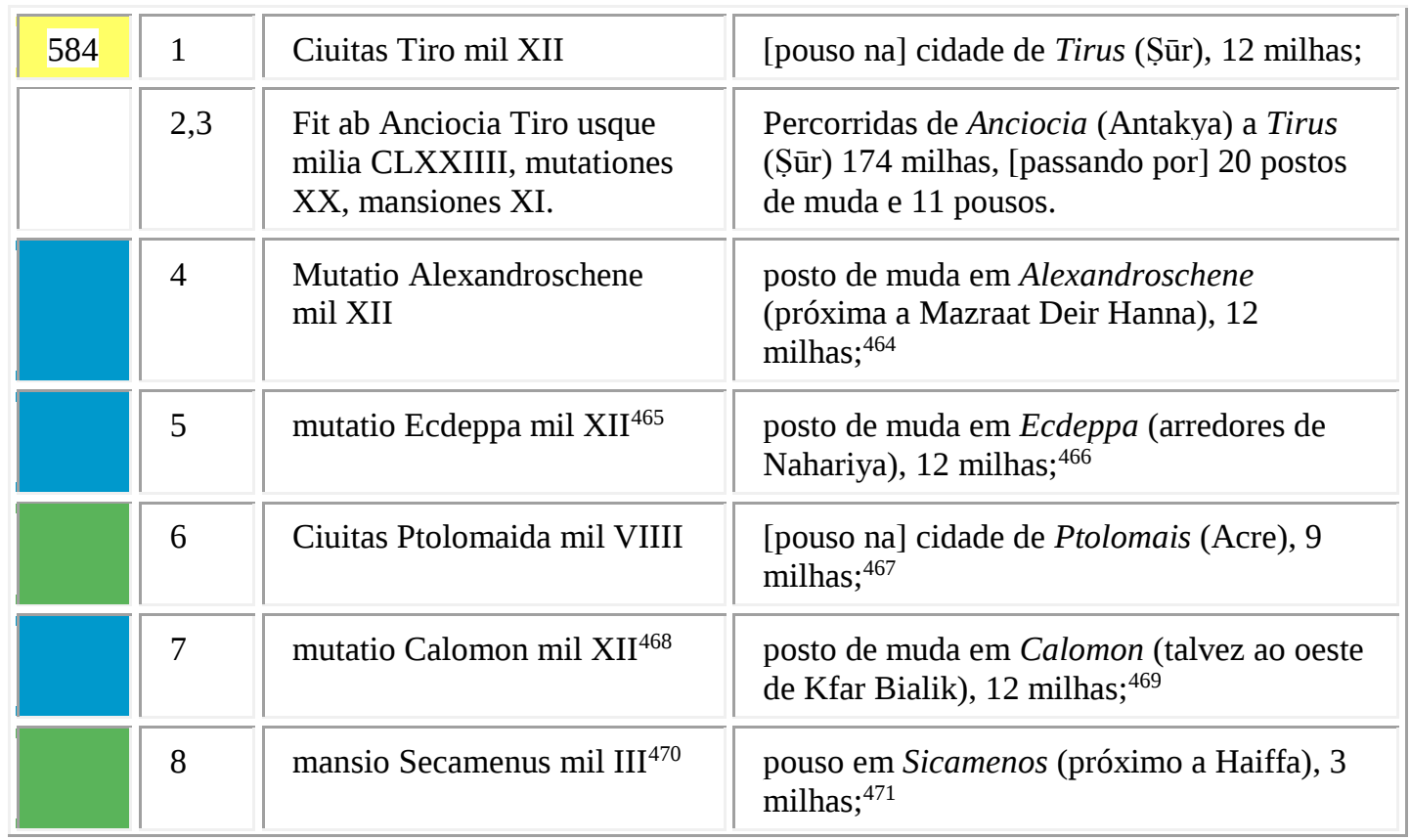

${ }^{464}$ DARE: <http://imperium.ahlfeldt.se/places/33251>.

${ }^{465}$ V: "Haecdepa" - P: "Ecdepa".

${ }^{466}$ DARE: <http://imperium.ahlfeldt.se/places/36493>.

467 OmnesViae: Ptolomaine (Akkô). DARE: <http://imperium.ahlfeldt.se/places/21662>.

${ }^{468}$ V: "Calomon" - P: "Calamon".

${ }^{469}$ DARE: <http://imperium.ahlfeldt.se/places/33300>.

${ }^{470}$ V: "Secaminus" - P: "Sicamenos".

${ }^{471}$ DARE: <http://imperium.ahlfeldt.se/places/36191>. 


\begin{tabular}{|c|c|c|c|}
\hline \multirow[t]{6}{*}{585} & 1 & $\begin{array}{l}\text { Ibi est mon Carmelus, ubi } \\
\text { Helias sacrificium } \\
\text { faciebat. }{ }^{472}\end{array}$ & $\begin{array}{l}\text { Aí fica o monte Carmelus (Carmelo), onde } \\
\text { Helias (Elias) ofereceu sacrifício. }\end{array}$ \\
\hline & 2 & Mutatio Cirtha mil VIIII 473 & $\begin{array}{l}\text { posto de muda em Cirtha (Atlit), } 8 \\
\text { milhas; }{ }^{474}\end{array}$ \\
\hline & 3 & Finis Syriae et Palestinae. ${ }^{475}$ & $\begin{array}{l}\text { Fronteira entre Syria (Síria) e Palestina } \\
\text { (Palestina). }\end{array}$ \\
\hline & 4 & $\begin{array}{l}\text { Ciuitas Caesarea Palestina, } \\
\text { id est Iudaea mil VIII. }{ }^{476}\end{array}$ & $\begin{array}{l}\text { [Pouso na] cidade de Caesarea Palestina } \\
\text { (Kesariya), ou seja, Iudea (Judeia), } 8 \\
\text { milhas; }{ }^{477}\end{array}$ \\
\hline & 5,6 & $\begin{array}{l}\text { Fit a Tiro Caesarea Palestina } \\
\text { milia LXXIII, mutationes II, } \\
\text { mansiones III. }{ }^{478}\end{array}$ & $\begin{array}{l}\text { Percorridas de Tirus (Șūr) a Caesarea } \\
\text { Palestina (Kaysaria) } 73 \text { milhas, [passando } \\
\text { por] } 2 \text { postos de muda e } 3 \text { pousos. }\end{array}$ \\
\hline & 7,8 & $\begin{array}{l}\text { Ibi est balneus Corneli } \\
\text { centoriones, qui multas } \\
\text { elymosynas faciebat. }{ }^{479} \text { In } \\
\text { tertio miliario est mons }\end{array}$ & $\begin{array}{l}\text { Aí fica o banho do centurião Cornelus } \\
\text { (Cornélio), que deu muitas esmolas. No } \\
\text { terceiro miliário está o monte }\end{array}$ \\
\hline \multirow[t]{5}{*}{586} & 1,2 & $\begin{array}{l}\text { Syna, ubi fons est in quem } \\
\text { mulier si lauerit, grauida fit. }\end{array}$ & $\begin{array}{l}\text { Syna (Sinai), onde está a fonte na qual, se } \\
\text { uma mulher se lavar, ficará grávida. }\end{array}$ \\
\hline & 3 & $\begin{array}{l}\text { Ciuitas Maximianopoli mil } \\
\text { XVII }\end{array}$ & $\begin{array}{l}\text { [Pouso na] cidade de Maximianopolis } \\
\text { (arredores de Omen), } 17 \text { milhas; } ; 80\end{array}$ \\
\hline & 4 & Ciuitas Istradela mil $\mathrm{X}^{481}$ & $\begin{array}{l}\text { [pouso na] cidade de Istradela (arredores de } \\
\text { Nurit), } 10 \text { milhas; } 482\end{array}$ \\
\hline & 5,6 & $\begin{array}{l}\text { Ibi sedit Acap rex et Helias } \\
\text { prophetauit; ibi est campus, } \\
\text { ubi Dauid Goliat occidit. } 8{ }^{83}\end{array}$ & $\begin{array}{l}\text { Aí governou o rei Acap (Acabe) e Helias } \\
\text { (Elias) profetizou; aí fica o campo onde } \\
\text { Dauid (Davi) matou Goliat (Golias). }\end{array}$ \\
\hline & 7 & Ciuitas Sciopoli mil XII & $\begin{array}{l}\text { [Pouso na] cidade de Sciopolis (Beit } \\
\text { She'an), } 12 \text { milhas; } 484\end{array}$ \\
\hline 587 & 1 & Aser, ubi fuit uilla Iob mil VI & $\begin{array}{l}\text { [pouso em] Aser (Tubas), onde era a } \\
\text { fazenda de Jó, } 6 \text { milhas. }{ }^{485}\end{array}$ \\
\hline & 2 & Ciuitas Neapolini mil XV $\mathrm{XV}^{486}$ & [Pouso na] cidade de Neapolinis (Nablus), \\
\hline
\end{tabular}

472 V: "mon Carmelus" - P: "mons Carmelus".

${ }^{473}$ V: "Cirtha" - P: "Certha”.

${ }^{474}$ DARE: $<$ http://imperium.ahlfeldt.se/places/33278>.

${ }^{475}$ V: "Finis Syriae Finices et Palestinae" - P: "Fines Syriae et Palestinae".

${ }^{476}$ V: "Caesaria Palastina" - P: "Caesaria Palestina”.

477 OmnesViae: Cesarea. DARE: <http://imperium.ahlfeldt.se/places/21149>.

${ }^{478}$ V: "Tiro" - P: "Tyro".

${ }^{479}$ V: "Ibi est balneus Corneli centoriones, qui multas elymosynas faciebat" - P: "Ibi est balneus Cornelii centurionis qui multas aelymosinas faciebat”.

${ }^{480}$ DARE: <http://imperium.ahlfeldt.se/places/21660>.

${ }^{481}$ V: "Istradela" - P: "Stradela".

${ }^{482}$ DARE: <http://imperium.ahlfeldt.se/places/33322>.

${ }^{483}$ V: “Acap” - P: “Achab”.

${ }^{484}$ DARE: < http://imperium.ahlfeldt.se/places/21150>.

${ }^{485}$ DARE: <http://imperium.ahlfeldt.se/places/36491>.

${ }^{486}$ V: "Neapolini” - P: “Neapoli”. 


\begin{tabular}{|c|c|c|c|}
\hline & & & 15 milhas. ${ }^{487}$ \\
\hline & 3 & $\begin{array}{l}\text { Ibi est mons Agazarem ibi } \\
\text { dicunt Samaritani Abraham } \\
\text { sacrificium obtulisse, et } \\
\text { ascenduntur montem } \\
\text { summum gradi numero } \\
\text { CCC. Inde ad pedem montis } \\
\text { ipsius locus est, }{ }^{488}\end{array}$ & $\begin{array}{l}\text { Aí fica o monte Agazarem, onde os } \\
\text { samaritanos dizem que Abraham (Abraão) } \\
\text { ofereceu sacrifício; ascende-se até o topo do } \\
\text { monte em trezentos degraus. A partir daí, ao } \\
\text { pé do próprio monte, está um local }\end{array}$ \\
\hline 588 & $1-5$ & $\begin{array}{l}\text { cui nomen est Sicem. Ibi est } \\
\text { monumentum ibi positus est } \\
\text { Ioseph in uilla, quam dedit ei } \\
\text { Iacob pater eius. Inde rapta } \\
\text { est Dina filia Iacob a filiis } \\
\text { Amorreorum. Inde passus } \\
\text { mille locus est, cui nomen } \\
\text { Sichar, unde discendit mulier } \\
\text { Samaritana ad eundem } \\
\text { locum, ibi Iacob puteum } \\
\text { fodit, ut de eo aqua impleret, } \\
\text { et dominus noster Ihesus } \\
\text { Christus cum ea locutus est; } \\
\text { ubi sunt arbores plantani, } \\
\text { quas plantauit Iacob, et } \\
\text { balneos, qui deo puteo } \\
\text { lauatur. } \\
\text { Inde milia XXVIII. Euntibus } \\
\text { Hierusalem in parte sinistra } \\
\text { est uilla, quae dicitur Betar. } \\
\text { Inde passus mille est locus, } \\
\text { ubi Iacob, cum iret in } \\
\text { Mesopotamia obdormiuit, et } \\
\text { est ibi arbor amigdoli, et } \\
\text { uidit uisum, et angelus cum } \\
\text { eo luctatus est. Ibi fuit rex } \\
\text { Hieroboam, ad quem missus } \\
\text { fuit propheta, }{ }^{489}\end{array}$ & $\begin{array}{l}\text { cujo nome é Sicem. Aí está localizado um } \\
\text { monumento onde jaz Iosephus (José), na } \\
\text { propriedade dada a ele por Iacob (Jacó), seu } \\
\text { pai. A filha de Iacob (Jacó) foi raptada daí } \\
\text { pelos filhos dos amoritas. A mil passos daí } \\
\text { está o local, cujo nome é Sichar, de onde a } \\
\text { mulher samaritana desceu ao mesmo local, } \\
\text { onde Iacob (Jacó) cavou um poço, para dele } \\
\text { com a água saciar-se, e nosso Senhor Ihesus } \\
\text { Christus (Jesus Cristo) falou com ela; é } \\
\text { onde estão as árvores de plátano, as quais } \\
\text { Iacob (Jacó) plantou, }{ }^{490} \text { e o banho, } \\
\text { abastecido pelo poço. } \\
\text { A vinte e oito milhas daí, quando se vai } \\
\text { para Hierusalem (Jerusalém), }{ }^{491} \text { do lado } \\
\text { esquerdo, está a propriedade conhecida } \\
\text { como Betar. A mil passos daí está o local } \\
\text { onde Iacob (Jacó) adormeceu quando foi a } \\
\text { Mesopotamia (Mesopotâmia). Aí, também, } \\
\text { é onde fica a amendoeira onde ele viu a } \\
\text { aparição e lutou com o anjo. }{ }^{492} \text { Aí estava o } \\
\text { rei Hierobom (Jeroboão), a quem foi } \\
\text { enviado um profeta }\end{array}$ \\
\hline
\end{tabular}

${ }^{487}$ OmnesViae: Neapolis (Nablus). DARE: <http://imperium.ahlfeldt.se/places/21655>.

488 S: "Agar" - V: "Agazam" - P: "Agazarem”.

S: "montem summum" - VP: "ad summum montem”.

${ }^{489}$ S: "Sichem" - V: "Sicem” - P: "Sechim”.

SP: "Ibi positum est monumentum ibi positus Ioseph in uilla" - V: "Ibi est monimentum ubi positus est Ioseph in uilla".

SP: "descendit" - V: “discendit”.

S: "Samatana" - VP: "Samaritana".

S: "ibi Iacob puteum fodit” - VP: "ubi Iacob putem fodit”.

SV: "de eo aquam impleret" - P: "de eo aqua impleret”.

S: "plantani" - VP: "platani".

S: "palneos" - VP: "balneus".

SP: "qui de eo puteo lauatur" - V: "qui deo puteo lauatur V".

SP: "Bethar" - V: "Betar".

S: "obdormiuit" - V: "dormiuit" - P: “addormiuit".

S: “amigdoli” - V: “amigdalae” - P: “amigdala”.

${ }^{490}$ O viajante refere-se a Gênesis 30:37.

${ }^{491}$ OmnesViae: Helyacapitolina (Jerusalem). DARE: <http://imperium.ahlfeldt.se/places/15896>.

492 O viajante refere-se a Gênesis 32:22-28. 


\begin{tabular}{|l|l|l|}
\hline 589 & \begin{tabular}{ll|l|}
\hline ut conueretur ad dominum \\
excelsum, et iussum fuerat \\
prophetae ne cum \\
seodoprophetam quos rex \\
secum habebat manducaret; \\
rediens ocurrit propheta leo \\
in uia occidit eum.
\end{tabular} & $\begin{array}{l}\text { para que se convertesse ao Senhor } \\
\text { altíssimo. E foi ordenado ao profeta que não } \\
\text { se alimentasse com o pseudoprofeta que o } \\
\text { rei tinha consigo. Quando o profeta } \\
\text { retornava pela estrada, um leão o atacou e } \\
\text { matou. }{ }^{494}\end{array}$ \\
\hline
\end{tabular}

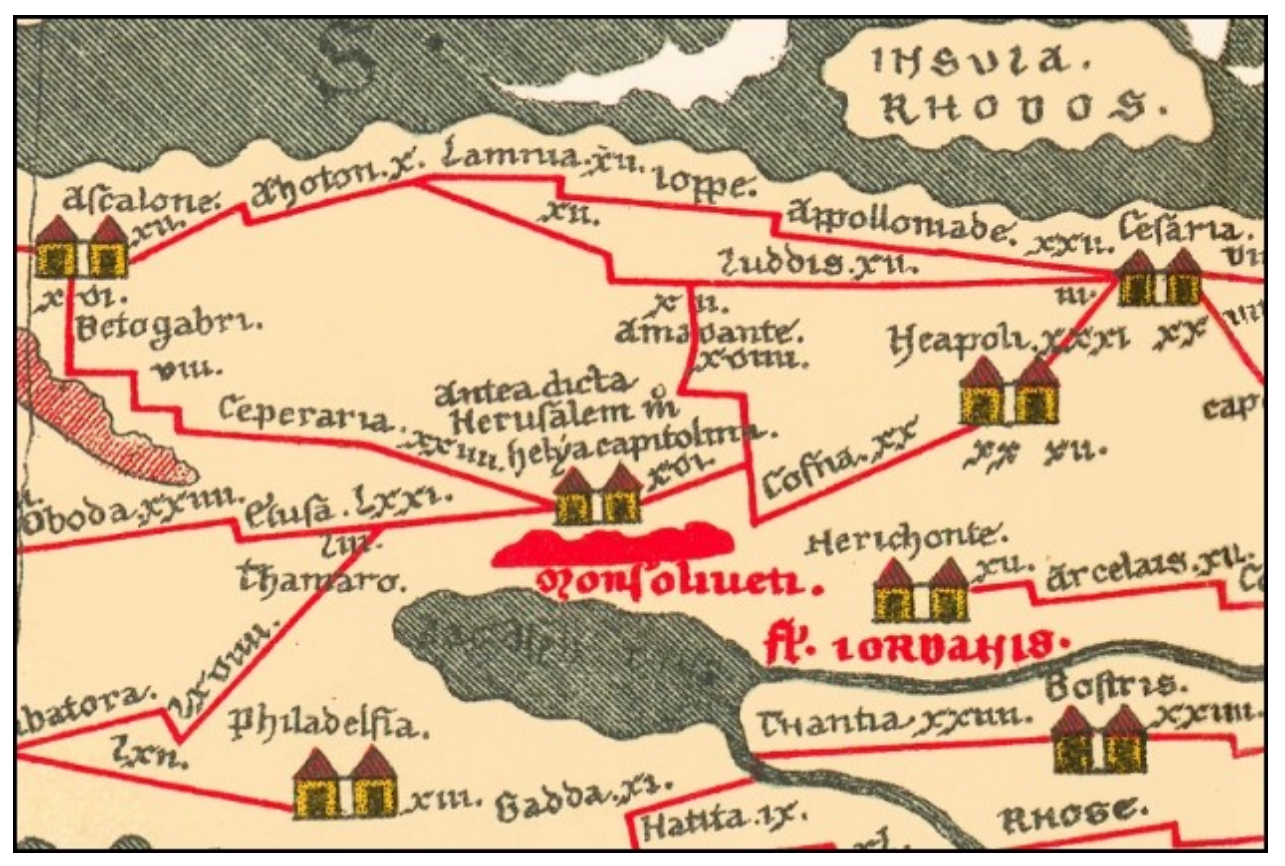

Figura 9: detalhe do fac-simile da Tabula Peutingeriana, com destaque para Herusalem/Hierusalém.; note-se que o caminho entre esta e Cesaria/Caesaria Palestina, passando por Neapoli/Neapolis, inclui Cofna (atual Jifnâ) - não mencionada no Itinerarium Burdigalense.

\begin{tabular}{|c|c|c|c|}
\hline 589 & 6 & $\begin{array}{l}\text { Inde Hierusalem milia XII } \\
\text { Fit a Caesarea Palestina } \\
\text { Hierusalem usque milia } \\
\text { CXVI, mansiones IIII, } \\
\text { mutationes IIII. } \\
\text { Sunt in Hierusalem piscinae } \\
\text { magnae duae a latus templi, } \\
\text { id est una ad dextris, alia } \\
\text { sinistris, quas Salomon fecit, } \\
\text { interius uero ciuitati sunt } \\
\text { piscinae gemillares, quinque } \\
\text { porticus habentes, quae } \\
\text { appellantur Vetaidae. Ibi egri }\end{array}$ & $\begin{array}{l}\text { A partir daí para Hierusalem (Jerusalém), } \\
12 \text { milhas. } \\
\text { Percorridas de Caesarea Palestina } \\
\text { (Kesariya) a Hierusalem (Jerusalém) } 116 \\
\text { milhas, [passando por] } 4 \text { pousos e } 3 \text { postos } \\
\text { de muda. } \\
\text { Existem em Hierusalem (Jerusalém) duas } \\
\text { grandes piscinas ao lado do templo, uma à } \\
\text { direita e outra à esquerda, feitas por } \\
\text { Salomon (Salomão); de fato, mais para o } \\
\text { interior da cidade existem piscinas } \\
\text { geminadas, com cinco pórticos, as quais são } \\
\text { chamadas Vetaidae (Betsaida). Aí muitos }\end{array}$ \\
\hline
\end{tabular}

493 SP: “deum”- V: “dominum”.

S: “cum pseudoprophetam” - V: “cum seodoprophetam” - P: “cum pseudopropheta”.

S: “quos rex secum habebat manducaret; rediens ocurrit propheta leo in uia occidit eum” - V: "quem secum habebat rex manducaret, et quia secutus est ad seodopropheta et cum eo manducauit rediens ocurrit prophetae leo in uia et occidit eum" - P: “quem secum rex habebat, manducaret, et quia seductus est a pseudopropheta et cum eo manducauit, rediens ocurrit prophetae leo in uia et occidit eum”.

${ }^{494} \mathrm{O}$ viajante refere-se a 1 Reis 13. 


\begin{tabular}{|l|l|l|}
\hline $\begin{array}{ll}\text { multorum annorum sanantur. } \\
\text { aquam autem habent }\end{array}$ & $\begin{array}{l}\text { doentes são curados anualmente. As águas } \\
\text { dessas piscinas ficam escarlate quando } \\
\text { immodum piscine coccini } \\
\text { turbatum est; est ibi crepta } \\
\text { tubi Salomon daemones } \\
\text { torquebat. }^{495}\end{array}$ & $\begin{array}{l}\text { onde Salomon (Salomão) torturou os } \\
\text { demônios. }\end{array}$ \\
\hline
\end{tabular}

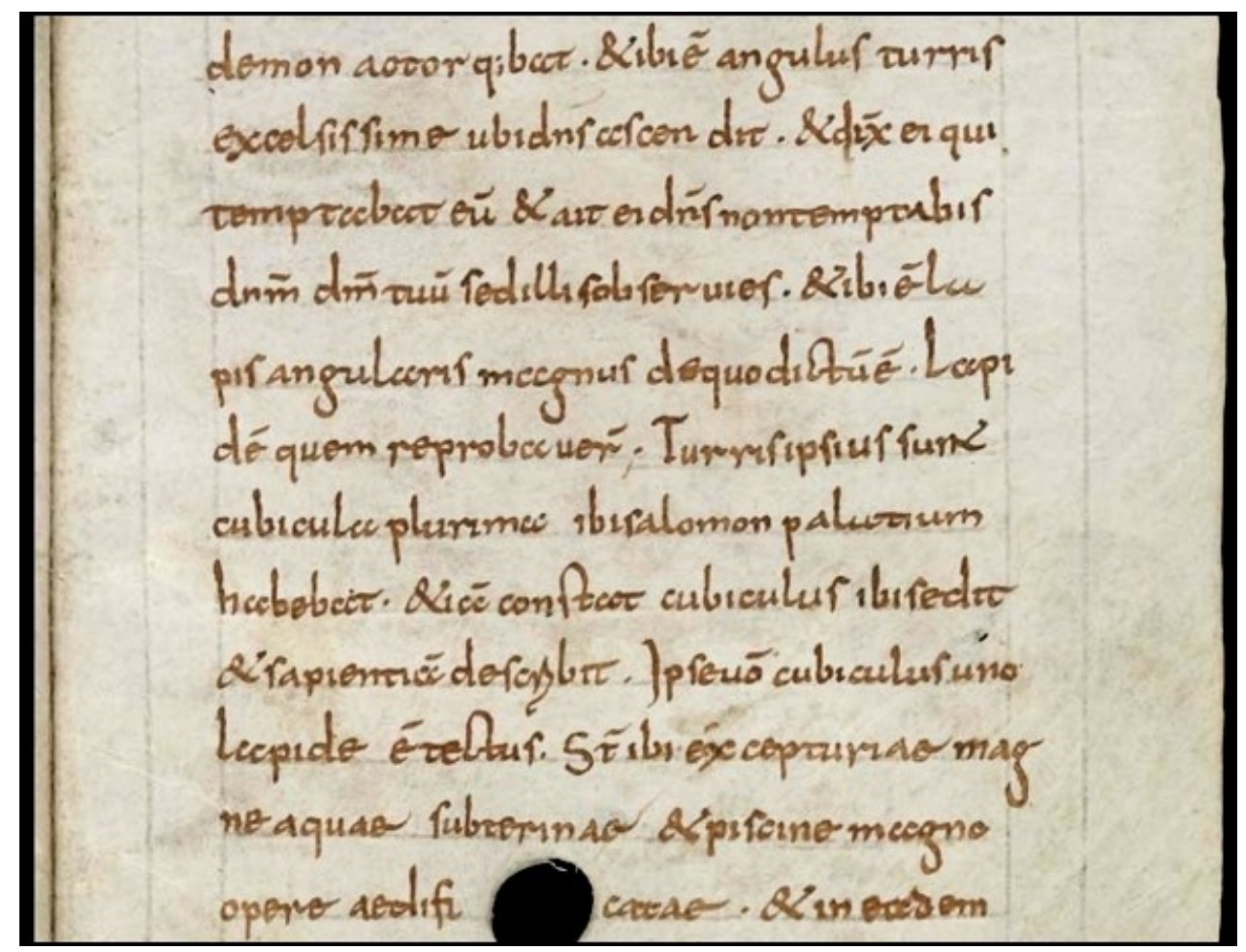

Figura 10: Detalhe da página 105 do Codex Sangallensis 732, correspondente à entrada 590 do Itinerarium Burdigalense (abaixo).

\begin{tabular}{|c|c|c|}
\hline 590 & $\begin{array}{l}\text { Et ibi est angulus turris } \\
\text { excelsissimae, ubi dominus } \\
\text { ascenditi, et dixit ei his qui } \\
\text { temptabat eum }{ }^{496} \ldots \text { et ait ei } \\
\text { dominus: Non temptabis } \\
\text { dominum deum tuum, sed illi } \\
\text { soli seruies. Et ibi est lapis }\end{array}$ & $\begin{array}{l}\text { Aí também fica uma esquina com uma torre } \\
\text { altíssima, onde o Senhor ascendeu e disse } \\
\text { isso a quem O tentava: [lacuna]. E o Senhor } \\
\text { lhe disse: “Não tentais o Senhor teu Deus, } \\
\text { mas a Ele apenas servis”. Aí fica uma } \\
\text { grande pedra angular, da qual se diz: “A } \\
\text { pedra que os construtores rejeitam”. } 498\end{array}$ \\
\hline
\end{tabular}

495 V: “ad latus templi” - SP: “a latus templi”.

S: "ad dextris" - VP: "ad dextera”.

S: "alia sinistris" - VP: "ad sinistra".

S: “pigne gemellares” - V: “piscinae gemillares” - P: “piscinae gemellares”.

$\mathrm{V}$ : "quinque porticus" - SP: "quinque porticos".

S: "Betsaida" - V: "Vetaidae" - P: "Vaetaida".

S: "egri” - VP: "aegri”.

S: "sanantur" - VP: "sanabantur".

S: “aquam autem habent immodum piscine coccini turbatum est” - V: “aquam bentae piscinae in modum cocci natura” - P: “aquam habent hae piscinae in modum coccini turbatam”.

S: "et ibi ad scripta ubi Salomon demon ac torquebat" - V: "est ibi cripta ubi Salomon daemones torquebat” - P: “est ibi crepta ubi Salomon daemones torquebat”.

496 “Temptabat eum”: uma construção análoga a empregada na nossa língua (“o tentava”), mas no mínimo incomum no Latim Clássico. 


\begin{tabular}{|c|c|c|}
\hline & $\begin{array}{l}\text { angularis magnus, de quo } \\
\text { dictum est: Lapidem quem } \\
\text { reprobauerunt aedificantes. } \\
\text { Item ad capud anguli et sub } \\
\text { pinna turris ipsius sunt } \\
\text { plurima ibi Salomon } \\
\text { palatium habebat. Ibi etiam } \\
\text { constat cubiculus ibi sedit et } \\
\text { sapientiam descripsit; ipse } \\
\text { uero cubiculus uno lapide est } \\
\text { tectus. Sunt ibi et excepturia } \\
\text { magne aquae subterinae et } \\
\text { piscine magno opere } \\
\text { aedificatae.497 }\end{array}$ & $\begin{array}{l}\text { Também junto à esquina e sob o topo da } \\
\text { própria torre estão muitos quartos, onde } \\
\text { Salomon (Salomão) possuía um palácio. Aí } \\
\text { também está o quarto no qual ele sentou e } \\
\text { descreveu a sabedoria }{ }^{499} \text { - esse mesmo } \\
\text { quarto tem por teto uma [única] pedra. } \\
\text { Foram aí [também] construídos com grande } \\
\text { labor grandes reservatórios de água } \\
\text { subterrânea e uma piscina. }\end{array}$ \\
\hline 591 & $\begin{array}{l}\text { Et in aedem ipsa, ubi } \\
\text { templum fuit quem Salomon } \\
\text { aedificauit, in marmore ante } \\
\text { aram sanguinem Zachariae } \\
\text { ibi dicas hodie fusum, etiam } \\
\text { parent uestigia clauorum } \\
\text { militum qui eum occiderunt } \\
\text { in totam aream, ut putes } \\
\text { incera fixum fuisse. Sunt ibi } \\
\text { et statuas duae Adriani, est et } \\
\text { non longe de statuas lapis } \\
\text { pertusus, ad quem ueniunt } \\
\text { Iudaei singulis annis et } \\
\text { unguent eum et lamentant se } \\
\text { cum gemitu et uestimenta } \\
\text { sua scindunt et sic recedunt. } \\
\text { Est ibi domus Ezezia regis } \\
\text { Iudae. Item euntibus } \\
\text { Hierusalem, ut ascendas } \\
\text { Sion, 500 }\end{array}$ & $\begin{array}{l}\text { E nesse edifício onde ficava o templo que } \\
\text { Salomon (Salomão) construiu, diz-se que, } \\
\text { no [pavimento de] mármore hoje existente } \\
\text { diante do altar, o sangue de Zacharias } \\
\text { (Zacarias) foi derramado; também são } \\
\text { visíveis por toda a área as marcas das clavas } \\
\text { dos soldados que o mataram, com se } \\
\text { tivessem sido feitas na cera. Aí estão duas } \\
\text { estátuas [do imperador] Adrianus (Adriano) } \\
\text { e não longe das estátuas está uma pedra } \\
\text { perfurada, às quais os judeus vêm uma vez } \\
\text { por ano e a untam e se lamentam com } \\
\text { gemidos e rasgam suas vestimentas e então } \\
\text { se retiram. Aí fica a casa de Ezezias } \\
\text { (Ezequias), o rei de Iuda (Judá). Também, } \\
\text { quando se sai de Hierusalem (Jerusalém) } \\
\text { para subir o [monte] Sion (Sião), }\end{array}$ \\
\hline
\end{tabular}

498 O viajante faz, nessa passagem, uma referência ao Salmo 118:22: “Lapidem quem reprobaverunt aedificantes, hic factus est in caput anguli;” (Da pedra que os construtores rejeitam é feita a pedra angular).

${ }^{497}$ S: "et dixit ei qui temptabat eum" - V: "et dixit ei his qui temptabat eum” - P: "et dixit ei is qui temptabat eum”.

S: "Lapide quem reprobauerunt. Turris ipsius" - V: "Lapidem quem reprobauerunt aedificantes hic factus est, ad caput anguli et sub pinna turre ipsius" - P: "Lapidem quem reprobauerunt aedificantes. item ad capud anguli et sub pinna turris ipsius”.

SP: "ibi Salomon palatium habebat" - V: "ubi Salomon palatium habebat”.

S: "ibi sedit" - VP: "in quo sedit".

$\mathrm{S}$ “magnae aequae subterranea” - V: "magne aquae subterinae” - P: "magna aquae subterranae”.

S: "piscine" - VP: "piscinae".

${ }^{499}$ O autor do itinerário faz, aí, referência aos "livros de sabedoria” atribuídos a Salomão.

${ }^{500}$ SV: "et in aedem ipsam" - P: "et in aede ipsa".

S: "Zachariae ubi dicas usque hodie fusum" - V: "Zacchariae ibi dicas hodiae fusum” - P: "Zachariae ibi dicas hodie fusum”.

S: “etiam parent uestigia clauorum militum per totam aream” - V: “etiam parent uestigia clauorum militum qui eum occiderunt per totam aream" - P: "etiam parent uestigia clauorum militum qui eum occiderunt in totam aream".

SV: "ut putes in cera" - (P) "utpote sincera”.

S: "Sunt ibi et statuae duae Adrianae" - V: "Sunt ibi et statuae duae Hadriani” - P: "Sunt ibi et statuas duae Adriani".

S: "Ezechiae regis Iude” - V: "Ezeziae regis Iudae” - P: "Ezechiae regis Iudae”.

S: "Item euntibus" - VP: "Item exeuntibus". 


\begin{tabular}{|c|c|c|}
\hline 592 & $\begin{array}{l}\text { in parte sinistra et deorsum } \\
\text { in ualle iuxta murum est } \\
\text { piscina, qui dicitur Silua; } \\
\text { habet quadriporticum; et in } \\
\text { alia piscina grandis foras. } \\
\text { Haec fons }{ }^{501} \text { sex diebus } \\
\text { atque noctibus currit, } \\
\text { septima uero die est } \\
\text { sabbatum; in totum nec nocte } \\
\text { nec die currit. } \\
\text { In eadem ascenditur Sion et } \\
\text { paret, ubi fuit domus Caifae } \\
\text { sacerdotis, et columna adhuc } \\
\text { ibi est in qua Christum } \\
\text { flagellis cederunt. Intus } \\
\text { autem intra murum Sion } \\
\text { paret locus ubi palatium } \\
\text { quam habuit Dauid et VII } \\
\text { sinagoge, quae illic fuerunt, } \\
\text { una tantum remansit, } \\
\text { reliquae autem arantur et } \\
\text { semirantur, sicut Esaias } \\
\text { propheta dixit. }\end{array}$ & $\begin{array}{l}\text { do lado esquerdo e descendo em direção ao } \\
\text { vale junto ao muro fica uma piscina, que é } \\
\text { chamada "Silua" e que tem um } \\
\text { quadripórtico; além de outra grande } \\
\text { [piscina] na parte de fora. Essa fonte corre } \\
\text { por seis dias e noites e no sétimo, que é o } \\
\text { sábado, não corre de forma alguma, seja dia } \\
\text { ou noite. } \\
\text { Nesse [lado], sobe-se o [monte] Sion (Sião) } \\
\text { e se observa onde era a casa do sacerdote } \\
\text { Caifas (idem), e lá ainda está a coluna na } \\
\text { qual ocorreram os flagelos do Christus } \\
\text { (Cristo). Porém, dentro do muro do [mons] } \\
\text { Sion (monte Sião), pode-se observar o local } \\
\text { onde Dauid (Davi) tinha um palácio. Das } \\
\text { sete sinagogas que ali existiam, resta apenas } \\
\text { uma - tendo sido as outras aradas e } \\
\text { semeadas, conforme disse o profeta Esaias } \\
\text { (Isaías). }\end{array}$ \\
\hline 593 & $\begin{array}{l}\text { Inde ut eas foris murus de } \\
\text { Sion, euntibus ad portam } \\
\text { Napolitana ad partem } \\
\text { dextram deorsum in ualle } \\
\text { sunt parietes, ubi domus fuit } \\
\text { siue praetorium Ponti Pilati, } \\
\text { ibi dominus auditus est, } \\
\text { antequam pateretur; a sinistra } \\
\text { autem parte est monticulus } \\
\text { Golgutta, ubi dominus } \\
\text { crucifixus est. }{ }^{503}\end{array}$ & $\begin{array}{l}\text { A partir daí, quando vais para fora do muro } \\
\text { do [monte] Sion (Sião), indo em direção à } \\
\text { porta Neapolitana na parte direita, abaixo } \\
\text { no vale, estão os muros onde era a casa ou } \\
\text { pretório de Pontius Pilatus (Pôncio Pilatos). } \\
\text { Aí o Senhor foi ouvido antes de padecer. Na } \\
\text { parte esquerda, porém, está o pequeno } \\
\text { monte Golgutta, onde o Senhor foi } \\
\text { crucificado. }\end{array}$ \\
\hline 594 & $\begin{array}{l}\text { Inde quasi ad lapidis missum } \\
\text { est cripta, ubi corpus eius } \\
\text { positum fuit et tercia die } \\
\text { surrexit: ibidem modo iusso } \\
\text { Constantini imperatoris } \\
\text { basilica facta est, id est } \\
\text { dominicum mire } \\
\text { pulchritudinis, habens ad }\end{array}$ & $\begin{array}{l}\text { A partir daí, quase que à distância de uma } \\
\text { pedra arremessada, está a cripta onde o } \\
\text { corpo Dele jazeu e ressuscitou no terceiro } \\
\text { dia. Nesse mesmo lugar, presentemente, foi } \\
\text { construída uma basílica por ordem do } \\
\text { imperador Constantinus (Constantino) - } \\
\text { isto é, uma propriedade de beleza } \\
\text { admirável, com reservatórios nas laterais, }\end{array}$ \\
\hline
\end{tabular}

${ }^{501}$ Se seguisse a gramática clássica, o viajante escreveria “hic fons”, pois “fons” era uma palavra masculina.

502 S: “qui dicitur Silua” - VP: “quae dicitur Siloa”.

S: "septimo autem die est sabbatum” - VP: "septima vero die est sabbatum”.

S: "Caiphae" - VP: "Caifae".

SV: “flagellis cederunt” - P: "flagellis caeciderunt” - M: “Christus flagellatus est”.

S: "Intus autem intra murum Sion paret locus ubi palatium quam habuit Dauid et VII sinagoge”-

V: "Intus autem intra murum Sion parit locus ubi palacium habuit Dauid et septe synagoge" -

P: "Intus autem intra murum Sion paret locus ubi palatium habuit David. et septem synagogae".

SP: "Isaias" - V: "Esaias".

503 SV: “ad portam Napolitanam” - P: “ad portam neappolitanam”.

S: "Inde ut eas foras murum" - V: "Inde ut eas foris murus" - P: "Inde ut eas foris murum".

SV: “ad portam Napolitanam” - P: “ad portam Neapolitanam”.

S: “dexteram - VP: dextram".

SV: "ubi dominus auditus est” - P: "ibi dominus auditus est”.

SP: "Golgotha" - V: “Golgutta”. 


\begin{tabular}{|c|c|c|}
\hline & $\begin{array}{l}\text { latus excepturia, unde qua } \\
\text { leuatur, et balneum a tergo, } \\
\text { ubi infantes lauantur. Item ab } \\
\text { Hierusalem euntibus ad } \\
\text { porta, quae est contra oriente, } \\
\text { ut ascendatur in montem } \\
\text { Oliveti, uallis quae dicitur } \\
\text { Iosafath; ad partem } \\
\text { sinistram, ubi sunt uinae, est } \\
\text { et petra ubi Iudas Scarioth } \\
\text { tradidit. }^{504}\end{array}$ & $\begin{array}{l}\text { nos quais a água é elevada; além de um } \\
\text { banho nos fundos, nos quais os infantes são } \\
\text { banhados. } \\
\text { Do mesmo modo, indo para fora de } \\
\text { Hierusalem (Jerusalém) pelo portão } \\
\text { oriental, de onde se eleva o monte das } \\
\text { Oliveiras, está o vale do qual falou Iosafath } \\
\text { (Josafá) - à esquerda, onde estão os } \\
\text { vinhedos, está a pedra onde Iudas Scarioth } \\
\text { (Judas Escariotes) cometeu traição. }\end{array}$ \\
\hline 595 & $\begin{array}{l}\text { Ad parte uero dextra est } \\
\text { arbor palme de qua infantes } \\
\text { ramos tulurent et uenient } \\
\text { Christo substrauerunt. Inde } \\
\text { non longe quasi lapidem } \\
\text { missum sunt monumenta duo } \\
\text { munibulis mire } \\
\text { pulchritudinis facta: in unum } \\
\text { positus est Esaias propheta, } \\
\text { qui est uere monolitus, et in } \\
\text { alio Ezezias, rex Iudaeorum. } \\
\text { Inde ascendis in montem } \\
\text { Oliueti, ubi dominus ante } \\
\text { passione discipulos docuit. } \\
\text { Ibi facta est basilica iussu } \\
\text { Constantini. Inde non longe } \\
\text { est monticulus ubi dominus } \\
\text { ascendit orare et apparuit } \\
\text { illic Moyses et Helias } \\
\text { quando Petrum et Iohannem } \\
\text { secum duxit. }{ }^{505}\end{array}$ & $\begin{array}{l}\text { À direita, de fato, está a palmeira da qual as } \\
\text { crianças colheram ramos que espalharam } \\
\text { pelo chão para a passagem do Christus } \\
\text { (Cristo). A partir daí, não longe, quase que } \\
\text { à distância de uma pedra arremessada, } \\
\text { existem dois monumentos comemorativos } \\
\text { de maravilhosa beleza: em um, que é um } \\
\text { verdadeiro monolito, jaz o profeta Isaías; e } \\
\text { no outro, Ezezias (Ezequias), rei dos judeus. } \\
\text { A partir daí, sobes o monte das Oliveiras, } \\
\text { onde o senhor demonstrou [sua] paixão } \\
\text { diante dos discípulos. Aí foi construída a } \\
\text { basílica por ordem de Constantinus } \\
\text { (Constantino). A partir daí não fica longe o } \\
\text { pequeno monte onde o Senhor subiu para } \\
\text { orar, levando consigo Petrus (Pedro) e } \\
\text { Iohannes (João), e [onde] Moyses (Moisés) } \\
\text { e Helias (Elias) apareceram [em uma visão]. }\end{array}$ \\
\hline 596 & $\begin{array}{l}\text { Inde ad orientem passos } \\
\text { mille quingentos est uilla, } \\
\text { quae appelatur Vetania. Est } \\
\text { ibi cripta ubi Lazarus positus } \\
\text { fuit, quem suscitauit } \\
\text { dominus. } \\
\text { Item ab Hierusalem in } \\
\text { Hiericho milia XVIII. } \\
\text { Descendentibus de monte in } \\
\text { parte dextra retro }\end{array}$ & $\begin{array}{l}\text { A partir daí, a mil e quinhentos passos em } \\
\text { direção ao oriente, está uma propriedade, a } \\
\text { qual é chamada "Vetania” (Betânia). Aí está } \\
\text { a cripta onde Lazarus (Lázaro), que foi } \\
\text { despertado pelo Senhor, jaz. } \\
\text { Igualmente, de Hierusalem (Jerusalém) até } \\
\text { Hiericho (Jericó), [são] } 18 \text { milhas. } \\
\text { Quando se desce o monte, à direita, ao } \\
\text { fundo, está o sicômoro-figueira na qual } \\
\text { subiu Zacheus (Zaqueu) para ver o Christus }\end{array}$ \\
\hline
\end{tabular}

504 SV: "Inde quasi ad lapidem” - P: "inde quasi ad lapidis”.

S: "missum est scripta" - VP: "missum est cripta".

SP: "et tertia die resurrexit" - V: "et tercia die surrexit".

S: "iussu" - VP: "iusso".

SV: "mire pulchritudinis” - P: "mirae pulchritudinis".

S: "uinae" - VP: "uineae".

505 S: “a parte autem dextera” - VP: “ad parte uero dextra”.

S: "palme” - VP: "palmae”.

S: "Inde longe quasi lapidem missum sunt monumenta duo munibulis mire pulchritudinis facta”-

$\mathrm{V}$ : "Inde non longe quasi ad lapides missum sunt monumenta duo monouiles mire pulchritudinis facta" - P: "Inde non longe quasi ad lapidis mussum sunt monumenta duo monubiles mirae pulchritudinis facta".

S: “Aesaias” - V: "Esaias”- P: “Isaias”.

S: "ante passione discipulos docuit" - VP: "ante passione apostolos docuit”.

S: "iussu Constantini mire pulchritudinis" - VP: "iusso Constantini”.

S: "Elias” - VP: "Helias". 


\begin{tabular}{|c|c|c|}
\hline & $\begin{array}{l}\text { monumentum est arbor } \\
\text { sicomori, in qua Zacheus } \\
\text { ascendit, ut Christum uideret. } \\
\text { A ciuitate passus mille D est } \\
\text { ibi fons Helisei prophete. } \\
\text { Antea si qua mulier ex ipsa } \\
\text { aqua biberat, non faciebat } \\
\text { natos. Adlatum }{ }^{506} \text { est uas } \\
\text { fictile Helisei misit in eo sale } \\
\text { et uenit et stetit supra } \\
\text { fontem, et haec dicit } \\
\text { dominus sanaui aquas has ex } \\
\text { eo si qua mulier inde biberit, } \\
\text { filios faciet. } \\
\text { (07 }\end{array}$ & $\begin{array}{l}\text { (Cristo). A mil e quinhentos passos da } \\
\text { cidade está a fonte do profeta Heliseus } \\
\text { (Eliseu). Anteriormente, a mulher que } \\
\text { bebesse dessa mesma água não teria bebês. } \\
\text { Ao lado está um vaso de cerâmica. Heliseus } \\
\text { (Eliseu), tendo nele atirado sal, vem até a } \\
\text { fonte e, de pé, [diz]: “O Senhor disse essas } \\
\text { [palavras]: "Eu purifiquei estas águas”. } \\
\text { Doravante, se uma mulher daí beber, terá } \\
\text { filhos. }\end{array}$ \\
\hline 597 & $\begin{array}{l}\text { Supra eadem fonte est domus } \\
\text { Rachab fornicariae, ad quam } \\
\text { exploratores introierunt et et } \\
\text { occultauit eos quando euersa } \\
\text { est e sola euasit. Ibi fuit } \\
\text { ciuitas Hierico, cuius murus } \\
\text { girauerunt cum arca filii } \\
\text { Isrhael et ceciderunt muri. } \\
\text { Ex eo non paret nisi locus, } \\
\text { ubi fuit archa testamenti et } \\
\text { lapides duodecim quos } \\
\text { leuauerunt de Iordane. Ibi } \\
\text { Iesus filius Naue circumcidit } \\
\text { filios Israel et circumcisiones } \\
\text { eorum sepeliuit. } \\
\text { Item ab Hiericho ad mare } \\
\text { mortuo milia nouem. Est } \\
\text { aqua ipsius ualde } \\
\text { amarissima, ubi in totum } \\
\text { nullius generis piscis est nec } \\
\text { aliqua nauis, et si quis }\end{array}$ & $\begin{array}{l}\text { Sobre essa mesma fonte está a casa da } \\
\text { prostituta Rachab (Raabe) - onde entraram } \\
\text { os espiões, que foram escondidos e salvo } \\
\text { por elas quando foi esvaziada [a cidade]. Aí } \\
\text { ficava a cidade de Hiericho (Jericó), cujas } \\
\text { muralhas os filhos de Isrhael (Israel) } \\
\text { cercaram com a arca da aliança; e as } \\
\text { muralhas caíram. Delas nada pode ser } \\
\text { observado a não ser o local onde estava a } \\
\text { arca da aliança e as doze pedras que os } \\
\text { filhos de Israel trouxeram da Iordania } \\
\text { (Jordânia). Aí Iesus (Josué), filho de Num, } \\
\text { circuncidou os filhos de Israel e destruiu } \\
\text { seus prepúcios. } \\
\text { Igualmente, a partir de Hiericho (Jericó) até } \\
\text { o mare Mortuus (mar Morto), [são] nove } \\
\text { milhas. A água do mesmo é muito } \\
\text { amarguíssima509, nela não há qualquer tipo } \\
\text { de peixe e nenhum barco; e, se um homem } \\
\text { [nela] se atira para nadar, a própria água o } \\
\text { vira [de volta]. }\end{array}$ \\
\hline
\end{tabular}

506 “Ad latum”: Construção análoga à existente em nossa língua, mas certamente incomum no Latim Clássico, especialmente com o sentido de "ao lado". Com esse exato sentido, aliás, a encontramos somente em um texto do século XVII: Germano de Silésia, Interpretatio Alcorani litteralis, 17.6-9: "Tu quidem aestimares illos expertos, cum sint uevere sopno sopiti, nosque reuoluimus eos nunc ad latum dextrum, nunc ad sinistrum, canisque ipsorum iacet extensis brachiis ad uestibulum portae. Quos si intuitus fuisses, illico auerus ab eis fuisses timore perculsus” (GARCÍA MASEGOSA, Antonio. Germán de Silesia; Interpretatio Alcorani litteralis. Parte I: la traducción latina, introducción y edición crítica. Madrid: Consejo Superior de Investigaciones Científicas, 2009. p. 228).

507 SV: "passus" - P: "passos".

S: "Bethania" - VP: "Vetania".

S: "scripta” - VP: “cripta”.

S: "quem suscitauit dominus" - VP: "quem dominus suscitauit”.

S: "Descendentibus de monte in parte dextera" - VP: "Descendentibus montem in parte dextra".

SP: "arbor sicomori" - V: "arbor sichomori".

S: "Zacheus descendit” - V: "Zacheus ascendit”- P: "Zachaeus ascendit”.

S: "A ciuitate passus mille quingentos et fons Helisei prophetae" - V: "A ciuitate passus mille D est ibi fons Helisei prophete" - P: "A ciuitate passus mille quingentos est fons Helisaei prophetae”.

S: "adlatum est uas fictile Helisei misit in eo sale et uenit et stetit supra fontem, et haec dicit: dominus sanaui aquas has exeo. Si qua mulier habenet filios facit” - V: "ad latum est uas fictile Heliseo misit in eo sales et uenit et stetit super fontem dixit: haec dicit dominus sanari aquas has ex eo si qua mulier inde biberit filius faciit - P: "adlatum est uas fictile Helyseo, missit in eo sales, et uenit et stetit super fontem et dixit haec dicit dominus, Sanaui aquas has; ex eo si qua mulier inde biberit, filios faciet”. 


\begin{tabular}{|c|c|c|}
\hline & $\begin{array}{l}\text { hominum miserit se, ut natet. } \\
\text { ipsa aqua eum uersat. }{ }^{508}\end{array}$ & \\
\hline 598 & $\begin{array}{l}\text { Inde ad Iordanem, ubi } \\
\text { dominus a Iohanne } \\
\text { baptizatus est, [lacuna] milia } \\
\text { quinque. Ibi locus est super } \\
\text { flumen, monticulus in illa } \\
\text { ripa, ubi raptus est Helias in } \\
\text { caelum. Item ab Hierusalem } \\
\text { euntibus Bethlem milia IIII. } \\
\text { Super strata in parte dextra } \\
\text { est monumentum ubi Rachel } \\
\text { posita est, uxor Iacob. Inde } \\
\text { milia II a parte sinistra } \\
\text { Bethlem, ubi natus est } \\
\text { dominus Ihesus Christus; ibi } \\
\text { basilica facta est iusso } \\
\text { Constantini; inde non longe } \\
\text { est monumentum Ezechiel, } \\
\text { Asaph, Iob, et Iesse, Dauid, } \\
\text { Salomon, et habet in ipsa } \\
\text { cripta ad latus deorsum } \\
\text { descendentibus Ebreis litteris } \\
\text { scriptum nomina supra } \\
\text { scripta. }{ }^{510}\end{array}$ & $\begin{array}{l}\text { A partir daí em direção à Iordania } \\
\text { (Jordânia), onde o Senhor foi batizado por } \\
\text { Iohannes (João), são cinco milhas. Aí fica } \\
\text { um local sobre um rio, um pequeno monte } \\
\text { sobre aquela margem, [de] onde Helias } \\
\text { (Elias) foi levado para o céu. } \\
\text { Do mesmo modo, quando se vai de } \\
\text { Hierusalem (Jerusalém) a Bethleem } \\
\text { (Belém), a quatro milhas, à direita, está o } \\
\text { monumento onde jaz Rachel (Raquel), } \\
\text { esposa de Iacob (Jacó). A partir daí, a duas } \\
\text { milhas, à esquerda, está Bethlem (Belém). } \\
\text { Onde nasceu nosso Senhor Ihesus Christus } \\
\text { (Jesus Cristo), foi construída uma basílica } \\
\text { por ordem de Constantinus (Constantino). } \\
\text { A partir daí, não longe está o monumento } \\
\text { de Ezechiel (Ezequiel), Asaph (Asafe), Iob } \\
\text { (Jó), Iesse (Jessé), Dauid (Davi) e Salomon } \\
\text { (Salomão); e essa mesma cripta tem nas } \\
\text { paredes, quando se desce para a parte baixa, } \\
\text { as letras hebraicas com as quais estão } \\
\text { escritos os nomes supracitados. }\end{array}$ \\
\hline 599 & $\begin{array}{l}\text { Inde Bettasora milia XIIII, } \\
\text { ubi est fons in quo Pylyppus } \\
\text { eunucum baptizauit. Inde } \\
\text { Tyribentum milia VIIII, ibi } \\
\text { Abraham habitauit et puteum } \\
\text { fodit sub arbore tyribentum }\end{array}$ & $\begin{array}{l}\text { A partir daí, em direção a Bettasora, } \\
\text { (Betsur) são } 14 \text { milhas até onde está a fonte } \\
\text { na qual [o evangelista] Pylyppus (Filipe) } \\
\text { batizou o eunuco. } \\
\text { A partir daí, em direção a Tyribentus, são } \\
\text { nove milhas. Onde Abraham (Abraão) }\end{array}$ \\
\hline
\end{tabular}

${ }^{509} \mathrm{O}$ texto original traz dois intensificadores, o advérbio “ualde” (muito), e o sufixo de superlativo, "-issima".

508 S: "supra eadem fonte” - VP: "supra eandem uero fontem”.

SV: "Raab”- P: "Rachab”.

S: "et occultauit eos quando euersa est e sola euasit" - V: "et occultauit eos quando Hiericho euersa est, et sola euasit" - P: "et occultauit eos, quando Hiericho uersa est, et sola euasit".

S: "Ibi fuit ciuitas Hiericho cuius murus girauerunt cum archa filii Israel" - V: "Ibi fuit ciuitas Hierico, cuius murus girauerunt cum arca filii Isrhael” - P: "Ibi fuit ciuitas Hiericho, cuius moros gyraverunt cum arca testamenti filii Israel”.

S: “archa testamenti et lapides XII quos leuauerunt de Iordanem filii Israel” - V: “arca testamenti et lapides duodecim quos filii Isrhael de Iordane leuauerunt” - P: “arca testamenti et lapides XII quos filii Israel de Iordane leuarerunt”.

S: "Ibi Iesus filius Naue" - V: "Ibidem Ihesus filius Naue" - P: "Ibidem Iesus filius Naue”.

S: "et si quis hominum miserit se" - VP: "et si qui hominum miserit se".

510 S: "De Iordanem ubi dominus baptizatus est millia V. Ibi est locus supra flument monticulus in illa ripa ubi raptus est Helias in caelo" - V: "Inde ad Iordane, ubi dominus batizatus est, milia V. Ibi raptus est Helias in caelo" - P: "Inde ad Iordanem, ubi dominus a Iohanne baptizatus est, [lacuna] milia quinque. Ibi locus est super flumen, monticulus in illa ripa, ubi raptus est Helias in caelum”. SV: "Bethlem" - P: "Bethleem".

S: "Supra strata est monumentum ibi Rachael posita uxor Iacob” - VP: "Super strata in parte dextra est monumentum ubi Rachel posita est uxor Iacob".

SV: "iussu Constantini” - P: "iusso Constantini”.

SV: "Ezechiel" - P: "Ezechihel”.

S: "scripta” - VP: “cripta”.

S: "ad latus deorum descendentibus Hebreis scriptum nomina supra scripta” - V: "ad latus deorsum descendentibus Ebreis litteris scriptum nomina supra scripta” - P: “ad latus deorsum descendentibus Hebraeis scriptum nomina superscripta”. 


\begin{tabular}{|c|c|c|c|}
\hline & & $\begin{array}{l}\text { et cum angelis locutus est et } \\
\text { cibum sumpsit, ibi basilica } \\
\text { facta est iussu Constantini. } \\
\text { Inde Tyribentum Cebron } \\
\text { milia II. Ubi est memoria per } \\
\text { quadrum ex lapidus mire } \\
\text { pulchritudinis, in qua positi } \\
\text { sunt Abraham, Isaac, Iacob, } \\
\text { Sarra, Rebecca et Lia. }{ }^{111}\end{array}$ & $\begin{array}{l}\text { morou, cavou um poço sob a árvore de } \\
\text { tyribentus (terebinto), falou com os anjos e } \\
\text { alimentou-se, foi construída a basílica de } \\
\text { beleza admirável por ordem de } \\
\text { Constantinus (Constantino). } \\
\text { A partir de Tyribentus (Therebinto) são } \\
\text { duas milhas até Cebron (Hebron), onde } \\
\text { existe um monumento quadrado de pedra de } \\
\text { beleza admirável, em que jazem Abraham } \\
\text { (Abraão), Isaac (Isaque), Iacob (Jacó), } \\
\text { Sarra (Sara), Rebecca (Rebeca) e Lia } \\
\text { (idem). }\end{array}$ \\
\hline \multirow[t]{6}{*}{600} & 1 & Item ab Hierusolyma sic: & $\begin{array}{l}\text { Igualmente, [segue-se] a partir de } \\
\text { Hierosolyma (Jerusalém): }\end{array}$ \\
\hline & 2 & Ciuitas Nicopoli mil XII ${ }^{512}$ & $\begin{array}{l}\text { [pouso na] cidade de Nicopolis (Imwas), } 12 \\
\text { milhas; } 513\end{array}$ \\
\hline & 3 & Ciuitas Lidda mil X & $\begin{array}{l}\text { [pouso na] cidade de Lidda (Lod), } 10 \\
\text { milhas; } 514\end{array}$ \\
\hline & 4 & mutatio Antipatrida mil X & $\begin{array}{l}\text { posto de muda em Antipatrida (Ras al- } \\
\text { Ayn), } 10 \text { milhas; }{ }^{515}\end{array}$ \\
\hline & 5 & mutatio Bettarum mil X ${ }^{516}$ & $\begin{array}{l}\text { posto de muda em Bettarum (Battir), } 10 \\
\text { milhas; } 517\end{array}$ \\
\hline & 6 & Ciuitas Caesarea mil XVI ${ }^{518}$ & $\begin{array}{l}\text { [pouso na] cidade de Caesarea (Kesariya), } \\
16 \text { milhas; }\end{array}$ \\
\hline \multirow[t]{2}{*}{601} & $1-3$ & $\begin{array}{l}\text { Fit omnis summa a } \\
\text { Constantinopoli usque } \\
\text { Hierusalem milia undecies } \\
\text { centena LXIIII, mutationes } \\
\text { LXVIIII, mansiones LVIII. }\end{array}$ & $\begin{array}{l}\text { Percorridas na soma total de } \\
\text { Constantinopolis (Istambul) a Hierusalem } \\
\text { (Jerusalém) } 1.159 \text { milhas, [passando por] } 69 \\
\text { postos de muda e } 58 \text { pousos. }\end{array}$ \\
\hline & 4,5 & $\begin{array}{l}\text { Item per Nicopolim } \\
\text { Caesaream milia LXXIII S, } \\
\text { mutationes V, mansiones III. }\end{array}$ & $\begin{array}{l}\text { Igualmente, de Nicopolis (Imwas) a } \\
\text { Caesarea (Kesariya), } 73 \text { milhas, } 5 \text { postos de } \\
\text { muda e } 3 \text { pousos. }\end{array}$ \\
\hline
\end{tabular}

511 S: “ibi basilica facta est iussu Constantini” - V: "ibi basilica facta est iussu Constantini mirae pulchritudinis" - P: "ibi basilica facta est iussu Constantini mirae pulchritudinis".

S: "Betsabedittha"? - V: "Bettasora" - P: "Bethasora".

S: "ibi est fons in quo" - VP: "ubi est fons in quo".

S: "Inde Tyribentum” - V: "Inde Terebinto" - P: “Inde Therebinto".

S: "Ibi Abraham habitauit" - VP: "Ubi Abraham habitauit".

S: "et puteum fodit sub arbore tyribentum et cum angelis locutus est" - V: "et puteum fodit sub arbore terebinto et cum angelis locutus est et cibum sumpsit" - P: "et puteum fodit sub arbore therebinto et cum angelis loquutus est et cybum sumpsit”.

S: "in quo positi sunt" - VP: "in qua positi sunt”.

512 V: "Nicopolen” - P: "Nicopoli Caesareia”.

513 DARE: <http://imperium.ahlfeldt.se/places/21656>.

${ }^{514}$ DARE: <http://imperium.ahlfeldt.se/places/21685>.

515 DARE: <http://imperium.ahlfeldt.se/places/21684>. Vide, também:

$<$ http://en.wikipedia.org/wiki/Antipatris>.

${ }^{516}$ V: "Bettarum" - P: "Bethar".

517 DARE: <http://imperium.ahlfeldt.se/places/36492>.

${ }^{518}$ VP: “Ciuitas Caesarea mil XVI”. O percurso em V: é interrompido após essa entrada e continua com "Ciuitas Tarracina mil XIII", o que equivale a passagem 611:10.

519 OmnesViae: Cesarea. DARE: <http://imperium.ahlfeldt.se/places/21149>. 


\section{Seção 11: de Eraclea (Marmara Ereğlisi) a Thessalonica (Saloniki)}

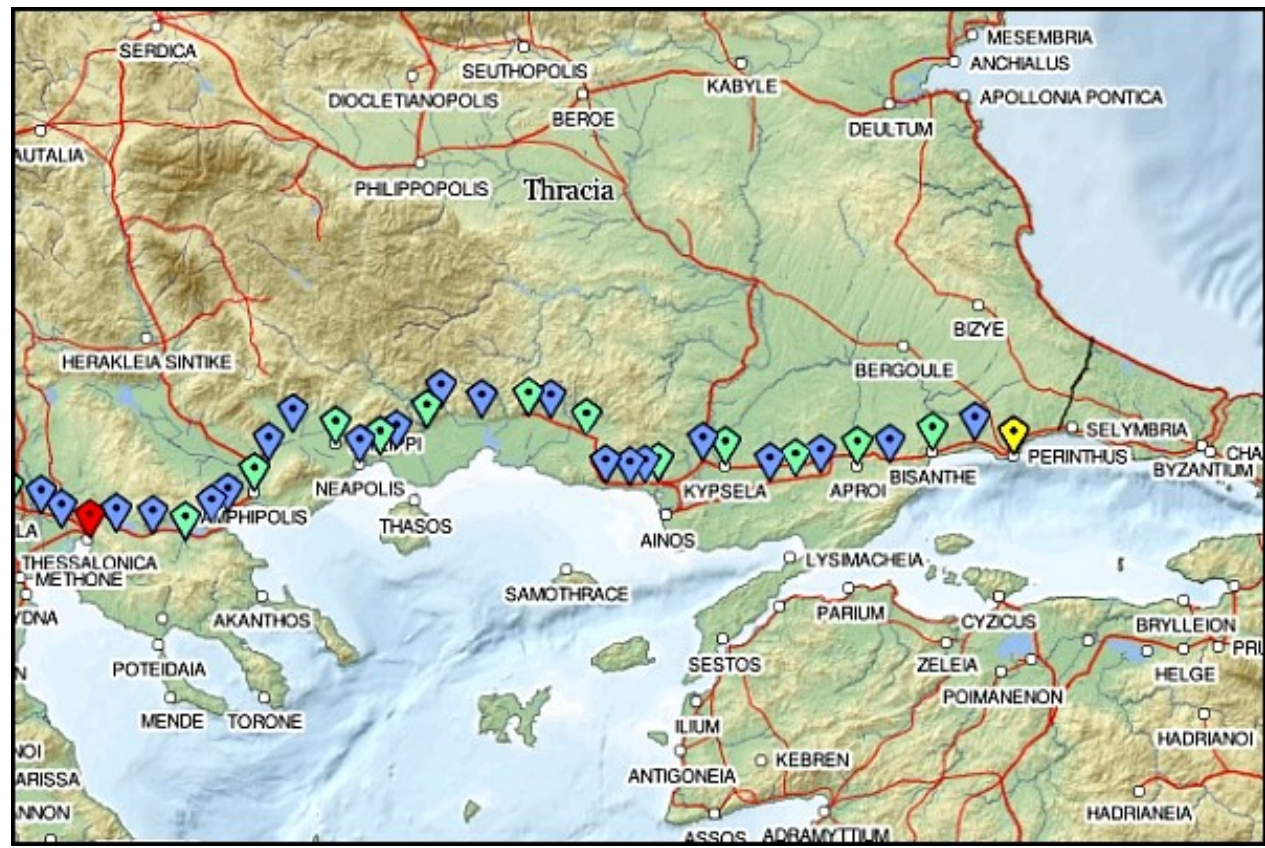

Mapa 11: trecho entre Eraclea (Marmara Ereğlisi), em amarelo, e Thessalonica (Saloniki), em vermelho; em azul estão registradas as mutationes (postos de muda) e em verde as mansiones (pousos).

\begin{tabular}{|c|c|c|c|}
\hline 600 & 6 & Ciuitas Caesarea mil XVI & $\begin{array}{l}\text { [pouso na] cidade de Caesarea (Kesariya), } \\
16 \text { milhas; }\end{array}$ \\
\hline \multirow[t]{6}{*}{601} & $1-3$ & $\begin{array}{l}\text { Fit omnis summa a } \\
\text { Constantinopoli usque } \\
\text { Hierusalem milia undecies } \\
\text { centena LXIIII, mutationes } \\
\text { LXVIIII, mansiones LVIII. }\end{array}$ & $\begin{array}{l}\text { Percorridas na soma total de } \\
\text { Constantinopolis (Istambul) a Hierusalem } \\
\text { (Jerusalém) } 1.159 \text { milhas, [passando por] } 69 \\
\text { postos de muda e } 58 \text { pousos. }\end{array}$ \\
\hline & 4,5 & $\begin{array}{l}\text { Item per Nicopolim } \\
\text { Caesaream milia LXXIII S, } \\
\text { mutationes V, mansiones III. }\end{array}$ & $\begin{array}{l}\text { Igualmente, de Nicopolis (Imwas) a } \\
\text { Caesarea (Kesariya), } 73 \text { milhas, } 5 \text { postos de } \\
\text { muda e } 3 \text { pousos. }\end{array}$ \\
\hline & 6 & $\begin{array}{l}\text { Item ab Eraclea per } \\
\text { Macedoniam. }\end{array}$ & $\begin{array}{l}\text { Igualmente, [saindo] de Eraclea (Marmara } \\
\text { Ereğlisi) através da Macedonia } \\
\text { (Macedônia). }{ }^{520}\end{array}$ \\
\hline & 7 & Mutatio Aerea mil XVI & $\begin{array}{l}\text { Posto de muda em Aerea (Ayetepe), } 16 \\
\text { milhas; } 521\end{array}$ \\
\hline & 8 & mansio Registo mil XII & pouso em Registo (Tekirdağ), 12 milhas; ${ }^{522}$ \\
\hline & 9 & mutatio Bedizo mil XII & $\begin{array}{l}\text { posto de muda em Bedizo (Inecik, } \\
\text { Tekirdağ), } 12 \text { milhas; }{ }^{523}\end{array}$ \\
\hline
\end{tabular}

${ }^{520}$ OmnesViae: Perynthus=Marmaraereğlisi. DARE: <http://imperium.ahlfeldt.se/places/21399>.

${ }^{521}$ DARE: <http://imperium.ahlfeldt.se/places/31391>.

${ }^{522}$ DARE: <http://imperium.ahlfeldt.se/places/21397>.

${ }^{523}$ OmnesViae: Bitenas. DARE: <http://imperium.ahlfeldt.se/places/23349>. 


\begin{tabular}{|c|c|c|c|}
\hline & 10 & Ciuitas Apris mil XII & $\begin{array}{l}\text { [pouso na] cidade de Apri (Kermeyan, na } \\
\text { província de Tekirdağ), } 12 \text { milhas; }{ }^{524}\end{array}$ \\
\hline \multirow[t]{11}{*}{602} & 1 & mutatio Zesutera mil XII & $\begin{array}{l}\text { posto de muda em Zesutera (provavelmente } \\
\text { ao norte de Kavakçeşme, na província } \\
\text { Tekirdağ), } 12 \text { milhas; }\end{array}$ \\
\hline & 2 & Finis Europae et Rhodopeae. & Fronteira entre Europa e Rhodopea. \\
\hline & 3 & Mansio Sirogellis mil X & $\begin{array}{l}\text { Pouso em Sirogelli (Malkara, na província } \\
\text { de Tekirdağ), } 10 \text { milhas; }{ }^{.25}\end{array}$ \\
\hline & 4 & mutatio Drippa mil XIIII & $\begin{array}{l}\text { posto de muda em Drippa (Keşan, na } \\
\text { província de Edirne), } 14 \text { milhas; }{ }^{.526}\end{array}$ \\
\hline & 5 & mansio Gipsila mil XIIII & pouso em Gypsela (Ipsala), 12 milhas;;527 \\
\hline & 6 & mutatio Demas mil XII & $\begin{array}{l}\text { posto de muda em Demas (Feres), } 12 \\
\text { milhas; } 528\end{array}$ \\
\hline & 7 & Ciuitas Traianopoli mil XIII & $\begin{array}{l}\text { [pouso na] cidade de Traianopolis (Loutra } \\
\text { Traianopolis), } 13 \text { milhas; }{ }^{529}\end{array}$ \\
\hline & 8 & $\begin{array}{l}\text { mutatio ad Unimpara mil } \\
\text { VIII }\end{array}$ & $\begin{array}{l}\text { posto de muda em Unumpara (arredores de } \\
\text { Antheia), } 8 \text { milhas; }\end{array}$ \\
\hline & 9 & mutatio Salei mil VII S & $\begin{array}{l}\text { posto de muda em Salei (próxima a } \\
\text { Alexandroupolis), } 7 \text { milhas; ;30 }\end{array}$ \\
\hline & 10 & mutatio Melalico mil VIII & $\begin{array}{l}\text { posto de muda em Melalicum (Makri), } 8 \\
\text { milhas; } 531\end{array}$ \\
\hline & 11 & mansio Berozicha mil XV & $\begin{array}{l}\text { pouso em Berozicha (próxima a Aratos), } 15 \\
\text { milhas; }\end{array}$ \\
\hline \multirow[t]{4}{*}{603} & 1 & mutatio Breierophara mil X & $\begin{array}{l}\text { posto de muda em Breierophara } \\
\text { (Kotomeni), } 10 \text { milhas; }{ }^{532}\end{array}$ \\
\hline & 2 & Ciuitas Maximianopoli mil X & $\begin{array}{l}\text { [pouso na] cidade de Maximianopolis } \\
\text { (próxima a Poliantho), } 10 \text { milhas; } 533\end{array}$ \\
\hline & 3 & $\begin{array}{l}\text { mutatio ad Stabulo } \\
\text { Dio[medis] mil XII }\end{array}$ & $\begin{array}{l}\text { posto de muda estábulo de Diomedes } \\
\text { (Amaxedes), } 12 \text { milhas; }{ }^{534}\end{array}$ \\
\hline & 4 & mutatio Rumbodona mil X & $\begin{array}{l}\text { posto de muda em Rumbodona (Makario), } \\
10 \text { milhas; } ; 35\end{array}$ \\
\hline
\end{tabular}

\footnotetext{
${ }^{524}$ OmnesViae: Apris. DARE: <http://imperium.ahlfeldt.se/places/21398>.

${ }^{525}$ OmnesViae: Sirascelle=Sirogellis. DARE: <http://imperium.ahlfeldt.se/places/23345> .

526 OmnesViae: Zorlanes=Kesan. DARE: <http://imperium.ahlfeldt.se/places/23344>.

${ }^{527}$ DARE: <http://imperium.ahlfeldt.se/places/21901>.

${ }^{528}$ OmnesViae: Dimis=Feres. DARE: <http://imperium.ahlfeldt.se/places/23339>.

${ }^{529}$ DARE: <http://imperium.ahlfeldt.se/places/32411>.

${ }^{530}$ DARE: <http://imperium.ahlfeldt.se/places/32394>.

${ }^{531}$ DARE: <http://imperium.ahlfeldt.se/places/25830>.

532 DARE: <http://imperium.ahlfeldt.se/places/32348>.

533 OmnesViae: Porsulis=Porsulae. DARE: $<$ http://imperium.ahlfeldt.se/places/23340>.

${ }^{534}$ DARE: <http://imperium.ahlfeldt.se/places/32297>.

${ }^{535}$ DARE: <http://imperium.ahlfeldt.se/places/34677>.
} 


\begin{tabular}{|c|c|c|c|}
\hline & 5 & Ciuitas Epyrum mil X & $\begin{array}{l}\text { [pouso na] cidade de Epyrum (Paradeisos), } \\
10 \text { milhas; }{ }^{536}\end{array}$ \\
\hline & 6 & mutatio Purdis mil VIII & $\begin{array}{l}\text { posto de muda em Purdi (próxima a } \\
\text { Petropighi), } 8 \text { milhas; } 537\end{array}$ \\
\hline & 7 & $\begin{array}{l}\text { Finis Rhodopeae et } \\
\text { Macedoniae. }\end{array}$ & $\begin{array}{l}\text { Fronteira entre Rhodopea e Macedonia } \\
\text { (Macedônia); }\end{array}$ \\
\hline & 8 & $\begin{array}{l}\text { mansio Hercontroma mil } \\
\text { VIIII }\end{array}$ & $\begin{array}{l}\text { pouso em Hercontroma (ao leste de } \\
\text { Kavala), } 9 \text { milhas; }{ }^{538}\end{array}$ \\
\hline & 9 & mutatio Neapolim mil VIIII & $\begin{array}{l}\text { posto de muda em Neapolis (Kavala), } 9 \\
\text { milhas; } 539\end{array}$ \\
\hline & 10 & Ciuitas Philippis mil X & $\begin{array}{l}\text { [pouso na] cidade de Philippi (Philippi), } 10 \\
\text { milhas. }{ }^{540}\end{array}$ \\
\hline \multirow[t]{7}{*}{604} & 1 & $\begin{array}{l}\text { ubi Paulus et Sileas in } \\
\text { carcere fuerunt. }\end{array}$ & $\begin{array}{l}\text { Onde Paulus (Paulo) e Sileas (Silas) foram } \\
\text { presos. }\end{array}$ \\
\hline & 2 & $\begin{array}{l}\text { Mutatio ad duodecimum mil } \\
\text { XII }\end{array}$ & $\begin{array}{l}\text { Posto de muda no décimo segundo } \\
\text { [miliário] (arredores de Drama), } 12 \\
\text { milhas; }{ }^{541}\end{array}$ \\
\hline & 3 & mutatio Domeros mil VII & $\begin{array}{l}\text { posto de muda em Domeros (próxima a } \\
\text { Alistrati), } 7 \text { milhas; } 542\end{array}$ \\
\hline & 4 & Ciuitas Amphipolim mil XIII & $\begin{array}{l}\text { [pouso na] cidade de Amphipolis } \\
\text { (Amfipoli), } 13 \text { milhas; }{ }^{543}\end{array}$ \\
\hline & 5 & mutatio Pennana mil X & $\begin{array}{l}\text { posto de muda em Pennana (próxima a } \\
\text { Asprovalta), } 10 \text { milhas; } 544\end{array}$ \\
\hline & 6 & mutatio Euripidis mil $\mathrm{X}$ & $\begin{array}{l}\text { estação de muda em Euripides (talvez } \\
\text { Rentina), } 10 \text { milhas; }{ }^{545}\end{array}$ \\
\hline & 7 & $\begin{array}{l}\text { ibi positus est Euripidis } \\
\text { poeta. }\end{array}$ & Aí jaz o poeta Euripides (Eurípides). \\
\hline \multirow[t]{2}{*}{605} & 1 & Mansio Apollonia mil XI & Pouso em Apollonia (idem), 11 milhas; ${ }^{546}$ \\
\hline & 2 & $\begin{array}{l}\text { mutatio Heracleustibus mil } \\
\text { XI }\end{array}$ & $\begin{array}{l}\text { posto de muda em Heracleustibus (Stivos), } \\
11 \text { milhas; }{ }^{547}\end{array}$ \\
\hline
\end{tabular}

${ }^{536}$ DARE: <http://imperium.ahlfeldt.se/places/32409>.

${ }^{537}$ DARE: <http://imperium.ahlfeldt.se/places/36456>.

${ }^{538}$ DARE: <http://imperium.ahlfeldt.se/places/36451>.

${ }^{539}$ OmnesViae: Neapolis=Kavala. DARE: <http://imperium.ahlfeldt.se/places/21896>.

${ }^{540}$ DARE: <http://imperium.ahlfeldt.se/places/21892>.

${ }^{541}$ DARE: <http://imperium.ahlfeldt.se/places/21879>.

542 DARE: <http://imperium.ahlfeldt.se/places/36452>.

${ }^{543}$ OmnesViae: Amphipoli=Amfípolis. DARE: <http://imperium.ahlfeldt.se/places/21889>.

${ }^{544}$ DARE: <http://imperium.ahlfeldt.se/places/36455>.

545 DARE: <http://imperium.ahlfeldt.se/places/32300>.

${ }^{546}$ DARE: <http://imperium.ahlfeldt.se/places/21883>. OmnesViae: Apollonia=Nea Apollonia.

${ }^{547}$ DARE: <http://imperium.ahlfeldt.se/places/36450>. 


\begin{tabular}{|c|c|c|}
\hline 3 & mutatio Duodea mil XIIII & $\begin{array}{l}\text { posto de muda em Duodea (Agios } \\
\text { Vasilios), } 14 \text { milhas; }{ }^{548}\end{array}$ \\
\hline 4 & $\begin{array}{l}\text { Ciuitas Thessalonica mil } \\
\text { XIII }\end{array}$ & $\begin{array}{l}\text { [pouso na] cidade de Thessalonica } \\
\text { (Saloniki), } 13 \text { milhas; }{ }^{.49}\end{array}$ \\
\hline
\end{tabular}

${ }^{548}$ DARE: <http://imperium.ahlfeldt.se/places/36448>.

${ }^{549}$ OmnesViae: Tessalonice=Salonici. DARE: <http://imperium.ahlfeldt.se/places/17068> . OmnesViae: Tessalonika=Saloniki 


\section{Seção 12: de Thessalonica (Saloniki) a Odrontum (Otranto)}

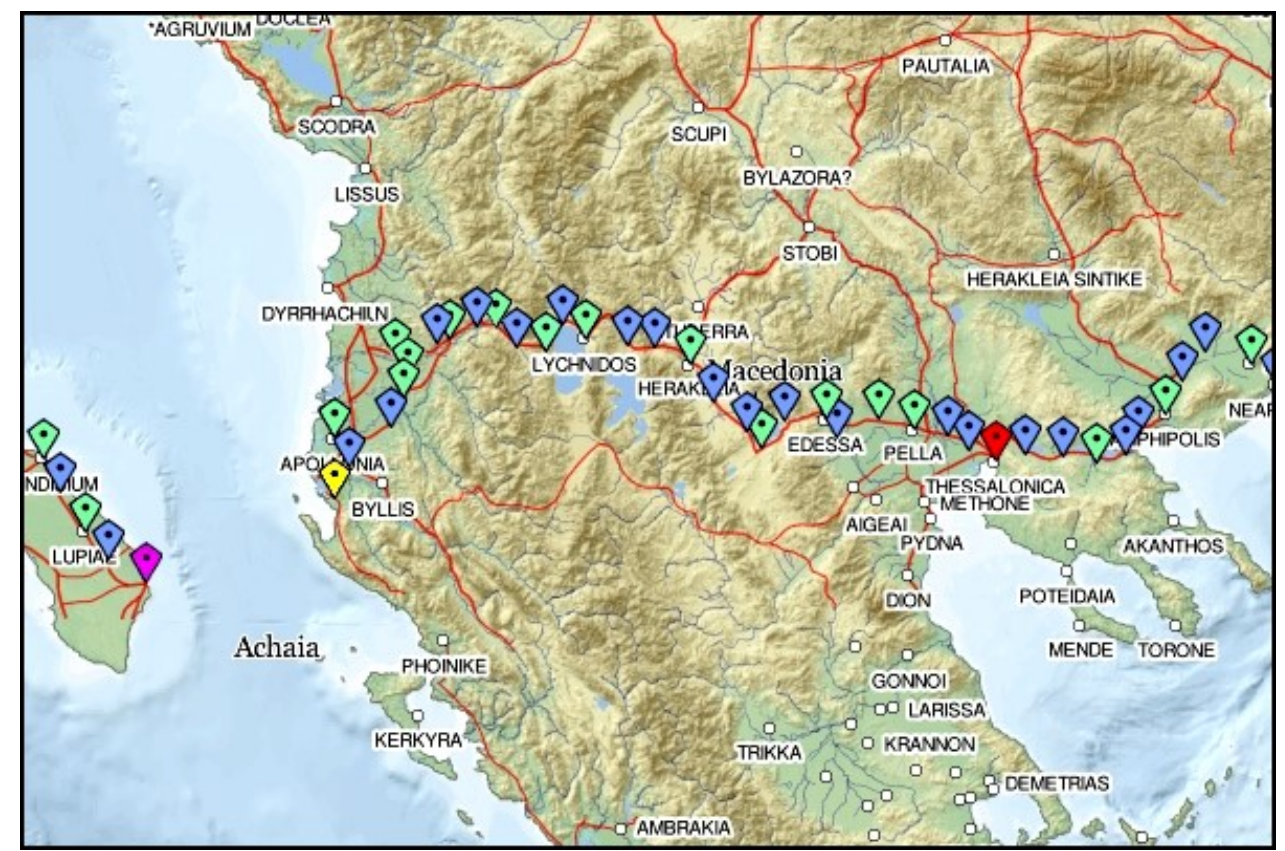

Mapa 12: trecho entre Thessalonica (Saloniki), em vermelho, e Aulona (Vlorë), em amarelo; Odrontum (Otranto), em lilás, é a continuação do trajeto; em azul estão registradas as mutationes (postos de muda) e em verde as mansiones (pousos).

\begin{tabular}{|c|c|c|c|}
\hline 605 & 4 & $\begin{array}{l}\text { Ciuitas Thessalonica mil } \\
\text { XIII }\end{array}$ & $\begin{array}{l}\text { [pouso na] cidade de Thessalonica } \\
\text { (Saloniki), } 13 \text { milhas; }\end{array}$ \\
\hline & 5 & mutatio ad Decimum mil X & $\begin{array}{l}\text { posto de muda no décimo [miliário] (talvez } \\
\text { ao norte de Sindos), } 10 \text { milhas; ;50 }\end{array}$ \\
\hline & 6 & mutatio Gephira mil X & $\begin{array}{l}\text { posto de muda em Gephira (Agios } \\
\text { Athanasios), } 10 \text { milhas; } 551\end{array}$ \\
\hline 606 & 1 & $\begin{array}{l}\text { Ciuitas Pelli, unde fuit } \\
\text { Alexander Magnus. }\end{array}$ & $\begin{array}{l}\text { [pouso na] cidade de Pella (idem), de onde } \\
\text { veio Alexandre o Grande. }{ }^{552}\end{array}$ \\
\hline & 2 & Macedo mil X & $\begin{array}{l}\text { [pouso em] Macedo (talvez ao sul de } \\
\text { Drosero), } 10 \text { milhas; } ; 53\end{array}$ \\
\hline & 3 & mutatio Scurio mil XV & $\begin{array}{l}\text { posto de muda em Scurio (Skidra), } 15 \\
\text { milhas; } ; 54\end{array}$ \\
\hline & 4 & Ciuitas Edissa mil XV & $\begin{array}{l}\text { [pouso na] cidade de Edissa (Edessa), } 15 \\
\text { milhas; } 555\end{array}$ \\
\hline
\end{tabular}

${ }^{550}$ DARE: <http://imperium.ahlfeldt.se/places/32160>.

${ }^{551}$ DARE: <http://imperium.ahlfeldt.se/places/36449>.

552 OmnesViae: Pella=Pella. DARE: < http://imperium.ahlfeldt.se/places/21891>.

553 DARE: <http://imperium.ahlfeldt.se/places/32106>.

554 DARE: <http://imperium.ahlfeldt.se/places/32163>.

555 DARE: <http://imperium.ahlfeldt.se/places/21890>. 


\begin{tabular}{|c|c|c|c|}
\hline & 5 & $\begin{array}{l}\text { mutatio ad duodecimum mil } \\
\text { XII }\end{array}$ & $\begin{array}{l}\text { posto de muda no décimo segundo } \\
\text { [miliário] (Arnissa), } 12 \text { milhas; } 556\end{array}$ \\
\hline & 6 & mansio Cellis mil XVI & pouso em Cellis (Aminteo), 16 milhas; ${ }^{557}$ \\
\hline & 7 & mutatio Grande mil XIIII & $\begin{array}{l}\text { posto de muda em Grande (Vevi), } 14 \\
\text { milhas; } 558\end{array}$ \\
\hline & 8 & mutatio Melitonus mil XIIII & $\begin{array}{l}\text { posto de muda em Melitonus (Meliti), } 14 \\
\text { milhas; } ; 59\end{array}$ \\
\hline & 9 & Ciuitas Heraclea mil XII & $\begin{array}{l}\text { [pouso na] cidade de Heraclea (Bitola), } 13 \\
\text { milhas; } 560\end{array}$ \\
\hline \multirow[t]{8}{*}{607} & 1 & mutatio Parambole mil XII & $\begin{array}{l}\text { posto de muda em Parambole (Kazhani), } 12 \\
\text { milhas; }{ }^{561}\end{array}$ \\
\hline & 2 & mutatio Brucida mil XVIIII. & $\begin{array}{l}\text { posto de muda em Brucida (arredores de } \\
\text { Resen), }{ }^{562} 19 \text { milhas. }\end{array}$ \\
\hline & 3 & Finis Macedoniae et Epiri. & $\begin{array}{l}\text { Fronteira entre Macedonia (Macedônia) e } \\
\text { Epirus (Épiro). }\end{array}$ \\
\hline & 4 & Ciuitas Cledo mil XIII & $\begin{array}{l}\text { [Pouso na] cidade de Cledus (Ohrid), } 12 \\
\text { milhas; } 563\end{array}$ \\
\hline & 5 & mutatio Patras mil XII & $\begin{array}{l}\text { posto de muda em Patrae (talvez Struga), } \\
12 \text { milhas; } 564\end{array}$ \\
\hline & 6 & mansio Claudanon mil IIII & $\begin{array}{l}\text { pouso em Claudanon (arredores de Rrajcë), } \\
4 \text { milhas; } 565\end{array}$ \\
\hline & 7 & $\begin{array}{l}\text { mutatio in Tabernas mil } \\
\text { VIIII }\end{array}$ & $\begin{array}{l}\text { posto de muda em Tabernae (talvez Qukës), } \\
9 \text { milhas. }{ }^{566}\end{array}$ \\
\hline & 8 & mansio Grandauia mil VIIII & $\begin{array}{l}\text { Pouso em Grandavia (próximo a Hotolisht), } \\
9 \text { milhas; } 567\end{array}$ \\
\hline 608 & 1 & mutatio Treiecto mil VIIII & $\begin{array}{l}\text { posto de muda na passagem [do } \\
\text { rio](Librazhd, cortada pelo rio Shkumbin), } \\
9 \text { milhas; } 568\end{array}$ \\
\hline & 2 & mansio Hiscampis mil VIIII & pouso em Hiscampis (Elbasan), 9 milhas; ${ }^{569}$ \\
\hline
\end{tabular}

${ }^{556}$ DARE: <http://imperium.ahlfeldt.se/places/21894>.

${ }^{557}$ OmnesViae: Cellis=Kélla. DARE: <http://imperium.ahlfeldt.se/places/31673>.

558 DARE: <http://imperium.ahlfeldt.se/places/36441>.

559 DARE: <http://imperium.ahlfeldt.se/places/36443>.

560 OmnesViae: Heracleia Bitola. DARE: <http://imperium.ahlfeldt.se/places/21413>.Vide, também: <http://en.wikipedia.org/wiki/Bitola>.

${ }^{561}$ DARE: <http://imperium.ahlfeldt.se/places/26387>.

562 DARE: <http://imperium.ahlfeldt.se/places/26385>.

563 OmnesViae: Lignido=Ohrid, Okhrid. DARE: <http://imperium.ahlfeldt.se/places/21412>.

${ }^{564}$ DARE: <http://imperium.ahlfeldt.se/places/26382>.

565 DARE: <http://imperium.ahlfeldt.se/places/26381>.

566 DARE: <http://imperium.ahlfeldt.se/places/26380>.

${ }^{567}$ DARE: <http://imperium.ahlfeldt.se/places/26379>.

${ }^{568}$ DARE: <http://imperium.ahlfeldt.se/places/26378>.

${ }^{569}$ OmnesViae: Scapis=Elbasan. DARE: <http://imperium.ahlfeldt.se/places/23285>.Vide, também: $<$ http://en.wikipedia.org/wiki/Elbasan>. 


\begin{tabular}{|c|c|c|c|}
\hline & 3 & mutatio ad quintum mil VI & $\begin{array}{l}\text { posto de muda no quinto [miliário] (talvez } \\
\text { nos arredores de Päper), } 6 \text { milhas; } 570\end{array}$ \\
\hline & 4 & mansio Coladiana mil XV & pouso em Coladiana (Peqin), 15 milhas; 571 \\
\hline & 5 & mansio Marusio mil XIII & $\begin{array}{l}\text { pouso em Marusium (arredores de } \\
\text { Hysgjokaj), } 8 \text { milhas; }\end{array}$ \\
\hline & 6 & mansio Absos mil XIIII & $\begin{array}{l}\text { pouso em Absos (provavelmente ao sul de } \\
\text { Fierzë), } 14 \text { milhas; }{ }^{572}\end{array}$ \\
\hline & 7 & $\begin{array}{l}\text { mutatio Stefanaphana mil } \\
\text { XII }\end{array}$ & $\begin{array}{l}\text { posto de muda em Stefanaphana (talvez } \\
\text { Strumë), } 12 \text { milhas; }{ }^{573}\end{array}$ \\
\hline & 8 & Ciuitas Apollonia mil XVIII & $\begin{array}{l}\text { [pouso na] cidade de Apollonia (Pojan), } 18 \\
\text { milhas; } 574\end{array}$ \\
\hline & 9 & mutatio Stefana mil XII & $\begin{array}{l}\text { posto de muda em Stefana (provavelmente } \\
\text { ao norte de Armen), } 12 \text { milhas; }{ }^{575}\end{array}$ \\
\hline & 10 & $\begin{array}{l}\text { mansio Aulona treiectum mil } \\
\text { XII }\end{array}$ & $\begin{array}{l}\text { pouso em Aulona (Vlorë), passagem } \\
\text { [marítima], } 12 \text { milhas; ;76 }\end{array}$ \\
\hline \multirow[t]{2}{*}{609} & $1-3$ & $\begin{array}{l}\text { Fit omnis summa ab Eraclea } \\
\text { per Macedoniam Aulona } \\
\text { usque milia DCLXXXVIII, } \\
\text { mutationes LVIII, mansiones } \\
\text { XXV. }\end{array}$ & $\begin{array}{l}\text { Percorridas na soma total de Eraclea } \\
\text { (Marmara Ereğlisi) a Aulona (Vlorë) } 668 \\
\text { milhas, [passando por] } 58 \text { postos de muda e } \\
25 \text { pousos. }\end{array}$ \\
\hline & 4,5 & $\begin{array}{l}\text { Trans mare stadia mille, } \\
\text { quod facit milia centum, et } \\
\text { uenis Odronto mansio mille } \\
\text { passus. }\end{array}$ & $\begin{array}{l}\text { Através do mar, [percorres] mil estádios, }{ }^{577} \\
\text { os quais perfazem cem milhas, e fazes } \\
\text { pouso em Odrontum (Otranto), por mil } \\
\text { passos. }{ }^{.78}\end{array}$ \\
\hline
\end{tabular}

${ }^{570}$ DARE: <http://imperium.ahlfeldt.se/places/26377>.

${ }^{571}$ OmnesViae: Clodiana=Peqin. DARE: <http://imperium.ahlfeldt.se/places/23286>.Vide, também: $<$ http://en.wikipedia.org/wiki/Peqin $>$.

${ }^{572}$ DARE: <http://imperium.ahlfeldt.se/places/26401>.

${ }^{573}$ DARE: <http://imperium.ahlfeldt.se/places/26402>.

574 OmnesViae: Apollonia=Pojan Fier. DARE: < http://imperium.ahlfeldt.se/places/21415>.

${ }^{575}$ DARE: <http://imperium.ahlfeldt.se/places/26400>.

${ }^{576}$ DARE: <http://imperium.ahlfeldt.se/places/23288>. Vide, também:

$<$ http://en.wikipedia.org/wiki/Vlor\%C3\%AB>.

577 Medida itinerária dos antigos gregos, equivalente a 125 passos, ou seja, 206,25m.

${ }^{578}$ OmnesViae: Ydrvnte=Otranto. DARE: < http://imperium.ahlfeldt.se/places/16899>. 


\section{Seção 13: De Odrontum (Otranto) a Roma (idem)}

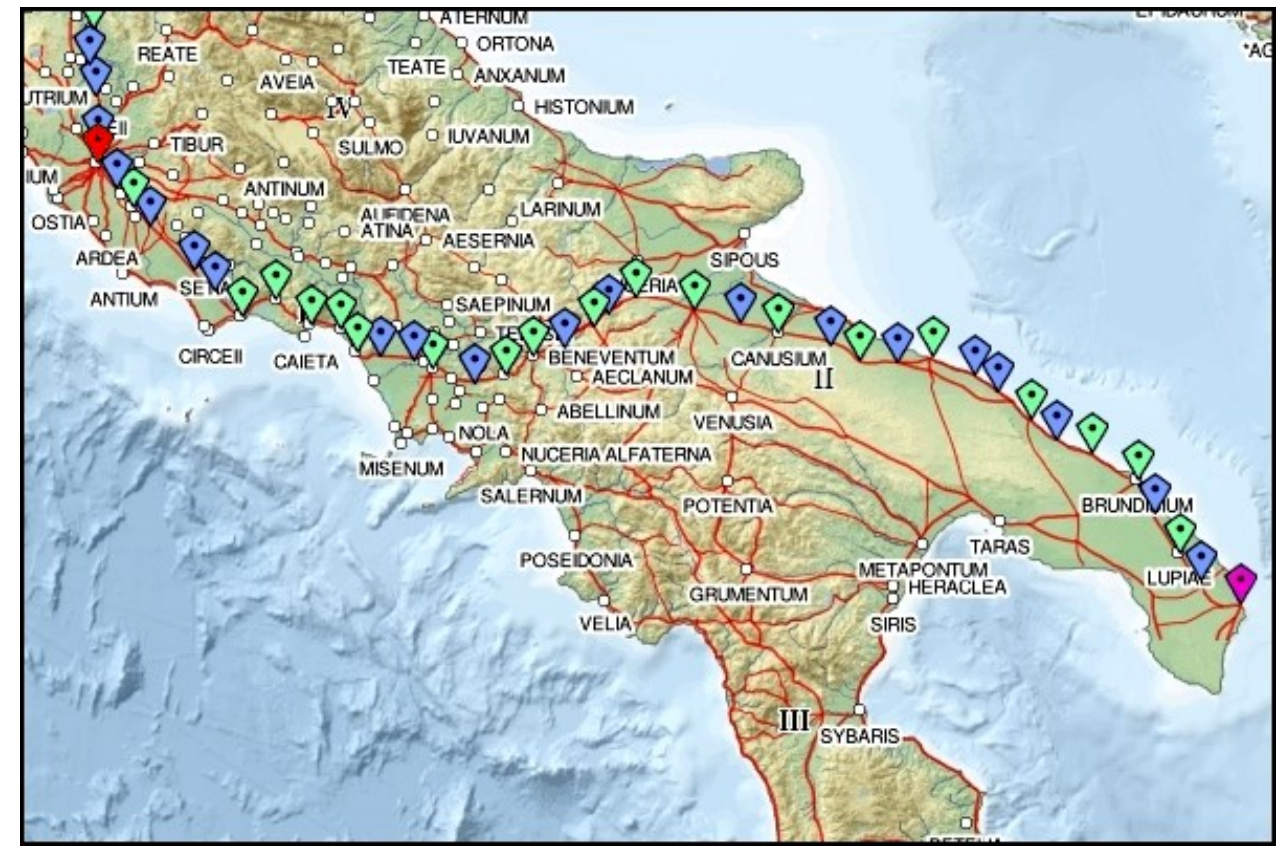

Mapa 13: trecho entre Odrontum (Otranto), em lilás, e Roma (idem), em vermelho; em azul estão registradas as mutationes (postos de muda) e em verde as mansiones (pousos).

\begin{tabular}{|c|c|c|c|}
\hline 608 & 10 & $\begin{array}{l}\text { mansio Aulona treiectum mil } \\
\text { XII }\end{array}$ & $\begin{array}{l}\text { pouso em Aulona (Vlorë), passagem } \\
\text { [marítima], } 12 \text { milhas; }\end{array}$ \\
\hline \multirow[t]{6}{*}{609} & $1-3$ & $\begin{array}{l}\text { Fit omnis summa ab Eraclea } \\
\text { per Macedoniam Aulona } \\
\text { usque milia DCLXXXVIII, } \\
\text { mutationes LVIII, mansiones } \\
\text { XXV. }\end{array}$ & $\begin{array}{l}\text { Percorridas na soma total de Eraclea } \\
\text { (Marmara Ereğlisi) a Aulona (Vlorë) } 668 \\
\text { milhas, [passando por] } 58 \text { postos de muda e } \\
25 \text { pousos. }\end{array}$ \\
\hline & 4,5 & $\begin{array}{l}\text { Trans mare stadia mille, } \\
\text { quod facit milia centum, et } \\
\text { uenis Odronto mansio mille } \\
\text { passus. }\end{array}$ & $\begin{array}{l}\text { Através do mar, [percorres] mil estádios, os } \\
\text { quais perfazem cem milhas, e vens ao pouso } \\
\text { em Odrontum (Otranto), por mil passos. }\end{array}$ \\
\hline & 6 & $\begin{array}{l}\text { Mutatio ad duodecimum mil } \\
\text { XIII }\end{array}$ & $\begin{array}{l}\text { Posto de muda no décimo segundo } \\
\text { [miliário], } 13 \text { milhas; } 579\end{array}$ \\
\hline & 7 & mansio Clipeas mil XII & pouso em Clipeae (Lecce), 12 milhas; ${ }^{580}$ \\
\hline & 8 & mutatio Ualentia mil XIII & $\begin{array}{l}\text { posto de muda em Ualentia, na comuna de } \\
\text { Torchiarolo, } 13 \text { milhas; }{ }^{581}\end{array}$ \\
\hline & 9 & Ciuitas Brindisi mil XI & $\begin{array}{l}\text { pouso na [cidade de] Brindisium (Brindisi), } \\
11 \text { milhas; }{ }^{582}\end{array}$ \\
\hline
\end{tabular}

${ }^{579}$ DARE: <http://imperium.ahlfeldt.se/places/42159>.

${ }^{580}$ OmnesViae: Luppia=Lecce. DARE: <http://imperium.ahlfeldt.se/places/16897>.

${ }^{581}$ DARE: <http://imperium.ahlfeldt.se/places/23194>;

582 OmnesViae: Brundisium=Brindisi. DARE: <http://imperium.ahlfeldt.se/places/10962>. 


\begin{tabular}{|c|c|c|c|}
\hline & 10 & mansio Spilenaes mil XIIII & $\begin{array}{l}\text { pouso em Spilenees (Carovigno), } 14 \\
\text { milhas; } 583\end{array}$ \\
\hline & 11 & mutatio ad decimum mil XI & $\begin{array}{l}\text { posto de muda no décimo [miliário], } 11 \\
\text { milhas; } 584\end{array}$ \\
\hline & 12 & Ciuitas Leonatiae mil X & $\begin{array}{l}\text { [pouso na] cidade de Leonatia (Agnazzo), } \\
10 \text { milhas; }{ }^{585}\end{array}$ \\
\hline & 13 & $\begin{array}{l}\text { mutatio Turres Aurilianas } \\
\text { mil XV }\end{array}$ & $\begin{array}{l}\text { posto de muda nas torres aurelianas (talvez } \\
\text { San Vito), } 15 \text { milhas;;86 }\end{array}$ \\
\hline & 14 & $\begin{array}{l}\text { mutatio Turres Iuliana mil } \\
\text { VIIII }\end{array}$ & $\begin{array}{l}\text { posto de muda nas torres julianas, } 9 \\
\text { milhas; } 587\end{array}$ \\
\hline & 15 & Ciuitas Beroes mil XI & $\begin{array}{l}\text { [pouso na] cidade de Beroes (Bari), } 11 \\
\text { milhas; }{ }^{588}\end{array}$ \\
\hline & 16 & mutatio Butontones mil XI & $\begin{array}{l}\text { posto de muda em Butontones (Bitonto), } 11 \\
\text { milhas; } 589\end{array}$ \\
\hline 610 & 1 & Ciuitas Rubos mil XI & $\begin{array}{l}\text { [pouso na] cidade de Rubi (Ruvo di Puglia), } \\
11 \text { milhas; } 590\end{array}$ \\
\hline & 2 & $\begin{array}{l}\text { mutatio ad quintodecimo mil } \\
\mathrm{XV}\end{array}$ & $\begin{array}{l}\text { posto de muda no décimo quinto [miliário] } \\
\text { (talvez em Lequile), } 15 \text { milhas;591 }\end{array}$ \\
\hline & 3 & Ciuitas Canusio mil XV & $\begin{array}{l}\text { [pouso na] cidade de Canusio (Canosa di } \\
\text { Puglia), } 15 \text { milhas; } 592\end{array}$ \\
\hline & 4 & mutatio undecimum mil XI & $\begin{array}{l}\text { posto de muda no décimo primeiro } \\
\text { [miliário] (Cerignola), } 11 \text { milhas; }{ }^{593}\end{array}$ \\
\hline & 5 & Ciuitas Serdonis mil XV & $\begin{array}{l}\text { [pouso na] cidade de Serdonis (Ordona), } 15 \\
\text { milhas; }{ }^{594}\end{array}$ \\
\hline
\end{tabular}

583 OmnesViae: Ad Speluncas=Spelunis. DARE: <http://imperium.ahlfeldt.se/places/23195>.

${ }^{584}$ DARE: <http://imperium.ahlfeldt.se/places/36242>.

585 OmnesViae: Gnatie=Torre Egnazia Fasano. DARE: <http://imperium.ahlfeldt.se/places/23196>.

${ }^{586}$ OmnesViae: ? Polignano a Mare. DARE: <http://imperium.ahlfeldt.se/places/23198>.

${ }^{587}$ DARE: <http://imperium.ahlfeldt.se/places/36301>.

588 OmnesViae: Barium=Bari. DARE: <http://imperium.ahlfeldt.se/places/1526>.

${ }^{589}$ OmnesViae: Butuntos=Bitonto. DARE: <http://imperium.ahlfeldt.se/places/23201>.

590 OmnesViae: Rubos=Ruvo di Puglia. DARE: <http://imperium.ahlfeldt.se/places/23203>.

${ }^{591}$ OmnesViae: Rudas=Budas. DARE: <http://imperium.ahlfeldt.se/places/36244>.

592 OmnesViae: Canosio=Canosa di Puglia, Canusium. DARE:

$<$ http://imperium.ahlfeldt.se/places/16747>.

593 DARE: <http://imperium.ahlfeldt.se/places/36247>. Vide, também: "Però il vero significato per la nostra città della Via Traiana fu che essa divenne polo di attrazione di attività economiche. Dato il grande traffico commerciale, che allora si svolgeva soprattutto con mezzi a trazione animale, in prossimità di quella che è oggi la sede della città di Cerignola, sorse nell'età tardo imperiale una mutatio (foto 13), precisamente la mutatio ad undecimum o mutatio XI, cioè un posto per il cambio dei cavalli che si trovava ad undici miglia dalla città di Canosa, quindi a poco più di 15 chilometri, andando verso Ordona. Si tratta più o meno della stessa distanza che ha oggi Cerignola da Canosa. La presenza di questa mutatio ci viene segnalata dall'Itinerario Burdigalense o Gerosolimitano, appunti di viaggio di un pellegrino nel suo viaggio da Bordegala (Bordeaux) a Gerusalemme, del 333 d. C., indicativo, tra l'altro, dei luoghi presenti nella nostra zona."

$<$ http://www.itaspavoncelli.it/Inventario\%20rurale/archivio/vieromane/vieromane.htm>.

${ }^{594}$ OmnesViae: Erdonia=Ordona. DARE: <http://imperium.ahlfeldt.se/places/16751>. 


\begin{tabular}{|c|c|c|c|}
\hline & 6 & Ciuitas Aecas mil XVIII & $\begin{array}{l}\text { [pouso na] cidade de Aecae (Troia), } 18 \\
\text { milhas; } 595\end{array}$ \\
\hline & 7 & mutatio Aquilonis mil X. & $\begin{array}{l}\text { posto de muda em Aquilo (talvez Faeto), } 10 \\
\text { milhas; } 596\end{array}$ \\
\hline & 8 & Finis Apuliae et Campaniae. & $\begin{array}{l}\text { Fronteira entre Apulia (Apúlia) e Campania } \\
\text { (Campânia). }\end{array}$ \\
\hline & 9 & $\begin{array}{l}\text { Mansio ad Equum Magnum } \\
\text { mil VIII }\end{array}$ & $\begin{array}{l}\text { Pouso em Equus Magnus (talvez Masseria } \\
\text { Starza), } 8 \text { milhas; }{ }^{597}\end{array}$ \\
\hline & 10 & $\begin{array}{l}\text { mutatio uicus Forno Nouo } \\
\text { mil XII }\end{array}$ & $\begin{array}{l}\text { posto de muda no povoado de Fornum } \\
\text { Novum (Buonalbergo), } 12 \text { milhas; } ; 98\end{array}$ \\
\hline & 11 & Ciuitas Beneuento mil X & $\begin{array}{l}\text { [pouso na] cidade de Beneuentum } \\
\text { (Benevento), } 10 \text { milhas; } 599\end{array}$ \\
\hline & 12 & $\begin{array}{l}\text { Ciuitas et mansio Claudiis } \\
\text { mil XII }\end{array}$ & $\begin{array}{l}\text { cidade e pouso em Claudii (Montesarchio), } \\
12 \text { milhas; } 600\end{array}$ \\
\hline & 13 & mutatio Nouas mil VIIII & $\begin{array}{l}\text { posto de muda em Novae (Santa Maria a } \\
\text { Vico), } 9 \text { milhas; }{ }^{601}\end{array}$ \\
\hline & 14 & Ciuitas Capua mil XII & $\begin{array}{l}\text { [pouso na] cidade de Capua (Cápua), } 12 \\
\text { milhas; } 602\end{array}$ \\
\hline \multirow[t]{4}{*}{611} & $1-3$ & $\begin{array}{l}\text { Fit summa ab Aulona usque } \\
\text { Capua milia CCLXXXVIIII, } \\
\text { mutationes XXV, mansiones } \\
\text { XIII. }\end{array}$ & $\begin{array}{l}\text { Percorridas no total de Aulona (Avlona) até } \\
\text { Capua (Cápua) } 289 \text { milhas, [passando por] } \\
25 \text { postos de muda e } 13 \text { pousos. }\end{array}$ \\
\hline & 4 & Mutatio ad octauum mil VIII & $\begin{array}{l}\text { posto de muda no oitavo [miliário], } 8 \\
\text { milhas; }{ }^{603}\end{array}$ \\
\hline & 5 & $\begin{array}{l}\text { mutatio Ponte Campano mil } \\
\text { VIIII }\end{array}$ & $\begin{array}{l}\text { posto de muda na ponte Campanus (talvez } \\
\text { sobre o rio Savone), } 9 \text { milhas; } ; 04\end{array}$ \\
\hline & 6 & Ciuitas Sonuessa mil VIIII & $\begin{array}{l}\text { [pouso na] cidade de Sonuessa } \\
\text { (Mongradone), } 9 \text { milhas; }{ }^{605}\end{array}$ \\
\hline
\end{tabular}

\footnotetext{
595 OmnesViae: Aecas=Troia. DARE: <http://imperium.ahlfeldt.se/places/16752>.

${ }^{596}$ DARE: <http://imperium.ahlfeldt.se/places/26486>.

${ }^{597}$ OmnesViae: Aequotutico=Masseria Starza. DARE: <http://imperium.ahlfeldt.se/places/23210>.

${ }^{598}$ OmnesViae: Foro Novo=Sant'Arcangelo Trimonte. DARE:

$<$ http://imperium.ahlfeldt.se/places/22394>.

599 OmnesViae: Benebento=Benevento. DARE: <http://imperium.ahlfeldt.se/places/1482>.

${ }^{600}$ OmnesViae: Caudio Montesarchio. DARE: <http://imperium.ahlfeldt.se/places/22188>. Vide, também: <http://en.wikipedia.org/wiki/Montesarchio>.

${ }^{601}$ OmnesViae: Adnovas=Santa Maria a Vico. DARE: <http://imperium.ahlfeldt.se/places/22187>. Vide, também: <http://en.wikipedia.org/wiki/Santa_Maria_a_Vico>.

602 OmnesViae: Capuae=Santa Maria Capua Vetere. DARE:

$<$ http://imperium.ahlfeldt.se/places/21762>.

${ }^{603}$ DARE: <http://imperium.ahlfeldt.se/places/22178>.

${ }^{604}$ DARE: <http://imperium.ahlfeldt.se/places/22185>.

605 OmnesViae: Sinuessa Mondragone. DARE: < http://imperium.ahlfeldt.se/places/21310>. "Pons Campanus, a bridge over Savo fl., in Campania, on Via Appia, bet. Sinuessa (3) and Urbana (3). S. Giovanni”. HAZLITT, William. The Classical Gazetteer: A Dictionary of Ancient Geography, Sacred and Profane. London: Whittaker and Co. Ave Maria Lane, 1851.
} 


\begin{tabular}{|c|c|c|c|}
\hline & 7 & Ciuitas Menturnas mil VIIII & $\begin{array}{l}\text { [pouso na] cidade de Menturnae } \\
\text { (Minturno), } 9 \text { milhas; }{ }^{606}\end{array}$ \\
\hline & 8 & Ciuitas Formis mil VIIII & $\begin{array}{l}\text { [pouso na] cidade de Formi (Formia), } 9 \\
\text { milhas; }{ }^{607}\end{array}$ \\
\hline & 9 & Ciuitas Fundis mil XII & $\begin{array}{l}\text { [pouso na] cidade de Fundi (Fondi), } 12 \\
\text { milhas; }{ }^{608}\end{array}$ \\
\hline & 10 & Ciuitas Tarracina mil XIII ${ }^{609}$ & $\begin{array}{l}\text { [pouso na] cidade de Tarracina (Terracina), } \\
13 \text { milhas; } 610\end{array}$ \\
\hline & 11 & mutatio ad medias mil $\mathrm{X}$ & $\begin{array}{l}\text { posto de muda em Mediae (Pontinia), } 10 \\
\text { milhas; } 611\end{array}$ \\
\hline & 12 & mutatio Appi Foro mil VIIII & $\begin{array}{l}\text { posto de muda em Appi Forum (Foro } \\
\text { Appio), } 9 \text { milhas; } 612\end{array}$ \\
\hline 612 & 1 & mutatio Sponsas mil VII & $\begin{array}{l}\text { posto de muda em Sponsae (sudeste de } \\
\text { Velletri), } 7 \text { milhas; } 613\end{array}$ \\
\hline & 2 & $\begin{array}{l}\text { Ciuitas Aricia et Albona mil } \\
\text { XIIII }^{614}\end{array}$ & $\begin{array}{l}\text { [pouso na] cidade de Aricia et Albona } \\
\text { (Ariccia), } 14 \text { milhas; }{ }^{615}\end{array}$ \\
\hline & 3 & mutatio ad nono mil VII & $\begin{array}{l}\text { posto de muda no nono [miliário] } \\
\text { (Ciampino), } 9 \text { milhas; } 616\end{array}$ \\
\hline & 4 & in urbe Roma mil VIIII & até a cidade de Roma (idem), 8 milhas. ${ }^{617}$ \\
\hline
\end{tabular}

${ }^{606}$ OmnesViae: Menturnae=Minturno. DARE: <http://imperium.ahlfeldt.se/places/16714>.

${ }^{607}$ OmnesViae: Formiae=Formis. DARE: <http://imperium.ahlfeldt.se/places/16716>.

${ }^{608}$ OmnesViae: Fundis=Fondi. DARE: <http://imperium.ahlfeldt.se/places/16713>.

${ }^{609}$ VP: “Ciuitas Tarracina mil XIII”. Este é o ponto em que o trajeto em V: é retomado, após ter sido interrompido em “Ciuitas Caesarea mil XVI” (600:3).

${ }^{610}$ OmnesViae: Tarracina=Tarracina. DARE: <http://imperium.ahlfeldt.se/places/16712>.

${ }^{611}$ DARE: <http://imperium.ahlfeldt.se/places/22183>.

${ }^{612}$ DARE: <http://imperium.ahlfeldt.se/places/22182>.

${ }^{613}$ OmnesViae: Foro Appi=Borgo Faiti Latina, Forum Appii. DARE:

$<$ http://imperium.ahlfeldt.se/places/22180>.

614 V: “Aritia et Albuna” - P: “Aricia et Albona”.

${ }^{615}$ OmnesViae: Aricia=Ariccia. DARE: <http://imperium.ahlfeldt.se/places/22206>.

${ }^{616}$ DARE: <http://imperium.ahlfeldt.se/places/22177>.

${ }^{617}$ DARE: <http://imperium.ahlfeldt.se/places/1438>. 


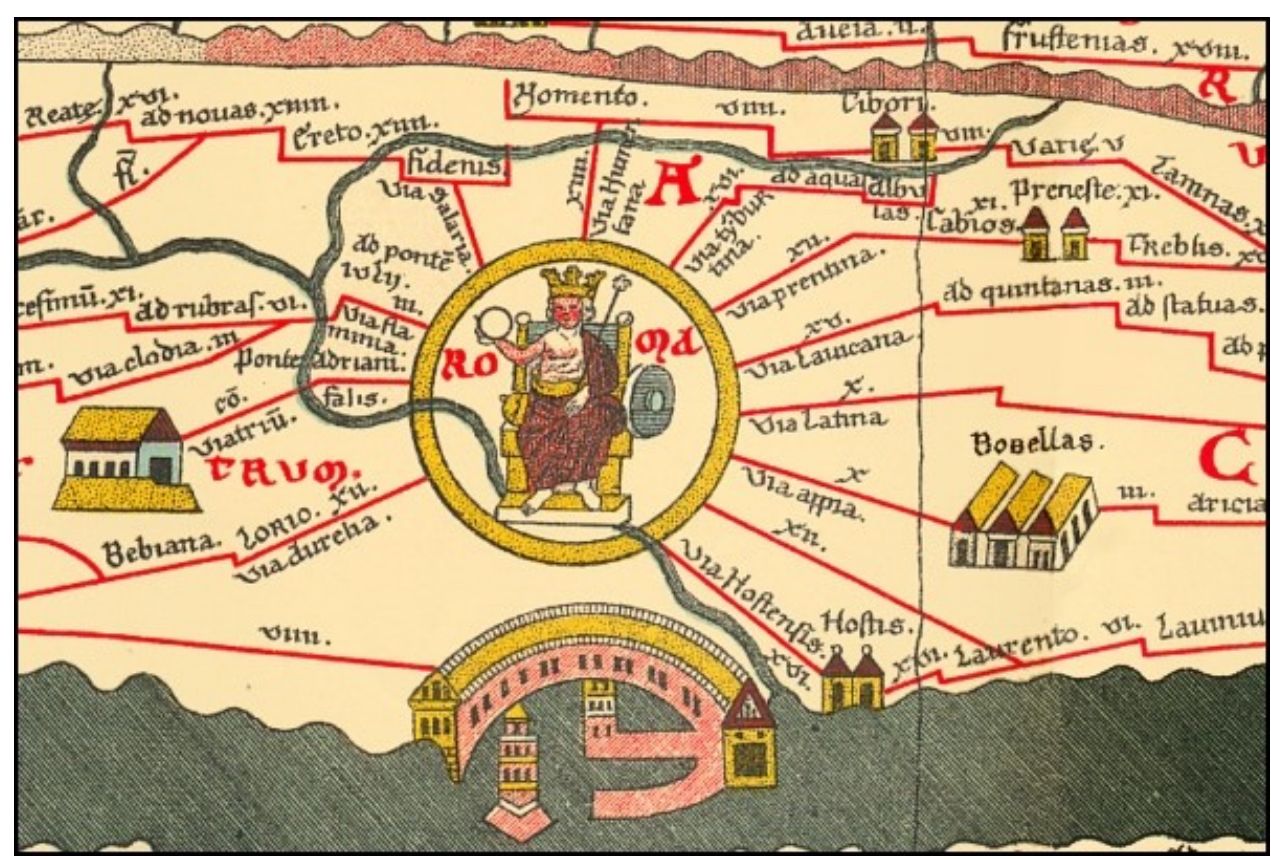

Figura 11: detalhe do fac-simile da Tabula Peutingeriana, com destaque para Roma (idem); o autor do Itinerarium Burdigalense ali chegou pela Via Appia.

\begin{tabular}{|c|c|c|c|}
\hline 612 & 5,6 & $\begin{array}{l}\text { Fit a Capua usque ad urbem } \\
\text { Romam milia CXXXVI, } \\
\text { mutationes XIIII, mansiones } \\
\text { VIIII. }\end{array}$ & $\begin{array}{l}\text { Percorridas de Capua (Cápua) até a cidade } \\
\text { de Roma (idem), } 136 \text { milhas; [passando } \\
\text { por] } 14 \text { postos de muda; } 9 \text { pousos. }\end{array}$ \\
\hline & $7-9$ & $\begin{array}{l}\text { Fit ab Eraclea per Aulona in } \\
\text { urbe Roma usque milia } \\
\text { undecies centena XIII, } \\
\text { mutationes XVII, mansiones } \\
\text { XLVI. }{ }^{618}\end{array}$ & $\begin{array}{l}\text { Percorridas de Eraclea (Marmara Ereğlisi) a } \\
\text { Aulona (Vlorë) até a cidade de Roma (idem) } \\
1.113 \text { milhas, [passando por] } 117 \text { postos de } \\
\text { muda, } 46 \text { pousos. }\end{array}$ \\
\hline & 10 & Ab urbe Medolanium; ${ }^{619}$ & $\begin{array}{l}\text { [Partindo] da cidade [rumo a] Medolanium } \\
\text { (Milão); }\end{array}$ \\
\hline
\end{tabular}

${ }^{618}$ V: “Eraclea per Aulona” - P: "Heraclea per Aulonam”. V: “milia XI centena XIII milia” - P: "milia CXXXVI”. ${ }^{619}$ V: "Medolanium” - P: "Mediolanium”. 


\section{Seção 14: de Roma (idem) a Riminum (Rimini)}

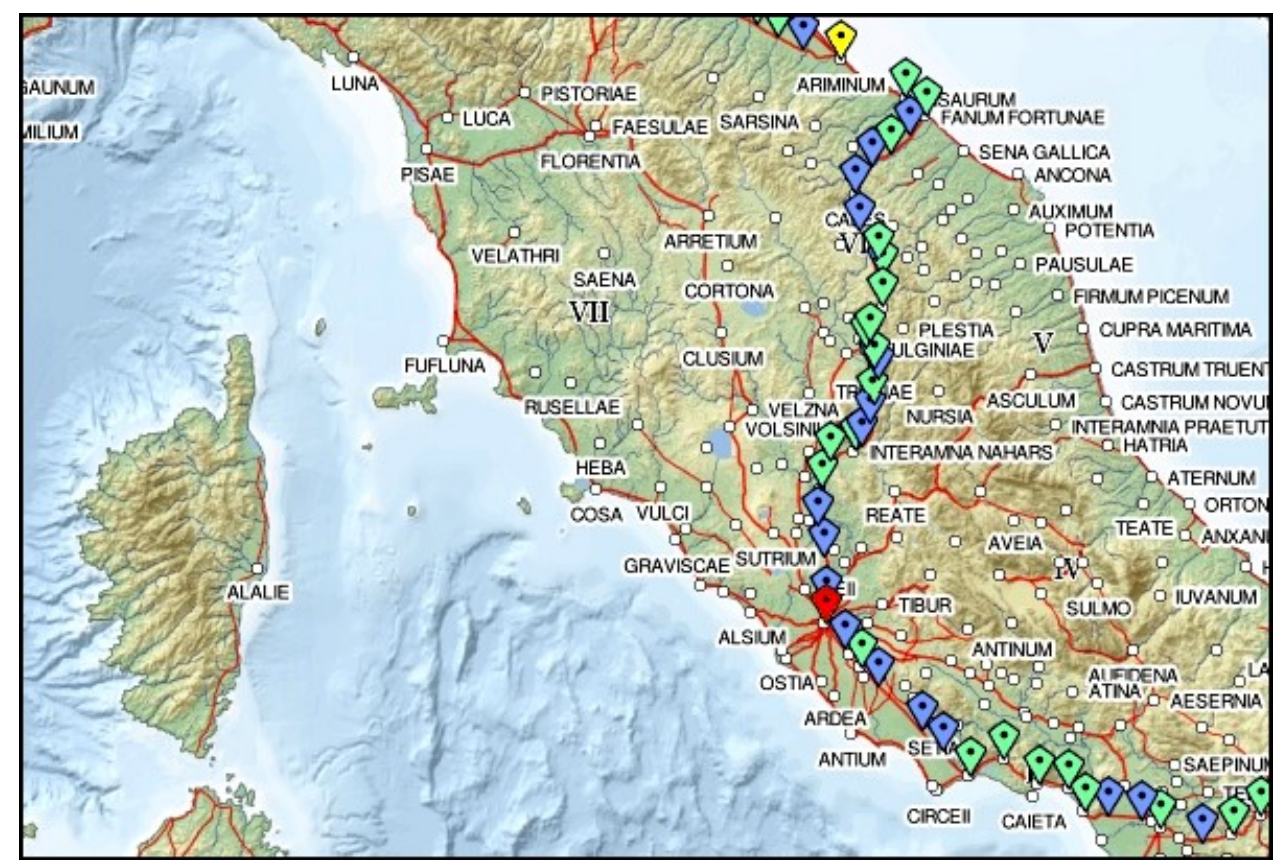

Mapa 14: Roma (idem), em vermelho e Riminum (Rimini), em amarelo; em azul estão registradas as mutationes (postos de muda) e em verde as mansiones (pousos).

\begin{tabular}{|c|c|c|c|}
\hline 612 & 4 & in urbe Roma mil VIIII & até a cidade de Roma (idem), 8 milhas. \\
\hline & 5,6 & $\begin{array}{l}\text { Fit a Capua usque ad urbem } \\
\text { Romam milia CXXXVI, } \\
\text { mutationes XIIII, mansiones } \\
\text { VIIII. }\end{array}$ & $\begin{array}{l}\text { Percorridas de Capua (Cápua) até a cidade } \\
\text { de Roma (idem), } 136 \text { milhas; [passando } \\
\text { por] } 14 \text { postos de muda; } 9 \text { pousos. }\end{array}$ \\
\hline & $7-9$ & $\begin{array}{l}\text { Fit ab Eraclea per Aulona in } \\
\text { urbe Roma usque milia } \\
\text { undecies centena XIII, } \\
\text { mutationes XVII, mansiones } \\
\text { XLVI. }\end{array}$ & $\begin{array}{l}\text { Percorridas de Eraclea (Marmara Ereğlisi) a } \\
\text { Aulona (Vlorë) até a cidade de Roma } 1.113 \\
\text { milhas, [passando por] } 117 \text { postos de muda, } \\
46 \text { pousos. }\end{array}$ \\
\hline & 10 & Ab urbe Mediolanum; & $\begin{array}{l}\text { [Partindo] da cidade [rumo a] Mediolanum } \\
\text { (Milão); }\end{array}$ \\
\hline & 11 & mutatio Rubras mil VIIII & $\begin{array}{l}\text { posto de muda em Rubrae (Grottarossa), } 9 \\
\text { milhas; } 620\end{array}$ \\
\hline 613 & 1 & mutatio ad vicensimum XI & $\begin{array}{l}\text { posto de muda no vigésimo [miliário] } \\
\text { (Morlupo), } 11 \text { milhas; }{ }^{621}\end{array}$ \\
\hline & 2 & mutatio Aquauiua mil XII ${ }^{622}$ & $\begin{array}{l}\text { posto de muda em Aquauiva (talvez } \\
\text { arredores de Civita Castelana), } 12 \text { milhas; }{ }^{623}\end{array}$ \\
\hline
\end{tabular}

${ }^{620}$ DARE: <http://imperium.ahlfeldt.se/places/42629>.

${ }^{621}$ OmnesViae: Advicesimv̄ Morlupo. DARE: <http://imperium.ahlfeldt.se/places/17248>.

${ }^{622} \mathrm{~V}$ : “Aquauiua” - P: “Aqua Uiua”.

${ }^{623}$ OmnesViae: Aqua Viva=Acqua Viva. DARE: <http://imperium.ahlfeldt.se/places/16786>. 


\begin{tabular}{|c|c|c|c|}
\hline & 3 & Ciuitas Ucriculo XII ${ }^{624}$ & $\begin{array}{l}\text { [pouso na] cidade de Ucriculo (Otricoli, } \\
\text { Terni), } 12 \text { milhas; }{ }^{625}\end{array}$ \\
\hline & 4 & Ciuitas Narniae mil XII & $\begin{array}{l}\text { [pouso na] cidade de Narniae (Narni, } \\
\text { Terni), } 12 \text { milhas; }{ }^{626}\end{array}$ \\
\hline & 5 & Ciuitas Interamna mil VIIII & $\begin{array}{l}\text { [pouso na] cidade de Interamna (Terni), } 9 \\
\text { milhas; }{ }^{627}\end{array}$ \\
\hline & 6 & $\begin{array}{l}\text { mutatio Tribus Taernis mil } \\
\text { III }^{628}\end{array}$ & $\begin{array}{l}\text { posto de muda em Tres Taernae (talvez San } \\
\text { Carlo, na província de Terni), } 3 \text { milhas; }{ }^{629}\end{array}$ \\
\hline & 7 & $\begin{array}{l}\text { mutatio Fani Fugitiui mil } \\
\mathrm{X}^{630}\end{array}$ & $\begin{array}{l}\text { posto de muda em Fanum Fugitivi (talvez } \\
\text { Torrecola, na província de Perugia), } 10 \\
\text { milhas; }^{631}\end{array}$ \\
\hline & 8 & Ciuitas Spolitio mil VII & $\begin{array}{l}\text { [pouso na] cidade de Spolitio (Spoleto), } 7 \\
\text { milhas; }{ }^{632}\end{array}$ \\
\hline & 9 & mutatio Sacraria mil VIII ${ }^{633}$ & $\begin{array}{l}\text { posto de muda em Sacraria (talvez San } \\
\text { Giacomo,na província de Perugia), } 8 \\
\text { milhas; } 634\end{array}$ \\
\hline & 10 & Ciuitas Treuis mil IIII ${ }^{635}$ & $\begin{array}{l}\text { [pouso na] cidade de Trevi (Trevi, na } \\
\text { província de Perugia), } 4 \text { milhas; } 636\end{array}$ \\
\hline & 11 & Ciuitas Fulginis mil V & $\begin{array}{l}\text { [pouso na] cidade de Fulgini (Foligno, na } \\
\text { província de Perugia), } 5 \text { milhas; }{ }^{637}\end{array}$ \\
\hline 614 & 1 & $\begin{array}{l}\text { Ciuitas Foro Flamini mil } \\
\text { III }^{638}\end{array}$ & $\begin{array}{l}\text { [pouso na] cidade de Forum Flamini (San } \\
\text { Giovani Profiamma, na comuna de } \\
\text { Foligno), } 3 \text { milhas; }{ }^{639}\end{array}$ \\
\hline & 2 & Ciuitas Noceria mil XII & $\begin{array}{l}\text { [pouso na] cidade de Noceria (Nocera } \\
\text { Umbra), } 12 \text { milhas; }{ }^{.40}\end{array}$ \\
\hline & 3 & Ciuitas Ptanias mil VIII & $\begin{array}{l}\text { [pouso na] cidade de Ptanias (Gualdo } \\
\text { Tadino), } 8 \text { milhas; }{ }^{641}\end{array}$ \\
\hline
\end{tabular}

${ }^{624}$ V: “Ciuitas Ucricolo mansio” - P: “Ciuitas Ucricolo”.

${ }^{625}$ DARE: <http://imperium.ahlfeldt.se/places/16791>.

${ }^{626}$ DARE: <http://imperium.ahlfeldt.se/places/16792>.

${ }^{627}$ OmnesViae: Intermanana=Terne. DARE: < http://imperium.ahlfeldt.se/places/16793>.

${ }^{628}$ V: "Tribus Taernis" - P: "Tribus Tabernis".

${ }^{629}$ DARE: <http://imperium.ahlfeldt.se/places/42236>.

${ }^{630}$ V: "Fano Fugenui" - P: "Fano Fugitiui".

${ }^{631}$ OmnesViae: Fanum Fugitivi=Monte Somma Spoleto. DARE:

$<$ http://imperium.ahlfeldt.se/places/17236>.

632 OmnesViae: Spoletio=Spoleto. DARE: <http://imperium.ahlfeldt.se/places/1455>.

633 V: "Scraria" - P: "Sacraria".

${ }^{634}$ DARE: <http://imperium.ahlfeldt.se/places/17234>.

635 V: “Tranes"- P: "Treuis”.

${ }^{636}$ DARE: <http://imperium.ahlfeldt.se/places/16795>.

${ }^{646}$ DARE: <http://imperium.ahlfeldt.se/places/16796>.

${ }^{647}$ V: "Foro Flameni" - P: "Foro Flamini".

${ }^{648}$ OmnesViae: Foro Flāmini=San Giovanni Profiamma. DARE:

$<$ http://imperium.ahlfeldt.se/places/16797>. Vide, também:

$<$ http://it.wikipedia.org/wiki/San_Giovanni_Profiamma>.

${ }^{640}$ OmnesVIae: Nucerio Camellaria=Nocera Umbra. DARE:

$<$ http://imperium.ahlfeldt.se/places/17233>.

${ }^{641}$ DARE: <http://imperium.ahlfeldt.se/places/16806>. 


\begin{tabular}{|c|c|c|c|}
\hline & 4 & mansio Erbelloni mil VII ${ }^{642}$ & pouso em Erbellum (Sigillo), 7 milhas; ${ }^{643}$ \\
\hline & 5 & mutatio ad Hesis mil $\mathrm{X}^{644}$ & $\begin{array}{l}\text { posto de muda em Hesis (Scheggia e } \\
\text { Pascelupo), } 10 \text { milhas; } 645\end{array}$ \\
\hline & 6 & mutatio ad Cale mil XIIII ${ }^{646}$ & $\begin{array}{l}\text { posto de muda em Cale (Cagli, na província } \\
\text { de Pesaro e Urbino), } 14 \text { milhas; }{ }^{647}\end{array}$ \\
\hline & 7 & mutatio Intercisa mil VIIII & $\begin{array}{l}\text { posto de muda em Intercisa (Gola del } \\
\text { Furlo), } 9 \text { milhas; }{ }^{448}\end{array}$ \\
\hline 615 & 1 & $\begin{array}{l}\text { Ciuitas Foro Simproni mil } \\
\text { VIIII }^{649}\end{array}$ & $\begin{array}{l}\text { [pouso na] cidade de Forum Simproni } \\
\text { (Fossombrone), } 9 \text { milhas; } 650\end{array}$ \\
\hline & 2 & $\begin{array}{l}\text { mutatio ad octauum mil } \\
\text { VIIII }^{651}\end{array}$ & $\begin{array}{l}\text { posto de muda no oitavo [miliário] (talvez } \\
\text { Lucrezia, na comuna de Fossombrone), } 9 \\
\text { milhas; } 652\end{array}$ \\
\hline & 3 & $\begin{array}{l}\text { Ciuitas Fano Furtunae mil } \\
\text { VIII }^{653}\end{array}$ & $\begin{array}{l}\text { [pouso na] cidade de Fanum Furtunae } \\
\text { (Fano), } 8 \text { milhas; } 654\end{array}$ \\
\hline & 4,5 & Ciuitas Pisauro [lacuna] ${ }^{655}$ & $\begin{array}{l}\text { [pouso na] cidade de Pisaurum (Pesaro), } \\
\text { [lacuna] }{ }^{656}\end{array}$ \\
\hline & $5 b$ & [lacuna] mil XXIIII & [lacuna], 24 milhas; \\
\hline & 6 & $\begin{array}{l}\text { [lacuna] usque ad } \\
\text { Riminum }^{657}\end{array}$ & [lacuna] até Riminum (Rimini); ${ }^{658}$ \\
\hline
\end{tabular}

${ }^{642} \mathrm{~V}$ : "Erbello" - P: "Herbelloni”.

${ }^{643}$ OmnesViae: Halvillo ? Fossato di Vicolo. DARE: <http://imperium.ahlfeldt.se/places/17232>.

${ }^{644}$ V: “Adesse” - P: “Ad Hessis”.

645 OmnesViae: Ad Ensem ? Scheggia. DARE: <http://imperium.ahlfeldt.se/places/22347>.

${ }^{646}$ V: "Ad Caloe" - P: "Ad Cale".

${ }^{647}$ OmnesViae: Adcalem=Cagli. DARE: <http://imperium.ahlfeldt.se/places/17231>.

${ }^{648}$ OmnesViae: Adintercisa=Passo di Furlo. DARE: <http://imperium.ahlfeldt.se/places/17229>.

${ }^{649}$ V: "Semproni” - P: "Simproni".

650 OmnesViae: Foro Semprone Fossombrone. DARE: <http://imperium.ahlfeldt.se/places/16703>.

651 V: "ad Octauum” - P: "ad Octauo”.

${ }^{652}$ DARE: <http://imperium.ahlfeldt.se/places/26556>.

${ }^{653}$ V: "Foro Furtunae" - P: "Fano Furtunae".

654 OmnesViae: Fano Fortunae=Fano. DARE: <http://imperium.ahlfeldt.se/places/10565>.

655 Segundo Parthey e Pinder (1848), que P: contém lacunas nesse trecho:

"Ciuitas Pisauro [lacuna]

[lacuna] mil XXIIII

[lacuna] usque Riminum [lacuna]”.

Note-se, ademais, que V: traz as duas primeiras linhas do trecho acima como se fossem uma só: “Ciuitas Pisauro mil XXIIII".

656 OmnesViae: Pisauro=Pésaro. DARE: <http://imperium.ahlfeldt.se/places/10564>.

${ }^{657}$ V: “usque ad Riminum” - P: “usque Riminum”.

658 OmnesViae: Arimino=Rimini. DARE: <http://imperium.ahlfeldt.se/places/10562>. 


\section{Seção 15: de Riminum (Rimini) a Mediolanum (Milão)}

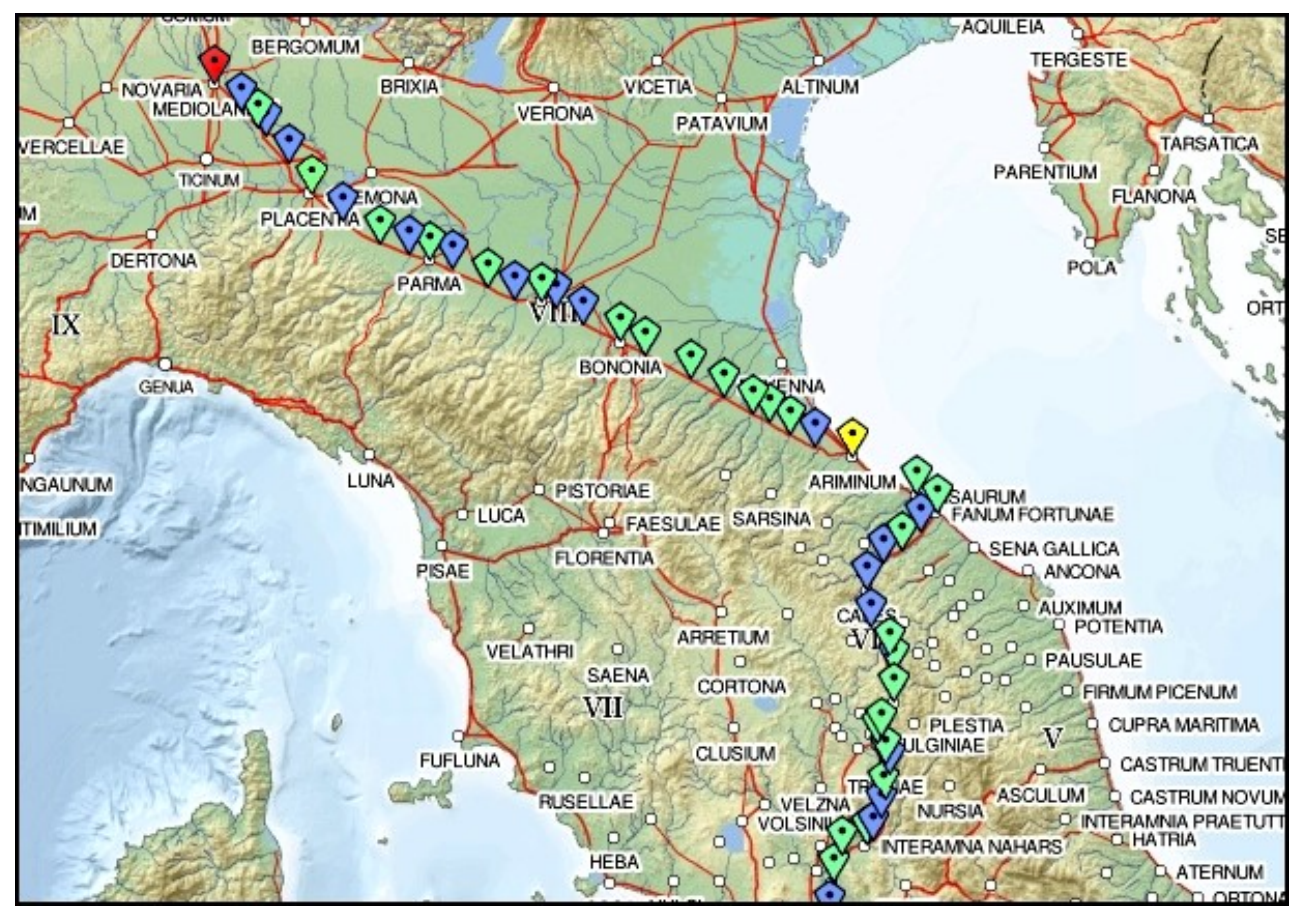

Mapa 15: trenho entre Riminum (Rimini), em amarelo, e Mediolanum (Milão), em vermelho; em azul estão registradas as mutationes (postos de muda) e em verde as mansiones (pousos).

\begin{tabular}{|c|c|c|c|}
\hline \multirow[t]{3}{*}{615} & 6 & usque Riminum [lacuna] & até Riminum (Rimini) [lacuna]; \\
\hline & 7 & mutatio Conpetu mil XII & $\begin{array}{l}\text { posto de muda em Conpetus (Savignano sul } \\
\text { Rubicone), } 12 \text { milhas; } 659\end{array}$ \\
\hline & 8 & Ciuitas Cesena mil VI & $\begin{array}{l}\text { [pouso na] cidade de Cesena (Idem), } 6 \\
\text { milhas; } 660\end{array}$ \\
\hline \multirow[t]{4}{*}{616} & 1 & Ciuitas Foro Populi mil VI ${ }^{661}$ & $\begin{array}{l}\text { [pouso na] cidade de Forum Populi } \\
\text { (Forlimpopoli), } 6 \text { milhas; }{ }^{662}\end{array}$ \\
\hline & 2 & Ciuitas Foro Liui mil VI 663 & $\begin{array}{l}\text { [pouso na] cidade de Forum Livi (Forli), } 6 \\
\text { milhas; } 664\end{array}$ \\
\hline & 3 & Ciuitas Fauentia mil V & $\begin{array}{l}\text { [pouso na] cidade de Faventia (Faenza), } 5 \\
\text { milhas; } 665\end{array}$ \\
\hline & 4 & Ciuitas Foro Corneli mil X & $\begin{array}{l}\text { [pouso na] cidade de Forum Corneli } \\
\text { (Imola), } 10 \text { milhas; }{ }^{666}\end{array}$ \\
\hline
\end{tabular}

${ }^{659}$ DARE: <http://imperium.ahlfeldt.se/places/17227>.

${ }^{660}$ OmnesViae: Curita Cesena=Cesena, Curva Casena. DARE:

$<$ http://imperium.ahlfeldt.se/places/10561>.

${ }^{661}$ V: "Foropuli" - P: "Foro Populi".

662 OmnesViae: Forum Populi=Forlimpopuli. DARE: <http://imperium.ahlfeldt.se/places/16613>.

663 V: "Foro Liti" - P: "Foro Liui"

${ }^{664}$ OmnesViae: Foro Livi=Forli. DARE: <http://imperium.ahlfeldt.se/places/10560>.

665 OmnesViae: Faventia=Faenza. DARE: <http://imperium.ahlfeldt.se/places/10559>.

666 OmnesViae: Foro Corneli=Imola. DARE: <http://imperium.ahlfeldt.se/places/10558>. 


\begin{tabular}{|c|c|c|}
\hline 5 & Ciuitas Claterno mil XIII & $\begin{array}{l}\text { [pouso na] cidade de Claternum (Ozzano } \\
\text { dell'Emilia), } 13 \text { milhas; } 667\end{array}$ \\
\hline 6 & Ciuitas Bononia mil X & $\begin{array}{l}\text { [pouso na] cidade de Bononia (Bologna), } 10 \\
\text { milhas; } ; 68\end{array}$ \\
\hline 7 & mutatio ad medias mil XV & $\begin{array}{l}\text { posto de muda em Mediae (Anzola } \\
\text { dell'Emilia), } 15 \text { milhas;669 }\end{array}$ \\
\hline 8 & mutatio Uicturiolas mil $\mathrm{X}^{670}$ & $\begin{array}{l}\text { posto de muda em Uicturiolae } \\
\text { (provavelmente San Cesario sul Panaro), } 10 \\
\text { milhas; }{ }^{671}\end{array}$ \\
\hline 9 & Ciuitas Motena mil III ${ }^{672}$ & $\begin{array}{l}\text { [pouso na] cidade de Motena (Modena), } 3 \\
\text { milhas; }{ }^{673}\end{array}$ \\
\hline 10 & mutatio Ponte Secies mil V & $\begin{array}{l}\text { posto de muda na ponte sobre o [rio] Secia } \\
\text { (próxima a Rubiera, na província de Reggio } \\
\text { Emilia), } 5 \text { milhas; } 674\end{array}$ \\
\hline 11 & Ciuitas Regio mil VIII & $\begin{array}{l}\text { [pouso na] cidade de Regio (Reggio } \\
\text { Emilia), } 8 \text { milhas; } 675\end{array}$ \\
\hline 12 & mutatio Canneto mil X & $\begin{array}{l}\text { posto de muda em Canneto (Taneto, na } \\
\text { comuna de Gattatico), } 10 \text { milhas; }{ }^{676}\end{array}$ \\
\hline 13 & Ciuitas Parme mil VIII & $\begin{array}{l}\text { [pouso na] cidade de Parma (idem), } 8 \\
\text { milhas;; } 677\end{array}$ \\
\hline 14 & mutatio ad Tarum mil VII & $\begin{array}{l}\text { posto de muda junto ao [rio] Tarus (Ponte } \\
\text { Taro, na comuna de Fontevivo), } 7 \text { milhas; }{ }^{678}\end{array}$ \\
\hline 15 & mansio Fidentiae mil VIII ${ }^{679}$ & pouso em Fidentia (Fidenza), 8 milhas; ${ }^{680}$ \\
\hline 16 & mutatio ad Fonteclos VIII & $\begin{array}{l}\text { posto de muda em Fonteclos (Fontana } \\
\text { Fredda), } 8 \text { milhas; }{ }^{681}\end{array}$ \\
\hline 17 & Ciuitas Placentia mil XIII & $\begin{array}{l}\text { [pouso na] cidade de Placentia (Piacenza), } \\
13 \text { milhas; } 682\end{array}$ \\
\hline
\end{tabular}

${ }^{667}$ OmnesViae: Claterna=Osteria Grande. DARE: $<$ http://imperium.ahlfeldt.se/places/18001>. Vide, também: <http://en.wikipedia.org/wiki/Claternae>.

${ }^{668}$ OmnesViae: Bononia=Bologna. DARE: <http://imperium.ahlfeldt.se/places/1449>.

${ }^{669}$ DARE: <http://imperium.ahlfeldt.se/places/22352>.

${ }^{670}$ V: "Victoriolas" - P: "Victuriolas".

${ }^{671}$ DARE: <http://imperium.ahlfeldt.se/places/17212> .

672 V: "Motena" - P: "Mutena".

${ }^{673}$ OmnesViae: Mutina=Modena. DARE: $<$ http://imperium.ahlfeldt.se/places/2720>.

${ }^{674}$ DARE: <http://imperium.ahlfeldt.se/places/17213>.

${ }^{675}$ OmnesViae: Lepidoregio=Reggio nell'Emilia. DARE: <http://imperium.ahlfeldt.se/places/5323>.

${ }^{676}$ OmnesViae: Tanneto. DARE: <http://imperium.ahlfeldt.se/places/17214>.

677 OmnesViae: Parna=Parma. DARE: <http://imperium.ahlfeldt.se/places/1448>.

${ }^{678}$ DARE: <http://imperium.ahlfeldt.se/places/17215>.

${ }^{679}$ V: "Sidonciae" - P: "Fidentia".

680 OmnesViae: Fidentia=Fidenza. DARE: < <http://imperium.ahlfeldt.se/places/16464>. Vide, também: <it.wikipedia.org/wiki/Fidenza>.

${ }^{681}$ DARE: $<$ http://imperium.ahlfeldt.se/places/17217>.

${ }^{682}$ OmnesViae: Placentia=Piacenza. DARE: <http://imperium.ahlfeldt.se/places/1466> . 


\begin{tabular}{|c|c|c|c|}
\hline 617 & 1 & mutatio ad Rota mil XI & $\begin{array}{l}\text { posto de muda junto a Rota (San Martino } \\
\text { Pizzolano), } 11 \text { milhas; }{ }^{683}\end{array}$ \\
\hline & 2 & $\begin{array}{l}\text { mutatio Tribus Tabernis mil } \\
\text { V }\end{array}$ & $\begin{array}{l}\text { posto de muda em Tres Tabernae (talvez } \\
\text { Secugnago, na província de Lodi), } 5 \\
\text { milhas; }{ }^{684}\end{array}$ \\
\hline & 3 & Ciuitas Laude mil VIIII & $\begin{array}{l}\text { [pouso na] cidade de Laude (Lodi), } 9 \\
\text { milhas; }{ }^{685}\end{array}$ \\
\hline & 4 & mutatio ad nonum mil VII & $\begin{array}{l}\text { posto de muda no nono [miliário] } \\
\text { (Melegnano), } 7 \text { milhas; } 686\end{array}$ \\
\hline & 5 & $\begin{array}{l}\text { Ciuitas Mediolanium mil } \\
\text { VII }^{687}\end{array}$ & $\begin{array}{l}\text { [pouso na] cidade de Mediolanium (Milão), } \\
7 \text { milhas; }{ }^{688}\end{array}$ \\
\hline & $6-8$ & $\begin{array}{l}\text { Fit omnis summa ab urbe } \\
\text { Roma Mediolanium usque } \\
\text { milia CCCCXVI, mutationes } \\
\text { XLII, mansiones XXIIII. }\end{array}$ & $\begin{array}{l}\text { Percorridas na soma total de Roma a } \\
\text { Mediolanium (Milão) } 416 \text { milhas, } \\
\text { [passando por] } 42 \text { postos de muda e } 24 \\
\text { pousos. }\end{array}$ \\
\hline
\end{tabular}

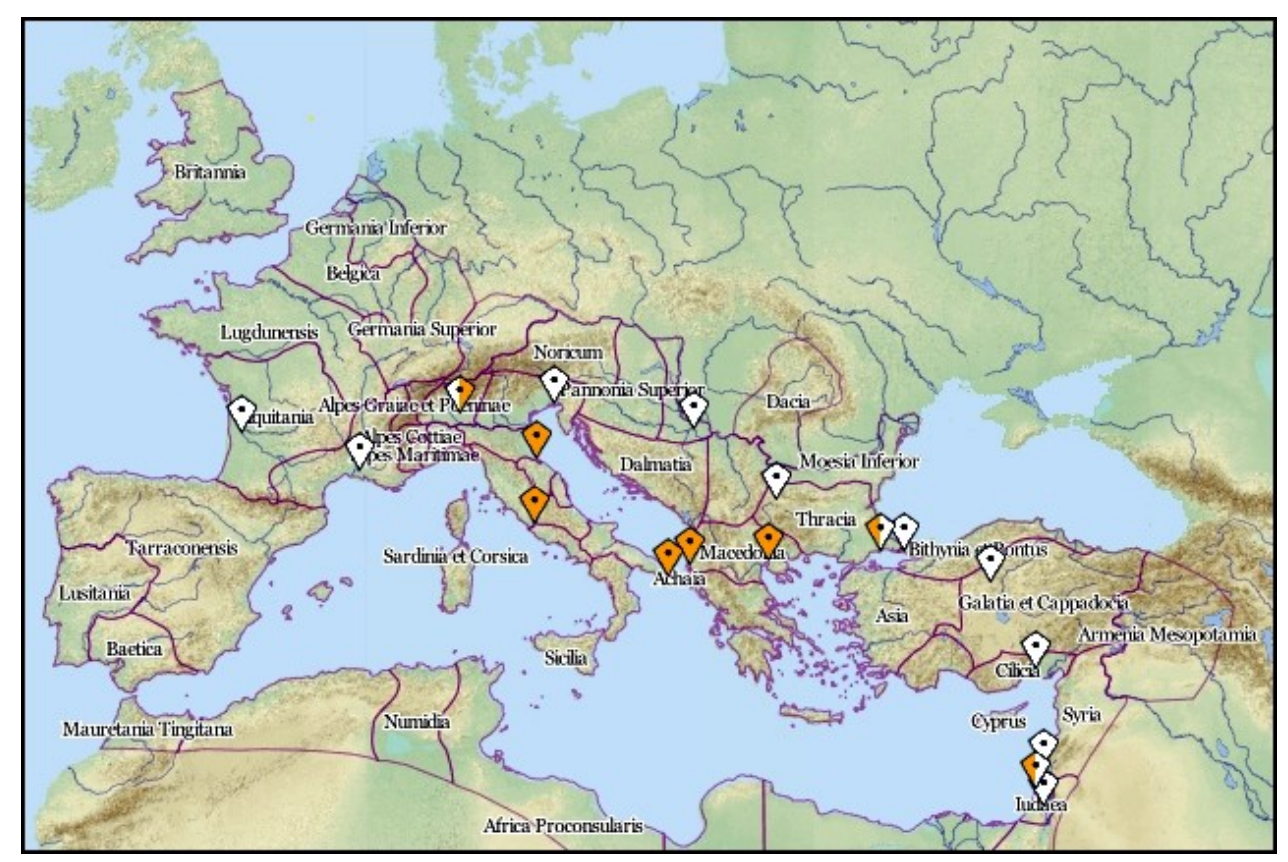

Mapa 16: locais destacados nos mapas anteriores; em branco estão os locais mencionados no trajeto de ida até Hierusalem e em laranja os mencionados na volta até Mediolanum (Milão). A sequência na ida foi: Bordegala (Bordeaux) > Arelate (Arles) > Mediolanum (Milão) > Aquileia (idem) > Sirmium (Sremska Mitrovica) > Serdica (Sófia) $>$ Eraclea (Marmara Ereğlisi) $>$ Constantinopolis (Istambul) $>$ de barco até a Bithynia, depois por terra até Anchira Galaciae (Ancara) > Tarsus (Tarso) > Tirus (Șūr) > Caesarea Palestina (Kesariya) > Hierusalem (Jerusalém). Na volta, a sequência foi: novamente Caesarea Palestina (Kesariya) > de barco até Eraclea (Marmara Ereğlisi) > Thessalonica (Saloniki) > Aulona (Vlorë) > de barco até Odrontum (Otranto), no extremo leste da península itálica > Roma (idem) > Riminum (Rimini) > novamente Mediolanum (Milão).

${ }^{683}$ DARE: <http://imperium.ahlfeldt.se/places/17137>.

${ }^{684}$ DARE: <http://imperium.ahlfeldt.se/places/17164>.

${ }^{685}$ OmnesViae: Laude Pompeia=Lode. DARE: <http://imperium.ahlfeldt.se/places/6023> .

${ }^{686}$ DARE: $<$ http://imperium.ahlfeldt.se/places/17140>.

${ }^{687}$ V: "Mediolanium" - P: "Mediolanum".

${ }^{688}$ DARE: <http://imperium.ahlfeldt.se/places/1445>. 


\section{Comentários de tradução}

\section{I. “acessa et recessa” (579:7-9)}

ciuitas Bordegala, ubi est fluuius garonna, per quem facit mare oceanum accessa et recessa per leugas plus minus centum.

A cidade de Bordegala (Bordeaux), onde está o rio Garonna (Garona), através do qual o oceano avança e retrocede por cem léguas, mais ou menos.

O texto se inicia já com uma dificuldade de leitura, por conta de "acessa et recessa". Embora esteja claramente dito que é o oceano que avança e retrocede através do rio Garonna (Garona) por cerca de cem léguas, o fenômeno descrito causou estranhamento. De saída imaginamos que talvez fosse o contrário; que o autor quisesse, ainda que com uma linguagem confusa, simplesmente dar a entender que um trecho de rio com cem léguas de comprimento avançava em direção ao oceano. O problema óbvio dessa interpretação era a palavra "recessa". Não faria qualquer sentido que o rio retrocedesse frente ao oceano. Pesquisando sobre o Garona, descobrimos que ele é palco de um macaréu (ou pororoca), a invasão do rio pelo mar durante a maré enchente. Diante dessa descoberta, o texto latino passou a fazer perfeito sentido.

\section{II. “Mutatio/mutationes"}

Mutatio Stomatas leug VII.

posto de muda em Stomatae (Castres-Gironde), 7 léguas.

“Mutatio” é uma palavra latina para mudança. Na primeira leitura, supomos que tais "mutationes" fizessem referência a mudanças de estrada. Nosso viajante, partindo de Bordegala (Bordeaux), teria chegado a Stomatae (CastresGironde) e lá tomado outra estrada até Sirio (Ceróns), de onde teria partido para Vasates (Bazas). O problema óbvio de tal interpretação é que o viajante permanecia na Via Aquitania, estrada romana que unia Narbo (Narbonne), às margens do Mediterrâneo, e Bordegala (Bordeaux), já próxima do Atlântico. Uma "mutatio" não poderia ser, portanto, uma mudança de estrada.

A versão em Inglês do Itinerarium Burdigalense, publicada por Aubrey Stewart em 1887, trazia "Change at Stomatae" como tradução de "Mutatio Stomatas", o que nos foi de pouca valia para entender o significado de "mutatio". Felizmente, o site "Vias Romanas em Portugal" 689 traz um glossário em que se pode ler: "Mutatio / Mutatione - muda de montadas de apoio à via em cada 10 a 12 milhas (15-18 km)". As mutationes eram, portanto, estações de apoio aos viajantes; até certo ponto análogas aos postos de abastecimento em nossas rodovias.

Historicamente, o desenvolvimento do sistema viário romano ligava-se às necessidades administrativas. Em um artigo de 1925, intitulado "The Speed of the

689 “Vias Romanas em Portugal”: <http://viasromanas.planetaclix.pt/vrinfo.html>. 
Roman Imperial Post”, A. M. Ramsay afirmou ser a mutatio uma "posting-station", enquanto as "mansiones" - sobre as quais direcionaremos nosso olhar no

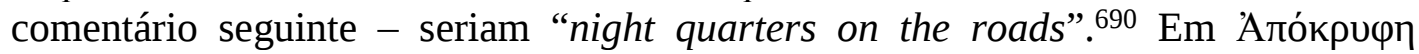
'Iotopía (História Secreta), publicada por volta do ano 560, Procópio de Cesareia menciona tais stations (doravante "estações"), enquanto explica o funcionamento

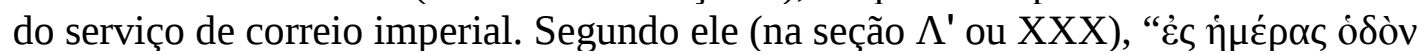

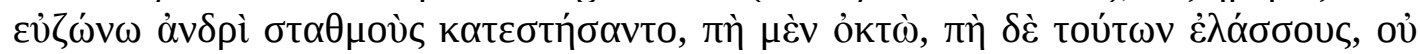

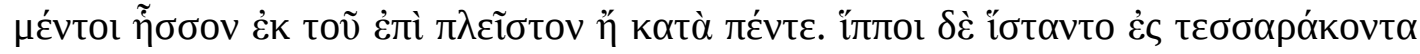

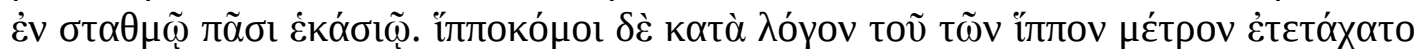

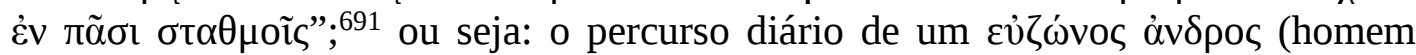
bem preparado) era fixado em oito $\sigma \tau \alpha \theta \mu$ o (estações) e, quando menos do que isso, em um mínimo de cinco - sendo quarenta o número de cavalos em cada estação, acompanhados por uma quantidade proporcional de îtтокó $\mu$ ог (cavalariços).

As mutationes, portanto, teriam existido sobretudo para fornecer apoio aos mensageiros oficiais. Esses, se assim o desejassem, poderiam trocar de montaria em cada uma delas (ao menos teoricamente). Não é certo que esse serviço estivesse disponível amiúde para viajantes comuns. De todo modo, os mensageiros oficiais teriam precisado trocar de montaria frequentemente por terem prazos a cumprir, enquanto o mesmo não pode ser dito dos viajantes comuns. Ainda assim, é certo que tais mutationes servissem de apoio mesmo a esses; talvez fornecendo refeições, pequenos reparos nos vehicula (charretes), ou mesmo abrigo temporário em caso de intempéries.

Diante disso tudo, decidimos traduzir "mutatio" por "posto de muda”, expressão que preserva a ideia de mudança presente no vocábulo latino, mas que deixa claro que se trata de um local de parada.

Cabe, aqui, uma última nota a respeito das mutationes: o viajante parece ter efetivamente visitado cada uma delas. Ele poderia, a princípio, estar apenas indicando os locais por onde passara. Em muitas das vias do trajeto, contudo, existiam outros locais de parada, que permaneceram sem menção mesmo que certamente tenham sido vistos pelo viajante.

\section{III. “Mansio/mansiones"}

Fit a Bordegala Arelate usque mil CCCLXXII, mutationes XXX, mansiones XI.

Percorridas de Bordegala (Bordeaux) até Arelate (Arles) 372 milhas, [passando por] 30 postos de muda e 11 pousos.

\footnotetext{
${ }^{690}$ RAMSAY, A. M. The Speed of the Roman Post Office. The Journal of Roman Studies, v. 15, 1925, pp. 60-74: "The only definite statement made by an ancient authority regarding the rate of speed required of the Imperial couriers is that of Procopius already quoted, to the effect that a day's

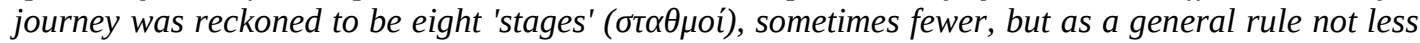
than five. The 'stage' is evidently the average distance from one mutatio or posting-station to the next, as Procopius ads that there were forty horses allotted to each stage. It appears from the Jerusalem Itinerary that the mansiones, or night quarters on the roads, were about twenty-five miles apart [...]” (p. 68).

${ }^{691} \mathrm{O}$ excerto que citamos vem de uma edição bilíngue Grego-Latim: "In via, quam diurno itinere expeditus viator conficit, octona ferme stabula, alicubi pauciora, infra quinque nusquam posuere. In singulis stabulis equi dispositi ferme quadraguinta, et ad equorum numerum stabularii” (p. 161). DINDORFIUS, Guilielmus (ed.). Procopius. Bonae: Impensis et Weberi, 1838, v. 3.
} 
O excerto acima $(553: 1,2)$ corresponde ao primeiro momento em que o autor do Itinerarium Burdigalense reflete sobre o seu trajeto. Ele já teria, àquela altura, percorrido 372 milhas, visitado trinta mutationes e onze mansiones. Curiosamente, se voltarmos ao início do texto e refizermos o percurso do viajante à procura da palavra "mansio" encontra-la-emo apenas uma vez, em "mansio Elusione mil VIIII” (551:5). Onde estariam, então, as dez mansiones faltantes?

Excetuando-se as mutationes, explicitamente situadas em outra categoria, o viajante já visitara, àquela altura, um uicus (Hebromagus), oito ciuitates (Vasates, Elusa, Auscius, Tholosa, Narbo, Biterrae, Cessaro e Arelate), além de um castellum (Carcasso). Se a essas adicionarmos o mansio em Elusio teremos um total de onze - o número de mansiones mencionado pelo viajante.

Em "The Roman City and its Periphery: from Rome to Gaul”, Penelope J. Goodman define "uicus" como um "secondary settlement", frequentemente associado a um ou mais pagi, distritos rurais (origem da nossa palavra "pagão"; originalmente nada mais do que um "camponês”). O termo “ciuitas”, em oposição, estaria associado aos "primary settlements". ${ }^{692}$ No que diz respeito ao nosso problema, importa que, enquanto as mutationes teriam sido meras estações de apoio aos viajantes, localizadas nos interstícios do território, uici e ciuitates consistiriam em legítimos núcleos populacionais, nos quais o viajante poderia (ao menos teoricamente) ser bem acomodado.

Vejamos, agora, a definição de "mansio" no glossário do site "Vias Romanas em Portugal”693: "Mansio / (pl. mansiones) - estação oficial de apoio à via com albergue e muda de montadas, em cada 20 a 30 milhas (30-44 km)". Ainda que não permita uma distinção clara inequívoca entre as mansiones e as mutationes, a definição nos é útil, pois estabelece que o termo "mansio", em um contexto como o nosso, refere-se explicitamente a um local. Isso é importante pois "mansio" relaciona-se etimologicamente com o verbo "maneo" (permanecer, parar) e, ao menos teoricamente, um romano poderia, ao pernoitar algures, ali mansionem facere (fazer uma mansio). Trata-se de uma construção linguística mais associada ao Latim Medieval do que ao clássico, mas o Itinerarium Burdigalense foi composto no século IV, uma época de transição. Alguns séculos mais tarde, Beda (ca. 673 - 735 e. c.) assim escreveria: "Precabantur quoque devoti, ut veniens mansionem facere dignaretur apud fortes fide [...]" (Os devotos também pregavam, caso o visitante se dignasse também a 'fazer mansio' junto aos fortes na fé [...]). ${ }^{694}$ O sentido de "mansionem facere", aí, é o de "pernoitar" ou, ao menos, de "coabitar temporariamente".

As mansiones indicadas no Itinerarium Burdigalense seriam, de todo modo, estações de apoio localizadas dentro de (ou junto a) uici (povoados) ou ciuitates (cidades). Podemos imaginar, assim, as mutationes como estações mais precárias, localizadas junto às vias mas em meio a regiões menos habitadas, enquanto as mansiones seriam hospedarias capazes de proporcionar aos viajantes (ao menos teoricamente) as "amenidades da civilização". Isso não implica que os

692 Sobre a natureza dos núcleos urbanos secundários na Gallia, vide a discussão entre as páginas 167 e 175 de: GOODMAN, Penelope J. The Roman City and its Periphery: from Rome to Gaul. London and New York: Routledge, 2007.

${ }^{693}$ Vias Romanas em Portugal: <http://viasromanas.planetaclix.pt/vrinfo.html>.

${ }^{694}$ Beda, In Samuelem Prophetam, Capitulum XX. BEDE. The Complete Works of Venerable Bede, in the original Latin, collated with the manuscripts, and various printed editions, accompanied by $a$ new English translation of the historical works, and a life of the author. By the Rev. J. A. Giles, D.C.L. London: Whittaker and Co., 1844, v. 8, p. 131. 
viajantes romanos jamais pudessem pernoitar em uma mutatio ou que não pudessem apenas se alimentar em uma mansio; implica, porém, que eles talvez preferissem fazer o oposto disso, em virtude da natureza das acomodações que encontrariam em cada tipo de local.

O leitor atento talvez haja notado que não discutimos o status de Carcasso, local identificado pelo viajante como um castellum (forte). Parece-nos seguro acreditar que, no que diz respeito à urbanidade ou às "amenidades da civilização", os castella estivessem abaixo não apenas das ciuitates mas mesmo dos uici. Por si só, porém, o termo é ambíguo; podendo ser aplicado tanto (1) a uillae fortificadas, como (2) a fortificações recém-construídas nos perímetros urbanos e, por vezes, (3) até mesmo a pequenos oppida (cidades muradas). No caso de Carcasso, todavia, Goodman nos informa que o local possuía o privilegiado status juridicoadministratio de "colonia" no início do período imperial, mas que aparece "demoted" (rebaixado) para "castellum" no Itinerarium Burdigalense. ${ }^{695} \mathrm{O}$ status anterior do local sugere, de todo modo, que se tratara outrora de uma próspera ciuitas, de forma que a existência de uma mansio no local mesmo no século IV não deve ser motivo de surpresa.

O leitor ainda mais atento talvez haja notado que o viajante não menciona as trinta mutationes que contabiliza na passagem 553:1,2. A lista consiste em vinte e um desses locais: Stomatae, Sirio, Tres Arbores, Oscincium, Scittium, Vanesia, ad Sextum, Hungunverrum, Buccones, ad Iovem, ad Nonum, ad Vicesimum, Sostomagus, Cedri, [ad] Tricensimum, Hosuerbas, Forum Domitii, Sostantio, Ambrosius, Neumaso e Pons Aerarius. A única explicação que encontramos para tal discrepância é uma falha na transmissão do texto. Em algum momento entre a elaboração do texto original (no século IV) e a feitura dos manuscritos mais antigos de que dispomos, os codices Parisinus 4808 e Sangallensis 732 (ambos do século IX), um desatento copista substituiu " $X X I$ ” por " $X X X$ ”. 696

Considerando todo o exposto, retomemos a questão tradutória. Que palavra ou expressão poderia dar conta, em Português, do sentido que "mansio" tem no Itinerarium Burdigalense? As possibilidades são várias: “albergue”, "hospedaria”, "estalagem”. O substantivo "albergue” vem do verbo "albergar”. Este seria derivado da forma gótica deduzida mas não atestada "haribergôn" e teria chegado ao Português no século XIII, via antigo Provençal. ${ }^{697}$ "Hospedaria”, por sua vez,

695 GOODMAN (2007, p. 171): "Sources such as Strabo, Pliny, road itineraries and local epigraphy, which can be used to identify the status of particular settlements during a given period, also reveal that this status could change over time. Thus, Carcassonne and Château-Roussillon were both coloniae in the early imperial period, but had been demoted to the status of castella by the time the Bordeaux-Jerusalemitinerary was written in ad 333. Conversely, certain particularly successful secondary agglomerations were promoted in the late imperial period to become the administrative centres of their own territories: examples include Boulogne, Geneva, Grenoble and Tournai”.

${ }^{696}$ Paul Geyer, editor do Itinerarium Burdigalense, interpreta essa discrepância de um modo que consideramos absurdo: "Mutationes autem sunt XXXII, mansiones praeter uicum et castellum X” (As mutationes, porém, são trinta e duas; e as mansiones, exceto o uicus e o castellum, dez). Em outras palavras, ele contabiliza por duas vezes as oito ciuitates, fazendo com que elas entrem não apenas na lista de mansiones mas também na lista de mutationes. Isso eleva o seu número de vinte e um para vinte e nove. Acrescentando a isso o uicus (Hebromagus) e o castellum (Carcasso), obtém trinta e um. Como ele teria chegado, então, a trinta e dois? Somente ao adicionar Bordegala, ponto inicial do trajeto! Para encontrar dez mansiones em vez das onze contabilizadas pelo viajante, Geyer provavelmente acrescentou a única mansio explícita do trecho em questão (Elusio) a Bordegala e às oito ciuitates nele mencionadas (Vasates, Elusa, Auscius, Tholosa, Narbo, Biterrae, Cessaro e Arelate)

697 “albergar. vb. 'acampar, pousar' 'hospedar, abrigar' XIII. Do a. prov. albergar, deriv. do gót. * 
descende do termo latino "hospitalia" (casa de hóspedes). "Estalagem” parece ter origem semelhante - viria do antigo Provençal "ostalatge"698 (hospedagem), certamente originário também no Latim. "Hospedaria” e “estalagem” podem, cremos, ser descartados por conta de derivarem de um termo latino diferente de "mansio", ainda que com sentido semelhante. Em outras palavras: o autor do Itinerarium Burdigalense poderia, em tese, ter escrito "hospitalia" ou algo com o mesmo radical, mas não o fez. O termo "albergue”não pode, todavia, ser descartado através da mesma alegação, posto que tem uma origem totalmente distinta. Ele não parece, porém, uma escolha tão boa quanto um quarto termo, "pouso". Em última análise, "pouso" também provém de uma palavra latina: o verbo "pauso" (infinitivo "pausare"), com o sentido de parar/pausar. Ainda assim, "pouso" não apenas pertence ao mesmo campo semântico dos três anteriores, mas também preserva a ideia de permanência, de parada, presente em "mansio".

\title{
IV. “mutatio ad sextum” (550:10)
}

\author{
LXXIX \\ IMP CAESAR DIVI NERVAE F \\ NERVA TRAIANVS \\ AVG GERM DACIC \\ PONT MAX TR POT \\ XIII IMP VI COS V \\ $\mathrm{P} P$ \\ VIAM A BENEVENTO \\ BRVNDISIVM PECVN SVA FECIT
}

O texto acima reproduz a inscrição ${ }^{699}$ de um marco viário encontrado próximo da Via Traiana - estrada construída no início do século II como uma alternativa mais curta à Via Appia na ligação entre Beneuentum (Benevento) e Brundisium (Brindisi). Marcos desse tipo eram dispostos pelos romanos ao longo das viae (estradas), quando de sua construção. ${ }^{700}$ Além de servir para divulgar o nome do benfeitor responsável pela obra, cada marco registrava a distância em relação ao início da estrada. Essa era obtida através do emprego de um odômetro mecânico, um carrinho que registrava o número de giros de suas próprias rodas (e, portanto, a distância percorrida). O valor obtido era, então, convertido para passus (pl. passūs), unidade-base para as distâncias viárias.

haribergôn 'hospedar' \| albergada XIII. Do a. prov. albergADA \| albergAMENTO XV | albergARIA XIII || albergue XIII || alberguEIRO | -geyro XIII, -gueyro XIII” (p. 21). CUNHA, Antônio Geraldo da. Dicionário Etimológico da Língua Portuguesa. 4a. edição revista e atualizada de acordo com a nova ortografia. Rio de Janeiro: Lexicon, 2010.

${ }^{698}$ CUNHA (2010): “estalagem. sf. 'hospedaria' 'conjunto de casinhas com saída comum para a rua' | stalagem XIII | provavelmente do prov. ostalatge || estalajADEIRA -deyra XVIII \| estalARIA XIII. Do prov. ostalaria.” (p. 268).

699 Corpus Inscriptionum Latinarum, IX 6021.

700 Seguimos Lawrence Keppie: "When the road-builders had completed each section of their work, they erected a stone pillar (a milliarium) at every Roman mile of 1000 paces (hence the name), that is $1481 \mathrm{~m}$ (4920ft). These milestones not only measured the distance along the road from its starting-point, they also reported construction work and who had been responsible for it”. KEPPIE, Lawrence. Understanding Roman Inscriptions. Baltimore: Johns Hopkins University Press: 1991. p. 65. 
Diferentemente do que normalmente chamamos de "passo", o passus romano consistia em dois movimentos de perna e não apenas um (daí equivaler a cerca de 1,48 metro). Mille passūs perfaziam uma millia (ou 1,48 quilômetro). Os pilares de pedra eram geralmente colocados nas estradas a cada millia e por isso eram chamados "milliaria” (sing. milliarium).

O leitor atento talvez haja notado que a abreviatura "mil", referente a "milliae" (milhas), não ocorre nas quatorze primeiras estações do Itinerarium Burdigalense. Em vez disso, o viajante registrou “leug”. Ocorre que, em algumas partes das Galliae (Gálias), os marcos viários eram colocados não a cada millia, mas a cada leuga (légua) - distância equivalente a aproximadamente uma millia e meia. Similarmente, as passagens "Mutatio Nassete mil VII S" (571:11) e "mansio Pandicia mil VII S” (572:1) indicam que, naqueles trechos, os marcos viários não distavam uma millia um do outro, mas somente uma semi millia (indicada pela letra "S”), metade da distância usual.

Dispostos por todo o império, os marcos viários serviam como referência constante para os viajantes. Algumas das estações de apoio a estes eram, inclusive, indicadas somente através da menção do marco viário mais próximo. É isso que explica a presença, no texto do itinerário de, de "mutatio ad sextum" (550:10), "mutatio ad nonum" (551:3), "mutatio ad vicesimum" (551:2), "Mutatio [ad] tricensimum" (551:10) e assim por diante - sempre com o marco viário sendo indicado pelo numeral ordinal referente à sua posição em um determinado trecho de estrada. Cabe acrescentar, ademais, que essas estações identificadas somente pelo marco viário tendiam a ser do tipo mais precário, a mutatio.

O leitor talvez esteja se perguntando o que significa, afinal, a inscrição supracitada. Como as inscrições epigráficas eram usualmente abreviadas, ela assim deve ser lida: "LXXIX Imp[erator] Caesar diui Neruae f[ilius] Nerua Traianus Aug[ustus] Germ[anicus] Dacic[us] pont[ifex] max([imus] tr[ibunicia] pot[estate] XIII imp[erator] VI co[n]s[ul] V p[ater] p[atriae] uiam a Beneuento Brundisium pecun[ia] sua fecit” (79. O Imperador César, filho do divino Nerva, Nerva Trajano Augusto, vitorioso contra os germânicos e os dácios, Pontífice Máximo, treze vezes [portador] do poder tribunício, seis vezes [saudado como] Imperador, cinco vezes Cônsul, Pai da Pátria, fez a estrada de Beneuentum a Brundisium com o próprio dinheiro). O numeral inicial registra a distância de Beneuentum até ali: setenta e nove milhas romanas (cerca de 117 quilômetros).

Retomemos, porém, a questão da tradução dos trechos do Itinerarium Burdigalense que mencionam estações identifacadas somente pelo marco viário. Como todas elas são mutationes, as passagens que se referem a elas podem ser vertidas para o Português através da seguinte fórmula: "posto de muda no N.O. [miliário]”, onde “N.O.” assinala um numeral ordinal. Por exemplo, o trecho "mutatio ad nonum mil VIIII" (551:3) pode ser traduzido por "posto de muda no nono [marco], 9 milhas”. A única exceção a isso é a primeira passagem desse tipo no texto, "mutatio ad sextum leug VI" (550:10). Nesse caso, como o marco viário não indica milliae e sim leugae, talvez seja problemático chamá-lo de "miliário". Optamos, nesse caso, por "marco": "posto de muda no sexto [marco], 7 léguas". 


\section{V. “haec dicit dominus sanaui aquas has” (596)}

A ciuitate passus mille D est ibi fons Helisei prophete. Antea si qua mulier ex ipsa aqua biberat, non faciebat natos. Adlatum est uas fictile Helisei misit in eo sale et uenit et stetit supra fontem, et haec dicit dominus sanaui aquas has ex eo si qua mulier inde biberit, filios faciet.

O trecho acima apresenta algumas peculiaridades que dificultaram não apenas a compreensão, mas também a elaboração da versão em Português. Há a menção a uma fonte, próxima de uma cidade (Hiericho, Jericó), cuja água, se bebida por uma mulher, não permitira que tivesse filhos. Para acabar com esse problema, o profeta Eliseu teria atirado sais em um vaso de cerâmica ao lado da fonte e citado palavras de Deus.

Nossa maior dificuldade na interpretação do trecho teve a ver com a pontuação. O viajante menciona ou cita Eliseu, que cita "o Senhor” (“haec dicit dominus:”). Não fica claro, ao menos de início, se após “sanaui aquas has” temos a fala de Deus, de Eliseu ou mesmo do autor do itinerário. Diante de uma dificuldade de tal monta, concebemos duas possibilidades de ação: (1) verificar a pontuação do texto em ao menos um dos manuscritos; (2) encontrar a passagem bíblica em que Eliseu purifica tal fonte. A primeira abordagem se justificava na medida em que as pontuações que encontramos nas edições impressas dos textos antigos são, ao menos em parte, obra de seus editores e seu objetivo é o de bem guiar a interpretação dos leitores; já a segunda talvez permitisse verificar a relação entre as palavras ditas por Eliseu segundo a Bíblia e segundo o autor do itinerário.

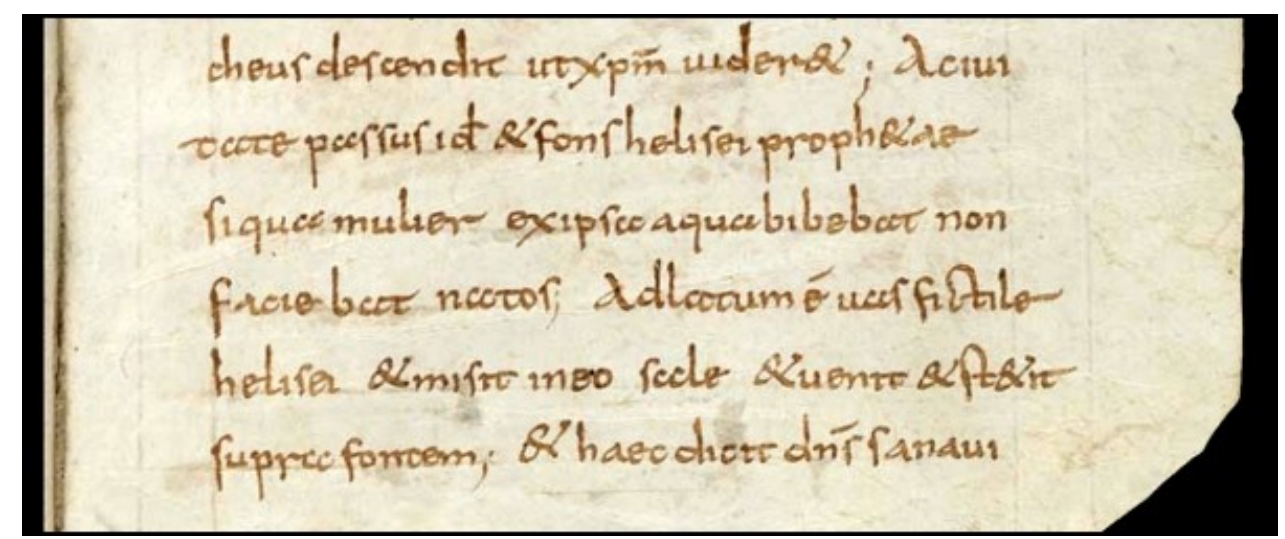

Figura 12: detalhe da página 109 do Codex Sangallensis 732.

A figura 12 (acima) reproduz a parte inferior da página 109 do Codex Sangallensis 732. Note-se que ela se encerra com “\& haec dicit dns' sanaui”. A figura 13 (abaixo) reproduz o início da página 110. Nele, pode-se ler: “aquas has ex eo. Si qua mulier haben \& filios faciet”. 


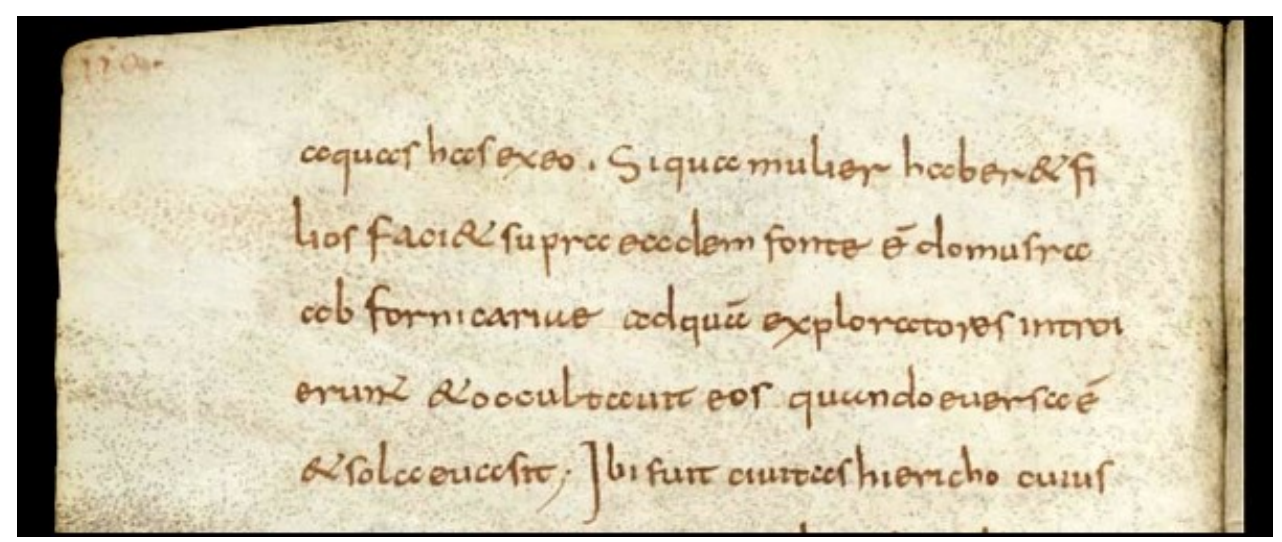

Figura 13: detalhe da página 110 do Codex Sangallensis 732.

\& haec dicit dns' sanaui

e esses disse senhor sanarei

aquas has ex eo. Si qua mulier haber \& filios faciet. águas estas desse/a partir desse. Se com a qual mulher tiver e filhos fará.

Observando nossa tradução interlinear palavra-por-palavra acima, mesmo o leitor não-latinista poderá dar-se conta de que a pontuação do manuscrito não nos ajuda a resolver a dificuldade de interpretação. Pelo contrário, o texto do manuscrito talvez seja de interpretação ainda mais difícil, pois “ex eo" não aparece iniciando o período composto que conclui a anedota, mas como parte do anterior. Faria mais sentido, todavia, se "ex eo" se referisse ao local (a fonte) do qual as mulheres futuramente poderão beber sem o risco de se tornarem inférteis, de modo que essa expressão se encaixa melhor no período final.

Restava-nos, nesse caso, verificar a passagem bíblica em que Eliseu purifica a fonte. Trata-se de "Liber Secundus Regum 2 19-21" (2 Reis 2 19-21). Podemos encontrá-la assim na Nova Vulgata, disponibilizada pelo site do Vaticano $^{701}$ :

19 Dixerunt quoque viri civitatis ad Eliseum: "Ecce habitatio civitatis huius optima est, sicut tu ipse, domine, perspicis; sed aquae pessimae sunt, et terra faciens abortium".

20 At ille ait: "Afferte mihi vas novum et mittite in illud sal”. Qui cum attulissent,

21 egressus ad fontem aquarum misit in eum sal et ait: "Haec dicit Dominus: Sanavi aquas has, et non erit ultra in eis mors neque abortium”.

O que poderia ser traduzido da seguinte forma:

19 Disseram, então, os homens da cidade a Eliseu: "Eis que a moradia nesta cidade é ótima, como mesmo podes perceber, ó senhor; mas as águas são péssimas e a terra ocasiona aborto”.

20 E aquele afirmou: "Buscai para mim um vaso novo e lançai nele sal”. Quando aqueles o trouxeram, [Eliseu], de volta à fonte d'água nela lançou o sal e

\footnotetext{
${ }^{701}$ Nova Vulgata, Liber Secundus Regum:

$<$ http://www.vatican.va/archive/bible/nova_vulgata/documents/nova-vulgata_vt_ii-regum_lt.html>.
} 
afirmou: "Estes [vocábulos] disse o Senhor: curarei estas águas e não haverá mais nela morte e nem aborto".

O autor do Itinerarium Burdigalense parece, então, estar tentando citar literalmente uma passagem bíblica. Que esse trecho do Itinerarium não seja igual ao da Nova Vulgata se explica pelo fato de ambos serem traduções. O original do Velho Testamento foi escrito em hebraico. O autor do Itinerarium poderia ter tido contato com ele tanto em uma versão grega ou, mais provavelmente, com uma versão conhecida como "Vetus Latina" (Velha Latina). ${ }^{702} \mathrm{O}$ que importa para nós, de todo modo, é que a interpretação católica oficial e tradicional é a de que a fala de Eliseu, em nome de Deus, vai até o final do trecho em questão.

É muito curioso, de todo modo, que na versão da história contada pelo autor do Itinerarium está explícita a noção de que a terra e água poluídas causam abortos nas mulheres, enquanto na Nova Vulgata isso não fica totalmente claro, possibilidando uma leitura alternativa de que não as mulheres, mas a terra em si ali é estéril. Tanto é assim que, no site "Bíblia Católica Online”703, encontramos:

19. Os habitantes da cidade disseram a Eliseu: A cidade está muito bem situada, como o pode ver o meu senhor, mas as águas são más e tornam a terra estéril. 20. Eliseu disse-lhes: Trazei-me um prato novo, e ponde nele sal. Eles lho trouxeram.

21. Eliseu foi à fonte e deitou sal nela, dizendo: Eis o que diz o Senhor: Sanei estas águas, e elas não causarão mais nem morte, nem esterilidade.

Seria possível parar a investigação a esse ponto, simplesmente reconhecendo como a anedota da purificação das águas de Hiericho (Jericó) por Eliseu é contada de modo diferente no Itinerarium Burdigalense, na Nova Vulgata e na Bíblia em Português apresentada no site "Bíblia Católica Online”. A curiosidade. porém, nos conduziu ao texto hebraico do Antigo Testamento. Nele, podemos

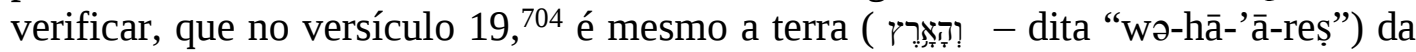
cidade que é estéril (e não as mulheres); enquanto no versículo 21 não há menção sequer à terra, apenas é dito que não haverá mais morte ou esterilidade. Isso significa que houve, em algum ponto da cadeia de transmissão que vai do original hebraico até o Itinerarium Burdigalense, uma falha na interpretação do que estava escrito.

É possível que o erro tenha ocorrido quando da leitura de alguma versão

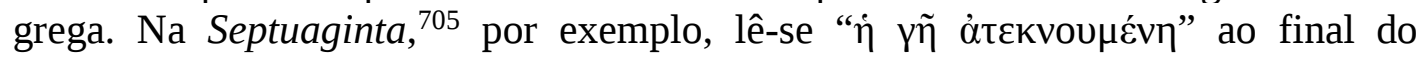
versículo 19, o que pode ser traduzido, grosso modo, por "a terra infértil”. Ocorre,

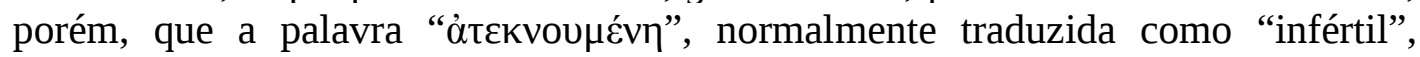
remete a algo como "o que não pode gerar crianças" - por conta de "tع́kvov" ser

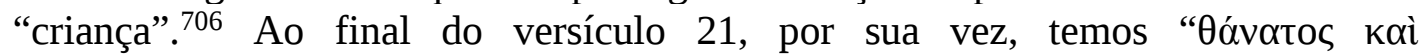

\footnotetext{
${ }^{702}$ Vide: <http://en.wikipedia.org/wiki/Vetus_Latina>.

${ }^{703}$ Bíblia Católica Online:

$<$ http://www.bibliacatolica.com.br/biblia-ave-maria/ii-reis/2/\#.VCePYhY_12A>.

${ }^{704}$ Vide: <http://biblehub.com/interlinear/2_kings/2.htm>.

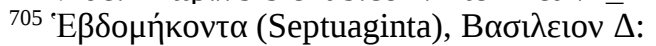

$<$ http://www.ellopos.net/elpenor/greek-texts/septuagint/chapter.asp?book=12\&page=2>.

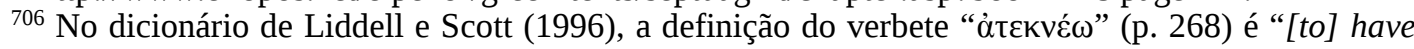

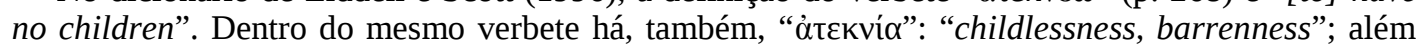

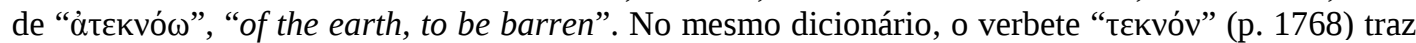

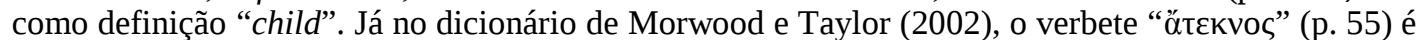
difinido como “childless”. LIDDELL, Henry George, SCOTT, Robert. A Greek-English Lexicon.
} 


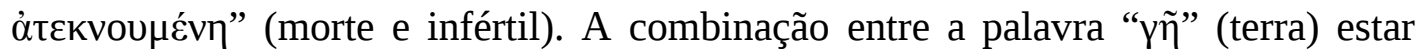

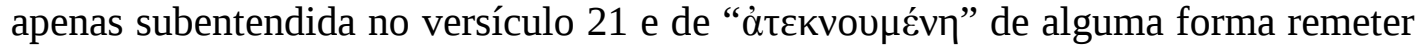
a crianças provavelmente ocasionava alguma dificuldade de compreensão para leitores ou ouvintes com um domínio mais precário da língua grega.

do Itinerário:

Considerando todo o exposto, ainda nos resta a tarefa de traduzir o texto

A ciuitate passus mille D est ibi fons Helisei prophete. Antea si qua mulier ex ipsa aqua biberat, non faciebat natos. Adlatum est uas fictile Helisei misit in eo sale et uenit et stetit supra fontem, et haec dicit dominus sanaui aquas has ex eo si qua mulier inde biberit, filios faciet.

O que poderia ser traduzido por:

A mil e quinhentos passos da cidade está a fonte do profeta Heliseus (Eliseu). Anteriormente, a mulher que bebesse dessa mesma água não teria bebês. Ao lado está um vaso de cerâmica. Heliseus (Eliseu), tendo nele atirado sal, veio até a fonte e, de pé, [diz]: "O Senhor disse essas [palavras]: "Eu purifiquei/sanei/tornei sãs/tornei saudáveis estas águas”. Doravante, se uma mulher daí beber daí, terá filhos.

Restam-nos, ainda, comentar duas outras questões de textualização. A primeira envolve "non faciebat natos". "Natos" é o acusativo plural de "natus" (nascido). A ideia por trás da passagem é de esterilidade ou mesmo de aborto. Parece-nos que o modo idiomático (e sintético) de dizer o mesmo em nossa língua seria "não teria bebês".

Embora tenhamos nos referido anteriormente ao episódio como a "purificação" das águas por Eliseu, o verbo empregado pelo viajante é "sano" (inf. sanare) - algo como "sanar", "tornar são" ou ainda "tornar saudável”. "Eu sanei estas águas" soa-nos estranho e arcaico. Inadequada, também, parece a construção "Eu tornei sãs estas águas", uma vez que "são" vem sendo cada vez mais usada no sentido específico de "saudável mentalmente". Por fim, "Eu tornei saudáveis estas águas” parece-nos uma escolha idiomática e adequada.

Tradução de:

Gustavo H. S. S. Sartin ghsartin@gmail.com Universidade Federal de Santa Catarina 


\section{Referências bibliográficas}

BARTHÉLEMY, Anatole de. Itinéraire de Bordeaux a Jérusalem d'après un manuscript de la Bibliothèque du Chapitre de Vérone Suivi d'une description des lieux saints tirée d'un manuscrit de la Bibliothèque impériale. Revue Archéologique, Nouvelle Série. v. 10, Juillet à Décembre 1864, pp. 98-112.

Cunha, Antônio Geraldo da. Dicionário Etimológico da Língua Portuguesa. 4a. edição revista e atualizada de acordo com a nova ortografia. Rio de Janeiro: Lexicon, 2010.

BEDE. The Complete Works of Venerable Bede, in the original Latin, collated with the manuscripts, and various printed editions, accompanied by a new English translation of the historical works, and a life of the author. By the Rev. J. A. Giles, D.C.L. London: Whittaker and Co., 1844, v. 8.

Bojesen, E. F. A Handbook of Roman Antiquities. London: Francis and John Rivington, 1848.

DindORfIUS, Guilielmus (ed.). Procopius. Bonae: Impensis et Weberi, 1838, v. 3.

García Masegosa, Antonio. Germán de Silesia; Interpretatio Alcorani litteralis. Parte I: la traducción latina, introducción y edición crítica. Madrid: Consejo Superior de Investigaciones Científicas, 2009.

GeYer, Paulus (ed.). Itinera Hierosolymitana: saeculi IIII - VIII. Pragae, Vindobonae et Lipsiae: F. Tempsky et G. Freytag, 1898.

Goodman, Penelope J. The Roman City and its Periphery: from Rome to Gaul. London and New York: Routledge, 2007.

HazlitT, William. The Classical Gazetteer: A Dictionary of Ancient Geography, Sacred and Profane. London: Whittaker and Co. Ave Maria Lane, 1851.

KePPIE, Lawrence. Understanding Roman Inscriptions. Baltimore: Johns Hopkins University Press: 1991.

LidDEll, Henry George, ScotT, Robert. A Greek-English Lexicon. Oxford: Clarendon Press, 1996.

Magnani, Stefano, BAnchig, Pierluigi, Ventura, Paola. Il ponte romano alla Mainizza e la via Aquileia-Enona. Estrato da Aquileia Nostra, anno LXXVI, 2005.

Miller, Konrad (ed). Castori Romanorum cosmographi tabula quae dicitur Peutingeriana. Revensburg: Meyer, 1887.

Morwood, James, TAYlor, John. Pocket Oxford Classical Greek Dictionary. Oxford and New York: Oxford University Press, 2002.

Parthey, G., Pinder, M. (eds.). Itinerarium Antonini Augusti et Hierosolymitanum: ex libris manu scriptis ediderunt. Berolini: Impensis Friderici Nicolai, 1848.

Peskan, Ivana, PAscutTini, Vesna. Transformation of the Roman Aglomerations in the Northwestern Croatia. Economia e Territorio nell'Adriatico Centrale tra tarda Antichità e alto Medioevol (IV-VIII secolo). Ravena: 28 Febbraio - 1 marzo 2014.

Ramsay, A. M. The Speed of the Roman Post Office. The Journal of Roman Studies, v. 15, 1925, pp. 60-74. 
SchotTus, Andreas (ed.). Itinerarium Antonini Augusti, et Burdigalense. Quorum hoc nunc primum est editum, illud ad diversos manusc. codices et impressos comparatum, emendatum et Hieronymi Suritae Casesaraugustani, doctissimo comentario explicatum. Colonia Agrippina: In officina Birckmannica suptibus Arnold Mylij, 1600.

Stewart, Aubrey, Wilson, C. W. (eds.). Itinerary from Bordeaux to Jerusalém. 'The Bordeaux Pilgrim' (333 A. D.). Translated by Aubrey Stewart and annotated by Colonel Sir C. W. Wilson. London: I, Adam Street, Adelphi, 1887.

Tobler, Titus, Molinier, Augustus (eds.). Itinera Hierosolyma et Descriptiones Terrae Sanctae bellis sacris anteriora \& Latina lingua exarata sumptibus Societatis illustrandis Orientis Latini monumentis. Genevae: J.-G. Fick, 1879.

Wesselingius, Petrus (ed.). Vetera Romanorum Itineraria, sive Antonini Augusti Itinerarium, cum integris Jos. Simleri, Hieron. Suritae, et and. Schotti Notis. Itinerarium Hierosolytanum, et Hieroclis Grammatici Synecdemus. Amstelaedami: Aput J. Wetstenium \& G. Smith, 1735. 